





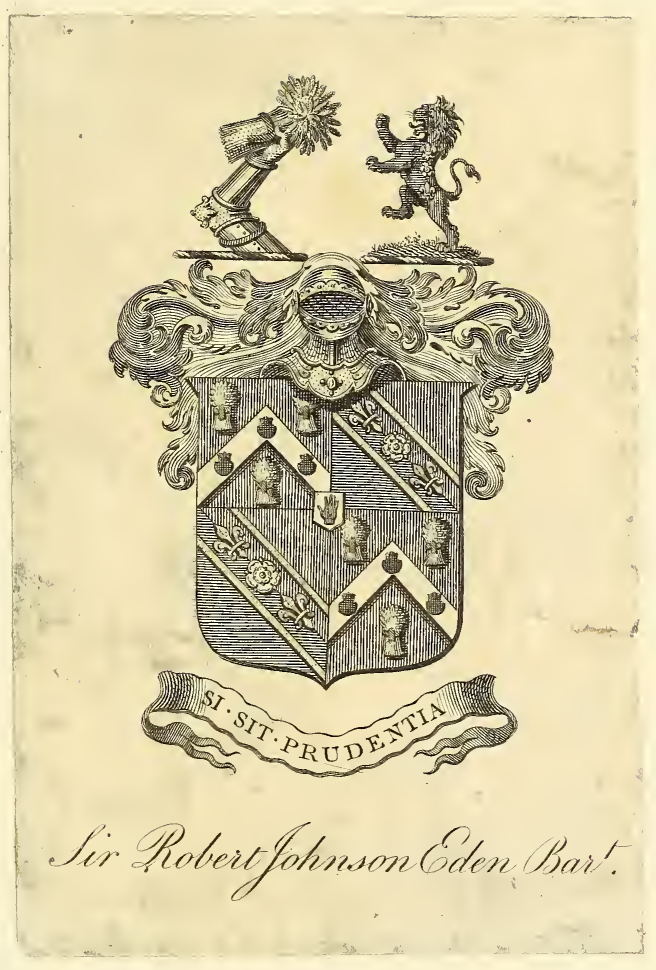





\title{
STATICAL ESSAYS:
}

CONTAINING

\section{VEGETABLE STATICKS;}

Or, An Account of fome

\section{Statical Experiments}

\section{O N T H E}

$S A P$ in $V E G E T A B E S$,

\author{
B E I N G
}

An Essay towards a Natural Hiftory of. Vegetation: Of Ufe to thofe who are curious in the Culture and Improvement of GARDENING, Eंc。

Alfo, A Specimen of an Attempt to Analyfe the Air, by a great Variety of Chymio-ST a тісAL EXPERIMENTS, which were reac at feveral Meetings before the R OYAL So C I E TY.

$$
\text { V O L. I. }
$$

2uid eft in bis, in quo non nature ratio intalligent is appareat? Tul. de Nat. Deor.

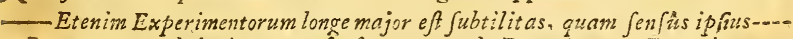
Itaque eo rem deducimus, ut fenfus tantum de Experimento, Experimentum de re judicet. Fran. deVerul. Inftauratio magna.

By $S \mathcal{T E P H} H A L E S$, B. D. F.R.S. Rector of Farringdon, Hampjoire, and Minilter of Teddington, Middlesex.

The SECOND Ei) IT I ON, with Ainendments,

$$
\text { L ONDON: }
$$

Brinted for W. INNYs, at the Weft End of St. Paul's; T.Wood WA RD, at the Half-Moon over-againft St. Dunfan's Church in Fleetffreet; and J. PEELE, at Locke's Heed in Amen.Corner. M, DCC, XXXI. 
Feb. 16, 1.726.7. Imprimatur

I saAc New tonoPr.Reg. Sob: 


\section{T O}

\section{His Royal Highnefs}

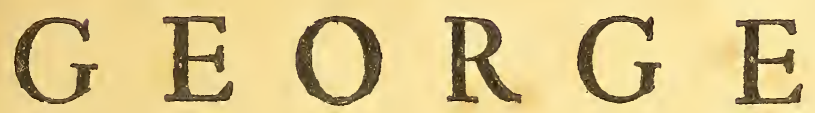

\section{Prince of WALES.}

May it please Your Royal Highness,

Humbly offer the following Experiments to Your Highnefs's $\mathrm{Pa}$ tronage, to protect them from the reproaches that the ignorant are apt

$$
\text { A } 2
$$

un= 


\section{DEDICATION.}

unreafonably to caft on refearches of this kind, notwithftanding they are the only folid and rational means whereby we may ever hope to make any real advance in the knowledge of $\mathrm{Na}$ ture: A knowledge worthy the attainment of Princes.

And as Solomon, the greateft and wifeft of men, difdained not to inquire into the nature of Plants, from the Cedar in Lebanon, to the HyfJop that fpringeth out of the wall: So it will not, I prefume, be an unacceptable entertainment to Your Royal Highnefs, at leaft at Your leifure hours; but will rather add to the pleafure, with which vegetable $\mathrm{Na}$ ture in her prime verdure charms us: To fee the fteps the takes in her productions, and the wonderful power the therein exerts: The admirable provifion the has made for them, not only 


\section{$D E D I C A T I O N$.}

only vigoroufly to draw to great heights plenty of nourifhment from the earth; but alfo more fublimed and exalted food from the air, that wonderful fluid which is of fuch importance to the life of Vegetables and Animals: And which by infinite combinations with natural bodies, produces innumerable furprizing effects; many inftances of which I have here fhewn.

The fearching into the works of Nature, while it delights and inlarges the mind, and ftrikes us with the ftrongeft affurance of the wifdom and power of the divine Architect, in framing for us fo beautiful and well regulated a world, it does at the fame time convince us of his conftant benevolence and goodners towards us.

$$
\text { A } 3 \text { That }
$$




\section{$D E D I C A T I O N$.}

\section{That this Great Author of Nature}

may thower down on Your Royal Highnefs an abundance of his Bleffings, both Spiritual and Temporal, is the fincere prayer of

\section{Your Royal Higbnes's}

\section{Moft Obedient}

\section{Humble Servant,}

\section{STEPHEN HALES.}




\section{T H E}

\section{PREFACE.}

Here have been within lefs than a Century very great and useful difcoveries made in the amazingly beautiful fructure and nature of the animal ceconomy; neither bave Plants pafjed unobferved in this inquifitive age, which bas with Juch diligence extended its inquiries, in fome degree, into almoft every branch of nature's in. exhauftible fund of wonderful works.

We find in the Pbilofophical Transactions, and in the Hiftory of the Royal Academy of Sciences, accounts of many curious Experiments and Obfervations made from time to time on Vegetables, by feveral ingenious and inquifitive Perfons: But our countryman Dr. Grew, and Malpighi, were the firft. who, tho in very diffant countries, did nearly at the Same time, unknown to each other, ingage in a very diligent and thorough in. quiry into the fructure of the veffels of Plants; a province, which till then had lain uncultivated. They have given us ve-

A 4. 
ry accurate and faithful accounts of the fructure of the parts, which they carefully traced, from their firft minute origin, the Seminal Plants, to their full growth and maturity, thro' their Roots, Trunk, Bark, Branches, Gems, Shoots, Leaves, Bloffoms and Fruit. In all wibich they obferved an exact and regular Jymmetry of $P$ arts moft curioufly wrought in fuch manner, that the great work of vegetaiion might effectually be carried on, by the uniform co-operation of the Several $P$ arts, according to the different offices afigned them by nature.

Had they fortuned to bave fallen into this fatical way of inquiry, perfons of their great application and fagacity had doubtlefs made confiderable advances in the knowledge of the nature of $P$ lants. This is the only fure way to meafure the feveral quantities of nourifbment, which Plants imbibe and perSpire, and thereby to see what infuence the different fates of Air bave on them. This is the likelieft method to find out the Sap's velocity, and the force with which it is imbibed: As alfo to eftimate the great power that nature exerts in extending and pufbing forth ber productions, by the expanfion of the Sap. 
About twenty years fince, I made feveral bemaftatical Experiments on Dogs, and fix Tears afterwards repeated the Same on Horfes and other Animals, in order to. find out the real force of the blood in the Arteries, fome of which are mentioned in the third chapter of this book: At which times I wijhed I could bave made the like Experiments, to difcover the force of the Sap in Vegetables; but despaired of ever effecting it, till about severs years fince, by mere accident I bit upon it, while $I$ was endeavouring by feveral ways to ftop the bleeding of an old flem of a Vine, which was cut too near the bleeding Seafon, which I feared might kill it: Having, after other means proved ineffectual, tied a piece of bladder over the tranfverse cut of the Stem, I found the force of the Sap did greatly extend the bladder; whence I concluded, that if a long glafs tube were fixed there in the Jame manner, as I had before done to the Arteries of feveral living Animals, I fhould thereby obtain the real afcends ing force of the Sap in that Stem, which fucceeded according to my expectation, and bence it is, that I have been infenfibly led on, to make farther and farther refearches, by variety of Experiments. 
As the art of $P$ hyjick has of late years beers much improved by a greater knowledge of the animal ceconomy; fo doubtlefs a farther infight into the vegetable ceconomy muft needs proportionably improve our skill in Agriculture and Gardening, which gives me reafon to bope, that inquiries of this kind will be acceptable to many, who are intent upon improving those innocent, delightful, and beneficial Arts: Since they cannot be insenfible that the moft rational ground for Success in this laudable purfuit muft arife from a greater in. Jight into the nature of Plants.

Finding by many Experiments in the ffth chapter, that the Air is plentifully inspired by Vegetables, not only at their roots, but alfo thro' Several parts of their Trunks and Branches; this put me upon making a more particular inquiry into the nature of the Air; and to difcover, if pofible, wherein its great importance to the life and support of Vegetables might conft; on which account I was obliged to delay the publication of the reft of. these Experiments, which were read two years fince before the Royal Society, till I bad made fome prograss in this inquiry. An account of which I bave given in the fixth chapter.

Where. 
Where it appears by many chymio-ftatica Experiments, that there is diffused thro' all natural, mutivally attracting bodies, a large proportion of particles, which, as the firft great Author of this important difcovery, Sir Ifaac Newton, obferves, are capable of being throwen off from denfe bodies by heat or fermentation into a vigorouly elaftick and permanently repelling ftate: And alfo of $r c_{0}$ turning by fermentaition, and fometimes roitbout it, into denfe bodies: It is by this amphibious property of the air, that the main and principal operations of Nature are carried on; for a mass of mutually attracting particles, without being blended with a due proportion of elaftick repelling ones, would in many cafes foon coalefce into a fuggifi lump. It is by these properties of the particles of matter that be folves the principal Pbonomena of Nature. And Dr. Freind has from the fame principles given a very ingeraious Rationale of the chief operations in Chymifry. It is therefore of importance to bave the fe very operative properties of natural bo. dies further afceriained by more Experiments and Obfervations: And it is with Satisfaction that we see them more and more confirm. ed to us, by every fartber enguiry we make; 


\section{vi \\ The PREACE.}

as the following Experiments will plainly prove, by hewing how great the power of the attraction of acid fulpbureous particles muft be at fome little diftance from the point of contact, to be able moft readily to fubdue and fix elaftick aereal particles, which repel with a force superior to vaft incumbent preffures: Which particles we find are thereby changed from a frongly repelling, to as frongly an attracting fate: And that elafticity is no immutable property of air, is further evident from thefe Experiments; becaufe it were impofsible for fuch great quantities of it to be confined in the fesbftances of Animals and Vegetables, in an elaficick ftaie, without rending their confituent parts with a vaft explofion.

$I$ bave been careful in making, and faith. ful in relating the refult of the experiments, and wifh I could be as happy in draw. ing the proper inferences from them. Hows ever I may fall jhort at firf seiting out in this fatical way of inquiring into the neture of Plants, yet there is good reafon to believe that confiderable advances in the knowledge of their nature may in process of time be made, by refearches of this kind. 


\section{The PREFACE:}

And I bope the publication of this Specithen of what I bave bitherto done, will put others upon the fame purfuits, there being in fo large a field, and among fuch an innumerable variety of fubjects, abundant room for many heads and hands to be employed in the work: For the wonderful and fecret operations of Nature are fo involved and intricate, fo far out of the reach of our fenfes, as they prefent themfelves to us in their natural order, that it is impofjible for the moft Sagacious and penetrating genius to pry into them, unle ss be will be at the pains of analysing Nature, by a numerous and regular Series of Experimenis; which are the only folid foundation whence we may reafonably expect to make any advance, in the real knowledge of the nature of things.

I muft not onit bere publickly to acknow: ledge, that I have in feveral respects been much olliged to my late ingenious and learned neighbour and friend Robert Mather, of the Inner-Temple, Efq; for bis affiftance berein.

$I$ had intended to have inferted many additional Obfervations and Experiments, in their proper places, in this fecond Edition of this book: But for the Jake of thoje who bave bought the firgt Edition, it is thought 
moft advifeable to print them, with many other Experiments, in another Volume; which, God willing, I purpose to do in a little time. For which reafon I call this the firf Volume; and have in this new Edition added the general Title of Statical ERfays, as moft fuitable to the feveral Subjects of boith Volumes.

Whereas fome complain that they do not underftand the fignification of thofe jhort figns or characters, which are bere made ufe of in many of the calculations, and which are ufual in Algebra; this mark + fignifies more, or to be added to. Thus page i 8 , line 4, 6 ounces +240 grains, is as much as to fay, 6 ounces more by, or to be added to 240 grains. And in line 16, of the fame page, this mark $x$ or crofs fignifies multiplied by; the two fhort parallel lines fignify equal to; thus I $820 \times 4=7280: I$, is as much as to $\int a y$, I 820 multiplied by 4 equal to 7280 is to 1 . 


\section{T H E}

\section{CONTENTS.}

C H A P. I.

HXperiments, Jhewing the quantities of 1 moifture imbibed and perfpired by Plants and Trees.

Page 4

\section{H A P. II.}

Experiments, whereby to find out the force with which Trees imbibe moifture. 84

\section{H A P. III.}

Experiments, Shewing the force of the Sap in the Vine in the bleeding Jeafon. I08

\section{H A P. IV.}

Experiments, Jhewing the ready lateral mow tion of the Sap, and consequently, the lateral communication of the Sap-veffels. The free paffage of it, from the fmall Branches towards the Stem, as well as from the Stem to the Branches, with an account of fome Experiments, relating to the Circulation, or Non-Circulation of the Sap. 


\section{The Contents.}

\section{H A P. V.}

Experiments, whereby to prove, that a confiderable quantity of air is inspired by Plants.

\section{H A P. VI.}

$A$ Specimen of an attempt to analyfe the Air by chymio-ftatical Experiments, which Shew, in how great a proportion Air is wrought into the compofition of Animal, Vegetable, and Mineral Subftances: And withal, bow readily it refumes its elaftick State, when in the diffolution of those Subfances it is difingaged from them. 162

\section{H A P. VII.}

Of Vegetation.

The Conclufiora. 
A TABle where to find each Experiment.

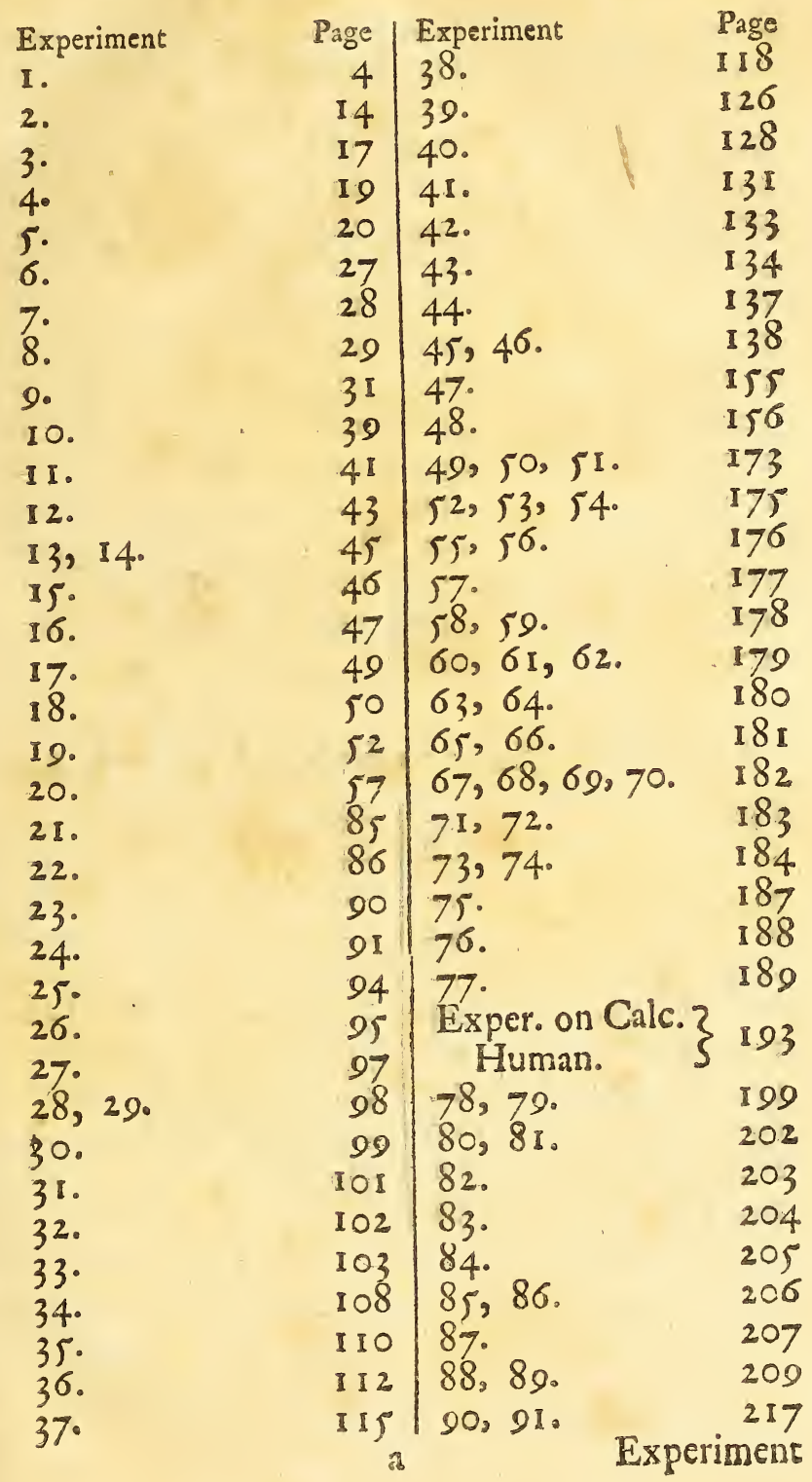


A TABLE where to find each Experiment.

\begin{tabular}{|c|c|c|c|}
\hline Experiment & Page & Experiment & Page \\
\hline 92. & $2 I 9$ & I 10. & 244 \\
\hline 93. & 220 & I I I. & 248 \\
\hline 94. & 22 I & I I 2 . & $2 \sqrt{2}$ \\
\hline 95. & 222 & I I 3 . & 253 \\
\hline $96,9 \%$. & 224 & II 4. & 255 \\
\hline 98. & 225 & II 5. & 263 \\
\hline 99. & 226 & I I 6. & 264 \\
\hline 100. & 227 & 117. & 273 \\
\hline 101. & 228 & I I 8. & $28 \mathrm{I}$. \\
\hline 102. & 229 & 19. & 288 \\
\hline 103 & 230 & I 20. & 299 \\
\hline 104 & 231 & I $2 \mathrm{I}$. & 304 \\
\hline $105,106$. & 232 & I 22. & 329 \\
\hline 107 & 236 & 123. & 33.1 \\
\hline 108. & 238 & 124. & 344 \\
\hline 109. & 239 & & \\
\hline
\end{tabular}

A TABLE where to find each FIGURE.

\begin{tabular}{|c|c|c|c|}
\hline Figure & Page & Figure & Page \\
\hline & 28 & & 132 \\
\hline $3,4,5$. & 42 & 25,26 & 134 \\
\hline & 44 & $27,28,29,30$. & I 52 \\
\hline $\begin{array}{l}7,8,9 . \\
10, \text { I I, I2. }\end{array}$ & 50 & $3 \mathrm{I}, 32$. & $\begin{array}{l}160 \\
168\end{array}$ \\
\hline $\begin{array}{l}10, \text { II, I2. } \\
13,14 .\end{array}$ & $\begin{array}{l}94 \\
98\end{array}$ & $\begin{array}{l}33,340 \\
35,36,37 .\end{array}$ & $\begin{array}{l}168 \\
210\end{array}$ \\
\hline $15,16,17,18$. & 112 & 38,39 & 266 \\
\hline 19. & IIs & $40,41,42,43,44$. & . 346 \\
\hline $20,2 I$. & 118 & 45,46 & 350 \\
\hline 22,230 & 130 & & \\
\hline
\end{tabular}




\section{T H E}

\section{INTRODUCTION.}

THE farther refearches we make into this admirable fcene of things, the more beauty and harmony we fee in them: And the ftronger and cleares convictions they give us, of the being, power and wifdom of the divine Architect, who has made all things to concur with a wonderful conformity, in carrying on, by various and innumerable combinations of matter, fuch a circulation of caufes, and effects; as was neceffary to the great ends of na: ture.

And fince we are afured that the all-wife Creator has oblerved the moft exact proportions, of number, weight and meafure, in the make of all things; the moft likely way therefore, to get any infight into the nature of thofe parts of the creation, which come within our obfervation, muft in all reafon be to number, weigh and meafure. And we have much encouragement to pur- 
fue this method, of fearching into the nature of things, from the great fuccefs that has attended any attempts of this kind.

Thus, in relation to thofe Planets which revolve about our Sun, the great Philofopher of our age has, by numbering and meafuring, difcovered the exadt proportions that are obferved in their periodical revolutions and diftances from their common centers of motion and gravity: And that God has not only comprebended the duft of the earth in a meafure, and weighed the mountains in fcales, and the bills in a balance, Ifai.xl. I2. but that he alfo holds the vaft revolving Globes, of this our folar Syftem, moft exactly poifed on their common center of gravicy.

And if we reflect upon the difcoveries that have been made in the animal oeconomy, we thall find that the moft confiderable and rational accounts of it have been chiefly owing to the ftatical examination of their fluids, viz. by enquiring what quantity of fluids, and folids diffolved into fluids, the animal daily takes in for its fupport and nourifhment: And with what force and different rapidities thofe fluids are car. ried 


\section{Vegetable Staticks.}

ried about in their proper channels, accord. ing to the different fecretions that are to be made from them: And in what proportion the recrementitious fluid is conveyed away, to make room for frefh fupplies: and what portion of this recrement nature allots to be carried off, by the feveral kinds of emunctories and excretory duets.

And fince in vegetables, their growth and the prefervation of their vegetable life is promoted and maintained, as in animals, by the very plentiful and regular motion of their fluids, which are the vehicles ordained by nature, to carry proper nutriment to every part; it is therefore reafonable to hope, that in them alfo, by the fame method of inquiry, confiderable difcoreries may in time be made, there being, in ma ny refpects, a great analogy between plants and animals.

$$
B 2 \text { CHAP }
$$


$4 \quad$ Vegetable Staticks.

\section{H A P. I.}

Experiments, Shereing the quantities imbibed and perpired by Plants and Trees.

\section{EXPERIMENTI.}

TLY 3.1724. in order to find out the quantity imbibed and perfpired by the Sun-Flower, I took a garden-pot (Fig. I.) with a large Sun-Flower, a, 3 feet $+\frac{1}{2}$ high, which was purpofely planted in it when young; it was of the large annual kind.

I covered the pot with a plate of thin milled lead, and cemented all the joints faft, fo as no vapour could pafs, but only air, thro" a fmall glafs tube $d$ nine inches long, which was fixed purporely near the ftem of the plant, to make a free communication with the outward air, and that under the leaden plate.

I cemented alfo another hort glafs tube $g$ into the plate, two inches long and one inch in diameter. Thro this tube I watered the plant, and then ftopped it up with a cork; I topped up alfo the holes $i, l$, at the bottom of the pot with corks.

I weighed 


\section{Vegetable Staticks.}

I weighed this pot and plant morning and evening, for fifteen feveral days, from Fuly 3. to Aug. 8. after which I cut off the plant clofe to the leaden plate, and then covered the ftump well with cement; and upon weighing found there perfpired thro the unglazed porous pot two ounces every twelve hours day, which being allowed in the daily weighing of the plant and pot, I found the greateft perfpiration of twelve hours in a very warm dry day, to be one pound fourteen ounces; the middle rate of perfpiration one pound four ounces. The perfpiration of a dry warm night, without any fenfible dew, was about three ounces; but when any fenfible, tho' fmall dew, then the perfpiration was nothing; and when a large dew, or fome little rain in the night, the plant and pot was increared in weight two or three ounces. N.B. The weights I made ufe of were Avoirdupoife weights.

I cut off all the leaves of this plant, and laid them in five feveral parcels, according: to their feveral fizes, and then meafured the furface of a leaf of each parcel, by laying over it a large lattice made with threads, in which the little fquares were $\frac{1}{4}$ of an inch

$$
\text { B } 3
$$

each: 


\section{6 \\ Vegetable Staticks.}

each; by numbering of which I had the furface of the leaves in fquare inches, which multiplied by the number of the leaves in the correfponding parcels, gave me the area of all the leaves; by which means I found the furface of the whole plant, above ground, to be equal to 5616 fquare inches, or 39 fquare feet.

I dug up another Sun flower, nearly of the fame fize, which had eight main roots, reaching fifteen inches deep and fideways from the ftem: It had befides a very thick buh of lateral roots, from the eight main roots, which extended every way in a Hemifphere, about nine inches from the ftem and main roots.

In order to get an entimate of the length of all the roots, I took one of the main roots, with its laterals, and meafured and weighed them, and then weighed the other feven roots, with their laterals, by which means I found the fum of the length of all the roots to be nyo lefs than 1448 feet.

And fuppofing the periphery of thefe roots at a medium, to be $\frac{10}{7}$ of an inch, then their furface will be 22.86 fquare inches, or 15.8 fquare feet; that is, e- 


\section{Vegetable Staticks.}

qual to $\frac{3}{8}$ of the furface of the plant above ground.

If, as above, twenty ounces of water, ate a medium, perfpired in twelve hours day (i.e.) thirty four cubick inches of water (a cubick inch of water weighing 254 grains) then the thirty four cubick inches divided by the furface of all the roots, is $=2286$ fquare inches; (i.e.) $\frac{34}{2 \frac{2}{8}} \mathrm{is}=\frac{\mathrm{I}}{6}$, this gives the depth of water imbibed by the whole furface of the roots, viz. $\frac{x}{67}$ part of an inch.

And the furface of the plant above ground being 5616 fquare inches, by which divid-

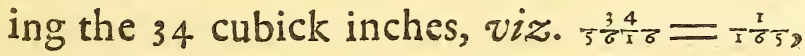
this gives the depth perfpired by the whole furface of the plant above ground, viz. $\frac{x}{5} \frac{x}{6}$ part of an inch.

Hence, the velocity with which water enters the furface of the roots to fupply the expence of perfiration, is to the velocity, with which the fap perfpires, as $165: 67$, or as $\frac{\pi}{67}: \frac{3}{6} \frac{1}{6}$, or nearly as $s: 2$.

The area of the tranfverfe cut of the middle of the ftem is a fquare inch; therefore the areas, on the furface of the leaves, the roots, and ftem, are $5616,2286.1$.

$$
\text { B } 4 \text { The }
$$


The velocities; in the furface of the leaves, roots, and tranfverfe cut of the ftem, are gained by a reciprocal proportion of the furfaces.

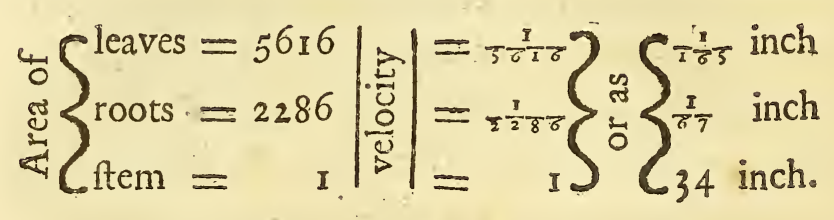

Now, their perfpiring 34 cubick inches in rwelve hours day, there muft fo much pafs 'thro' the ftem in that time; and the velocity would be at the rate of 34 inches in ewelve hours, if the ftem were quite hollow.

In order therefore to find out the quantity of folid matter in the ftcm, Fuly $27 t h$ at 7.a.m. I cut up even with the ground a Sunflower; it weighed 3 pounds; in thirty days it was very dry, and had wafted in all 2 pounds 4 ounces; that is $\frac{3}{4}$ of its whole weight: So here is a fourth part left for folid parts in the ftem, (by throwing a piece of green Sunflower fiem into water, I found it very near of the fame fpecifick gravity with water) which filling up fo much of the ftem, the velocity of the fap muft be increafed proportionably, riz. $\frac{1}{5}$ part more, (by 


\section{Vegelable Staticks.}

reafon of the reciprocal proportion) that 34 . cubick inches may pals the frem in twelve hours; whence its velocity in the ftem will be $45 \frac{2}{3}$ inches in twelve hours, fuppofing there be no circulation nor return of the fap downwards.

If there be added to 34 , (which is the leant velocity) $\frac{x}{3}$ of $\mathrm{it}=\mathrm{I} I \frac{1}{3}$, this gives the greateft velocity, viz. $45^{\frac{\pi}{3}}$. The fpaces being as $3: 4$. the velocities will be $4: 3:: 45 \frac{\pi}{3}: 34$.

But if we fuppofe the pores in the furface of the leaves to bear the fame proportion, as the area of the fap veffels in the frem do to the area of the ftem; then the velocity, both in the leaves, root and ftem, will be increafed in the fame proportion.

A pretty exact account having been taken, of the weight, fize, and furface of this plant, and of the quantities it has imbibed and perfpired, it may not be improper here, to enter into a comparifon, of what is taken in and perfpired by a human body, and this plant.

The weight of a well fized man is equal to 160 pound: The weight of the Sunflower is 3 pounds, fo their weights are to sach other as $160: 3$, or as $53: x$.

The 
The furface of fuch human body is equal to Is fquare feet, or 2 I 60 fquare inches.

The furface of the Sun-flower is 5616 fquare inches, fo its furface is to the furface of a human body as $26: 10$.

The quantity perfpired by a man in twenty four hours is about $3 \mathrm{I}$ ounces, as Dr. Keill found, vid. Medic. Stat. Britan. p. 14.

The quantity perfpired by the plant, in the fame time, is 22 ounces, allowing two ounces for the perfpiration of the beginning and ending of the night in $\mathcal{F} u l y$, viz. after evening and before morning weighing, juft before and after night.

So the perfpiration of a man to the Suriflower is as $14 \mathrm{I}: \mathrm{r} 00$.

Abating the fix ounces of the thirty one ounces, to be carried off by refpiration from the lungs in the twenty four hours; (which I have found by certain experiment to befo. much if not more) the twenty five ounces multiplied by $437 \frac{1}{2}$ the number of grains in an ounce Avoirdupois, the product is I0937 $\frac{1}{2}$ grains; which divided by 254 , the number of grains in a cubick inch of water, gives 43 cubick inches perfpired by a man: Which divided by the furface of his body, viz. 


\section{Vegetable Staticks.}

viz. 2160 fquare inches, the quotient is $\frac{7}{5:-p a r t ~ o f ~ a ~ c u b i c k ~ i n c h ~ p e r f p i r e d ~ o f f ~ a ~ f q u a r e ~}$ inch in twenty four hours. Therefore in equal furfaces and equal times the man perfpires $\frac{x}{50}$, the plant $\frac{2}{105}$, or as $50: 15$.

Which excefs in the man is occafioned by the very different degrees of heat in each: For the heat of the plant cannot be greates than the heat of the circum-ambient air, which heat in fummer is from 25 to 35 degrees above the freezing point, (vide Exp. 20.) but the heat of the warment external parts of a man's body is 54 fuch degrees; and the heat of the blood 64 degrees; which is nearly equal to water heated to fuch a degree as a man can well bear to hold his hand in, frirring it about; which heat is fufficient to make a plentiful evaporation.

$2 u$. Since then the perfpirations of equal areas in a man and a Sunflower, are to each other as $165: 50$, or as $3 \frac{\pi}{3}: I$; and fince the degrees of heat are as $2: I$, mult not the fum or quantity of the areas of the pores lying in equal furfaces, in the man and Sunflower, be as $16: I$ ? for it feems that the quantities of the evaporated fluid will be as the degrees of heat, and the fum of the areas of the pores traken together.

Dr. 


\section{2 \\ Vegetable Staticks.}

Dr. Keill, by eftimating the quantities of the feveral evacuations of his body, found that he eat and drank, every 24 hours, 4 pounds 10 ounces.

The Sunflower imbibed and perfpired in the fame time 22 ounces, fo the man's food, to that of the plant, is as 74 ounces to 22 ounces, or as $7: 2$.

But compared bulk for bulk, the plant imbibes I 7 times more freth food than the man: For deducting s ounces, which Dr.Keill allows for the faces alvi, there will remain 4 pounds $s$ ounces of freth liquor, which enters a man's veins; and an equal quantity paffes off every 24 hours. Then it will be found, that I 7 times more new fluid enters the fap veffels of the plant, and paffes off in 24 hours, than there enters the veins of a man, and paffes off in the fame time.

And fince, compared bulk for bulk, the plant perfpires feventeen times more than the man, it was therefore very neceffary, by giving it an extenfive furface, to make a large provifion for a plentiful perfiration in the plant, which has no other way of dir. charging fuperfuities; whereas there is provifion made in man, to carry off above 
half of what he takes in, by other eva: cuations.

For fince neither the furface of his body was extenfive enough to caufe fufficient exhalation, nor the additional wreak, arifing from the heat of his blood, could carry off above half the fluid which was neceffary to be difcharged every 24 hours; there was a neceffity of providing the kidneys, to percolate the other half through.

And whereas it is found, that 17 times more enters, bulk for bulk, into the fap veffels of the plant, than into the veins of a man, and goes off in 24 hours: One reafon of this greater plenty of frefh fluid in the vegetable than the animal body, may be, becaufe the fluid which is filtrated thro' the roots immediately from the earth, is not near fo full fraighted with nutritive particles as the chyle which enters the lacteals of animals; which defect it was neceffary to fupply by the entrance of a much greater quantity of fluid.

And the motion of the fap is thereby much. accelerated, which in the heartleis vegetable would otherwife be very llow; it having probably only a progreffive and not a circulating motion, as in animals. 
Since then a plentiful perfpiration is found fo neceffary for the health of a plant or tree, 'tis probable that many of their diftempers are owing to a ftoppage of this perfpiration, by inclement air.

The perfpiration in men is often ftopped to a fatal degree; not only by the inclemency of the air, but by intemperance, and violent heats and colds. But the more temperate vegetable's perfpiration can be ftopped only by inclement air; unlefs by an un. kindly foil, or want of genial moifture it is deprived of proper or fufficient nourifhment.

As Dr. Keill obferved in himfelf a confiderable latitude of degrees of healthy perfpiration, from a pound and half to 3 pounds; I have alfo obferved, a healthy latitude of perfiriration in this Sunflowcr, from 16 to 28 ounces, in twelve hours day. The more it was watered, the more plentifully it perfpired, (cateris paribus) and with fcanty watering the perfpiration much abated.

\section{EXPERIMENT II.}

From Fuly $3 d$. to Aug. $3 d$. I weighed for nine feveral mornings and evenings a 


\section{Vegetable Staticks.}

middle fized Cabbage plant, which grew in a garden pot, and was prepared with a leaden cover, as the Sunflower, Exper. Ift. Its greateft perfpiration in twelve hours day Was I pound 9 ounces; its middle perfpira: tion I pound 3 ounces, $=32$ cubick inches.' Its furface 2736 fquare inches, or 19 fquare feet. Whence dividing the 32 cubick inches by 2736 fquare inches, it will be found that a little more than the $\frac{\pi}{8}$ of an inch depth perfpires off its furface in twelve hours day.

The area of the middle of the Cabbage ftem is $\frac{x}{1} \frac{0}{5} 6$ of a fquare inch; hence the ve. locity of the fap in the ftem, is to the velocity of the perfpiring fap on the furface of the leaves, as $2736: \frac{1}{1} \frac{0}{5} 6:: 4268: 1$. for $\frac{2736 \times 156}{100}=4268$. But if an allow: ance is to be made for the folid parts of the ftem (by which the paffage is narrowed) the velociry will be proportionably increafed.

The length of all its roots $470 \mathrm{feet}$, their periphery at a medium $\frac{\pi}{2}$ of an inch, hence their area will be 256 fquare inches nearly; which being fo fmall in proportion to the area of the leaves, the fap mut go with 


\section{I6 Vegetable Staticks.}

near eleven times the velocity through the furface of the roots, that it does thro' the furface of the leaves.

And fetting the roots at a medium at i 2 inches long, they mut occupy a hemirphere of earth two feet diameter, that is, 2. I cubick fect of earth.

By comparing the furfaces of the roots of plants, with the furface of the fame plant above ground, we fee the neceffity of cutting off many branches, from a tranfplanted tree: For if 256 fquare inches of root in lurface was neceffary to maintain this $\mathrm{Cab}$ bage in a healthy natural thate: fuppofe upon digging it up, in order to tranfplant, half the roots be cut off (which is the cafe of mont young tran(planted trees) then it's plain, that but half the ufual nourithment can be carried up, through the roots, on that account; and a very much lefs proportion on account of the fmall hemifphere of earth, the new planted fhortened roots occupy; and on account of the loofe pofition of the new turned earth, which touches the roots at firf but in few points. This (as well as experience) Arongly evinces the great neceflity of well watering new plartations.

Which 


\section{Vegetable Staticks.}

Which yet muft be done with caution, for the skillful and ingenious Mr. Pbilip Miller F. R. S. Gardiner of the Botanick garden at Chelfea, in his very ufeful Gardiners and Florifts Dictionary, fays, "That he has often " Seen trees, that have had too much water "given them after planting, which has rotted "all the young fibres, as faft as they have " been pufhed out; and fo many times has "killed the tree." Supplement Vol. II. of planting. And I obferved that the dwarf pear-tree, whofe root was fet in water, in Exper. 7. decreafed very much daily in the quantity imbibed; viz. becaufe the fap veffels of the roots, like thofe of the cut off boughs, in the fame experiment, werc fo faturated and clogged with moifture, by ftanding in water, that more of it conld not be drawn up to fupport the leaves.

\section{EXRERIMENTIII}

From fuly 28. to Aug. 25. I weighed for twelve feveral mornings and evenings a thriving Vine growing in a por; I was furnifhed, with this and other trees, from his Majefty's garden at Hamoston-court, by the C. fayour 


\section{8 Vegetable Staticks.}

favour of the eminent Mr. Wife. This vine was prepared with a cover, as the Sunfower was. Its greateft perfpiration in 12 hours day, was 6 Ounces +240 grains; its middle perfpiration $s$ ounces +240 grains $=$ to $9^{\frac{x}{2}}$ cubick inches.

The furface of its leaves was I 820 fquare inches, or 12 fquare feet +92 fquare inches; whence dividing $9 \frac{x}{2}$ cubick inches, by the area of the leaves it is found that $7 \frac{7}{9}$ part of an inch depth, perfpires off in I 2 hours day.

The area of a tranfverfe cut of its ftem, was equal to $\frac{a}{4}$ of a fquare inch: hence the fap's velocity here to its velocity on the furface of the leaves, will be as $1820 \times 4=$ $7280: 1$. Then the real velocity of the fap's motion in the ftem is $=\frac{228}{19} \frac{8}{1}=38$ inches in $\mathrm{twelve}$ hours.

This is fuppofing the ftem to be a hollow tube: but by drying a large vine branch (in the chimney corner) which I cut off, in the bleeding feafon, I found the folid parts were $\frac{3}{4}$ of the frem; hence the cavity thro' which the fap paffes, being fo much narrowed, its velocity will be 4 times as great, viz. Is 2 inches in I 2 hours. 
But it is furcher to be confidered, that if the fap moves in the form of vapor and not of water, being thereby rarified, its velocity will be increafed in a direet proportion of the fpaces, which the fame quan. tity of water and vapor would occupy: And if the vapor is fuppofed to occupy ro times the fpace which it did, when in the form of water, then it mutt moveren times fafter; fo that the fame quantity or weight of each may pars in the fame time, thro" the fame bore or tube: And fuch allowance ought to be made in all thefe calculations concerning the motion of the fap in vegetables.

\section{EXPERIMENTIV.}

From July 29. to Aug. 25. I weighed for 12 feveral mornings and evenings, a paradife ftock Apple-tree, which grew in a garden pot, covered with lead, as the Sunflower: it had not a buhy head full of leaves, but thin fpread, being in all but 163 leaves whofe furface was equal to is 89 fquare inches, or I I fquare feet +5 , fquare inches.

The greatef quantity it perfpired in 12

$$
\text { C } 3
$$
hours 
hours day, was I i ounces, its middle quan. tity 9 ounces, or I $\frac{T}{2}$ cubick inches.

The I $5 \frac{T}{2}$ cubick inches perfpired, divided by the furface I 589 fquare inches, gives the depth perfpired off the furface in 12 hours day, viz. $x^{\frac{8}{0}} \overline{4}$ of an inch.

The area of a tranfverfe cut of its ftem, $\frac{x}{4}$ of an inch fquare, whence the fap's velocity here, will be to its velocity on the furface of the leaves as $15: 9 \times 4=6356: \mathrm{I}$.

\section{EXPEIIMENT V.}

From July 28. to Aug. 25. I weighed for Io feveral mornings and evenings a very thriving Limon-tree, which grew in a garden pot, and was covered as above: Its greatcft perfpiration in I 2 hours day was 8 ounces, its middle perfpiration 6 ounces, equal to 10 $0^{\frac{\pi}{3}}$ cubick inches. In the night it perfpired fometimes half an ounce, fometimes nothing, and fometimes increafed 1 or 2 ounces in weight, by large dew or rain.

i. The furface of its leaves was 2557 fquare inches; or 17 fquare feet +59 fquare inches; dividing then the Io cubick inches perfpired by this furface, gives the 2 depth 


\section{Vegetable Staticks.}

depth perfired in 12 hours day, viz. $\frac{7}{2 \frac{3}{4}}$ of an inch.

$$
\begin{aligned}
& \int \begin{array}{l}
T \frac{x}{9} T \text { in the vine in } I 2 \\
\text { hours day. }
\end{array} \\
& \frac{\pi}{50} \text { in a man, in a day } \\
& \text { and a night. } \\
& \frac{r}{65} \text { in a funflower, } \\
& \text { in a day and night. } \\
& \frac{1}{86} \text { in a cabbage, in I2 } \\
& \text { hours day. } \\
& \frac{7}{10.4} \text { in an apple-tree, } \\
& \text { in } 12 \text { hours day. } \\
& \frac{x}{2} \frac{x}{4} \text { in a limon-tree, } \\
& \text { in I } 2 \text { hours day. }
\end{aligned}
$$
going perfpirations in equal areas arc,

The area of the tranfverfe cut of the ftem of this Limon-tree was $=\mathrm{I}$. 44 of a fquare inch; hence the fap's velocity here, will be to its velocity on the furface of the leaves, as 1768 : I for $\frac{2557 \times 100}{\mathrm{I} 44}=1768$. This is fuppofing the whole ftem to be a hollow tube; but the velocity will be increafed both in the ftem and the leaves, in proportion as the paffage of the fap is narrowed by the folid parts.

By comparing the very different degrees of perfpiration, in there $s$ plants and trees,

$$
\mathrm{C}_{3}
$$


we may obferve, that the Limon-tree, which is an ever-green, perfpires much lefs than the, Sunflower, or than the Vine or the Appletree, whore leaves fall off in the winter: and as they perfpire lefs, fo are they the better able to furvive the winter's cold, becaufe they want proportionably but a very fmall fupply of frefh nourifhment to fupport them; like the exangueous tribe of animals, frogs, toads, tortoifes, ferpents, infects, $\& c$. which as they perfpire little, fo do they live the whole winter without food. And this I find holds true in $I_{2}$ other different forts of ever-greens, on which I have made Experiments.

The above mentioned Mr. Miller made the like experiments in the Botanick-garden at Chelfea, on a Plantain-tree, an Aloe, and a Paradife Apple-tree; which he weighed morning, noon, and night, for feveral fucceffive days, I thall here infert the diaries of them, as he communicated them to me, that the influence of the different temperatures of the air, on the perfpiration of thefe plants, may the better be feen.

The pots which he made ufe of were glazed, and had no holes in their bottoms as 


\section{Vegerable Staticks.}

garden pots ufually have; fo that all the moifture, which was wanting in them upon weighing, muft neceffarily be imbibed, by the roots of thofe plants, and thence per. fpired off thro' their leaves.

A diary of the perfpiration of the Mura Arbor, or Plantain-tree of the Weft-Indies. The whole furjace of the plant was i4 square feet, $8+\frac{x}{2}$ inches. The different degrees of beat of the air are here noted by the degrees above the freezing point in. my Thermometer, defcrib'd in Expcr. 20.

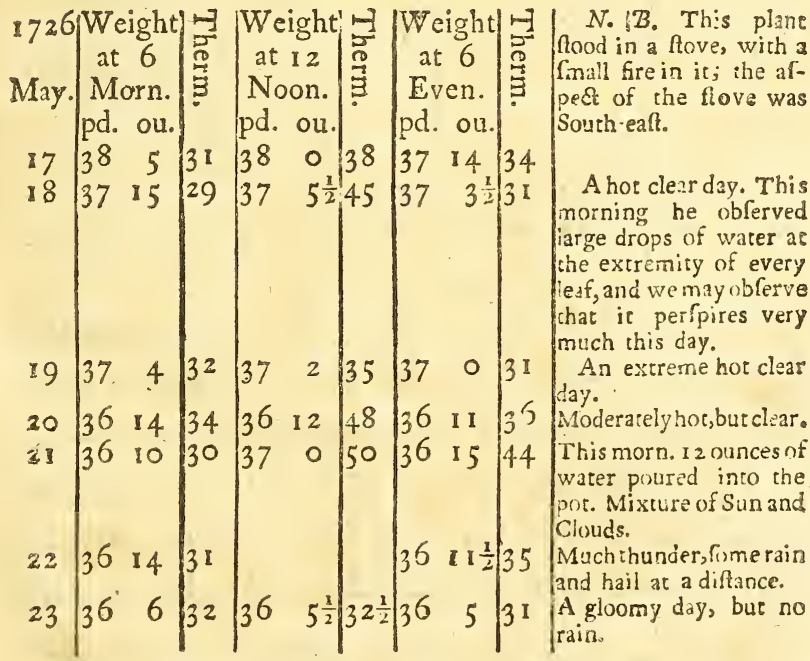

This evening 12 ounces of water were poured into the pot; and it was semoved from the flove into a cool room, where it thad a tree air but no. $3 u n$, the windows being North-wett.

$$
\mathrm{C}_{4} \text { Calm }
$$




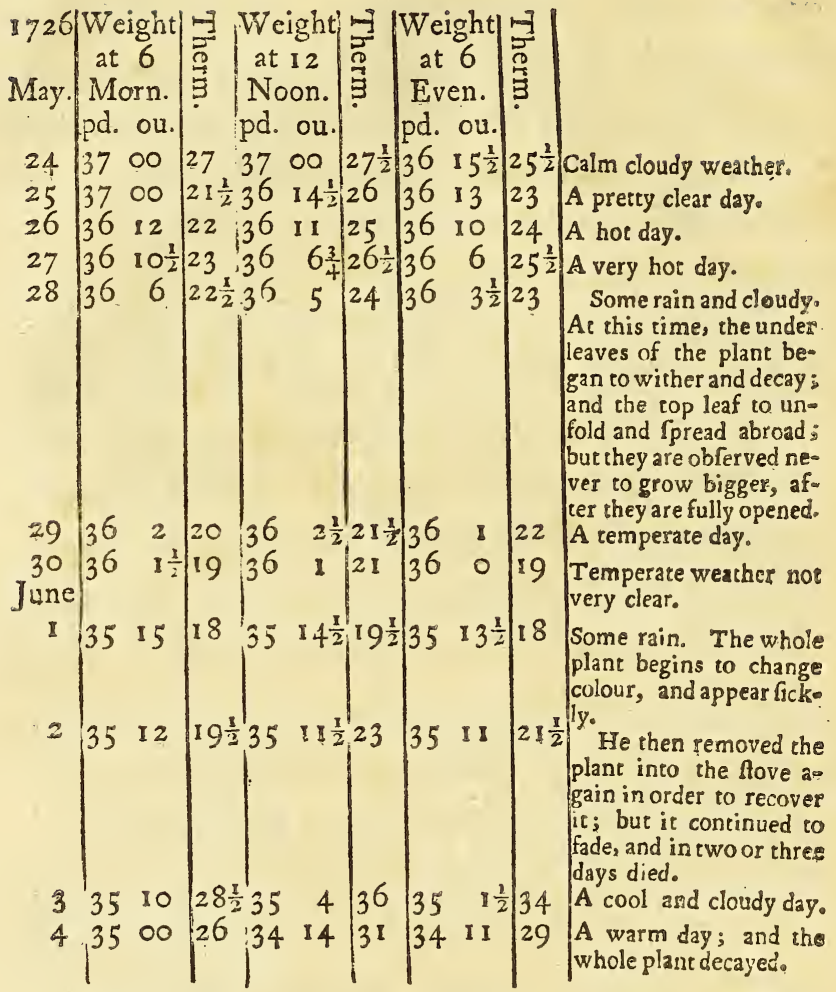

We may obferve from this diary, that this plant, when in the fove, ufually perfpired more in fix hours before noon than in 6 hours after noon; and that it perfpired much lefs in the night than in the day time; And fometimes increafed in weight in the night, by imbibing the moifture of the ambient air; and that both in the frove and 


\section{Vegetable Staticks.}

in the cool room. Upon making an eftimate of the quantity perfpired off a fquare inch of this plant, in I 2 hours day, it comes but to $-\frac{\mathrm{r}}{\sqrt{3}}=$ of a cubick inch; on the I 8 th day of May, when by far its greateft perfpiration was; for on feveral other days it was much lefs.

A diary of the Aloe Africana Caulefcens foliis Jpinofis, maculis ab utraque parte al. bicantibus notatis, Commelini hort. Am/t. commonly called the Carolina Aloe. It was a large plant of its kind. It ftood in a glafs-cafe, which had a South aspect without a fire.

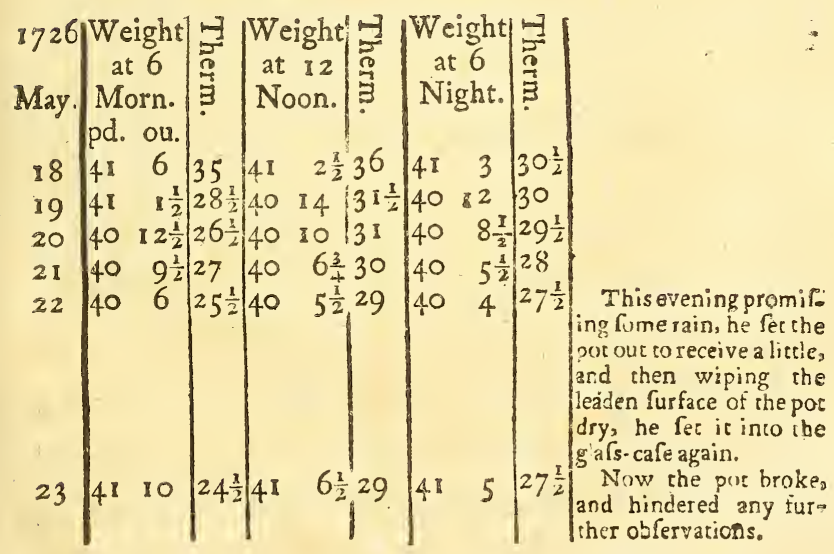

We may obferve, that this Aloe increafed in weight moft nights, and perfpired moft in the morning. 


\section{Vegetable Staticks.}

$A$ diary of a fmall Paradire-Apple, with one upright ftem 4 feet high; and two fmall lateral branches about 8 inches long. This plant ftood under a cover of wood which was open on all fides.

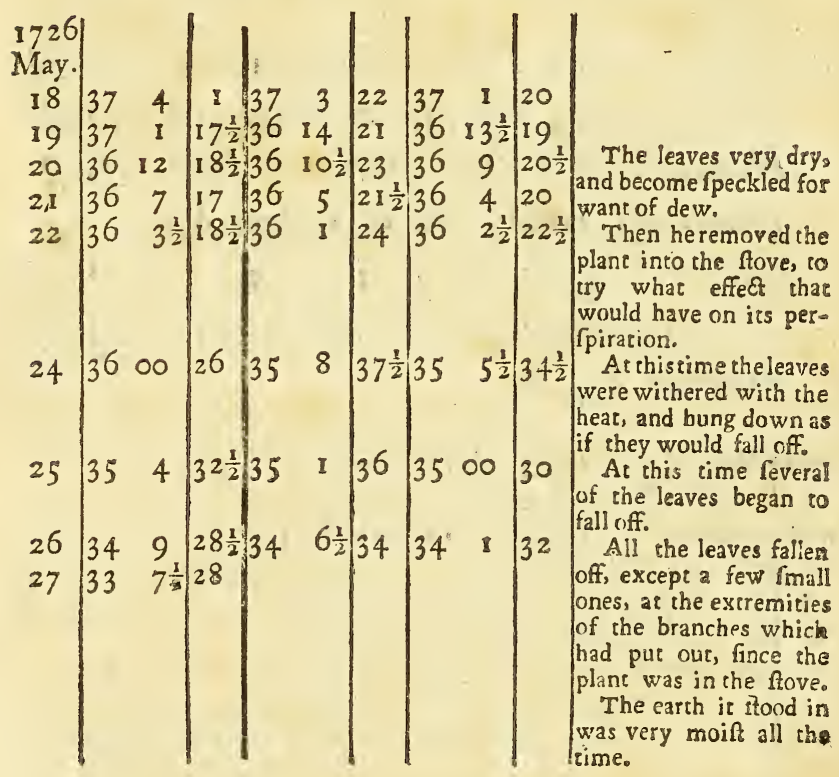

In OEtober 1725. Mr. Miller took up an African Briony-root, which when cleared from the mould weighed eight ounces $\frac{x}{2}$; he laid it on a thelf in the ftove, where it remained till the March following; when upon weighing he found it had loft of its weight. 
weight. In April it thot out 4 branches; two of which were $3 \frac{\pi}{2}$ feet long, the other two were one of them I4 inches, the other 9 inches, in length: Thefe all produced fair large leaves, it had loft $1 \frac{3}{4}$ ounce in weight, and in three weeks more it loft $2 \frac{1}{4}$ ounces more, and was much withered.

\section{EXPERIMENT VI.}

Spear-mint being a plant that thrives mott kindly in water, (in order the more accurately to obferve what water it would imbibe, and perfpire by night and day, in wet or dry weather) I cemented at $r$ a plant of it $m$, into the inverted fyphon $r y x b$ (Fig. 2.) the fyphon was $\frac{r}{4}$ inch diam. at $b$, but larger at $r$.

I filled it full of water, the plant imbibed the water fo as to make it fall in the day, (in March) near an inch and half from $b$ to $t$, and in the night $\frac{t}{4}$ inch from $t$ to $i$ : but one night, when it was fo cold, as to make the Thermometer fink to the freezing point, then the mint imbibed nothing, but hung down its head; as did alfo the young beans in the garden, their fap being great- 


\section{8 \\ Vegetable Staticks.}

ly condenfed by cold. In a rainy day the mint imbibed very little.

I purfued this Experiment no farther, Dr. Woodward having long fince, from feveral curious experiments and obfervations, given an account in the Philofophical Tranfactions, of the plentiful perfpirations of this plant.

\section{EXPERIMENT VII.}

In Auguf, I dug up a large dwarf Peartree, which weighed 7 I pounds 8 ounces; I fet its root in a known quantity of water; it imbibed is pounds of water in ten hours day, and perfpired at the fame time Is pounds 8 ounces.

In Fuly and Auguft I cut off feveral branches of Apple-trees, Pear, Cherry, and Apricot-trees, two of a fort; they were of feveral fizes from 3 to 6 feet long, with proportional lateral branches; and the tranfverfe cut of the largeft part of their ftems was a bout an inch diameter.

I ftripped the leaves off of one bough of each fort, and then fet their ftems in reparate glaffes, pouring in known quantities of water. 


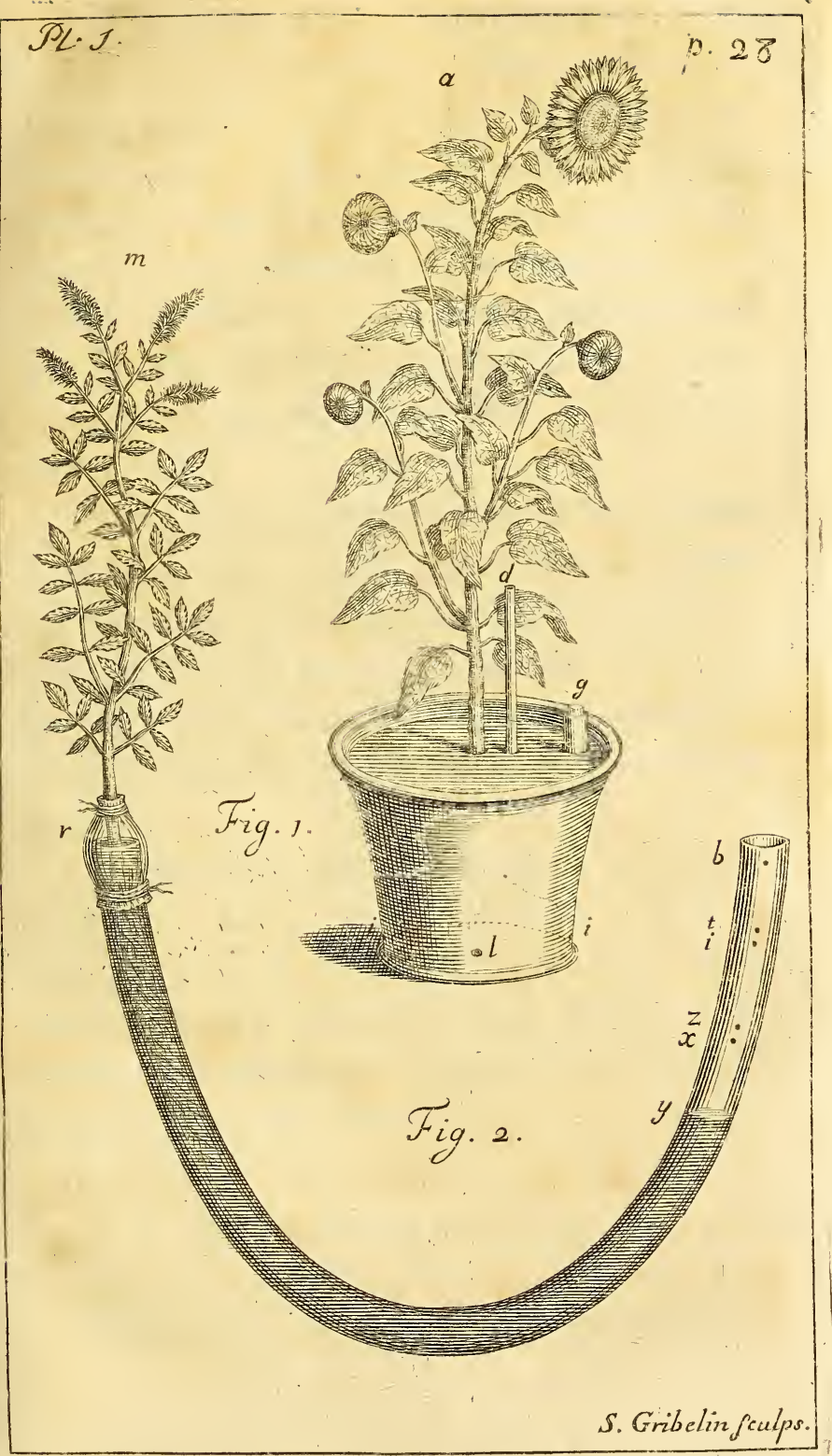





\section{Vegetable Staticks.}

The boughs with leaves on them im. bibed fome is ounces, fome 20 ounces 25 or 30 ounces in 12 hours day, more or lefs in proportion to the quantity of leaves they had; and when I weighed them at night they were lighter than in the morning.

While thofe without leaves imbibed but one ounce, and were heavier in the evening than in the morning, they having perspired little.

The quantity imbibed by thofe with leaves decreafed very much every day, the fap veffels being probably fhrunk, at the traneverfe cut, and too much faturate with water, to let any more pafs ; fo that ufually in 4 or 5 days the leaves faded and withered much.

I repeated the fame experiment with Elm. branches, Oak, Ofier, Willow, Sallow, Afpen, Curran, Goosberry; and Philbert branches; but none of the re imbibed fo much as the foregoing, and feveral forts of ever-greens very much lefs.

\section{EXPERIMENT VIII,}

Auguft Is. I cut off a large Ruflet-pippin ? 
with two inches ftem, and its $I 2$ adjoining leaves; I fet the ftem in a little viol of wa. ter it imbibed and perfpired in three days ${ }_{5}^{4}$ of an ounce.

At the fame time I cut off from the fame tree another bearing twig of the fame length, with 12 leaves on it, but no apple; it imbibed in the fame three days near $\frac{3}{4}$ of an ounce.

About the fame time I fet in a viol of water a fhort ftem of the fame tree, with two large Apples on it without leaves; they imbibed near $\frac{\pi}{4}$ ounce in two days.

So in this Experiment, the apple and the reaves imbibe $\frac{4}{5}$ of an ounce; the leaves alone near $\frac{3}{4}$, but the two large apples imbibed and perfpired but $\frac{x}{3}$ part fo much as the I 2 leaves; then one apple imbibed the $\frac{x}{5}$ part of what was imbibed by the 12 leaves, there. fore two leaves imbibe and perfpire as much as one apple; whence their perfpirations feem to be proportionable to their furfaces; the furface of the apple being nearly equal to the fum of the upper and under furfaces of the two leaves.

Whence it is probable, that the ufe of thefe leaves, (which are placed, juft where 


\section{Vegetable Staticks.}

the fruit joins to the tree) is to bring nourifhment to the fruit. And accordingly I obferve that the leaves, next adjoining to bloffoms, are, in the fpring, very much expanded, when the other leaves, on barren thoots, are but beginning to thoot: And that all peach leaves are pretty large before the bloffom goes off: And that in apples and pears the leaves are one third or half grown, before the bloffom blows: So provident is nature in making timely provifion for the nourifhing the yet embrio fruit.

\section{EXPERIMENT IX.}

Fuly Is. I cut off two thriving Hop vines near the ground, in a thick hady part of the garden, the pole ftill ftanding; I ftrip. ed the leaves off one of thefe vines, and fet both their ftems, in known quantities of water, in little bottles; that with leaves imbibed in 12 hours day 4 ounces, and that without leaves $\frac{3}{4}$ of an ounce.

I took another hop pole with its vines on it, and carried it out of the hop ground, into a free open expofure; thefe imbibed and perfired as much more as the former 


\section{Vegetable Staticks.}

in the hop-ground: Which is doubtlers the reafon why the hop-vines on the outfides of gardens, where moft expofed to the air, are thort and poor, in comparifon of thofe in the middle of the ground; viz. becaufe being much dried, their fibres harden fooner, and therefore they cannot grow ro kindly as thofe in the middle of the ground; which by thade are always kept moifter, and more ductile.

Now there being 1000 hills in an acre of hop-ground, and each hill having three poles, and each pole three vines, the number of vines will be 9000 ; each of which imbibing 4 ounces, the fum of all the ounces, imbibed in an acre in I 2 hours day, will be 36000 ounces, $=$ I\$750000 grains $=$ 62007 cubick inches or 220 gallons; which divided by 6272640 , the number of fquare inches in an acre, it will be found, that the quantity of liquor perfpired by all the hopvines, will be equal to an area of liquor, as broad as an acre, and $-\frac{\pi}{0}$ - part of an inch deep, befides what evaporated from the earth.

And this quantity of moifture in a kindly frate of the air is daily carried off, in a fuffi: 


\section{Vegetable Staticks.}

a fufficient quantity, to keep the hops in a healthy ftate; but in a rainy moift ftate of air, without a due mixture of dry weather, too much moifture hovers about the hops, fo as to hinder in a good meafure the kindly perfiriation of the leaves, whereby the ftagnating fap corrupts, and breeds moldy fen, which often fpoils vaft quantities of flourithing hop-grounds. This was the cafe in the year 1723 , when 10 or 14 days almoft continual rains fell, about the latter half of $7 u l y$, after four months dry weather; upon which the moft flourifhing and promifing hops were all infeeted with mold or fen, in their leaves and fruit, while the then poor and unpromifing hops efcaped, and produced plenty; becaufe they being fmall, did not perfpire fo great a quantity as the others; nor did they confine the perfpired vapour, fo much as the large thriving vines did, in their fhady thickets.

This rain on the then warm earth made the grafs thoot out as faft as if it were in a hot-bed; and the apples grew fo precipitately, that they were of a very flafhy conftitution, fo as to rot more remarkably thart had ever been remembred. 


\section{Vegetable Staticks.}

The planters obferve, that when a mold or fen has once feized any part of the ground, it foon runs over the whole; and that the grafs, and other herbs under the hops, are infected with it.

Probably becaufe the fmall feeds of this quick growing mold, which foon come to maturity, are blown over the whole ground: Which fpreading of the feed may be the reafon why fome grounds are infected with fen for feveral years fucceffively; viz. from the feeds of the lant year's fen: Might it not then be advifeable to burn the fenny hopvines as foon as the hops are picked, in hopes thereby to deftroy fome of the feed of the mold?

"Mr. Auftin of Canterbury obferves fen " to be more fatal to thofe grounds that " are low and fheltered, than to the high " and open grounds; to thofe that are fhel" ving to the North, than to the fhelving " to the South; to the middle of grounds, "than to the outfides; to the dry and "gentle grounds, than to the moift and Atiff " grounds. This was very apparent through" out the Plantations, where the land had "s the fame workmanthip and help beftow- 
"ed upon it, and was wrought at the fame " time; but if in either of thefe cafes there "was a difference, it had a different effect; " and the low and gentle grounds, that lay " neglected, were then feen lefs diftemper"ed than the open and moint, that were "carefully managed and looked after. "The honey dews are obferved to come " about the I I of Fune, which by the mid" dle of fuly turn the leaves black, and " make them ftink.

I have in Fuly (the feafon for fire-blafts, as the planters call them) feen the vines in the middle of a hop-ground all fcorched up, almolt from one end of a large ground to the other, when a hot gleam of Sunthine has come inmediately after a hower of rain; at which time the vapours are often feen with the naked eye, but efpecially with reflecting Telefcopes, to arcend fo plentifully, as to make a clear and diftinct object become immediately very dim and rremulous. Nor was there any dry gravelly vein in the ground, along the courfe of this fcorch. It was therefore probably owing to the much greater quantity of fcorching vapours in the middle than outfides of

$$
\text { D 2。 }
$$

the 


\section{Vegetable Staticks.}

the ground, and that being a denfer medium, it was much hotter than a more rare medium.

And perkaps, the great volume of afcending vapour might make the Sun-beams converge a little toward the middle of the ground, that being a denfer medium, and thereby increafe the heat confiderably; for I obferved, that the courfe of the fcorched hops was in a line at right angles, to the Sunbeams about eleven a clock, at which time the hot gleam was: The hop-ground was in a valley which run from South-weft to North-eaft : And to the beft of my remembrance there was then but little wind, and that in the courfe of the fcorch; but had there been fome other gentle wind, either North or South, 'tis not improbable but that the North wind gently blowing the Volume of rifing wreak on the South fide of the ground, that fide might have been moft fcorched, and fo vice ver $\hat{a}_{\text {. }}$.

As to particular fire-blafts, which fcorch here and there a few hop-vines, or one or two branches of a tree, without damaging the next adjoining; what Aftronomers obferve, may hint to us a no very improbable 


\section{Vegetable Staticks.}

caure of it; viz. they frequently obferve (efpecially with the reflecting Telefcopes) fmall feparate portions of pellucid vapors floating in the air; which tho' not vifible to the naked eye, are yet confiderably denfer than the circumambient air: And vapors of fuch a degree of denfity may very probably, either acquire fuch a fcalding heat from the Sun, as will fcorch what plants they, touch, efpecially the more tender : an effect which the gardiners about London have too often found to their coft, when they have incautiouly put bell-glaffes over their Collyfowers early in a frofty morning, before the dew was evaporated off them; which dew being raifed by the Sun's warmth, and confined within the glafs, did there form a denfe tranfparent fcalding vapor, which burnt and killed the plants. Or perhaps, the upper or lower furface of thefe tranfparent feparate flying volumes of vapors may, among the many forms they revolve into, fometimes approach fo near to a hemifphere, or hemicylinder, as thereby to make the Sun-beams converge enough, often to fcorch the more tender plants they thall fall on: And fometimes alfo, parts of the more hardy plants

D 3 and 
$3^{8}$ Vegetable Staticks.

and trees, in proportion to the greater or lefs convergency of the Sun's rays.

The learned Boerbaave, in his Theory of Chemiftry, Dr. Share's Edition, p. 245. obferves, "That thofe white clouds which ap"pear in fummer-time, are as it were fo ma"ny mirrors, and occafion exceffive heat. "Thefe cloudy mirrors are fometimes "round, fomctimes concave, polygonous, " $d w$. when the face of heaven is covered "with fuch white clouds, the Sun thining " among them, mult of neceffity produce 2 "vehement heat; fince many of his rays, "which would otherwife, perhaps, never "touch our earth, are hereby reflected to "us; thus if the Sun be on one fide, and " the clouds on the oppofite one, they will "be perfect burning glaffes. "I have fometimes (continues he) ob. " Ferved a kind of hollow clouds, full of "hail and fnow, during the continuance " of which the hear was extreme; fince by "fuch condenfation they were enabled to "reflect much more frongly. After this " came a tharp cold, and then the clouds " difcharged their hail in great quantity; " to which fucceeded a moderate warmth. 


\section{Vegetable Staticks.}

"Frozen concave clouds therefore, by their

" great reflections, produce a vigorous heat, " and the fame when refolved excefive " cold.

Whence we fee that blafts may be occafioned by the reflections of the clouds, as well as by the above mentioned refraction of denfe tranfparent vapors.

Fuly 2 $\mathrm{I}$. I obferved that at that feafon the top of the Sunflower being tender, and the flower near beginning to blow, that if the Sun rife clear the flower faces towards the Eaft 3 and the Sun continuing to fhine, at noon it faces to the South; and at fix in the evening to the Weft : And this not by turning round with the Sun, but by Nutation; the caufe of which is, that the fide of the ftem next the Sun perfpiring moft, it thrinks, and this plant perfpires much.

I have obferved the fame in the tops of Ferufalem-artichokes, and of garden-beans, in very hot Sun-hhine.

EXPERIMENT X.

Fuly 27. I fixed an Apple-branch, $m, 3$ feet long, $\frac{2}{2}$ inch diameter, full of leaves,

D 4 and 
40 Vegetable Staticks.

and lateral fhoots to the tube $t, 7$ feet long, $\frac{5}{8}$ of an inch diameter, (Fig. 3.) Ifilled the tube with water, and then immerfed the whole branch as far as over the lower end of the tube, into the veffel $u u$ full of water.

The water fubfided 6 inches the firft two hours, (being the firft filling of the fap verfels) and 6 inches the following night, 4 inches the next day; and $2+\frac{x}{4}$ the following night.

The third day in the morning I took the branch out of the water, and hung it with the tube affixed to it in the open air; it imbibed this day $27+\frac{\pi}{2}$ inches in 12 hours.

This Experiment thews the great power of perfiration; fince when the branch was immerfed in the veffel of water, the 7 feet column of water in the tube, above the furface of the water, could drive very little thro' the leaves, till the branch was expored to the open air.

This alfo proves, that the perfpiring matter of trees is rather actuated by warmth, and fo exhaled, than protruded by the force of the fap upwards. 


\section{Vegetable Staticks.}

And this holds true in animals, for the perfpiration in them is not always greatert in the greateft force of the blood; but then often leaft of all, as in fevers.

I have fixed many other branches in the fame manner to long tubes, without immerfing them in water; which tubes, being filled with water, I could fee precifely, by the defcent of the water in the tube $t$, how falt it perfpired off; and how very little perfpired in a rainy day, or when there were no leaves on the branches.

\section{EXPERIMENTXI。}

Aug. I7. At II $a: m$, I cemented to the tube $a b$ (Fig. 4.) 9 feet long, and $\frac{x}{2}$ inch diameter, an Apple-branch d, s feet long, $\frac{6}{8}$ inch diameter; I poured water into the tube, which it imbibed plentifully, at the rate of 3 feet length of the tube in an hour. At I a clock I cut off the branch at $c$, I 3 inches below the glafs tube. To the bottom of the remaining ftem I tied a glars ciftern $\mathscr{z}_{\text {, }}$ covered with ox-gut, to keep any of the water which dropped from the ftem $c$ b from evaporating. At the fame time I fet the branch 


\section{Vegetable Staticks.}

branch $d r$ which I had cut off in a known quantity of water, in the veffel $x$, (Fig. 5.) the branch in the veffel $x$ imbibed 18 oun ces of water in 18 hours day and 12 hours night; in which time only 6 ounces of water had paffed thro the ftem $c b$ (Fig. 4.) which had a column of water 7 feet high, preffing upon it all the time.

This again thews the great power of perfpiration; to draw thrice as much water, in the fame time, through the long flender parts of the branch $r$ (Fig. 5.) as was preffed thro' a larger ftem $c b$ (Fig. 4.) of the fame branch; but 13 inches long, with 7 feet preffure of water upon it, in the tube $a b$.

I tried in the fame manner another Apple-branch, which in 8 hours day imbibed 20 ounces, while only 8 ounces paffed thro' the ftem $c b$, (Fig. 4.) which had the column of water on it.

The fame I tried with a quince branch, which in 4 hours day imbibed 2 ounces $+\frac{x}{3}$, while but $\frac{x}{3}$ ounce paffed thro' the ftem $c b$ (Fig. 4.) which had 9 feet weight of water preffing on it.

Note, All thefe (under this Experiment iI.) were made the firt day, before the ftcm 


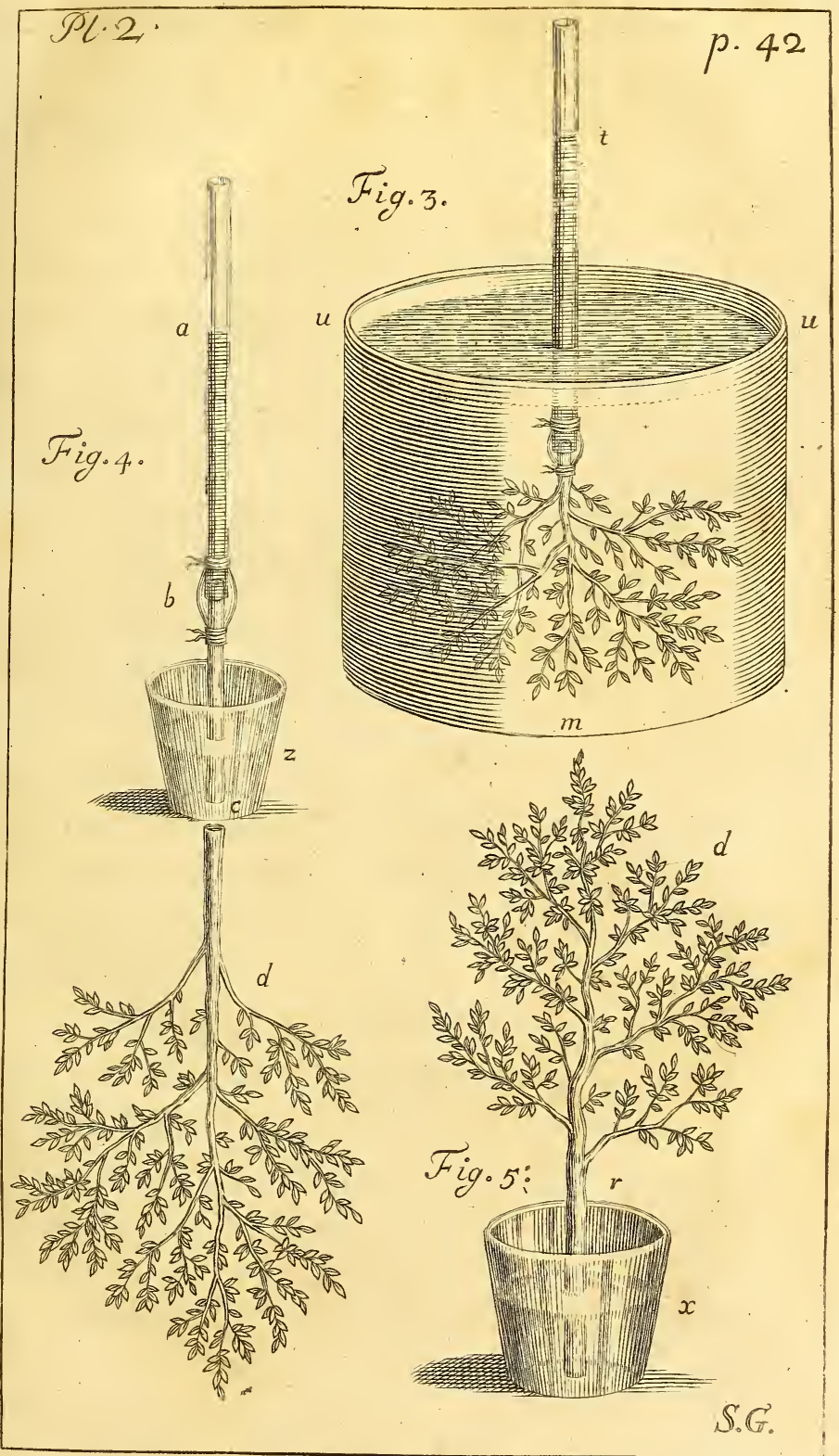





\section{Vegetable Staticks.}

ftem could be any thing faturate with water, or the fap-veffels thrunk fo as to hinder its paffage.

\section{EXPERIMENT XII.}

I cut off from a dwarf Apple-tree ew the top of the branch $l$, (Fig. 6.) which was an inch diameter, and fixed to the ftem $l$, the glais tube $l b$ : then I poured water into the tube, which the branch would imbibe, at fuch a rate as to drink down 2 or 3 pints in a day, efpecially if I fucked with my mouth at the top of the tube $b$, fo as that a few air bubbles were drawn out of the ftem $l$; then the water was imbibed fo faft, that if I immediately fcrewed on the mercurial gage, m r y $z$, the mercury would be drawn up to $r$, I 2 inches higher than in the other leg.

At another time I poured into the tube $l$, fixed to a golden Renate-tree, a quart of high rectified Spirit of wine camphorated, which quantity the ftem imbibed in 3 hours Space; this killed one half of the tree: this I did to try if I could give a flavour of camphire to the apples which were in great plenty 


\section{Vegetable Staticks.}

plenty on the branch. I could not perceive any alteration in the tafte of the apples, tho they hung feveral weeks after; but the fmell of the camphire was very ftrong in the ftalks of the leaves, and in every part of the dead branch.

I made the fame experiment on a vine, with ftrongly-fcented orange-flower-water; the event was the fame, it did not penetrate into the grapes, but very fenfibly into the wood and ftalks of the leaves.

I repeated the fame experiment on two diftant branches of a laige Catharine peartree, with ftrong decoctions of Saffafrafs, and of Elder-flowers, about 30 days before the pears were ripe; but I could not perceive any tafte of the decoctions in the pears.

Tho' in all thefe cafes the fap-veffels of the ftem were ftrongly impregnated with a good quantity of thefe liquors; yet the capillary fap-veffels near the fruit were fo fine, that they changed the texture of, and affimilated to their own fubftance thofe high tafted and perfumed liquors; in the fame manner as graffs and buds change the very different fap of the ftock to that of their own Ipecifick nature. 


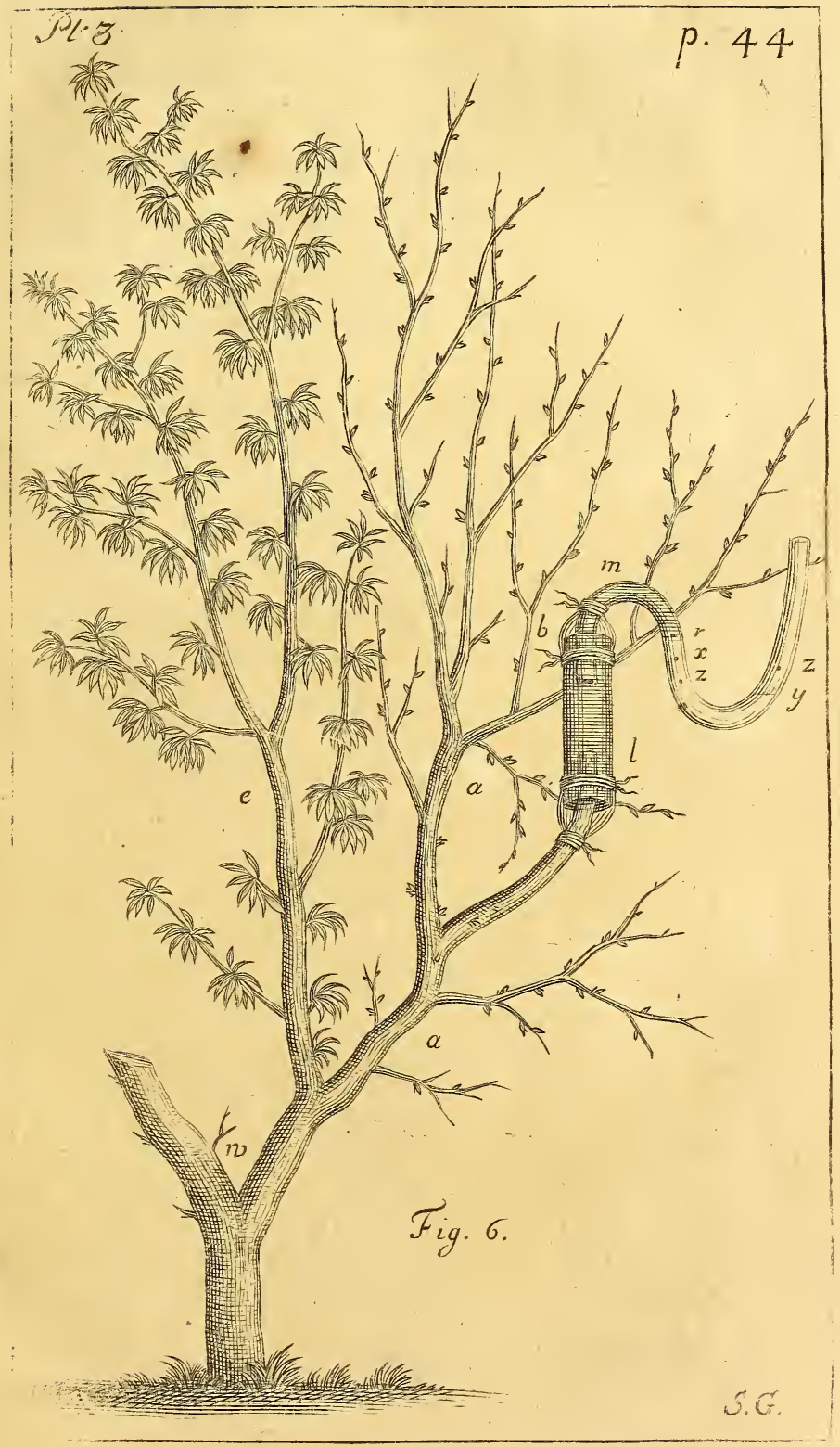





\section{Vegetable Staticks.}

This experiment may fafely be repeated with well fcented and perfumed common water, which trees will imbibe at $l b$ without any danger of killing them.

\section{EXPERIMENT XIII。}

In order to try whether the capillary fap. veffels had any power to protrude fap out at their extremities, and in what quantity, I made the three following experiments, viz.

In Auguft I took a cylinder of an applebranch, 12 inches long $\frac{7}{8}$ diameter: I fet it with its great end down wards in a mint glafs, (full of water) tyed over with ox-gut. The top of the ftick was moift for ten days, while another ftick of the fame branch (but out of water) was very dry. It evaporated an ounce of water in thofe ten days.

\section{EXPERIMENT XIV.}

In Sept. I fix'd a tube $t$ (Fig. 7.) 7 feet long, to a like ftem $\int$, as the former, and fet the ftem in water $x$, to try if, as the water evaporated out of the top of the ftem $r_{3}$ it would rife to any height in the tube $t$; but 


\section{$46 \quad$ Vegetable Staticks.}

it did not rife at all in the tube, tho" the top of the Atem was wet: I then filled the tube with water, but it paffed freely into the veffel $x$.

\section{EXPERIMENT XV.}

Sept. 10. $2+\frac{x}{2}$ feet from the ground, I cut off the top of a half ftandard Duke Cberry. tree againft a wall, and cemented on it the neck of a Florence flask $f$, (Fig. 8.) and to that flask neck a narrow tube $g$, five feet long, in order to catch any moifture that fhould arife out of the trunk $y$; but none arofe in four hours, except a little vapor that was on the flask's neck.

I then dug up the tree by the roots, and fet the root in water, with the glaffes affixed to the top of the ftem; after feveral hours nothing rofe but a little dew, which hung on the infide of $f$; yet it is certain by many of the foregoing experiments, that if the top and leaves of this tree had been on, many ounces of water would in this time have paffed thro' the trunk, and been evaporated thro' the leaves. 


\section{Vegetable Staticks.}

I have tryed the fame experiment with feveral vine branches cut off, and fet in water thus, but no water rofe into $f$.

Thefe three laft experiments all thew, that tho' the capillary fap veffels imbibe moifture plentifully; yet they have little power to protrude it farther, without the affiftance of the perfipiring leaves, which do greatly promote its progrefs.

\section{EXPERIMENT XVI.}

In order to try whether any fap rofe in the winter, I took in Fanuary feveral parcels of Filberd-fuckers, Vine-branches, green Jeffamine-branches, Philarea and Laurelbranches, with their leaves on them, and dipped their tranfverfe cuts in melted cement, to prevent any moifture's evaporating thro the wounds; I tyed them in feparate bundles and weighed them.

The Filberd-fuckers decreafed in 8 days (fome part of which were very wet, but the laft 3 or 4 days drying winds) the IIth part of their whole weight.

The Vine-cuttings in the fame time the $\frac{\pi}{3.4}$ part. 
The Jeffamine in the fame time the $\frac{\pi}{6}$ part.

The Philarea decreafed the $\frac{x}{4}$ part in five days.

The Laurel the $\frac{x}{4}$ part in 5 days, and more.

Here is a confiderable daily wafte of fap, which muft therefore neceflarily be fupplied from the root; whence it is plain that fome fap rifes all the winter, to fupply this continual wafte, tho' in much lefs quantity than in fummer.

Hence we fee good reafon why the llex and the Cedar of Libanus (which were grafted the firft on an Englifh-oak, the other on the Larix) were verdant all the winter, notwithftanding the Oak and Larix leaves were decayed and fallen off; for tho' when the winter came on, there did not fap enough rife to maintain the Oak and Larix leaves, yet by this prefent experiment we fee, that fome fap is continually rifing all the winter; and by experiment the sth on the Limon-tree, and by feveral other the like experiments, on many forts of ever-greens, we find that they perfpiring little, live and thrive with little nourifhment; the Ilex and Cedar might well therefore continue green all the winrer, notwithttanding the leaves of the trees they 


\section{Vegetable Staticks.}

they were grafted on fell off. See the late curious and induftrious Mr. Fairchild's account of thefe graftings in Mr. Miller's Gardiner's Dictionary, Vol. II. Supplement. Sap.

\section{EXPERIMENT XVÍI.}

Having by many evident proofs in the foregoing experiments feen the great quantities of liquor that were imbibed and perfpired by trees, I was defirous to try if I could get any of this perfpiring matter; and in order to it, I took feveral glafs chymical retorts; $b a p$ (Fig. 9.) and put the boughs of feveral forts of trees, as they were growing with their leaves on, into the retorts, ftoping up the mouth $p$ of the retorts with biadder. By this means I got feveral ounces of the perfpiring matter of Vines, Fig-trees, Apple-trees, Cherry-trees, Apricot and Peach-trees; Rue, Horfe-radifh, Rheubarb, Parfnip, and Cabbage leaves: the liquor of all of them was very clear, nor could I difcover any different tafte in the feveral liquors: But if the retort Atand expofed to the hot fun, the liquor will. tafte of the coddled leaves. Its Specifick gravity was nearly the fame with that of 


\section{Vegetable Staticks.}

common water; nor did I find many air bubbles in it, when placed in the exhaufted receiver, which I expected to have found; but when referved in open viols, it ftinks fooner than common water; an argument that it is not pure water, but has fome heterogeneous mixtures with it.

I put alfo a large Sun-flower full blown, and as it was growing, into the head of a glafs-till, and put its roftum into a bottle, by which means there diftilled a good quantity of liquor into the bottle. It will be very eafy in the fame manner to collect the perfpirations of fweet fcented Flowers, tho' the liquor will not long retain its grateful odor, but fink in few days.

\section{EXPERIMENT XVIII.}

In order to find out what ftores of moiAture nature had provided in the earth, (againf the dry fummer feafon) that might anfwer this great expence of it, which is fo neceffary for the production and fupport of vegerables.

Fuly 31. I724. I dug up a cubick foot earth, in an alley which was very litrle rampled on; it weighed (after deducting the weight of the containing verel) 104 


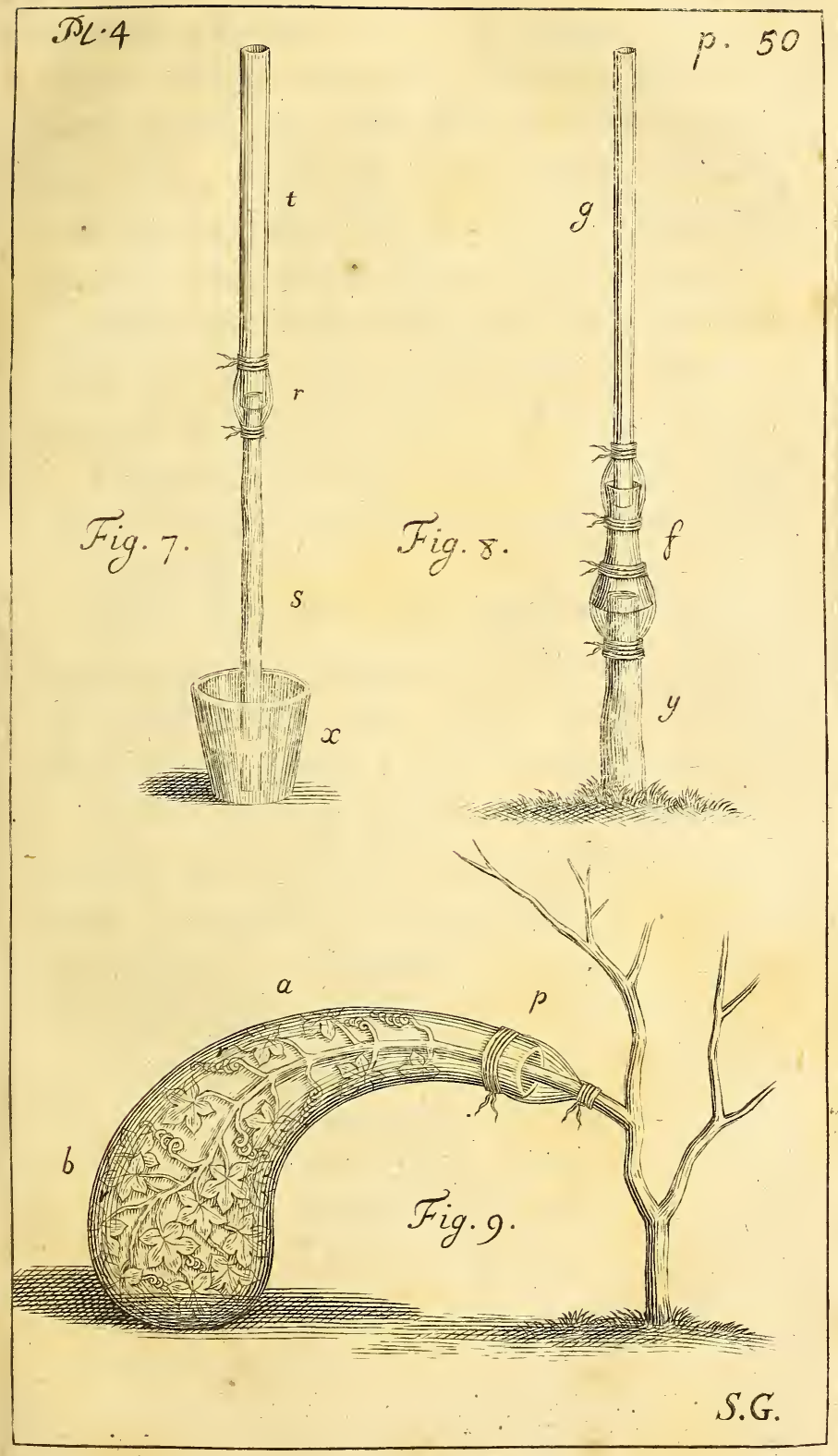





\section{Vegetable Staticks. $\quad 5$} pounds 4 ounces $+\frac{7}{3}$. A cubick foot of water weighs nearly 62 pounds, which is little more than half the fpecifick gravity of earth. This was a dry feafon, with a mixture of fome few fhowers, fo that the grafs-plat adjoining was not burnt up.

At the fame time I dug up another cubick foot of earth, from the bottom of the former, it weighed 106 pound 6 ounces $+\frac{1}{3}$.

I dug up alfo a third cubick foot of earth, at the bottom of the two former, it weighed II I pounds $+\frac{\pi}{3}$.

Thefe three feet depth were a good brick earth, next to which was gravel, in which at 2 feet depth, viz. 5 feet below the furface of the earth, the fprings did then run.

When the firft cubick foot of earth was fo dry and dufty, as to be unfit for vegetation I weighed it, and found it had lort 6 pound + II ounces, or 194 cubick in. ches of water, near $\frac{7}{8}$ part of its bulk.

Some days after, the fecond cubick foot being dryer than either the firft or third, was decreafed in weight ro pounds.

The third cubick foot, being very dry and dufty, had loft 8 pounds 8 ounces, or 247 cubick inches, vizo $\frac{1}{7}$ part of its bulk.

$$
E=\quad \text { Now }
$$


Now fuppofing the roots of the Sunflower (the longeft of which reached $I 5$ inches every way from the ftem) to occupy and draw nourifhment from 4 cubick feet of earth, and fuppofe each cubick foot of earth to afford 7 pounds of moifture, before it be too dry for vegetation; the Plant imbibing and perfpiring 22 ounces every 24 hours, that will be 28 pounds of water, which will be drawn off in 21 days and 6 hours; after which the Plant would perifh if there were not frefh fupplies to thefe 4 cubick feet of earth, either from dew or moifture arifing from below is inches (the depth of the roots) up into the earth occupied by the roots.

\section{EXPERIMENT XIX.}

In order to find out the quantity of Dew that fell in the night, Aug. I s. at 7.p.m. I chofe rwo glazed earthen Pans, which were 3 inches deep, and I 2 inches diameter in furface; I flled them with pretty moift earth taken off the furface of the earth. I fet thefe Pans in other broader Pans, to prevent any moifture from the earth ficking to the bottoms of them. The moifter the carth, the more Dew there falls on it in a night, 
night, and more than a double quantity of Dew falls on a furface of water, than there does on an equal furface of moift earth. The evaporation of a furface of water in 9 hours winter's dry day is $\frac{r}{2 T}$ of an inch. The evaporation of a furface of ice, fet in the fhade during 9 hours day, was $\frac{1}{3}$.

There Pans increafed in weight by the night's Dew 180 grains; and decrcafed in weight by the evaporation of the day I ounce, 282 grains. So here are 540 grains more evaporated from the earth every 24 hours in fummer, than falls in Dew in the night; that is, in 2 I days near 26 ounces, from a circular area of a foot diameter; and circles being as the fquares of their diameters, 10 pounds +2 ounces will in $2 \mathrm{I}$ days be evaporated from the hemifphcre of 30 inches diameter, which the Sunflower's root occupies: Which with the 29 pounds drawn off by the Plant in the fame time, makes 39 pounds, that is, 9 pounds and 3 out of every cubick foot of earth, the Plant's roots occupying more than 4 cubick feet; but this is a much greater degree of drynefs than the furface of the earth ever fuffers for is inches depth, even in the dry: ef feafons in this country.

$$
\text { E } 3 \text {. }
$$


54 Vegetable Staticks.

In a long dry feafon, therefore, efpecially within the Tropicks, we muft have recourfe for fufficient moifture (to keep Plants and Trees alive) to the moift ftrata of earth, which lay next below that in which the. roots are. Now moift bodies always communicate of their moifture to more dry adjoining bodies; but this now motion of the afcent of moifture is much accelerated by the Sun's heat to confiderable depths in the earth, as is probable from the following 2oth Experiment.

Now I 80 grains of Dew falling in one nighe, on a circle of a foot diameter, $=$ I 3 fquare inches; thefe 180 grains being equally fpread on this furface, its depth will be ${ }_{-\frac{8}{5} 5}$ part of an inch $=\frac{180}{113 \times 254^{\circ}}$ I found the depth of Dew in a winter night to be the $\frac{1}{5}$ part of an inch; fo that if we allow I I nights for the extent of the fummer's Dew, it will in that time arife to one inch depth. And reckoning the remaining 2 I4 nights for the extent of the winter's. Dew, it will produce 2. 39 inches depth, which makes the Dew of the whole year amount to 3.39 inches depth.

And the quantity which evaporated in a 


\section{Vegetable Staticks.}

fair fummer's day from the fame furface, being I ounce +282 grains, gives $\frac{1}{40}$ part of an inch depth for evaporation, which is four times as much as fell at night.

I found, by the fame means, the evaporation of a winter's day to be nearly the fame as in a fummer's day; for the earth being in winter more faturate with moifture, that excefs of moifure anfwers to the excefs of heat in fummer.

Nic. Cruquius, $\mathrm{N}^{\circ} 38 \mathrm{I}$. of the Philorophical Tranfactions, found that 28 inches depth evaporated in a whole year from water, i.e. $\frac{\mathrm{r}}{\mathrm{T}} \mathrm{s}$ of an inch each day, at a mean rate; but the earth in a fummer's day evaporates $\frac{\mathrm{r}}{40}$ of an inch; fo the evaporation of a furface of water, is to the evaporation of a furface of earth in fummer, as $10: 3$.

The quantity of Rain which falls in a year is at a medium 22 inches: The quantity of the earth's evaporation in a year is at leaft $9+\frac{1}{2}$ inches, fince that is the rate, at which it evaporates in a fummer's day: From which $9+\frac{\pi}{2}$ inches is to be deducted 3.39 inches for circulating daily Dew; there remains 6.2 inches, which 6.2 inches deducted from the quantity of Rain which falls in a year, there remains at leaft 16 inches

$$
\text { E } 4
$$

depth, 


\section{;6 Vegetable Staticks.}

depth, to replenifh the earth with moifture for vegetation, and to fupply the Springs and Rivers.

In the cafe of the hop-ground, the evaporation from the hops may be confidered only for three months at $\div \frac{x}{\circ}-\mathrm{T}$ part of an inch each day, which will be $\frac{2}{i}$ of an inch; but before we allow 6.2 inches vapor to evaporate from the furface of the ground, which added to $\frac{}{10}$ inch, gives 7.1 inches, which is the utmoft that can be evaporated from a furface of hop-ground in a year. So that of 22 inches depth of rain, there remains is inches to fupply fprings; which are more or lefs exhaufted, according to the drynefs or wetnels of the year. Hence we find that 22 inches depth of rain in a year is fufficient for all the purpores of nature, in fuch flat countries as this about Teddington near Hampton:Court. But in the hill countries, as in Lancafbire, there falls 42 inches depth of rain-water; from which deduating 7 inches for evaporation, there remains 35 inches depth of water for the fprings; befides great fupplies from much more plentiful dews, than fall in plain countries: Which vaft ftores feem fo abundantly fufficient to anfwer the great quantity of

water, 


\section{Vegetable Staticks.}

water, which is conveyed away, by fprings and rivers, from thofe hills, that we need not have recourfe, for fupplies, to the great $A b y \int S$, whofe furface, at high water, is furmounted fome hundreds of feet by ordinary hills, and fome thoufands of feet by thofe vaft hills from whence the longeft and greateft rivers take their rife.

\section{EXPERIMENT XX.}

I provided me fix Thermometers, whofe ftems were of different lengths, viz. from Is inches to 4 feet. I graduated them all by one proportional fcale, beginning from the freezing point; which may well be fixed as the utmoft boundary of vegetation on the fide of cold, where the work of vegetation ceafes, the watry vehicle beginning then to condenfe and be fixed; tho' many trees, and fome plants, as grafs, mors, \&oc. do furvive it; yet they do not vegetate at that time.

The greatef degree of heat, which I at firt marked on my Thermometers, was equal to that of water, when heated to the greateft degree that I could bear my Hand in it, . without ftirring it about. But finding by experience, that plants can endure, with- 


\section{Vegetable Staticks.}

out prejudice, a fomething greater Heat than this, I have pitched upon the heat in which melted wax fwimming on hot water firft begins to coagulate; for fince a greater heat than this will diffolve the wax, which is a vegetable fubftance, this may therefore well be fixed as the utmoft boundary of vegetation, on the warm fide; beyond which plants will rather fade than vegetate, fuch degree of heat feparating and difperfing, infiead of congregating, and uniting the nutritive particles.

This fpace I divided into a 100 degrees on all the Thermometers, beginning to number from the freezing point. Sixty four of thefe degrees is nearly equal to the heat of the blood of animals; which I found by the rule given in the Philosopbical Tranfattions, Vol.II. p. I. of Mr. Motte's Abridgment, which is fuppored to be Sir Ifaac Newton's eftimate, viz. by placing one of the Ibermometers in water heated to the greateft degree that I could bear my hand in it firring it about: And which I was further affured of, by placing the ball of my Thermometer in the flowing blood of an expiring $O x_{0}$. The hear of the blood to that of boiling water is as $14+\frac{3}{3}$ to 33 . 


\section{Vegetable Staticks.}

By placing the ball of one of thefe Thermometers in my bofom, and under an armpit, I found the external heat of the body 54 of thefe degrees. The heat of milk, as it comes from the Cow, is equal to ss degrees, which is nearly the fame with that for hatching of eggs. The heat of urine 58 degrees. The common temperate point in Thermometers is about I 8 degrees.

The hotteft Sun-hine in the year 1727 raifed the fpirit in the Thermometer expofed to it, 88 degrees; a heat 24 degrees greater than that of the blood of animals: And tho' plants endure this and a confiderably greater heat within the tropicks, for fome hours each day, yet the then hanging of the leaves of many of them fhews that they could not long fubfift under it, were they not frequently refrefhed by the fucceeding evening and night.

The common noon-tide heat in the Sun in $\mathcal{F}$ ly is about 50 degrees: The heat of the air in the thade in $\mathcal{F} u l y$ is at a medium 38 degrees. The May and $\mathcal{F}$ une heat is from I 7 to 30 degrees; the moft genial heat for the generality of plants, in which they flourifh moft, and make the greateft progrefs in their growth. The autumnal and vernal 


\section{0 \\ Vegetable Staticks.}

heat may be reckoned from 10 to-20 degrees. The winter heat from the freezing point to ro degrees.

The fcorching heat of a hot-bed of horfedung, when too hot for plants, is equal to 85 degrees and more, and hereabout is probably the heat of blood in high fevers.

The due healthy heat of a hot-bed of horfe-dung, in the fine mold, where the roots of thriving Cucumber-plants were, in Feb. was equal to s6 degrees, which is nearly the bofom heat, and that for hatching of eggs. The heat of the air under the glafs-frame of this hot-bed was equal to 34 degrees; fo the roots had 26 degrees more heat than the plants above ground. The heat of the open air was then 17 degrees.

It is now grown a common and very reafonable practice, to regulate the heat of ftoves and green-houfes, by means of $T$ hermometers hung up in them. And for greater accuracy, many have the names of fome of the principal exoticks written upon their Thermometers, over-againt the feveral degrees of heat, which are found by experience to be propereft for them. And I am informed that many of the moft cu- 


\section{Vegetable Staticks. 6 I}

rious Gardiners about London have agreed to make ufe of Thermometers of this fort; which are made by Mr. Fohn Fowler in Swithins-Alley, near the Royal-Exchange; which have the names of the following plants, oppofite to their refpective moft kindly degrees of heat; which in my Ther. mometers anfwer nearly to the following degrces of heat above the freezing point, viz. Melon-thiftle 3 I, Ananas 29, Piamento 26, Euphorbium 24, Cereus 2 I $\frac{\pi}{2}$, Aloe 19, Indian-fig $16 \frac{1}{2}$, Ficoides I4, Oranges 12, Myrtles 9.

Mr. Boyle, by placing a Thermometer in a cave which was cut furait into the bottom of a cliff, fronting the Sea, to the depth of $130 \mathrm{feet}$, found the fpirit ftood, both in winter and fummer, at a fmall divifion above temperate; the cave had 80 feet depth of earth above it. Boyle's Works, Vol. III. p. 54 .

I marked my fix Thermometers numerically, $1,2,3,4,5,6$. The Thermometer numb. I, which was fhorteft, I placed with a. South arpect, in the open air; the ball of numb. 2, I fet two inches under ground; that of numb. 3 , four inches under ground; numb. 4 , sinches; numb. 5, 16 inches; and

numb. 
62 Vegetable Staticks.

numb. 6, 24 inches under ground. And that the heat of the earth, at thefe feveral depths, may the more accurately be known, it is proper to place near each Thermometer a glafs-tube fealed at both ends, of the fame length with the ftems of the feveral Ther. mometers; and with tinged fpirit of wine in them, to the fame height, as in each correfponding Thermometer; the fcale of degrees, of each Thermometer, being marked on a niding ruler, with an index at the back of it, pointing to the correfponding tube. When at any time an obfervation is to be made, by moving the index, to point to the top of the fpirit in that tube, an accurate allowance is hereby made, for the very different degrees of heat and cold, on the ftems of the Thermometers, at all depths; by which means the fcale of degrees will fhew truly the degrees of heat in the balls of the Thermometers, and confequently, the refpective heats of the earth at the feveral depths where they are placed. The ftems of thefe Thermometers, which were above ground, were fenced from weather and injuries by fquare wooden tubes; the ground they were placed in was a brick earth in the middle of my garden. 
Fuly 30. I began to keep a regifter of their rife and fall. During the following month of Auguft, I obferved that when the Spirit in the Thermometer numb. $I$; (which was expofed to the Sun) was about noon rifen to 48 degrees, then the fecond Thermometer was 45 degrees, the fifth 333 and the fixth. $3 \mathrm{I}$; the third and fourth at intermediate degrees. The fifth and fixth Thermometer kept nearly the fame degree of heat both night and day, till towards the latter end of the month; when as the days grew thorter and cooler, and the nights longer and cooler, they then fell to 25 and 27 degrees.

Now, fo confiderable a heat of the Sun, at two feet depth, under the earth's furface, muft needs have a ftrong influence in raifing the moifture at that and greater depths; whereby a very great and continual wreak muft always be afcending, during the warm fummer feafon, by night as well as day; for the heat at two feet depth is nearly the fame night and day: The impulfe of the Sunbeams giving the moifture of the earth a brisk undulating motion, which watery particles, when feparated and rarified by heat, do arcend in the form of vapour: And the 


\section{Vegetable Staticks.}

vigour of warm and confined vapour, (fuch as is that which is $\mathrm{r}, 2$, or 3 fcet decp in the earth) muft be very confiderable, fo as to penetrate the roots with fome vigour; as we may reafonably fuppofe, from the vaft force of confined vapour in Eolipiles, in the digefter of bones, and the engine to raife water by fire.

If plants were not in this manner fupplied with moifure, it were impoffible for them to fubfift under the fcorching heats within the tropicks, where they have no rain for many months together: For tho the dews are much greater there, than in thefe more Northern climates; yet doubtlers where the heat fo much exceeds ours, the whole quantity evaporated in a day there, does as far exceed the quantity that falls by night in dew, as the quantity evaporat ed here in a fummer's day, is found to exceed the quantity of dew which falls in the night. But the dew, whicn falls in a hot fummer feafon, cannot polfibly be of any benefit to the roots of trees; becaufe it is remanded back from the earth by the following day's heat, before fo fmall a quanti. ty of moifture can have foaked to any confiderable depth. The great benefit there: 


\section{Vegetable Staticks.}

fore of dew, in hot weather, muft be, by being plentifully imbibed into vegetables; thereby not only refrefhing them for the prefent, but alfo furnifhing them with a freth fupply of moifture towards the great expences of the fucceeding day.

'Tis therefore probable, that the roots of trees and plants are thus, by means of the Sun's warmth, conftantly irrigated with frefh fupplies of moifture; which, by the fame means, infinuates it felf with fome vigour into the roots. For if the moifture of the earth were not thus aduated, the roots muft then receive all their nourifhment meerly by imbibing the next adjoining moifture from the earth; and confequently the fhell of earth, next the furface of the roots, would always be confiderably dricr the nearer it is to the root; which I have not obferved to be fo. And by Exper. I 8, and 19 , the roots would be very hard put to it to imbibe fufficient moifture in dry fummer weather, if it were not thus conveyed to them, by the peinetrating warmth of the Sun: Whence by the fame genial heat, in conjunction with the attraction of the capillary fap veffels, it is carried up thro' the bodies and branches of vegetables, and

thence 
66 Vegetable Staticks.

thence paffing into the leaves, it is there moft vigorounly acted upon, in thofe thin plates, and put into an undulating motion, by the Sun's warmth, whereby it is moft plentifully thrown off, and perfired thro' their furface; whence, as foon as it is difintangled, it mounts with great rapidity in the free air.

But when, towards the latter end of $\mathrm{OC}$ tober, the vigour of the Sun's influence is fo much abated, that the firft Thermometer was fallen to 3 degrees above the freezing point, the fecond to Io degrees, the fifth to 14 degrees, and the fixth Thermometer to 16 degrees; then the brisk undulations of the moifture of the earth, and alfo of the afcending fap, much abating, the leaves faded and fell off.

The greateft degree of cold, in the following winter, was in the firft $\mathrm{I}_{2}$ days of November; during which time, the fpirit in the firf Thermometer was fallen 4 degrees below the freezing point, the deepert Thermometer 10 degrees, the ice on ponds was an inch thick. The Sun's greateft warmth, at the winter folftice, in a very ferene, calm, frofty-day, was, againft a South afpect of a wall, i 9 degrees, and in a free open air, bue 


\section{Vegetable Staticks.}

It degrees above the freezing point. From the roth of Fanuary to the 29th of March was a very dry feafon; when the green Wheat was generally the fineft that was ever remembred. But from the 29th of March I 725, to the 29th of September following, it rained more or lefs almoft every day, except ten or twelve days about the beginning of $\mathcal{F u l y}$; and that whole feafon continued fo very cool, that the fpirit in the firt Thermometer rofe but to 24 degrees; except now and then in a thort interval of Sunhine; the fecond only to 20 degrees; the fifth and fixth to 24 and 23 degrees, with very little variation: So that during this whole fummer, thofe parts of roots which were two feet under ground, had 3 or four degrees more warmth than thofe which were but two inches under ground: And at a medium the general degree of heat thro' this whole fummer, both above and under ground, was not greater than the heat of the middle of the preceding September.

The year 1725 , having been, both in this Inand, and in the neighbouring Nations, moft remarkably wet and cold; and the year 1723 , in the other extreme, as remarkably dry, as has ever been known 3 it may

$$
\text { F }
$$
not 


\section{Vegetable Staticks.}

not be improper here to give a thort account of them, and the influence they had on their productions.

"Mr. Miller, in the account which he took of the year 1723 , obferved that the " winter was mild and dry, except that in

"February it rained almoft every day, which "kept the fpring backward. March, April, " May, Fune, to the middle of $\mathcal{F} u l y$, proved " extremely dry, the wind North-eaft moft " part of the time. The fruits were for" ward, and pretty good; but kitchen-ftuff, "efpecially Beans and Peafe, failed much. "The latter half of fuly the weather prov" ed very wet, which caufed the fruits to "grow fo faft, that many of them rotted " on the trees; fo that the autumn fruits "were not good. There were great plenty cs of Melons, very large, but not well tafted. "Great plenty of Apples; many kinds of "fruits bloffomed in Auguft, which pro" duced many fmall Apples and Pears in "October, as alfo Strawberries and Rafp. "berries in great plenty. Wheat was good, " little Barley, much of which was very un"equally ripe, fome not at all, becaure fown c. late, and no timely rain to fetch it up. "There were innumerable Warps; how it 


\section{Vegetable Staticks.}

"fared with the hops this dry year, is men" tioned under Exper.9.

"The following winter 1724 , proved "very mild; the fpring was forward in $\mathcal{F a}$ " nuary, fo that the Snow-drops, Crocus's, "Polyanthus's, Hepatica's, and Narcifus's, "were in Flower. And it was remarkable, " that moft of the Colliflower-plants were " deftroyed by the mildew, of which there " was more, all this winter, than had been " known in the memory of man. In $F e$ "bruary we had cold tharp weather, which " did fome damage to the early crops, and " it continued variable till April; fo that " much of the early Wall-fruit was cut off: "And again the 6th of May was a very " Tharp froft, which much injured tender "plants and fruits. The fummer in gene" ral was moderately dry, the common fruits "proved pretty good, but late: Melons " and Cucumbers were good for little: "Kitchen-ftuff was in great plenty in the " markets.

In the very wet and cold year 1725 , moft things were a full month backwarder than ufual. Not half the Whear in by the 24th of Auguft, in the Southern parts of England; very few Melons or Cucumbers, and thofe 
not good. The tender Exoticks fared but ill; fcarce any grapes, thofe fmall, and of very unequal fizes, on the fame bunch, not ripe; Apples and Pears green and infipid; no fruit nor products of the ground good, but crude: Pretty good plenty of Wheat, tho' coarfe, and long ftraw; Barley coarfe, but plenty of it in the uplands. Beans and Peafe mont flourifhing and plentiful; few Wafps or other infects, except Flies on hops. Hops were very bad thro' the whole Kingdom. Mr. Auftin of Canterbury fent me the following particular account, how it fared with them there; where they had more than at Farnbam, and moft other places, viz.

"At mid-April not half the thoots ap"peared above ground; fo that the plant" ers knew not how to pole them to the " beft advantage. This defect of the hoot, "z upon opening the hills, was found to be " owing to the multitude and variety of "vermin that lay preying upon the root; "the increafe of which was imputed to " the long and almof uninterrupted feries "s of dry weather, for three months paft: "Towards the end of April, many of the " hop-vines were infefted with the Flies, About the zoth of May there was a 


\section{Vegetable Staticks.}

"very unequal crop, fome Vines being " run feven feet, others not above three or "four feet; fome juft tied to the poles, and " fome not vifible: And this difpropor"tionate inequality in their fize continued " through the whole time of their growth. " The Flies now appeared upon the leaves " of the forwardent Vines, but nor. in fuch " numbers here, as they did in molt other " places. About the middle of Fune, the "Flies increafed, yet not fo as to endanger " the crop; but in diftant plantations they "were exceedingly multiplied, fo as to " fwarm towards the end of the month. "Fune 27 th fome rpecks. of Fen appeared: "From this day to the 9th of fuly, was "very fine dry weather. At this time, "when it was faid that the Hops in moft " other parts of the Kingdom looked black " and fickly, and feemed paft recovery, ours " held it out pretty well, in the opinion " of the molt skilful Planters. The great "leaves were indeed difcoloured, and a lit"tle withered, and the Fen was fomewhat " increafed. From the gth of Fuly to the " $23 \mathrm{~d}$ the Fen increafed a good deal, but " the Flies and Lice decreafed, it raining ".- daily much: In a week more the Fen,

$$
\text { F4 "which }
$$




\section{Vegetable Staticks.}

"which feemed to be almoft at a ftand,

"was confiderably increafed, efpecially in " thore grounds where it firft appeared. "About the middle of Auguft, the Vines " had done growing, both in ftem and " branch; and the forwardeft began to be " in Hop, the reft in Bloom: The Fen " continued fpreading, where it was not "before perceived, and not only the leaves, " but many of the Burrs alfo were tainted "with it. About the 2oth of Auguf, " fome of the Hops were infected with the "Fen, and whole branches corrupted by it. "Half the Plantations had hitherto pretty "well efcaped, and from this time the Fen " increafed but little: But feveral days vio" lent wind and rain, in the following " week, fo difordered them, that many of " them began to dwindle, and at laft came " to nothing; and of thofe that then re" mained in bloom, fome never turned to "Hops; and of the reft which did, many "s of them were fo fmall, that they very " little exceeded the bignefs of a good " thriving Burr. We did not begin to pick "till the 8th of September, which was st eighteen days later than we began the "t year before. The crop was little above 


\section{Vegetable Staticks.}

"two hundred on an acre round, and not "good." The beft Hops fold this year at Way-Hill Fair for fixteen pounds the hundred.

The almoft uninterrupted wetners and coldnefs of the year 1725 , very much affected the produce of the Vines the enfuing year; and we have fufficient proof from the obfervations that the four or five laft years afford us, that the moifture or drynefs of the preceding year has a confiderable influence on the productions of the Vine the following year. Thus in the year 1722 , there was a dry feafon, from the beginning of Auguft thro' the following autumn and winter, and the next fummer there was good plenty of Grapes. The year 1723 was a remarkably dry year, and in the following year 1724 , there was an unufual plenty of Grapes. The year 1724 was moderately dry, and the following fpring the Vines produced a fufficient quantity of bunches, but by reafon of the wetnefs and coldnefs of the year 1725 they proved abortive, and produced hardly any Grapes. This very wet year had an ill effect, not only upon its own productions, but alfo on thofe of the following year: For notwithftanding there 
74 Vegetable Staticks.

was a kindly fpring and blooming feafon in the year 1726 , yet there were few bunches produced, except here and there in fome very dry foils. This many Gardiners forefaw early, when upon pruning of the Vines, they obferved the bearing fhoots to be crude and immature; which was the reafon why they were not fruitful. The firt crop thus failing in many places, the Vines produced a fecond, which had not time to come to maturity before the cold weather came on.

Mr. Miller fent me the following account, of the long and fevere winter in the year 1728 ; and of the effect it had on the Plants and Trees in this and the neighbouring countries, viz.

"The autumn began with cold North "s and Eaft winds, and early in November

"the nights were generally frofty; tho" "t the froft did not enter the ground deeper "t than the fucceeding days thaw'd. But " towards the end of November the winds er blew extreamly cold from the North, "which was fucceeded by a great fnow, "which fell in fuch quantities in one night, "as to break off large arms and tops of " many ever-green Trees on which it " lodged. 


\section{Vegetable Staticks.}

"After the fnow was down it began to "freeze again, the wind continuing to " blow from the North, the days were " dark and cloudy for fome time, but af" tẹrwards it cleared up, and the Sun ap"peared almoft every day, which melted " the fnow where expored to it, whereby " the froft penetrated the deeper into the "ground. It was obfervable that during " thefe clear days, a great mift or vapour " appeared in the evenings, floating near " the furface of the ground, till the cold " of the night came on, when it was fud"denly condenfed and difappeared; the " nights now began to be extreme tharp. "The firit in the Thermometer was 18 de"grees below the freezing point, (as mark" ed upon Mr. Fowler's Thermometers) and " it was at this time that vaft quantities of "Lauruftinus's, Pbilerea's, Alaternus's, "Rofemary, and other tender plants began " to fuffer; efpecially fuch as were trimm'd " up to naked ftems, or had been clipp'd "late in the fummer. At this time alfo " there were great numbers of trees dif"barked, fome of which werc of a confi" derable bulk, particularly two Weft-India "Plane Trees, in the Phyfick Garden at ¿Chelfes, 
"Chelfea, which are near 40 feet high,

"and a fathom in Circumference, were

" disbarked almoft from the bottom to

" the top, on the Weft fide of the trees.

"And in a nurfery belonging to Mr. Fran-

"cis Hurft great numbers of large Pear-

" trees were all of them disbarked on the

"Weft or South-Weft fides of 'em. And

" in feveral other places I obferved the

" like accident, and found it was conftant-

"ly on the fame fide of the trees.

"About the middle of December the

"Froft abated of its Intenfenefs, and feem-

" ed to be at a ftand, till the $23 \mathrm{~d}$ of the

" month, when the wind blew extreme

" tharp and cold from the Eaft, and the

"froft continued very hard to the 28 th day,

" at which time it began to abate again,

" and feemed to be going off, the wind

" changing to the South; but it did not

" continue long in this point, before it

" changed to the Eaft again, and the froft

" returned, tho" not fo violent as before.

"Thus the weather continued for the

" molt part frofty, till the middle of March,

" with a few intervals of mild weather;

"which brought forward fome of the early

"flowers, but the cold returning, foon de- 


\section{Vegetable Staticks.}

"ftroyed them; fo that thofe plants which "ufually flower in Fanuary and February, " did not this year appear till the latter " end of March, or the beginning of $A$ "pril, as the Crocus's, Hepatica's, Perfan "Iris's, Black Hellebores, Polyanthus's, "Mezerions, and many others.

"The Colliflower-plants which were "planted out during the intervals between " the froft, were moft of them deftroyed, " or fo much pinched as to lofe the great" eft part of their leaves; whereas thore " which had been planted out in October " efcaped very well. The early Beans and "Peafe were moft of them deftroyed; " and great quantities of Timber and Fruit" trees, which had been lately removed, " were quite killed.

"The lofs was very great in moft cu" rious collections of plants; there being "s a great deftruction made of many Trees, "Shrubs, and Plants, which had endured " the open air many years, without being " the leaft hurt by cold; as the Granadilla " or Paffion-Flower, Arbutus or Strawe. "berry Tree, Cork Tree, with mont of the "Aromatick Plants, as Rofemary", Laven"der, Stachas, Sage, Maftick, Marum, 
78 Vegetable Staticks.

" and many others, which were deftroyed

" to the ground, and were by many peo-

" ple pulled up and thrown away; but in

" warm dry foils, where they were fuffer-

" ed to remain undifurbed, many of them

" broke out from the root again, tho" it

" was very late in the fummer before they

" fhewed any figns of recovery.

"The Plants in the Confervatories fuf-

" fered very much by being fo long thut

" up clofe; for the days being for the moft

" part cloudy, and the wind blowing very

" tharp, the windows of the Green-houfes

" could not be with fafety opened, which

"occafioned a noxious damp in the houfes,

" whereby the Plants became fickly, lan-

"guifhed and decayed foon after.

"Nor was the Froft more fevere with us

" than in other parts of Europe, but on "the contrary in comparifon favourable, "for in the Southern parts of France the "Olives, Myrtles, Ciffus's, and other "Trees and Shrubs, which grow there al" moft fpontaneoufly, were deftroyed; and " in the Northern parts of France, as a" bout $\mathcal{P}$ aris, $\& c$. the buds of many kinds " of fruit-trees were deftroyed, although "clofed to that many of them never open- 
"ed, but decayed and perifhed; and the "Fig-trees which were expofed to the " open air were alfo deftroyed. "In Holland the Pines, Firs, and other " hardy refinous trees, were moft of them " killed, altho" many of them are natives " of the Alps, and other mountainous " cold countries; but this I apprehend to " be owing to the lownefs of their fitua" tion and foil, whereby their roots eafily "ran down into the water, which is more " injurious to thefe trees than froft.

" But it was obferved that the Trees and "Shrubs which are natives of Virginio " and Carolina, efcaped well in Holland; " when almoft all thofe which were brought " from Italy, Spain, or the South parts of "France, were entirely deftroyed. Which " will greatly enhance the value of the for"mer trees, efpecially fuch of them as are " either proper for ufe or beauty.

"In Germany the winter was fo fevere " as to deftroy almoft all their plants and " flowers, which were not either removed " into the Green-houres, or protected by " coverings from the Froft, as I was inform. ". ed by letters from thence. 
"And in Scotland the Froft and Snow

" did great damage, fome of the particu-

" lars of which I thall tranfcribe from a

" letter, which I received from a Gentle-

" man living near Edinburgh, who is a cu-

.66 rious obferver.

"About the 2oth of November, he fays,

" they had much Snow, which lay ten

" days, and then went off very pleafantly

"without rain; and from that time till

" the middle of December, we had vcry

" good winter weather, when a great Snow

"fell, which was attended with a ftorm

"from the North-Eaft; which Snow lay

"very thick upon the ground till the I 2 th

" day of Fanuary, during which time there

“. was a very intenfe Froft: After which

" the cold abated, and the Snow went off

" gradually; and about the end of Fanu-

"ary I obferved in my Green-houfe the

"flowers and young thoots of the Orange

" and other exotick trees did begin to ap-

" pear, and all of them began to prepare

"for vegetation. In the open ground we

" had Spring Cyclamens, Primrofes, Winter

"Aconites, Snowdrops, Hellebores, Poly-

"anthus's, Glaftenbury Thorn, Winter Hya-

"cinths, and Mezereons in flower. 
"But before I proceed to give a farther "account of the weather, I thall offer you " my thoughts upon the reafon of this $\mathrm{Ve}$ "getation fo early, whilft the cold was fo " intenfe with you. Firft it is to be obferv" ed that our ftorms of Snow at that feafon " came on before the Froft had entered the "ground; fo that the Snow kept the ground. "warm and fecure from the Froft, which " only crufted the top of the fnow: Du" ring this feafon the wind blew from the "Eaft, which coming off the fea, (from " which we are but eight miles diftant) was " not attended with fo much cold as if it " had blown over the land, which was " covered with Snow, where there is no " fea fo" two hundred miles. Till the sth " of February we enjoyed this weather; at "which time we had a violent Snow with " a ftorm from the South-weft, and the "Froft having entered the ground before it "fell, checked our early flowers from ap"pearing: During this Snow, which con" tinued moft part of February, we had a "great deal of fun-fhine, which contribut" ed very much to our early crops of $\mathrm{Cu}$ "cumbers and Melons; but during the "nights it froze very hard, which deftroyed 
" great numbers of plants that were not " Theltered.

"Every thing was now at a ftand; the "Apricot and Peach bloffoms consinued " turgid; but not being opened they fuf"fered very little; the Laurus Timus's fuf"fered extreamly by this laft fevere feafon, " efpecially where the Snow had been melt"cd from their roots.

"This Snow went off with a violent "South-weft wind, which was very bleak " and cold, and where the fun had no ac"cefs the Snow lay till the 2 th of March, "at which time we had for fix days very " mild weather, which occafioned our put" ting abroad our Carnations, whereby we " loft molt of them. The wind continued " cold, varying from the South-weft to the "North-weft, and fometimes North-eaft; "and upon the 23 d day it was very cold, " the wind at North-weft and by North; " in the evening the fun was clouded, and "the wind abated, the Mercury in the $\mathrm{Ba}$ "rometer fell at night; at two a clock the "next morning a violent Hurricane at "Norch-eaf brought a Snow in many "places 6 , IO, and I2 feet deep, with a es moft piercing cold; the fnow continued 


\section{Vegetable Staticks. $\quad 83$}

"to fall till ten a clock in the morning; "when the wind chopped about to the " North-weft with incredible fiercenefs, " and extream cold. Now it was that in" numerable theep and other cattle were " loft in the mountains of fnow; and ma" ny poor people going that morning to " look after their cattle, the remembrance " of which is terrible, were equally fuf" ferers with them, being buried in the "Snow.

"The Apricots and Peaches which were " now in bloffom upon warm walls, were " all deftroyed, and not only the Blofloms, " but the Trees alfo, their bark burfting "off.

I have often obferved from thefe Thep: mometers, when that kind of hovering lam. bent Fog arifes, (either mornings or evenings) which frequently betokens fair weather, that the air which in the preceding day was much warmer, has upon the $a b$ fence of the fun become many degrees cooler than the furface of the earth; which being near I 500 times denfer than the air, cannot be fo foon affected with the alternacies of hot and cold; whence 'tis probable, that thore vapours which are raifed 
84

Vegetable Staticks.

by the warmth of the earth, are by the cooler air foon condenfed into a vifible form. And I have obferved the fame difference between the coolnefs of the air, and the warmth of water in a pond, by putting my Thermometer, which hung all night in the open air in fummer time, into the water, juft before the rifing of the fun, when the like reek or fog was rifing on the furface of the water.

*

\section{H A P. II.}

Experiments, whereby to find out the force with which Trees imbibe moifture.

TAving in the firft chapter feen many 11 proofs of the great quantities of liquor imbibed and perfpired by vegetables, I propofe in this, to enquire with what force they do imbibe moifture.

Tho' vegetables (which are inanimate) have not an engine, which, by its alternate dilatations and contractions, does in animals forcibly drive the blood through the arteries and veins; yet has nature wonderfully 


\section{Vegetable Staticks.}

contrived other means, moft powerfully to raife and keep in motion the fap, as will in fome meafure appear by the experiments in this and the following chapter.

I thall begin with an expcriment upon roots, which nature has providently taken care to cover with a very fine thick ftrainer; that nothing thall be admitted into them, but what can readily be carried off by perfpiration, vegetables having no other provifion for difcharging their recrement.

\section{EXPERIMENT XXI.}

Anguft 13. in the very dry year 1723 , I dug down $2+\frac{1}{2}$ feet deep to the root of a thriving baking Pear-tree, and laid bare a root $\frac{2}{2}$ inch diameter $n$ (Fig. IO.) I cut off the end of the root at $i$, and put the remaining ftump in into the glafs tube $d r$, which was I inch diameter, and 8 inches long, cementing it faft at $r$; the lower part of the tube $d z$ was 18 inches long, and $\frac{r}{4}$ inch diameter in bore.

Then I turned the lower end of the tube $z$ uppermoft, and filled it full of water, and then immediately inmerfed the fmall end $z$ into the ciftern of mercury $x$; taking away my finger, which fiopped up the end of the tube $z$. 


\section{Vegetable Staticks.}

The root imbibed the water with fo much vigour, that in 6 minutes time the mercury was raifed up the tube $d z$ as high as $z$, viz. 8 inches.

The next morning at 8 a clock, the mercury was fallen to 2 inches height, and 2 inches of the end of the root $i$ were yet immerfed in water. As the root imbibed the water, innumerable air bubbles iffued out at $i$, which occupicd the upper part of the tube at $r$ as the water left it.

\section{EXPERIMENT XXII.}

The eleventh Experiment Thews, with what great force branches imbibe water, where a branch with leaves imbibed much more than a column of 7 feet height of water could in the fame time drive through I 3 inches length of the biggeft part of its ftem. And in the following Experiments we Thall find a farther proof of their ftrong imbibing power.

May 25, I cut off a branch of a young thriving Apple-tree 6, (Fig. II.) about 3 fect long, with lateral branches; the diameter of the tranfverfe cut $i$, where it was cut off, was $\frac{3}{4}$ of an inch: The great end of 


\section{Vegetable Staticks.}

this branch I put into the cylindrical glafs $e r$, which was an inch diameter within, and eight inches long.

I then cemented faft the joynt $r$, firft fold. ing a ftrap of fheeps-skin round the ftem, fo as to make it fit well to the tube at $r$; then I cemented faft the joynt with a mixture of Bees-wax and Turpentine melted together in fuch a proportion, as to make a very ftiff clammy Pafte when cold, and over the cement I folded feveral times wet Bladders, binding it firm with Packthread.

At the lower end of the large tube $e$ was cemented, on a leffer tube $z e, \frac{r}{4}$ inch diameter in bore, and 18 inches long: The fubftance of this tube ought to be full $\frac{?}{5}$ of an inch thick, elfe it will too eafily break in making this experiment.

Thefe two tubes were cemented together at $e$, firft with common hard brick-duft cement to keep the tubes firm to each other; but this hard cement would, both by being long moift, and by the different dilatations and contractions of the glars and cement, feparate from the glafs in hot weather, fo as to let in air ; to prevent which inconvenience, I further fecured the joynt with

$$
\mathrm{G}_{4} \text { the }
$$


the cement of Bees-wax and Turpentine, binding a wet bladder over all. If the hard cement be made of powder'd chalk inftead of brick-duft, it is more binding, and is not fo apt to be loofened by water.

When the branch was thus fixed, I turned it downwards, and the glafs tube upwards, and then filled both tubes full of water; upon which I immediately applied the end of my finger to clofe up the end of the fmall tube, and immerfed it as faft as I could into the glafs ciftern $x$, which was full of mercury and water.

When the branch was now uppermoft, and placed as in this figure, then the lower end of the branch was immerfed 6 inches in water, viz. from $r$ to $i$.

Which water was imbibed by the branch, at its tranfverfe cut $i$; and as the water afcended up the fap veffels of the branch, fo the mercury afcended up the tube $e z$ from the ciftern $x$; fo as in half an hour's time the mercury was rifen $s$ inches and $\frac{3}{4}$ high up to $z$.

And this height of the mercury did in fome meafure hew the force with which the fap was imbibed, tho' not near the whole force; for, while the water was imbibing, 


\section{Vegetable Staticks.}

the tranfverfe cut of the branch was co-

vered with innumerable little hemifpheres of air, and many air bubbles iffued out of the fap veffels, which air did in part fill the tube $e r$, as the water was drawn out of it; fo that the height of the mercury could only be proportionable to the excefs of the quantity of water drawn off, above the quantity of air which iffued out of the wood.

And if the quantity of air, which iffued from the wood into the tube, had been equal to the quantity of water imbibed, then the mercury would not rife at all; becaufe there would be no room for it in the tube.

But if 9 parts in 12 of the water be im: bibed by the branch, and in the mean time but three fuch parts of air iffue into the tube, then the mercury muft needs rife near 6 inches, and fo proportionably in different cares.

I obferved in this, and mott of the following experiments of this fort, that the mercury rofe higheft, when the fun was very clear and warm; and towards evening it would fubfide 3 or 4 inches, and rife again. the next day as it grew warm, but feldom to the fame height it did at firt. For I have always found the fap veffels grow every day, 
after cutting, lefs pervious, not only for water, but alfo for the fap of the vine, which never paffes to and fro fo freely thro' the tranfverfe cut, after it has been cut 3 or 4 days, as at firft; probably, becaufe the cut capillary veffels are thrunk, the veficles alfo, and interftices between them, being faturate and dilated with extravafated fap, much more than they are in a natural ftate.

If I cut an inch or two off the lower part of the ftem, which has been much faturated by ftanding in water, then the branch will imbibe water again afrefh; tho' not altogether fo freely, as when the branch was firft cut off the tree.

I repeated the fame experiment as this $22 \mathrm{~d}$, upon a great variety of branches of feveral fizes and of different kinds of trees, fome of the principal of which are as fol. low, viz.

\section{EXPERIMENT XXIII.}

Fuly 6th and 8 th, I repeated the fame experiment with feveral green thoots of the Vine, of this year's growth, each of them full two yards long.

The mercury rofe much more leifurely in thefe experiments, than with the Apple-tree branch: 


\section{Vegetable Staticks.}

branch; the more the fun was upon it, the fafter and higher the mercury rofe, but the Vine-brandes could not draw it above 4 inches the firft day, and 2 inches the third day.

-And as the fun fet, the mercury fometimes fubfided wholly, and would rife again the next day, as the fun came on the Vinebranch.

And I obferved, that where fome of thefe Vine-branches were fix'd on the North-fide of the large trunk of a Pear-tree, the mercury then rofe moft in the evening about $\sigma$ a-clock, as the fun came on the Vine branch.

\section{EXPERIMENT XXIV.}

Anguft 9, at 10 ante Merid. (very hot funthine) I fixed in the fame manner as Ex. 22. a Non-pareil branch, which had 20 Apples on it; it was 2 feet high, with lateral branches, its tranfverfe cut $\frac{5}{8}$ inch diameter: It immediately began to raife the mercury moft vigorounly, fo as in 7 minutes it was got up to $z$ I 2 inches high.

Mercury being $I_{3} \frac{2}{3}$ times rpecifically heavier than water, it may eafily be eftimated to what height the feveral branches in thefe experiments would raife water; for 
if any branch can raife mercury 12 inches, it will raife water 13 feet 8 inches: A further allowance being alfo madelfor the perpendicular height of the water in the tubes, between $r$ and $z$ the top of the column of mercury; for that column of water is lifted up by the mercury, be it more or lefs.

At the fame time, I tried a Golden Renate branch 6 feet long, the mercury rofe but 4 inches, it rifing higher or lower in branches nearly of the fame fize and of the fame kind of tree, according as the air iffucd thro' the ftem, more or lefs freely. In the preceding experiment on the Nonparcil branch, I had fucked a little with my mouth at the fmall end of the tube, to get fome air bubbles out of it, before I immerfed it in the mercury; (but thefe air bubbles are beft got out by a fmall wire run to and fro in the tube) and this fuction made air bubbles arife out of the tranfverfe cut of the branch; but tho' the quantity of thofe air bubbles thus fucked out, was but fmall; yet in this and many other experiments, I found that after fuch fuction, the water was imbibed by the branch, much more greedily, and in much greater quantity than the bulk of the air was, which 


\section{Vegetable Staticks.}

was fucked out. Probably therefore, thefe air bubbles, when in the fap veffels, do ftop the free afcent of the water, as is the cafe of little portions of air got between the water in capillary glafs tubes.

When the mercury is raifed to its greateft height, by precedent fuction with the mouth, (which height it reaches fometimes in 7 minutes, fometimes in half an hour or an hour) then from that time it begins to fall, and continues fo to do, till it is fallen 5 or 6 inches, the height the branch would have drawn it to, without fucking with the mouth.

But when in a very warm day, the mercury is drawn up 5 or fix inches, (without precedent fuction with the mouth) then it will ufually hold up to that height for feveral hours, viz. during the vigorous warmth of the fun; becaufe the fun is all that time Atrongly exhaling moifture from the branch thro' the leaves, on which account it mut therefore imbibe water the more greedily, as is evident by many experiments in the firnt chapter.

When a branch is fixed to a glass tube fet in mercury, and the mercury fubfides at night, it will not rife the next morning 
94 Vegetable Staticks.

(as the warmth of the fun increafes upon it) unlefs you fill the tube firf full of water: For if half or $\frac{2}{4}$ of the large tube $c r$ be full of air, that air will be rarified by the fun; which rarefaction will deprefs the water in the tube, and confequently the mercury cannot rife.

But where little water is imbibed the firftay, (as in the cafe of the green thoots of the Vine, Exper. XXIII.) then the mercury will rife the fecond and third day, as the warmth of the fun comes on, without refilling the little water that was imbibed.

\section{EXPERIMENT XXV.}

In order to make the like experiment on larger branches (when I expected the mercury would have rifen much higher than in fmall ones) I caufed glaffes to be blown of the thape of this here defribed (Fig. I2.) of feveral dimenfions at $r$, from two to five inches diameter, with a proportionably large cavity $c$ : the ftem $z$ as near $\frac{z}{4}$ inch diameter as could be, the length of the ftem I 6 inches.

I cemented one of thefe glars veffels to a large fmooth barked thriving branch of an Apple-tree, which was I 2 feet long, I + 录 


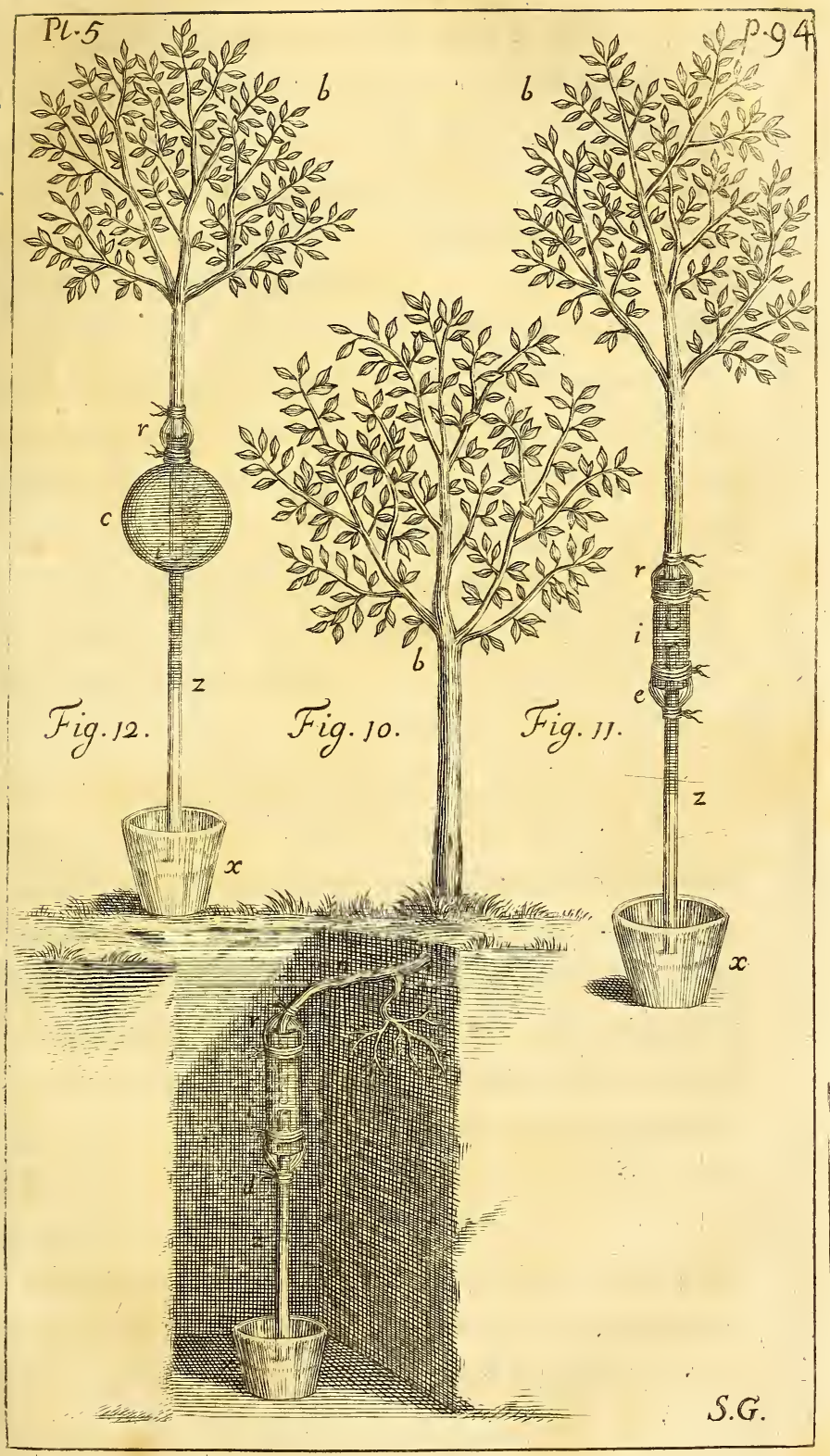





\section{Vegetable Staticks.}

inch diameter at $i:$ I filled the glafs tube with water, and immerfed the fmall end in the mercury $x$, which rofe but 4 inches, yet it imbibed water plentifully; but the air iffued too faft out of the branch at $i$, for the mercury to rife high.

This, and many other experiments of this kind, convince me that branches of 2,3 , or 4 years old, are the beft adapted to draw the mercury higheft: The veffels of thofe that are older being too large and pervious to the air, which paffes moft freely thro' the bark, efpecially at old eyes; as will be more fully proved in the fifth chapter.

\section{EXPERIMENT XXVI。}

Fuly 3 oth at noon, a mixture of fun and clouds, the day and night before, 24 hours continual rain: I cut off a branch of 2 Golden Pippin-tree b b, (Fig. I 3.) about 3 feet long, with feveral large lateral branches: its diameter at the great end $p$ near an inch, which end I cemented well, and tied over it a piece of wet bladder.

Then I cut off at $i$ the main top twig where it was $\frac{x}{2}$ inch diameter: I cemented. the glafs tube $z r$, to the remaining branch 


\section{Vegetable Staticks.}

$i r$, and then filling the tube with water; fer its lower end in the mercury $x$; fo that now the branch was placed with its top $i$ downwards in the water, in the Aqueomercurial gage.

It imbibed the water with fuch ftrength, as to raife the mercury with an almoft equable progreffion I I $+\frac{x}{2}$ inches by 3 a clock, (the fun (hining then very warm) at which time the water in the tube $r i$ being all imbibed; fo that the end $i$ of the branch was out of the water, then the air bubbles paffing more freely down to $i$, and no water being imbibed, the mercury fubfided 2 or 3 inches in an hour.

At a quarter paft 4 a clock, I refilled the gage with water, upon which the mercury rofe afrefh from the ciftern, viz. 6 inches the firtt $\frac{1}{4}$ of an hour, and in an hour more the mercury reached the fame height as before, viz. I I $+\frac{1}{2}$ inches. And in an hour and $\frac{1}{4}$ more it rofe $\frac{1}{4}$ inch more than at firft; but in half an hour after this it began gently to fubfide; viz. becaufe the fun declining and fetting, the perfpiration of the leaves decreafed, and confequently the imbibing of the water at $i$ abated, for the end $i$ was then an inch in water. 


\section{Vegetable Staticks.}

Fuly 3 Ift, it raining all this day, the mercury rofe but 3 inches, which height it ftood at all the next night. Auguft ift fair fun-fhine; this day the mercury rofe to 8 in: ches: This thews again the influence of the fun, in raifing the mercury.

This Experiment proves that branches will ftrongly imbibe from the fmall end immerfed in water to the great end; as well as from the great end immerfed in water to the fmall end; and of this we thall have further proof in the fourth chapter.

\section{EXPERIMENT XXVII.}

In order to try whether branches would imbibe with the like force with the bark off, I took two branches, which I call $M$ and $N$; I fixed $M$ in the fame manner as the branch in the foregoing Experiment, with its top downwards, but firf I took off all the bark from $i$ to $r$. Then I fix'd in the fame manner the branch $N$, but with its great end downwards, having alfo taken off all the bark from $i$ to $r$; both the branches drew the mercury up to $z, 8$ inches; fo they imbibed with equal Atrength at either end, and that without bark. 
98

Vegetable Staticks.

EXPERIMENT XXVIII.

Auguft I 3. I ftripped the leaves off an Apple-tree branch, and then fixed the great end of the ftem in the gage; it raifed the mercury $2+\frac{\pi}{2}$ inches, but it foon fubfided, for want of the plentiful perfpiration of the leaves, fo that the air came in almoft as falt as the branch imbibed water.

\section{EXPERIMENT XXIX.}

I tried alfo with what force branches would imbibe at their fmall ends, as they are in their natural ftate, growing to the trees.

Auguft $2 \mathrm{~d}$ I cemented faft the gage $r i z$ (Fig. I 4.) to the pliant branch $b$, of a dwarf Golden Pippin-tree, the fame from which I cut the branch in Experiment 26: As the tranfverfe cut $i$ imbibed the water, the mercury rofe $s$ inches obliquely in the tube $z$, and 4 inches perpendicular.

In this, as alfo in many of the preceding Experiments, there were feveral wounds in that part of the branch which was with in the large tube $r i$; which were made by cutting off little lateral twigs, and fwelling eyes, that the branch might eafily enter the tube : 


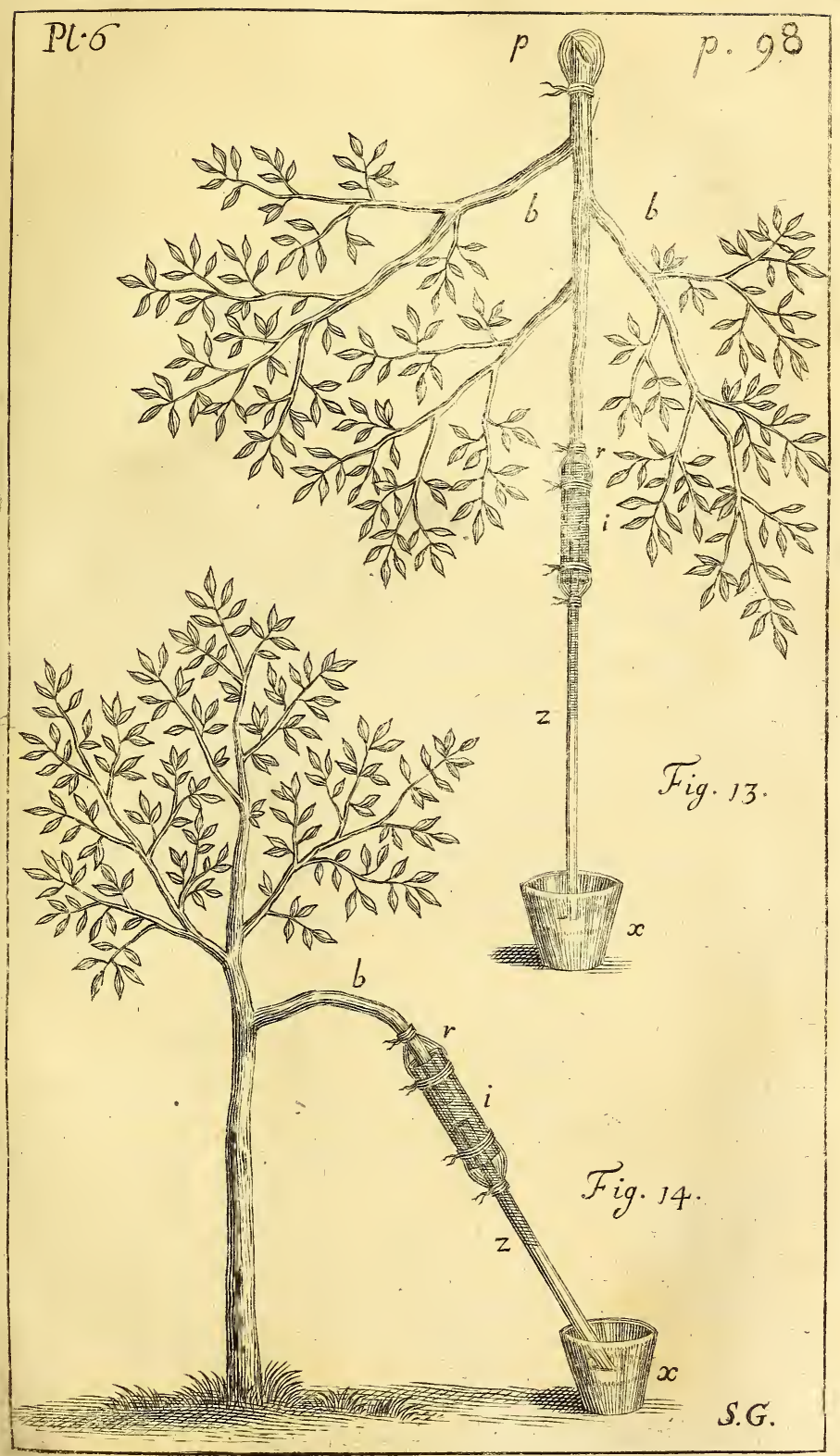





\section{Vegetable Staticks.}

tube: And if thefe wounds (thro' which the air always iffued plentifully) were well covered with theeps gut, bound over with packthread, it would in a good meafure prevent the inconvenience: But I always found that my Experiments of this kind fucceeded beft, when that part of the branch which was to enter the tube $r i$, was clear of all knots or wounds; for when there were no knots, the liquor paffed moft freely, and lefs air iffued out.

The fame day I fixed in the fame manner a gage to an Apricot-tree, it raifed the mercury three inches; and tho' all the water was foon imbibed, yet the mercury rofe every day an inch, for many days, and fub. fided at night; fo that the branch muft daily imbibe thus much air, and remit it at night.

\section{EXPERIMENT XXX.}

We have a further proof of the influence of the leaves in raifing the fap in this following Experiment.

Auguft 6th, I cut off a large Rufet Pippin a, (Fig. Is.) with a ftalk $I+\frac{1}{2}$ inch long, and $\mathrm{I} 2$ adjoining leaves $g$ growing to it. 
I cemented the ftalk faft into the upper end of the tube $d$, which tube was 6 inches long, and $\frac{x}{7}$ inch diameter; as the ftalk imbibed the water, it raifed the mercury to $z$, four inches high.

I fix'd another Apple of the fame fize and tree, in the fame manner, but firft pulled off the leaves; it raifed the mercury but I inch. I fixed in the fame manner a like bearing $t$ wig with $\mathrm{r} 2$ leaves on it, but no apple; it raifed the mercury 3 inches.

I then took a like bearing $\mathrm{twig}$, without either leaves or apple, it raifed the mercury $\frac{\pi}{4}$ inch.

So a twig with an apple and leaves raifed the mercury 4 inches, one with leaves only 3 inches, one with an apple without leaves I inch.

A Quince which had two leaves, juft at the twig's infertion into it, raifed the mercury $2+\frac{1}{2}$ inches, and held it up a confiderable time.

A fprig of Mint fix'd in the fame manner, raifed the mercury $3+\frac{x}{2}$ inch, equal to 4 feet $s$ inches height of water. 


\section{EXPERI MENT XXXI.}

I tried alfo the imbibing force of a great variety of trees, by fixing Aqueo-mercurial gages to branches of them cut off, as in Experiment 22.

The Pear, Quince, Cherry, Walnut, Peach, Apricot, Plumb, Black-thorn, White-thorn, Goofeberry, Water-Elder, Sycamore, raifed the mercury from 6 to 3 inches high: Thore which imbibed water mot freely, in the Experiments of the firft chapter, raifed the mercury higheft in thefe Experiments, except the Horfe-Chefnut, which though it imbibed water moft freely, yet raifed the mercury but one inch, becaufe the air paffed very faft through its fap-veffels into the gage.

The following raifed the mercury but I or 2 inches, viz. the Elm, Oak, HorfeChefnut, Filberd, Fig, Mulberry, Willow, Sallow, Ofier, Ath, Lynden, Currans.

The Ever-greens and following trees and plants, did not raife it at all; the Laurel, Rolemary, Laurus-Tinus, Philarea, Fuz, Rue, Berberry, Jeflamine, Cucumber-branch, Pum. kin, Jerufalem Artichoke.

$$
\text { H3. EXPE- }
$$




\section{2 \\ Vegetable Staticks.}

\section{EXPERIMENT XXXII.}

We have a further proof of the great force with which vegetables imbibe moinure, in the following Experiment, viz. I filled near full with Peafe and water, the iron Pot (Fig. 37.) and laid on the Peafe a leaden cover, between which and the fides of the Pot, there was room for the air which came from the Peare to pais freely. I then laid I 84 pounds weight on them, which (as the Peafe dilated by imbibing the water) they lifted up. The dilatation of the Peafe is always equal to the quantity of water they imbibe: For if a few Peafe be put into a Veffel, and that Vefiel be filled full of water, tho' the Peafe dilate to near double their natural fize, yet the water will not flow over the Veffel, or at moft very inconfiderably, on account of the expanfion of little air bubbles, which are iffuing from the Peare.

Being defirous to try whether they would raife a much greater weight, by means of a lever with weights at the end of it, I compreffed feveral frefh parcels of Peafe in the fame Pot, with a force equal to I 600,800 , and 400 pounds; in which Experiments, tho' 


\section{Vegetable Staticks.}

the Peafe dilated, yet they did not raife the lever, becaufe what they increafed in bulk was, by the great incumbent weight, preffed into the interftices of the Peafe, which they adequately filled up, being thereby formed into pretty regular Dodecahedrons.

We fee in this Experiment the vaft force with which fwelling Peafe expand, and 'tis doubtlefs a confiderable part of the fame force which is exerted, not only in pufhing the Plume upwards into the air, but alfo in enabling the firft thooting radicle of the $\mathrm{Pea}_{\text {, }}$ and all its fubfequent tender Fibres, to penetrate and thoot into the carth.

\section{EXPERIMENT XXXIII.}

We fee, in the Experiments of this chap: ter, many inftances of the great efficacy of attraction; that univerfal principle which is fo operative in all the very different works of nature; and is moft eminently fo in vegetables, all whofe minuteft parts are curiounly ranged in fuch order, as is beft adapted by their united force, to attract proper nourifhment.

And we thall find in the following Experiment, that the diffevered particles of vegetables, and of other bodies, have a

$$
\mathrm{H}_{4}
$$

ftrong 
Atrong attractive power when they lay con: fuifed.

That the particles of wood are Specifically heavier than water (and can therefore ftrongly attract it) is evident, becaufe feveral forts of wood fink immediately; others (even cork) when their interftices are well foaked, and filled with water: As Dr. Defaguliers informed me, he found a cork which had been fealed up in a tube with water for 4 years, to be then fpecifically heavier than water; others (as the Peruvian Bark) fink when very finely pulverized, becaufe all their cavitics which made them fwim, are thereby deftroyed.

In order to try the imbibing power of common wood afhes, I filled a glass tube $c r i, 3$ feet long, and $\frac{7}{8}$ of an inch diameter; (Fig. 16.) with well dried and fifted wood alhes, preffing them clofe with a rammer; I tied a piece of linen over the end of the tube at $i$, to keep the alhes from falling out; I then cemented the tube $c$ fatt at $r$ to the Aqueo-mercurial gage $r z$, and when I had filled the gage full of water, I immerfed it in the ciftern of mercury $x$; then to the upper end of the tube $c$, at $o$ I fcrewed on the mercurial gage $a b$. 
The athes as they imbibed the water drew the mercury up 3 or 4 inches in a few hours towards $z$; but the three following days it rofe but I inch, $\frac{x}{2}$ inch, and $\frac{\pi}{4}$, and fo lefs and lefs, fo that in $s$ or 6 days it ceafed rifing: The highent it rofe was 7 inches, which was equal to raifing water 8 feet high.

This had very little effect on the mercury in the gage $a b$, unlers it were, that it would rife a little, viz. an inch or little more in the gage at $a$, as it were by the fuction of the alhes, to fupply fome of the air bubbles which were drawn out at $i$.

But when I feparated the tube $c 0$ from the gage $r z$, and fet the end $i$ in water, then the moifture (being not reftrained as before) rofe fafter and higher in the afhes $c 0$, and depreffed the mercury at $a$, fo as to be 3 inches lower than in the leg $b$, by driving the air upwards, which was intermixed with the afhes.

I filled another tube 8 feet long, and $\frac{r}{2}$ inch diameter with red lead; and affixed it in the place of $c 0$ to the gages $a b, q z$. The mercury rofe gradually 8 inches to $z$.

In both thefe Experiments, the end $i$ was covered with innumerable air bubbles, many 


\section{Vegetable Staticks.}

of which continually paffed off, and were fucceeded by others, as at the tranfverfe cuts in the Experiments of this chapter. And as there, fo in thefe, the quantity of air bubbles decreafed every day, fo as at laft to have very few : The part $i$ immerfed in the water, being become fo faturate therewith, as to leave no room for air to pals.

After 20 days $I$ picked the minium out of the tube, and found the water had rifen 3 feet 7 inches, and would no doube have rifen higher, if it had not been clogged by the mercury in the gage $z$. For which reafon the moifture rofe but 20 inches in the afhes, where it would otherwife have rifen 30 or 40 inches,

And as Sir Ifaac Nereton (in his Opticks, query 3 I.) obferves, "The water rifes " up to this height, by the action only of " thofe particles of the afhes which are up" on the furface of the elevated water; the "particles which are within the water, at" tracting or repelling it as much down"wards as upwards; and therefore the ac"tion of the particles is very ftrong: But "the particles of the afhes being not fo " denfe and clofe together as thofe of glafs, "t their action is not fo ftrong as that of "glals, 


\section{Vegetable Staticks.}

"glafs, which keeps quick-filver fufpended " to the height of 60 or 70 inches, and " therefore acts with a force, which would " keep water fufpended to the height of a"bove 60 feet.

"By the fame principle, a fponge fucks "6 in water, and the glands in the bodies of " animals, according to their feveral natures "and difpofitions, fuck in various juices "from the blood."

And by the fame principle it is, that we fee in the preceding Experiments plants imbibe moifture fo vigoroully up their fine capillary veffels; which moifture, as it is carried off in perfpiration, (by the action of warmth) thereby gives the fap veffels liberty to be almoft continually attracting of frefh fupplies, which they could not do, if they were full faturate with moifture: For without perfpiration the fap muft neceffarily ftagnate, notwithftanding the fap veffels are fo curiounly adapted by their exceeding finenefs, to raife the fap to great heights, in a reciprocal proportion to their very minute diameters. 


\section{H A P. III.}

Experiments, Shewing the force of the Sap in the Vine in the bleeding seafon.

T AVIN G in the firft chapter fhewn 11 many inftances of the great quantities imbibed, and perfpired by trees, and in the fecond chapter, feen the force with which they do imbibe moifture; I propore next to give an account of thore Experiments, which prove with what great force the fap of the Vine is puthed forth, in the bleeding feafon.

\section{EXPERIMENT XXXIV.}

March 3 oth at 3 p. m. I cut off a Vine on a weftern afpect, within feven inches of the ground, the remaining ftump $c$ (Fig. 17.) had no lateral branches: It was 4 or 5 years old, and 'inch diameter. I fix'd to the top of the ftump, by means of the brafs collar $b$, the glafs tube $b f$, feven feet long, and $\frac{7}{4}$ inch diameter; I fecured the joynt $b$ with ftiff cement made of melted Bees-wax and Turpentine, and bound it faft over with feveral folds of wet bladder and pack-thread: 


\section{Vegetable Staticks:}

I then frewed a fecond tube $f g$ to the firt; and then a third $g$ a to $2 s$ feet height.

The ftem not bleeding into the tube, I filled the tube two feet high with water, the water was imbibed by the ftem within 3 inches of the bottom, by 8 a clock that evening. In the night it rained a fmall fhower. The next morning at $6+\frac{5}{2}$, the water was rifen three inches above what it was fallen to laft night at eight a clock. The Thermometer which hung in my porch was I I degrees above the freezing point. March 3 ift from $6+\frac{\pi}{2} a . m$. to $10 p . m$. the fap rofe $8+\frac{1}{4}$ inches. April ift at 6 a. $m$. Thermometer $3 \frac{x}{2}$ degrees above the freezing point, and a white hoar froft, the fap rofe from ten a clock lant night $3+\frac{\pi}{4}$ inches more; and fo continued rifing daily till it was above 21 feet high, and would very probably have rifen higher, if the joynt 6 had not feveral times leaked: After ftopping of which it would rife fometimes at the rate of an inch in 3 minutes, fo as to rife to feet or more in a day. In the chief bleeding feafon it would continue rifing night and day, but much more in the day than night, and mott of all in the greatef heat of the day; and what little frnking it 


\section{Io Vegetable Staticks.}

had of 2 or 3 inches was always after funfet, which I furpect was principally occafioned by the fhrinking and contraction of the cement at $b$, as it grew cool.

When the fun thined hot upon the Vine, there was always a continued feries of air bubbles, conftantly afcending from the ftem thro' the fap in the tube, in fo great plenty as to make a large froth on the top of the fap, which thews the great quantity of air which is drawn in thro' the roots and ftem.

From this Experiment we find a confiderable energy in the root to pufh up fap in the bleeding feafon.

This put me upon trying, whether I could find any proof of fuch an energy, when the bleeding feafon was over, in order to which,

\section{EXPERIMENT XXXV.}

Fuly 4 th at noon, I cut off within 3 in. ches of the ground, another Vine on a fouth afpect, and fixed to it a tube 7 feet high, as in the foregoing Experiment: I filled the tube with water, which was imbibed by the root the firf day, at the rate of a foot in an hour, but the next day much more flowly, yet it was continually finking, 


\section{Vegetable Staticks.}

fo that at noon day I could not fee it fo much as ftationary.

Yet by Experiment the $3 d$, on the Vine in the garden pot, it is plain, that a very confiderable quantity of fap was daily prefe fing thro' this ftem, to fupply the perfpiration of the leaves, before I cut the Vine off. And if this great quantity were carried up by pulfion or trufion, it muft needs have rifen out of the ftem into the tube.

Now fince this flow of fap ceares at once, as foon as the Vine was cut off the ftem, the principal caufe of its rife muft at the fame time be taken away, viz. the great perfpiration of the leaves.

For tho' it is plain by many Experiments, that the fap enters the fap veffels of plants with much vigour, and is probably carried up to great heights in thofe veffels, by the vigorous undulations of the fun's warmth, which may reciprocally caufe vibrations in the veficles and fap veffels, and thereby make them dilate and contract a little; yet it feems as plain (from many Experiments, as particularly Exper. I 3, I4, Is. and Exper. 43.) where tho' we are affured that a great quantity of water paffed by the notch cut 2 or 3 feet above the end of the Atem; yet was the notch 
12 Vegetable Staticks.

notch very dry, becaufe the attraction of the perfpiring leaves was much greater than the force of trufion from the column of water. From thefe Experiments, I fay, it feems evident, that the capillary fap veffels, out of the bleeding feafon, have little power to protrude fap in any plenty beyond their orifices; but as any lap is evaporated off, they can by their ftrong attraction (affifted by the genial warmth of the fun) fupply the great quantities of fap drawn off by perspiration.

EXPERIMENT. XXXVI.

April 6th at 9. a. m. rain the evening before, I cut off a Vine on a fouthern afpect, at $a$ (Fig. 18.) two feet nine inches from the ground, the remaining ftem $a b$, had no lateral branches, it was $\frac{7}{8}$ inch diameter; I fixed on it the mercurial gage a $y$. At I I a. $m$. the mercury was rifen to $z$, is inches higher than in the leg $x$, being puthed down at $x$, by the force of the fap which came out of the ftem at $a$.

At $4 p . m$. it was funk an inch in the leg $z y$.

April 7 th at $8 a . m$. rifen very little, a fog: at II $a . m$. 't is I 7 inches high, and the fog gone. 


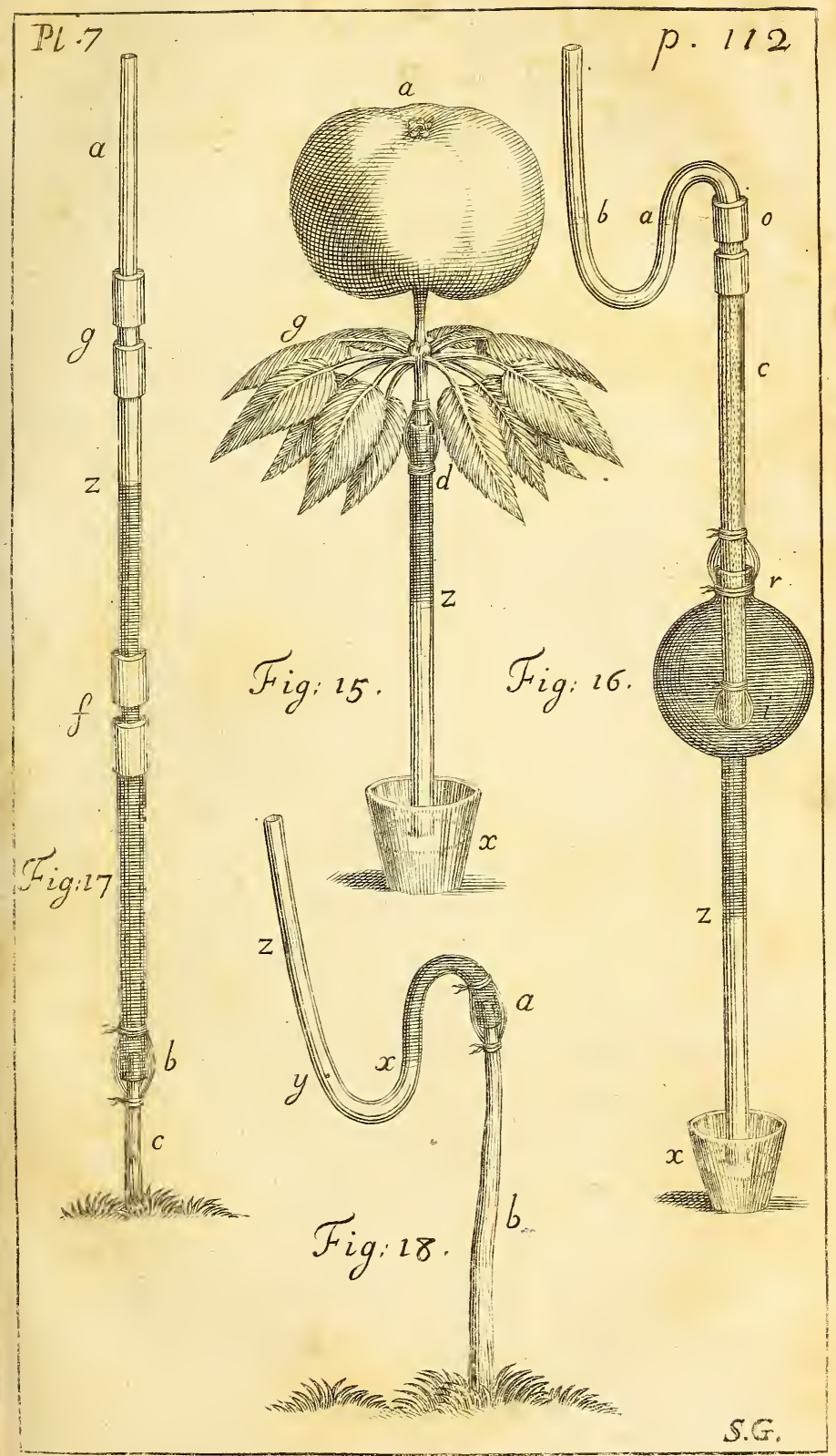



April ioth at $7 a . m$. mercury is inches high; I then added more mercury, fo as to make the furfacc $z 23$ inches higher than $x$; the fap retreated very little into the ftem, upon this additional weight, which thews with what an abfolute force it advances: at noon it was funk one inch.

April r I th at 7 a.m. $24+\frac{3}{4}$ inches high, fun-fhine: at $7 p . m .18$ inches high.

April I 4th at 7 a.m. $20+\frac{1}{4}$ inches high, at $9 a . m .22+\frac{r}{2}$, fine warm fun-thine; here we fee that the warm morning fun gives a frefh vigour to the fap. At i $a . m$. the fame day $16+\frac{5}{2}$, the great perfpiration of the ftem makes it fink.

April I 6 th at 6 a.m. I $9+\frac{\mathrm{x}}{2}$ rain. At 4 $p . m$. I 3 inches. The fap (in the foregoing Experiment, numb. 34.) rifen this day fince noon 2 inches, while this funk by the perfpiration of the ftem; which there was little room for, in the very thort ftem of the other.

April I 7 at I I a.m. $24+\frac{1}{4}$ inch high, rain and warm; at 7 p. m. $29+\frac{1}{2}$, fine warm rainy weather, which made the fap rife all day, there being little perfpiration by reafon of the rain.

April I 8th at $7 a . m .32+\frac{1}{2}$ inches high, and would have rifen higher, if there had 


\section{Vegetable Staticks.}

been more mercury in the gage; it being all forced into the $\operatorname{leg} y z$. From this time to May sth, the force gradually decreafed.

The greateft height of the mercury being $32+{ }^{~}$ inches; the force of the fap was then equal to 36 feet $s+\frac{1}{3}$ inches height of water.

Here the force of the rifing fap in the morning is plainly owing to the energy of the root and ftem. In another like mercurial gage, (fixed near the bottom of a Vine which run 20 feet high) the mercury was raifed by the force of the fap 38 inches equal to 43 feet +3 inches $+\frac{x}{3}$ height of water.

Which force is near five times greater than the force of the blood in the great crural artery of a Horfe; feven times greater than the force of the blood in the like artery of a Dog; and eight times greater than the blood's force in the fame artery of a fallow Doe: Which different forces I found by tying thofe feveral animals down alive upon their backs; and then laying open the great left crural artery, where it firft enters the thigh, I fixed to it (by means of two brafs pipes, which run one into the other (a glafs tube of above ten feet long, and $\frac{\pi}{8}$ th of an inch diameter in bore: In which tube the 



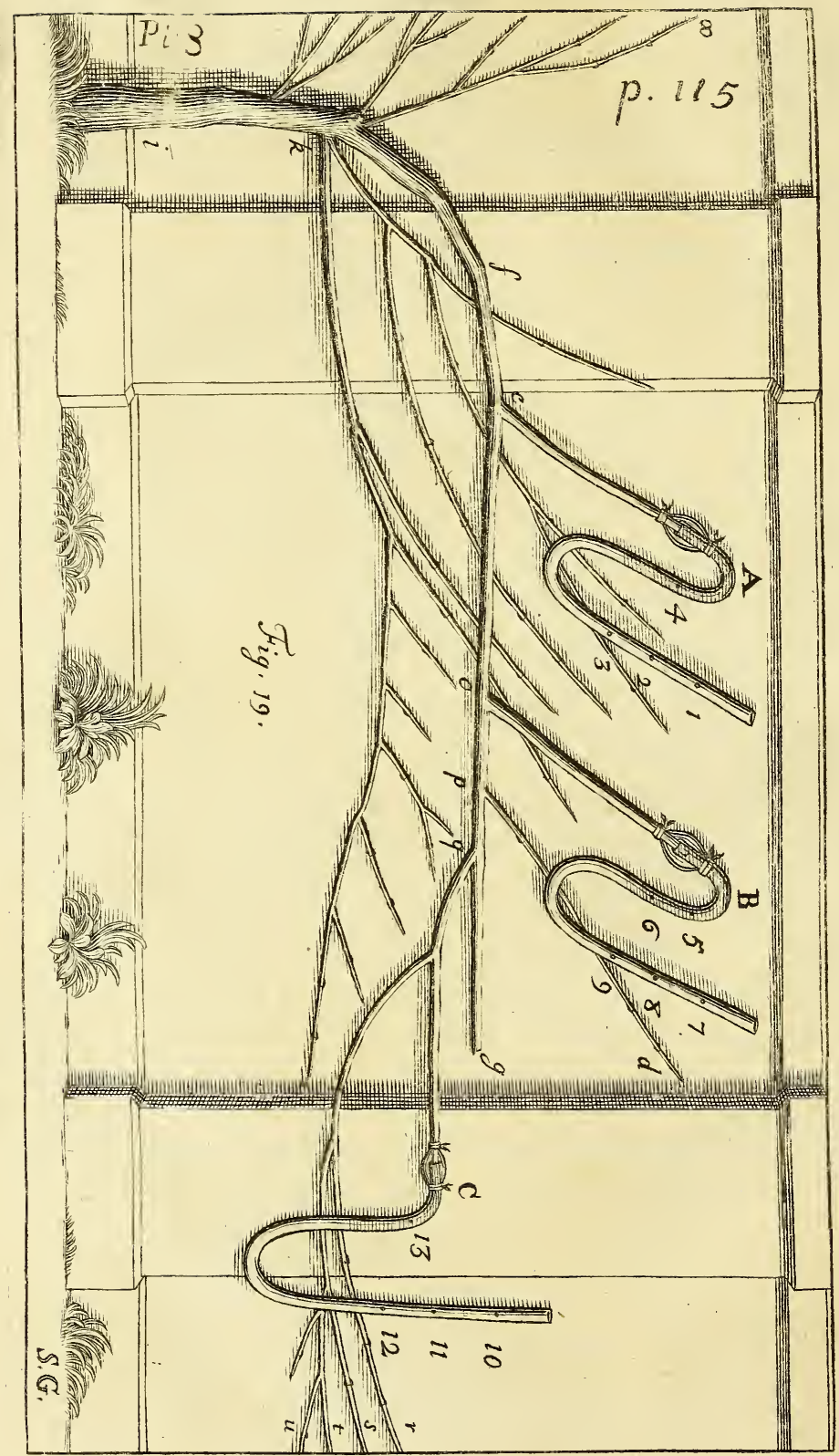




\section{Vegetable Staticks.}

blood of one horfe rofe cight feet three inches, and the blood of another Horfe eighe feet nine inches. The blood of a little Dog fix feet and half high: In a large Spaniel feven feet high. The blood of the fallow Doe mounted five feet feven inches.

EXPERIMENT XXXVII.

April 4th, I fixed three mercurial gages (Fig. I 9.) $A, B, C$ to a Vine, on a fouthealt afpeet, which was 50 feet long, from the root to the end $r u$. The top of the wall was is $+\frac{1}{2}$ feet high; from $i$ to $k, 8$ feet; from $k$ to $e, 6$ feet $+\frac{r}{3}$; from $e$ to $A$, I foot 10 inches; from $e$ to 0,7 feet; from 0 to $B, 5+\frac{x}{2}$ fect; from $O$ to $C, 22$ feet 9 inches; from $o$ to $u, 32$ feet 9 inches.

The branches to which $A$ and $C$ were fixed were thriving thoots two years old, but the branch $O B$ was much older.

When I firf fixed them, the mercury was pufhed by the force of the fap, in all the gages down the legs 4, 5, I3, fo as to rife nine inches higher in the other legs.

The next morning at $7 a, m$. the mercury in $A$ was puthed I $4+$ inches high, in $B 12+\frac{x}{4}$, in $C$ I $3+\frac{1}{3}$ 
The greateft height to which they pufhed the fap feverally was $A$ 2 I inches, $B 26$ inches, $C 26$ inches.

The mercury conftantly fubfided by the retreat of the fap about 9 or ro in the morning, when the Sun grew hot; but in a very moin foggy morning the fap was later before it retreated, viz. till noon, or fome time after the fog was gone.

Abour 4 or 5 a clock in the afternoon, when the Sun went off the Vine, the fap began to pufh afreth into the gages, fo as to make the mercury rife in the open legs; but it always rofe fafteft from fun-rife till 9 or 10 in the morning.

The fap in $B$ (the oldeft ftem) play'd the mont freely to and fro, and was therefore fooneft affected with the changes from hot to cool, or from wet to dry, and vice versâ.

And April 1o, toward the end of the bleeding feafon, $B$ began firft to fuck up the mercury from 6 to 5 , fo as to be 4 inches higher in that leg than the other. But April 24, after a night's rain, $B$ puined the mercury 4 inches up the other leg; $A$ did not begin to fuck till April 29, viz. 9 days after $B$; $C$ did not begin to fuck till May 3. viz. I 3 days after $B$, and 4 days after $A$. May 5 . 


\section{Vegetable Staticks.}

at 7 a. $m$. $A$ puthed I inch, $C$ I $+\frac{2}{3}$, but towards noon they all three fucked.

I have frequently obferved the fame difference in other Vines, where the like gages have been fixed at the fame time, to old and young branches of the fame Vine, viz. the oldef began firft to fuck.

In this Experiment we fee the great force of the fap, at 44 feet 3 inches diftance from the root, equal to the force of a column of water 30 feet I I inches $+\frac{3}{4}$ high.

From this Experiment we fee too, that this force is not from the root only, but muft alfo proceed from fome power, in the ftem and branches: For the branch $B$ was much fooner influenced by changes from warm to cool, or dry to wet, and vice vers $\hat{a}_{2}$ than the other two branches $A$ or $C$; and $B$ was in an imbibing (tate, 9 days before $A$, which was all that time in a ftate of puthing fap; and $C$ puthed I 3 days after $B$ had ceafed pufhing, and was in an imbibing ftate.

Which imbibing ftate Vines and Appletrees continue in all the fummer, in every branch, as I have found by fixing the like gages to them in Fuly. 
II 8 Vegetable Staticks.

\section{EXPERIMENT XXXVIII.}

March 10. at the beginning of the bleeding feafon, (which is many days fooner or later, according to the coldnefs or warmth, moifure or drynefs of the feafon) I then cut off a branch of a vine $b f c g$ at $b$, (Fig. 20.) which was 3 or 4 years old, and cemented faft on it a brafs-collar, with a fcrew in it; to that I ferewed another brafs collar, which was cemented fatt to the glafs tube $\approx, 7$ fect long and $\frac{1}{4}$ inch diam. (which I find to be the propereft diam.) to that I fcrewed others, to 38 feet height. Thefe tubes were faftened and fecured in long wooden tubes, 3 inches fquare, one fide of which was a door opening upon hinges; the ufe of thofe wooden tubes was to preferve the glars tubes from being broke by the freezing of the fap in them in the night. But when the danger of hard frofts was pretty well over, as at the beginning of April, then I ufually fix'd the glaffes without the wooden tubes, faftening them to feaffold poles, or two long iron fpikes drove into the wall.

Before I proceed to give an account of the rife and fall of the fap, in the tubes I

wil! 


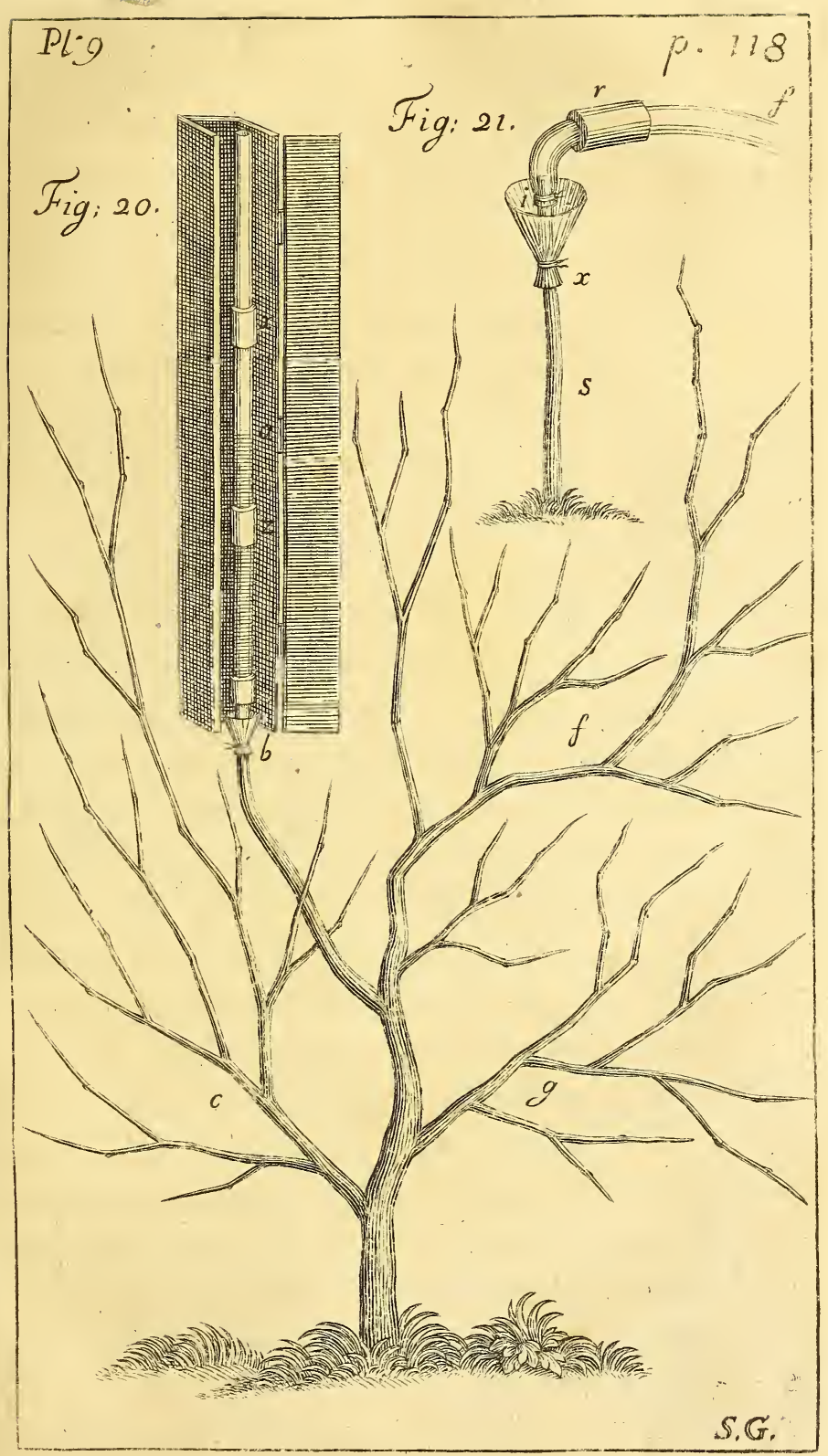



will firt defcribe the manner of cementing on the brafs collar $b$, to the ftem of the Vine in which I have been often difappointed, and have met with difficulties; it muft therefore be done with great care.

Where I elefign to cut the ftem, I fint pick off all the rough ftringy bark carefully with my nails to avoid making any wound thro' the green inner bark; then I cut off the branch at $i$, (Fig. 2I.) and immediately draw over the ftem a piece of dried theepsgut, which I tie faft, as near the end of the ftem as I can, fo that no fap can get by it ; the fap being confined in the gut if: Then I wipe the ftem at $i$ very dry with a warm cloth, and tie round the ftem a ftiff paper funnel $x i$, binding it faft at $x$ to the ftem; and pinning clofe the folds of the paper from $x$ to $i$ : Then I flide the brafs collar $r$ over the gut, and immediately pour into the paper funnel melted brick-duft cement, and then fet the brafs collar into it; which collar is warmed, and dipped before in the cement, that it may the better now adhere: When the cement is cold, I pull away the gut, and fcrew on the glafs tubes.

But finding fome inconvenience in this hot cement (becaufe its heat kills the fap

$$
\text { I } 4
$$

veffels 


\section{0 \\ Vegetable Staticks.}

vefiels near the bark, as is evident by their being difcoloured) I have fince made ufe of the cold cement of Bees-wax and Turpentine, binding it faft over with wet bladder and pack-thread, as in Exper. 34.

Inftead of brafs-collars, which fcrewed into each other, I often (erpecially with the Syphons in Exper. 36, and 37.) made ufe of two brals collars, which were turned a little tapering, fo that one cntered and exactly fitted the other.

This joining of the rwo collars was effectually fecured from leaking, by firt anointing them with a foft cement; and they were fecured from being disjoined, by the force of the afcending fap, by twifring pack-thread round the protuberant knobs on the fides of the collars. When I would feparate the collars, I found it neceffary (except in hot Sun-fhine) to melt the loft cement by applying hot irons on the outfide of the collars.

It is necdful to fhade all the cemented joints from the Sun with loofe folds of paper, elfe its heat will often melt them, and fo dilate the cement, as to make it be drove forcibly up the tube, which defeats the Experiment.

The 
The Vines to which the tubes in this Experiment were fixed, were 20 feet high from the roots to their top; and the glafs tubes fixed at feveral heights $b$ from the ground, from 6 to 2 feet.

The fap would rife in the tube the firft day, according to the different vigour of the bleeding ftate of the Vine, either $1,2,5$, I2, Is, or 25 feet; but when it had got to its greatef height for that day, if it was in the morning, it would conftantly begin to fubfide towards noon.

If the weather was very cool about the middle of the day, it would fubfide only from 1 I or 12 to 2 in the afternoon; but if it were very hot weather, the fap would begin to fubfide at 9 or 10 a clock, and continue fubfiding till 4,5 , or 6 in the evening, and from that time it would continue ftationary for an hour or two; after which it would begin to rife a little, but not much in the night, nor till after the fun was up in the morning, at which time it rofe faftert.

The frefher the cut of the Vine was, and the warmer the weather, the more the fap would rife, and fubfide in a day, as 4 or 6 feet. 
But if it were $s$ or 6 days fince the Vine was cut, it would rife or fubfide but little; the fap-veffels at the tranfverfe cut being faturate and contracted.

But if I cut off a joint or two off the item, and new fixed the tube, the fap would then rife and fubfide vigoroufly.

Moifture and warmth made the fap moft vigorous.

If the beginning or middle of the bleeding feafon, being very kindly, had made the motion of the fap vigorous, that vigout would immediately be greatly abated by cold eafterly winds.

If in the morning, while the fap is in a rifing ftate, there was a cold wind with a mixture of fun-thine and cloud; when the Sun was clouded, the fap would immediately vifbly fubfide, at the rate of an inch in a minute for feveral inches; if the Sun continued fo long clouded: But as foon as the Sun-beams broke out again, the rap would immediately return to its then rifing ftate; juft as any liquor in a Thermometer rifes and falls with the alternacies of heat and coid; whence 'tis probable, that the plentiful rife of the fap in the Vine in the bleeding feafon, is effected in the fame manner.

When 


\section{Vegetable Staticks.}

When three Tubes were fixed at the fame time to Vines on an eaftern, a fouthern, and a weftern Afpect, rownd my Porch, the fap would begin to rife in the morning firft in the eaftern tube, next in the fouthern, and laft in the weftern tube: And towards noon it would accordingly begin to fubfide, firt in the eaftern tube, next in the fouthern, and laft in the weftern tube.

Where two branches arofe from the fame old weftern trunk, is inches from the ground; and one of thefe branches was fpread on a fouthern, and the other on a weftern Afpect; and glafs tubes were at the fame time fixed to each of them; the fap would in the morning, as the Sun came on, rife firft in the fouthern, then in the weftern tube; and would begin to fubfide, firft in the fouthern, then in the weftern tube.

Rain and warmth, after cold and dry, would make the fap rife all the next day, without fubfiding, tho' it would rife then nloweft about noon; becaufe in this cafe the quantity imbibed by the root, and raifed from it, exceeded the quantity perspired. 
The fap begins to rife fooner in the morning in cool weather, than after hot days; the reafon of which may be, becaufe in hot weather much being evaporated, it is not fo foon fupplied by the roots as in cool weather, when lefs is evaporated.

In a prime bleeding feafon I fix'd a tube 25 feet long to a thriving branch two years old, and two feet from the ground, where it was cut off; the fap flowed fo briskly, as in 2 hours to flow over the top of the tube, which was 7 feet above the top of the Vine; and doubtlefs would have rifen higher, if I had been prepared to lengthen the tube.

When at the diftance of four or five days, tubes were affixed to two different branches, which came from the fame ftem, the fap would rife higheft in that which was laft fixed; yet if in the fixing the fecond tube there was much fap loft, the fap would fubfide in the firft tube; but they would not afterwards have their fap in equilibrio; i.e. the furface of the fap in each was at very unequal heights; the reafon of which is, becaufe of the difficulty with which the fap paffes thro' the almoft faturate and contracted Capillaries of the firft cut frem. 


\section{Vegetable Staticks.}

In very hot weather many air bubbles would rife, fo as to make a froth an inch deep, on the top of the fap in the tube.

I fix'd a fmall air Pump to the top of a long tube, which had I 2 feet height of fap in it; when I pumped great plenty of bubbles arofe, tho the fap did not rife, but fall a little, after I had done pumping.

In Experiment 34. (where a tube was fixed to a very thort ftump of a Vine, without any lateral branches) we find the fap rofe all day, and fafteft of all in the greateft heat of the day: But by many obfervations under the $37^{\text {th }}$ and this 38 th Experiments, we find the fap in the tubes conftantly fubfided as the warmth came on towards the middle of the day, and fafteft in the greateft heat of the day. Whence we may reafonably conclude (confidering the great perfpirations of trees, thewn in the firft chapter) that the fall of the fap in thefe fap gages; in the middle of the day, efpecially in the warmer days, is owing to the then greater perfpiration of the branches, which perfpiration decreafes, as the heat decreafes towards evening, and probably wholly ceares when the dews fall. 


\section{I26 Vegetable Staticks.}

But when towards the latter end of April the fpring advances, and many young thoots are come forth, and the furface of the Vine is greatly increafed and enlarged, by the expanfion of feveral leaves; whereby the perfpiration is much increafed, and the fap more plentifully exhaufted, it then ceares to flow in a vifible manner, till the return of the following fpring.

And as in the Vine, fo is the cafe the fame in all the bleeding trees, which ceare bleeding as foon as the young leaves begin to expand enough to perfpire plentifully, and to draw off the redundant fap. Thus the bark of Oaks, and many other trees, moft eafily feparates while it is lubricated with plenty of fap: But as foon as the leaves expand fufficiently to perfpire off plenty of fap, the bark will then no longer run (as they term it) but adheres molt firmly to the wood.

\section{EXPERIM E T XXXIX.}

In order to try if I could perceive the Atem of the Vine dilate and contraat with heat or cold, wet or dry, a bleeding or not bleeding feafon, fome time in February, I fix'd to the ftem of a Vine an inftrument in 


\section{Vegetable Staticks.}

fuch a manner, that if the ftem had dilated or contracted but the one hundredth part of an inch, it would have made the end of the inftrument (which was a pieee of ftrong brafs-wire, 18 inches long) rife or fall very fenfibly about one tenth of an inch; but I could not perceive the inftriment to move, either by heat or cold, a bleeding or not bleeding feafon. Yet whenever it rained the ftem dilated fo as to raife the end of the inftrument or lever $\frac{3}{50}$ of an inch, and when the ftem was dry it fubfid. ed as much.

This Experiment fhews, that the fap (e? ven in the bleeding (eafon) is confined in its proper veffels, and that it does not confufedly pervade every interftice of the ftem, as the rain does, which entering at the perfpiring pores, foaks into the interftices, and thereby dilates the ftem. 


\section{H A P. IV.}

Experiments, 乃hewing the ready lateral mo tion of the Sap, and confequently the lateral communication of the Sap vefJels. The free pasfage of it from the fmall branches towards the ftem, as well as from the ftcm to the branches. With an account of fome Experiments, relating to the circulation or non-circulation of the Sap.

\section{EXPERIMENT XL。}

T $N$ order to find whether there was any 1 lateral communication of the fap and fap veffels, as there is of the blood in animals, by means of the ramifications, and lateral communications of their veffels:

Anguft I sth, I took a young Oak branch $\frac{7}{8}$ inches diameter, at its tranfverfe cut; 6 feet high, and full of leaves. Seven inches from the bottom, I cut a large gap to the pith, an inch long, and of an equal depth the whole length; and four inches above that, on the oppofite fide, I cut fuch another gap; I fet the great end of the ftem in water: It imbibed and perfpired in two nights and two days I 3 ounces, while another 


\section{Vegetable Staticks.}

another like Oak branch, fomewhat bigger than this, but with no notch cut in its ftem, imbibed 25 ounces of water.

At the fame time I tried the like Exper. with a Duke-Cherry branch; it imbibed and perfirired 23 ounces in 9 houts the firft day, and the next day is ounces.

At the fame time I took another Duke. Cherry branch, and cut 4 fuch fquare gaps to the pith, 4 inches above each other; the int North, 2d Eaft, 3d South, 4th Weft: It had a long flender ftem, 4 feet length, without any branches, only at the very top; yet it imbibed in 7 hours day 9 ounces, and in two days and two nights 24 ounces.

We fee in thefe Experiments a moft free lateral communication of the fap and fap veffels, thefe great quantities of liquor having paffed laterally by the gaps; for by Experiment I3, I4, I s. (on Cylinders of wood) little evaporated at the gaps.

And in order to try whether it would not be the fame in branches as they grew on trees, I cut two fuch oppofite gaps in a Duke-Cherry branch, 3 inche's diftant from each other: The leaves of this branch continued green, within 8 or 10 days as long as the leaves on the other branches of the fame tree. 
The fame day, viz. Aug. Isth, I cut two fuch oppofite gaps 4 inches diftant, in an horizontal young thriving Oak-branch; it. was I inch diameter, I 8 days after many of the leaves begun to turn yellow, which none of the leaves of other boughs did then.

The fame day I cut off the bark for one inch length, quite round a like branch of the fame $O a k$; eighteen days after the leaves were as green as any on the fame tree; but the leaves fell off this and the foregoing branch early in the winter; yet continued on all the reft of the boughs of the tree (except the top ones) all the winter.

The fame day I cut four fuch gaps, two inches wide, and nine inches diftant from each other, in the upright arm of a GoldenRenate-tree; the diameter of the branch was $2+\frac{\pi}{2}$ inch, the gaps faced the four cardinal points of the compars; the apples and leaves on this branch flourifhed as well as thofe on other branches of the lame tree.

Here again we fee the very free lateral paffage of the fap, where the direct paffage is feveral times intercepted. 


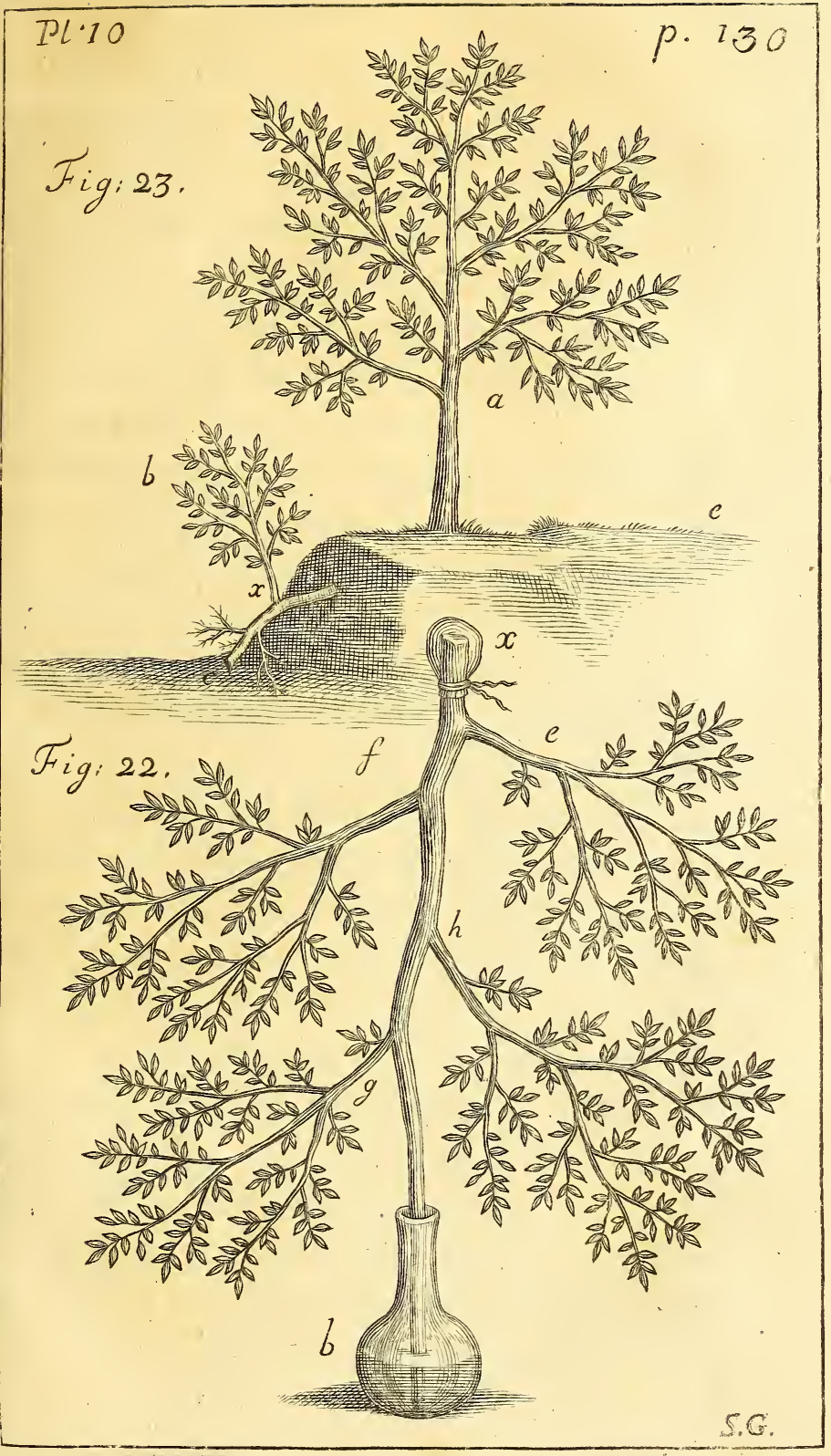





\section{Vegetable Staticks.

EXPERIMENT XLI。

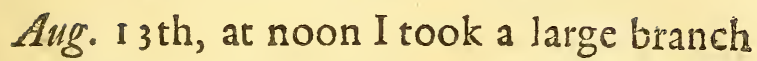
of an Apple-tree, (Fig. 22.) and cemented up the tranfverfe cut, at the great end $x_{3}$ and tied a wet bladder over it: I then cut off the main top branch at $b$; where it was $\frac{6}{8}$ inch diameter, and fet it thus inverted into the bottle of water $b$.

In three days and two nights it imbibed and perfpired 4 pounds 2 ounces $+\frac{1}{2}$ of water, and the leaves continued green; the leaves of a bough cut off the fame tree at the fame time with this, and not fet in water, had been withered forty hours before. This, as well as the great quantities imbibed and perfpired, fhews, that the water was drawn from $b$ moft freely to $e$, $f, g, h$, and from thence down their rerpective branches, and fo perfpired off by the leaves.

This Experiment may ferve to explain the reafon, why the branch 6 , (Fig. 23.) which grows out of the root $c x$, thrives very well, notwithftanding the root $c x$ is here fuppofed to be cut off at $c$, and to be out of the ground: For by many Experiments in the firft and fecond chapters, it

$$
\text { K } 2
$$




\section{Vegetable Staticks.}

is evident, that the branch $b$ attracts fap at $x$ with great force: And by this prefent Experiment, 'tis as evident, that fap will be drawn as freely downwards from the tree to $x$, as from $c$ to $x$, in cafe the end $c$ of the root were in the ground; whence 'tis no wonder, that the branch $b$ thrives well, tho' there be no circulation of the fap.

This Experiment 4I, and Experiment 26 , do alfo thew the reafon why, where three trees (Fig. 24.) are inarched, and thereby incorporated at $x$ and $z$, the middle tree will then grow, tho it be cut off from its roots, or the root be ding out of the ground, and fufpended in the air; viz. becaufe the middle tree $b$ attracts nourifhment ftrongly at $x$ and $z$, from the adjoining trees $a c$, in the fame manner as we fee the inverted boughs imbibed water in thefe Exper. 26 , and $4 \mathrm{r}$.

And from the fame reafon it is that Elders, Sallows, Willows, Briars, Vines, and moft Shrubs, will grow in an inverted ftate, with their tops downwards in the earth. 


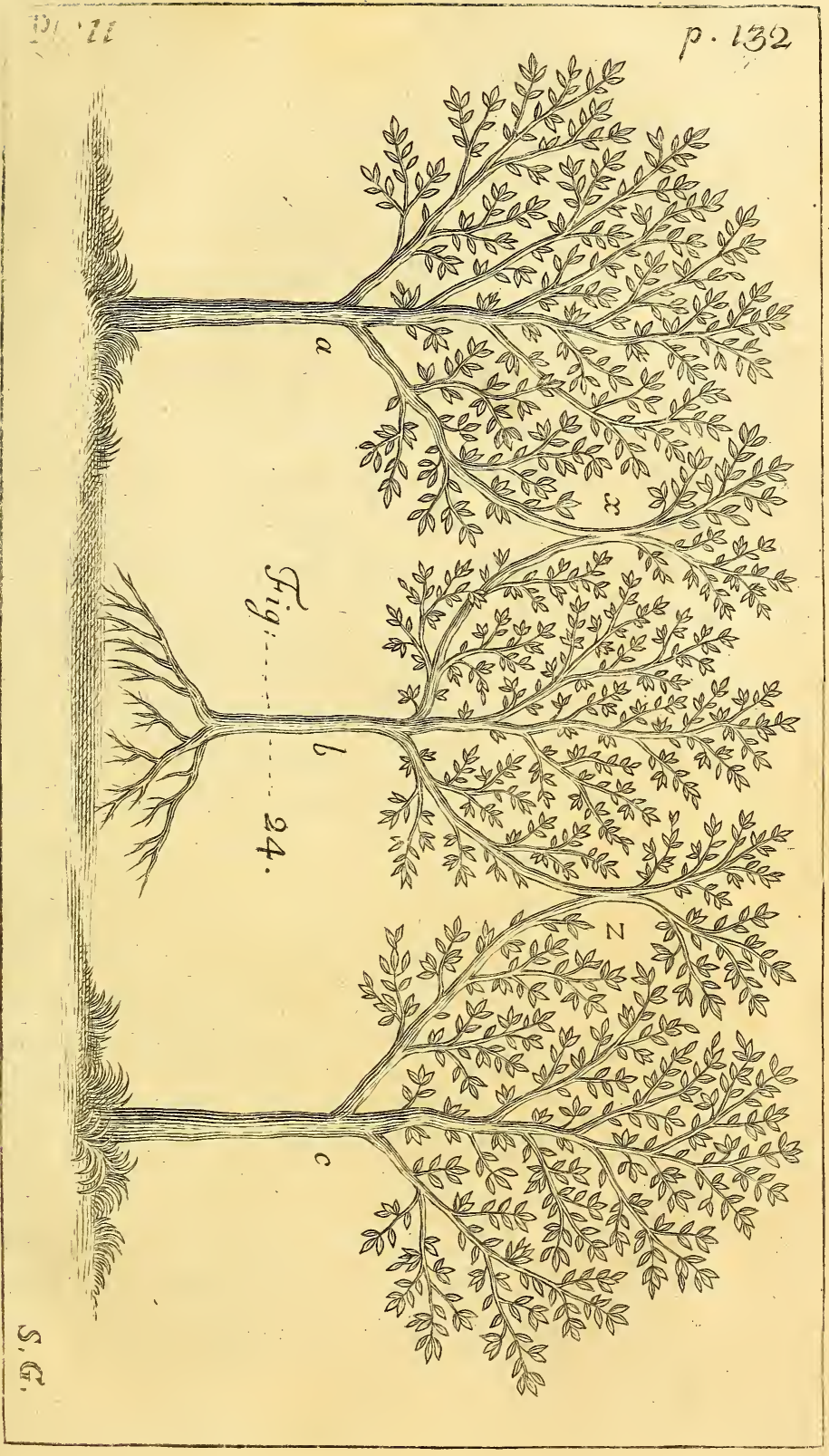



EXPERIMENT XLII.

Fuly 27 th, I repeated Monfieur Perault's Experiment, viz. I took Duke-Cherry, Apple and Curran-Boughs, with two branches each, one of which a $c$ (Fig. 25.) I immerfed in the large veffel of water $e d$, the other branch hanging in the open air: I hung on a rail, at the fame time, other branches of the fame forts, which were then cut off。 After three days, thofe on the rails were very much withered and dead, but the branches $b$ were very green; in 8 days the branch $b$ of the Duke-Cherry was much withered; but the Currans and Apple-branch $b$ did not fade till the eleventh day: Whence'tis plain, by the quantities that mut be perfpired in eleven days, to keep the leaves $b$ green fo long, and by the wante of the water, out of the veffel, that thefe boughs $b$ muft have drawn much water, from and through the other boughs and leaves $c$, which were immerfed in the veffel of water.

I repeated the like Experiment on the branches of Vines and Apple-trees, by running their boughs as they grew into large glafs chymical retorts full of water, where the leaves continued green for feveral $\mathrm{K}_{3}$ weeks, 


\section{I34 Vegetable Staticks.}

weeks, and imbibed confiderable quantities of water.

This thews how very probable it is, that rain and dew is imbibed by vegetables, efpecially in dry feafons.

Which is further confirmed by Experiments lately made on new-planted trees; where by frequently wafhing the bodies of the mot unpromifing, they have out-ftripped the other trees of the fame plantation. And Mr. Miller advifes, "Now and then " in an evening to water the head, and with "s a brufh to wath and fupple the bark all "e round the trunk, which (fays he) I have "c often found very ferviceable." Supplement to his Gardener's Dictionary, Vol. II. under Planting.

\section{EXPERIMENT XLIII.}

Auguif 2oth, at I p.m. I took an Applebranch b, (Fig. 26.) nine feet long, I + $\frac{3}{4}$ inch diameter, with proportional lateral branches, I cemented it faft to the tube $a_{\text {, }}$ by means of the leaden Syphon l: But firt I cut away the bark, and laft year's ringlet of wood, for 3 inches length to $r$. I then filled the tube with water, which was I 2 feet long, and $\frac{x}{2}$ inch diameter, having firt cut 


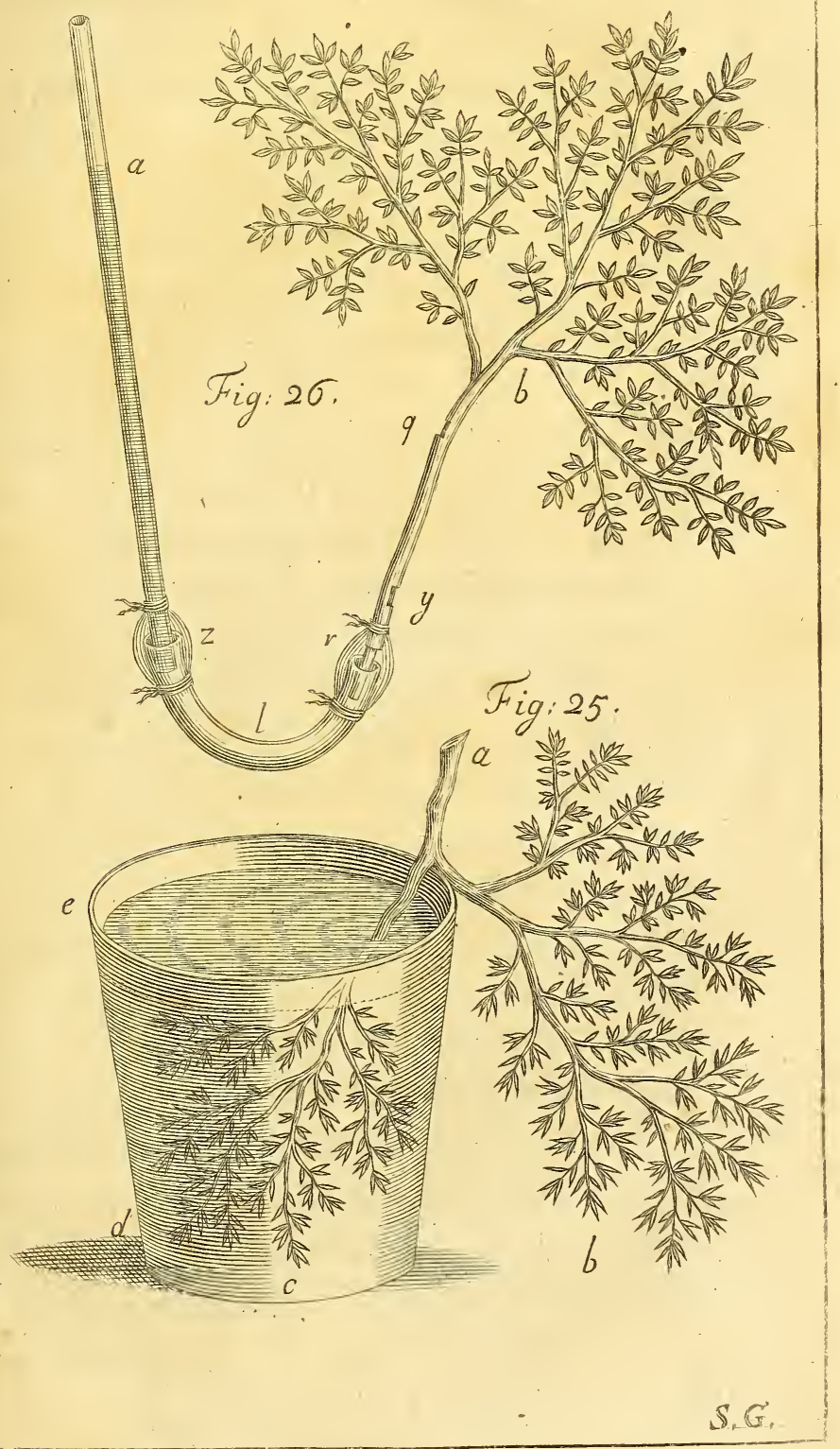





\section{Vegetable Staticks.}

a gap at $y$ through the bark, and laft ycar's wood, I 2 inches from the lower end of the ftem : the water was very freely imbibed, viz. at the rate of $3+\frac{x}{2}$ inches in a minute. In half an hour's time I could plainly perceive the lower part of the gap $y$ to be moifter than before; when at the fame time the upper part of the wound looked white and dry.

Now in this care the water muf necelfarily arcend from the tube, thro' the innermolt wood, becaure the laft year's wood was cut away, for 3 inches length, all round the ftem; and confequently, if the fap in its natural courfe defcended by the laft year's ringlet of wood, and between that and the bark (as many have thought) the water Thould have defcended by the laft year's wood, or the bark, and fo have firf moiftened the upper part of the gap $y$; but on the contrary, the lower part was moiftened, and not the upper part.

I repeated this Experiment with a large Duke-Cherry branch, but could not perceive more moifture at the upper than the lower part of the gap, which ought to have been, if the fap defcends by the laft year's wood or the bark.

$$
\mathrm{K}_{4}
$$




\section{6 \\ Vegetable Staticks.}

It was the fame in a Quince-branch as the Duke-Cherry.

$N$. B. When I cut a notch in either of thefe branches, 3 fcet above $r$, at $q$, I could neither fee nor feel any moifture, notwithftanding there was at the fame time a great quantity of water paffing by; for the branch imbibed at the rate of 4,3 , or 2 inches per minute, of a column of water which was half inch diameter.

The reafon of which drynefs of the notch $q$ is evident from Experiment II, viz. becaufe the upper part of the branch above the notch imbibed and perfpired three or four times more water, than a column of feven feet height of water in the tube could impel from the bottom of the ftem to $q$, which was three feet length of ftem; and confequently, the notch muft neceffarily be dry, notwithftanding folarge 2 Atream of water was paffing by; viz. becaufe the branch and ftem above the notch was in a ftrongly imbibing ftate, in order to fupply the great perfiriation of the leaves, 
EXPERIMENT XLIV.

Auguft $\mathrm{gth}$, at ro a.m. I fix'd in the rame manner (as in the foregoing Experiment) a Duke-Cherry branch five feet high, and one inch diameter, but did not cut away any of the bark or wood at the great end; I filled the tube with water, and then cut a nice off the bark an inch long, 3 inches above the great end; it bled at the lower part moft freely, while the upper part continued dry.

The fame day I tried the fame Experiment on an Apple-branch, and it had the fame effect.

From thefe Experiments 'tis probable that the fap afcends between the bark and wood, as well as by other parts.

And fince by other Experiments it is found that the greatent part of the fap is raifed by the warmth of the Sun on the leaves, which feem to be made broad and thin for that purpole; for the fame reafon, it's mont probable, it fhould rife alfo in thofe parts which are molt expored to the Sun, as the bark is.

And when we confider, that the fap verfels are fo very fine as to reduce the fap al. 
138 Vegetable Staticks.

moft to a vapour, before it can enter them, the Sun's warmth on the bark thould moft eafily difpore fuch rarified fap to afcend, inftead of defcending.

\section{EXPERIMENT XLV.}

Fuly 27th, I took feveral branches of Currans, Vines, Cherry, Apple, Pear and Plumb-tree, and fet the great ends of each in veffels of water $x$, (Fig. 3 I.) but firt took the bark for an inch off one of the branches, as at $z$, to try whether the leaves above $z$ at $b$ would continue green longer than the leaves of any of the other branches $a, c, d$; but I could find no difference, the leaves withering all at the fame time: Now if the return of the fap was ftopped at $z$, then it would be expected, that the leaves at $b$ fhould continue green longer than thofe on the other branches; which did not happen, neither was there any moifture at $z$.

EXPERIMENT XLVI.

In Auguft, I cut off the bark for an inch round, of a young thriving Oak-branch, on the North-Weft fide of the tree. The lcaves of this and another branch, which 
had the bark cut at the fame time, fell early, viz. about the latter end of October, when the leaves of all the other branches of the fame tree, except thofe at the very top of the tree, continued on all the winter.

This is a further proof, that lefs fap goes to branches which have the bark cut off, than to others.

The r gth of April following, the buds of this branch were 5 or 7 days forwarder than thofe of other branches of the fame tree; the reafon of which may probably be, becaufe lefs frefh crude fap coming to this branch than the others, and the perfirirations in all branches being ceteris paribus nearly equal, the leffer quantity of fap in this branch muft fooner be infpiffated into a glutinous fubftance, fit for ncw productions, than the fap of other branches, that abounded with a greater plenty of frefh thin fap.

The fame is the reafon why Apples, Pears, and many other fruits, which have fome of their great fap veffels eaten afunder by infects bred in them, are ripe many days before the reft of the fruit on the fame trees; as alfo that fruit which is gathered 


\section{40 Vegetable Staticks.}

thered fome time before it is ripe, will rio pen fooner than if it had hung on the tree, tho' it will not be fo good; becaufe in thefe cafes the worm-eaten fruit is deprived of part of its nourifhment, and the green gathered fruit of all.

And for the fame reafon fome fruits are fooner ripe towards the tops of the trees, than the other fruit on the fame tree; viz. not only becaufe they are more expofed to the fun; but alfo, becaufe being at a greate: diftance from the root, they have fomewhat lefs nourifhment.

And this is, doubtlefs, one reafon why plants and fruits are forwarder in dry, fandy, or gravelly foils, than in moifter foils; viz. not only, becaufe thofe foils are warmer, on account of their drynefs; but alfo, becaure lefs plenty of moifture is conveyed up the plants; which plenty of moifture, tho' it promotes their growth, yet retards their coming to maturity. And for the fame reafon, the uncovering the roots of trees for fome time, will make the fruit be confide. rably the forwarder.

And on the other hand, where trees a. bound with too great a plenty of frefh drawn fap, as is the cale of trees whofe roots are 


\section{Vegetable Staticks.}

planted too deep in cold moift earth, as alfo of too luxuriant Peach and other Wall trees; or which comes almoft to the fame, where the fap cannot be perfpired off in a due proportion; as in Orchards where trees ftand too near each other, fo as to hinder perfpiration, whereby the fap is kept in too thin and crude a ftate; in all thefe cales little or no fruit is produced.

Hence alfo, in moderately dry fummers, cateris paribus, there is ufually greateft plenty of fruit; becaufe the fap in the bearing twigs and buds is more digefted, and brought to a better confiftence, for thooting out with vigour and firmners, than it is in cool moint fummers: And this obfervation has been verified in the years 1723 , 1724 , and 1725. See an account of them under it, Exp. 20.

But to return to the fubject of the motion of the fap; when the fap has firft paffed thro' that thick and fine ftrainer, the bark of the root, we then find it in greatent quantities, in the moft lax part, between the bark and wood, and that the fame thro' the whole tree. And if in the early fpring, the Oak and feveral other trees were to be examined near the top and bottom, when the fap firft 


\section{Vegetable Staticks.}

begins to move, fo as to make the bark eafily run, or peel off, I believe it would be found that the lower bark is firt moiftened; whereas the bark of the top branches ought firft to be moiftened, if the fap defcends by the bark: As to the Vine, I am pretty well affured that the lower bark is firft moiftened.

We fee in many of the foregoing Experiments, what quantities of moifure trees do daily imbibe and perfpire: Now the celerity of the fap muft be very great, if that quantity of moifture mult, moft of it, afcend to the top of the tree, then defcend, and afcend again, before it is carried off by perfpiration.

The defect of a circulation in vegetables feems in fome meafure to be fupplied by the much greater quantity of liquor, which the vegetable takes in, than the animal, whereby its motion is accelerated; for by Experiment I, we find the Sunfower, bulk for bulk, imbibes and perfpires feventeen times more frefh liquor than a man, every 24 hours.

Befides, nature's great aim in vegetables being only that the vegetable life be carried on and maintained, there was no occafion 
to give its fap the rapid motion which was neceffary for the blood of animals.

In animals, it is the heart which fets the blood in motion, and makes it continually circulate; but in vegetables we can difcover no other caufe of the fap's motion, but the ftrong attraction of the capillary fap veffels, aflifted by the brisk undulations and vibrations, caufed by the Sun's warmth, whereby the fap is carried up to the top of the talleft trees, and is there perfpired off thro' the leaves: But when the furface of the tree is greatly diminithed by the lors of its leaves, then alfo the perfiration and motion of the fap is proportionably diminithed, as is plain from many of the foregoing Experiments: So that the afcending velocity of the fap is principally accelerated by the plentiful perfpiration of the leaves, thereby making room for the fine capillary veffels to exert their vaftly attracting power, which perfpiration is effected by the brisk rarifying vibrations of warmth: A power that does not feem to be any ways well adapted, to make the fap defcend from the tops of vegetables by different veffels to the root. 


\section{4 \\ Vegetable Staiicks.}

If the fap circulated, it mutt needs have been feen defcending from the upper part of large gafhes cut in branches fet in water, and with columns of water preffing on their bottoms in long glafs tubes, in Experiment 43 , and 44. In both which cafes, it is certain that great quantities of water paffed thro' the ftem, fo that it muft needs have been feen defcending, if the seturn of the fap downwards were by trufion or pulfion, whereby the blood in animals is returned thro' the veins to the heart: And that pulfion, if there were any, muft neceffarily be exerted with prodigious force, to be able to drive the fap thro' the finer capillaries. So that if there be a return of the fap downwards, it muft be by attraction, and that a very powerful one, as we may fee by many of there Experiments, and particularly by Experiment I I. But it is hard to conceive, what and where that power is which can be equivalent to that provifion nature has made for the afcent of the fap in confequence of the great perfpiration of the leaves.

The inftances of the Jeffamine tree, and of the Paffion tree, have been looked upon as ftrong proofs of the circulation of the 


\section{Vegetable Staticks. $\quad$ I4}

fap, becaufe their branches, which were far below the inoculated Bud, were gilded: But we have many vifible proofs in the Vine, and other bleeding trees, of the fap's receding back, and pufhing forwards alternately, at different times of the day and night. And there is great reafon to think, that the fap of all other trees has fuch an alternate, receding and progreffive motion, occafioned by the alternacies of day and night, warm and cool, moift and dry.

For the fap in all vegetables does proba bly recede in fome meafure from the tops of branches, as the Sun leaves them; becaufe its rarifying power then ceafing, the greatly rarified fap, and air mixt with it, will condenfe and take up lefs room than they did, and the dew and rain will then be ftrongly imbibed by the leaves, as is pro: bable from Exper. 42. and feveral others: whereby the body and branches of the vegetable which have been much exhaufted by the great evaporation of the day, may at night imbibe fap and dew from the leaves: for by feveral Experiments in the firf chapter, plants were found to increafe confiderably in weight, in dewy and moift nights? And by other Experiments on the Vine in 
146 Vegetable Staticks.

the third chapter, it was found, that the trunk and branches of Vines were always in an imbibing ftate, caufed by the great perfiration of the leaves, except in the bleeding feafon; but when at night that perfpiring power ceafes, then the contrary imbibing power will prevail and draw the fap and dew from the leaves, as well as moifture from the roots.

And we have a further proof of this in Experiment I2, where by fixing mercurial gages to the ftems of feveral trees, which do not bleed, it is found that they are always in a ftrongly imbibing ftate, by drawing up the mercury feveral inches: whence it is eafy to conceive, how fome of the particles of the gilded Bud, in the inoculated Jeffamine, may be abforbed by it, and thereby communicate their gilding Miafma to the fap of other branches; efpecially when fome months after the inoculation, the ftock of the inoculated Jeffamine is cut off a little above the Bud; whereby the ftock, which was the counter acting part to the ftem, being taken away, the ftem attracts more vigorouly from the Bud. 


\section{Vegetable Staticks.}

Another argument for the circulation of the fap, is, that fome forts of graffs will infeet and canker the ftocks they are grafted on: But by Exper. 12, and 37, where mercurial gages were fixed to frefh cut ftems of trees, it is evident that thofe ftems were in a ftrongly imbibing ftate; and confequently the cankered ftocks might very likely draw fap from the graff, as well as the graff alternately from the ftock; juft in the fame manner as leaves and branches do from each other, in the vicifitudes of day and night. And this imbibing power of the ftock is fo great, where only fome of the branches of a tree are grafted, that the remaining branches of the ftock will, by their ftrong attraction, ftarve thofe graffs; for which reafon it is ufual to cut off the greateft part of the branches of the ftock, leaving only a few fmall oncs to draw up the fap.

The inftance of the Ilex grafted upon the Englifh Oak, reems to afford a very confiderable argument againft a circulation. For if there were a free uniform circulation of the fap thro' the Oak and Ilex, why fhould the leaves of the Oak fall in winter, and not thofe of the Ilex?

L $2 . \quad$ Another: 


\section{Vegetable Staticks.}

Another argument, againft a uniform circulation of the fap in trees as in animals, may be drawn from Exper. 37. where it was found by the three mercurial gages fix'd to the fame Vine, that while fome of its branches changed their ftate of protruding fap into a ftate of imbibing, others continued protruding fap, one nine, and the other thirteen days longer.

In the fecond Vol. of Mr. Lowthorp's Abridgment of the Philos. Tranfact. p. 708 . is recited an Experiment of Mr. Brotherton's, viz. A young Hazel $n$ (Fig. 27.) was cut into the body at $x z$ with a deep gafh; the parts of the body below at $z$, and above at $x$, were cleft upwards and downwards, and the fplinters $x z$ by wedges were kept off from touching each other, or the reft of the body. The following year, the upper fplinter $\mathcal{X}$ was grown very much, but the lower fplinter $z$ did not grow, but the reft of the body grew, as if there had been no gafh made: I have not yet fucceeded in making this Experiment, the wind having broken at $x z$ all the trees I prepared for it: But if there was a Bud at $x$ which thot out leaves, and none at $z$, then by Experiment 4I, 'tis plain that thofe leaves might 
draw much nourifhment thro' $t x$, and thereby make it grow; and I believe; if, vice ver $\int a$, there were a leaf bearing Bud at $z$, and none at $x$, that then the fplinter $z$ would grow more than $x$.

The reafon of my conjecture, I ground upon this Experiment, viz. I chofe two thriving hoots of a dwarf Pear-tree l $l$ a a. Fig. 28, 29. At three quarters of an inch diftance I took half an inch breadth of bark off each of them, in feveral places, viz. $2,4,6,8$, and at 10, 12, 14. every one of the remaining ringlets of bark had a leaf bearing bud, which produced leaves the following fummer, except the ringlet 13 , which had no fuch Bud. The ringlet 9 and I I of $a$ a grew and fwelled at their bottoms, till Auguft, but the ringlet I 3 did not increafe at all, and in Auguft the whole fhoot $a$ a withered and died; but the thoot $l l$ lives and thrives well, each of its ringlets fwelling much at the bottom: Which fwellings at their bottoms muft be attributed to fome other caufe than the ftoppage of the fap in its return downwards, becaufe in the fhoot $l l$, its return downwards is intercepted three feveral times by cuiting $a$. way the bark at 2, 4, 6. The larger and 


\section{50 Vegetable Staticks.}

more thriving the leaf bearing Bud was, and the more leaves it had on it, fo much the more did the adjoining bark fwell at the bottom,

Fig. 30. Reprefents the profile of one of the divifions in Fig. 28. fplit in halves; in which may be feen the manner of the growth of the laft year's ringlet of wood fhooting a little upwards at $x x$; and hooting downwards and fwelling much more at $z z$; where we may obferve, that what is fhot end-ways is plainly parted from the wood of the preceding year, by the narrow interftices $x r, z r$, whence it fhould feem, that the growth of the yearly new ringlets of wood confifts in the fhooting of their fibres lengthways under the bark.

That the fap does not defcend between the bark and the wood, as the favourers of a circulation fuppofe, feems evident from hence, viz. that if the bark be taken off for three or four inches breadth quite round, the bleeding of the tree above that bared place will much abate, which ought to have the contrary effect, by intercepting the courfe of the refluent fap, if the fap defcended by the bark. 


\section{Vegetable Staticks. ISI}

But the reafon of the abatement of the bleeding in this cafe may well be accounted for, from the manifeft proof we have in thefe Experiments, that the fap is ftrongly attracted upwards by the vigorous ope. ration of the perfpiring leaves, and attracting Capillaries: But when the bark is cut off for fome breadth below the bleeding place, then the fap which is between the bark and the wood below that disbarked place, is deprived of the ftrong attracting power of the leaves, $\delta c c_{\text {. and }}$ confequently the bleeding wound cannot be fupplied fo faft with fap, as it was before the bark was taken off.

Hence alfo we have a hint for a probable conjecture why in the alternately disbarked fticks, $l l$ a a, Fig. 28, 29. the bark fwelled more at the upper part of the disbarked places than at the lower, viz. becaufe thofe lower parts were thereby deprived of the plenty of nourifhment which was brought to the upper parts of thofe disbarked places by the ftrong attraction of the leaves on the Buds 7 , \&rc. of which we have a further confirmation in the ringlet of bark, $\mathrm{N}^{\circ} .13$. Fig.29. which ringlet did not fwell or grow at either end, being not only deprived of

$$
\text { I } 4
$$

the 
the attraction of the fuperior leaves, by the bared placed $\mathrm{N}^{\circ}$. I2. but alfo without any leaf Bud of its own, whofe branching fap veffels, being like thofe of other leaf Buds rooted downwards in the wood, might thence draw fap, for the nourifhment of its felf and the adjoining bark, $\mathrm{N}^{\circ}$. I3. But had thefe rooting fap veffels run upwards, inftead of downwards, 'tis probable, that in that cafe the upper part of each ringlet of bark, and not the lower, would have fwelled, by having nourifhment thereby brought to it from the inmolt wood.

We may hence alfo fee the reafon why, when a tree is unfruitful, it is brought to bear fruit, by the taking ringlets of bark off from its branches, viz. becaufe thereby a lefs quantity of fap arifing, it is better digefted and prepared for the nourifhment of the fruit; which from the greater quantity of oil, that is ufually found in the feeds, and their containing veffels, than in other parts of plants, thews that more fulphur and air is requifite for their production, than there is for the production of wood and leaves.

But the moft confiderable objedion 2gainst this progreflive motion of the fap, without 


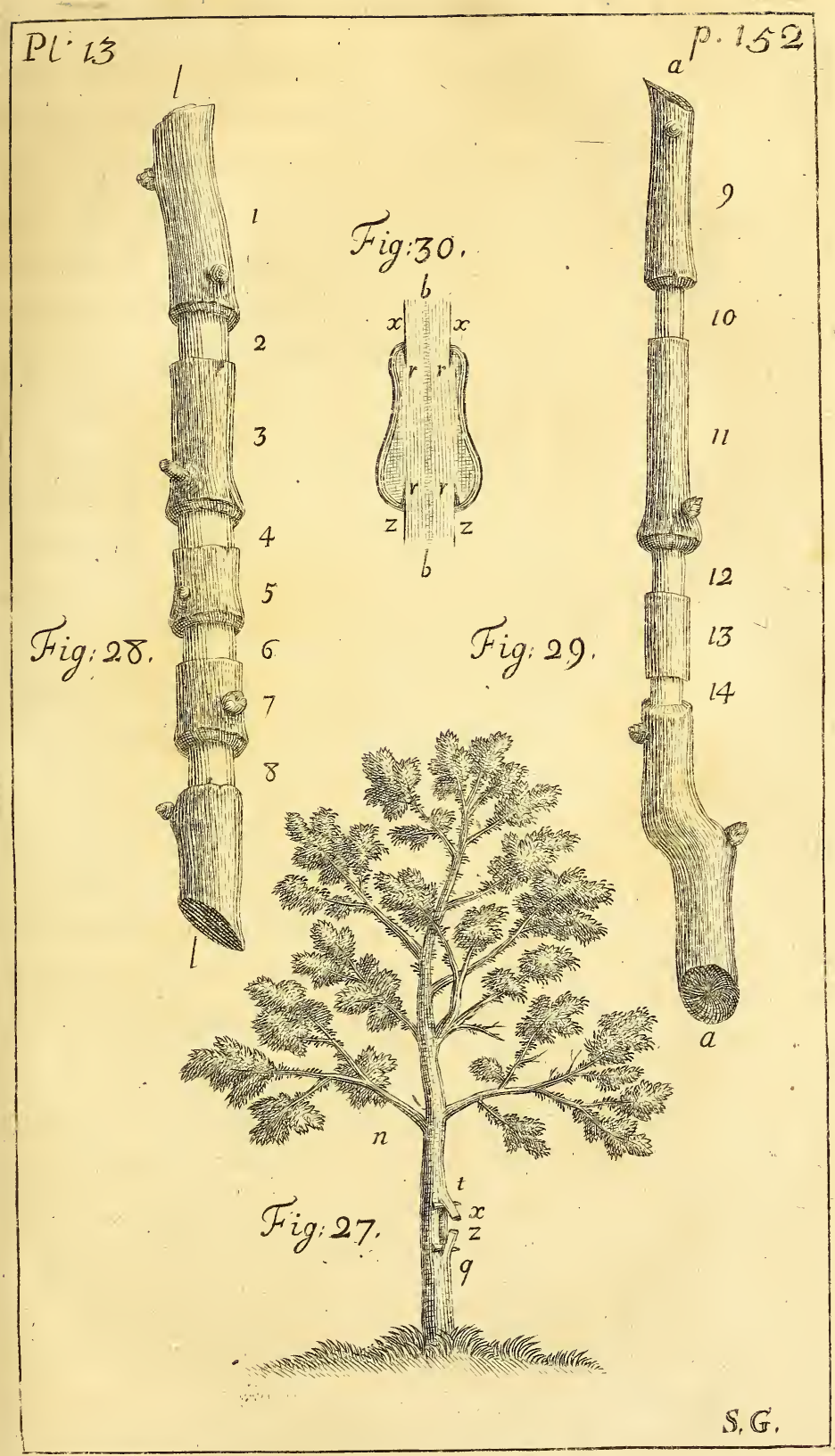





\section{Vegetable Staticks.}

without a circulation, arifes from hence, viz. that it is too precipitate a courfe, for a due digettion of the fap, in order to nutrition: Whereas in animals nature has provided, that many parts of the blood thall run a long courfe, before they are either applied to nutrition, or difcharged from the animal.

But when we confider, that the great work of nutrition, in vegetables as well as animals, (I mean after the nutriment is got into the veins and arteries of animals) is chiefly carried on in the fine capillary verfels, where nature felects and combines, as fhall beft fuit her different purpofes, the feveral mutually attracting nutritious particles which were hitherto kept disjoined by the motion of their fluid vehicle; we thall find that nature has made an abundant provifion for this work in the ftructure of vegetables; all whofe compofition is made up of nothing elfe but innumerable fine capillary veffels, and glandulous portions or veficles.

Upon the whole, I think we have, from thefe experiments and obfervations, fuficient ground to believe that there is no circulation of the fap in vegetables; notwithftanding many ingenious perfons have been 


\section{I54 Vegetable Staticks.}

induced to think there was, from feveral carious obfervations and experiments, which evidently prove, that the fap does in fone meafure recede from the top towards the lower parts of plants, whence they were with good probability of reafon induced to think that the fap circulated.

The likelieft method effectually and convincingly to determine this difficulty, whether the fap circulates or not, would be by ocular infpection, if that could be attained : And I fee no reafon we have to defpair of it, fince by the great quantities imbibed and perfpired, we have good ground to think, that the progreflive motion of the fap is confiderable in the largeft fap veffels of the tranfparent ftems of leaves: And if our eyes, affifted with microfcopes, could come at this defirable fight, I make no doubt but that we fhould fee the fap which was progreffive in the heat of the day, would on the coming on of the cool evening, and the falling dew, be retrograde in the fame veffels. 


\section{Vegetable Staticks. I5s}

\section{H A P. V.}

Experiments, whereby to prove, that a confiderable quantity of air is inspired by Plants.

$T \mathrm{~T}$ is well known that air is a fine ela1 ftick fluid, with particles of very different natures floating in it, whereby it is admirably fitted by the great Author of na: ture, to be the breath of life, of vegetables, as well as of animals, without which they can no more live nor thrive than animals can.

In the Experiments on Vines, Chap. III. we faw the very great quantity of air which was continually afcending from the Vines, thro' the fap in the tubes; which manifently thews what plenty of it is taken in by vegetables, and is perfpired off with the fap thro: the leaves.

\section{EXPERIMENT XLVII.}

Sept. 9 th, at 9 a.m. I cemented an Applebranch 6 (Fig. II.) to the glafs tube $r i$ e $:$ I put no water in the tube, but fet the end of it in the ciftern of water $x_{0}$. Three 


\section{I56 Vegetable Staticks.}

hours after I found the water fucked up in the tube many inches to $z$; which thews, that a confiderable quantity of air was imbibed by the branch, out of the tube $r$ ie $z$ : And in like manner did the Apricot-branch (Exper. 29.) daily imbibe air.

\section{EXPERIMENT XLVIII.}

I took a cylinder of Birch with the bark on, 16 inches long and $\frac{3}{4}$ diameter, and cemented it fat at $z$; (Fig. 32.) to the hole in the top of the air pump receiver $p P$, fetting the lower end of it in the ciftern of water $x$; the upper end of it at $n$ was well clofed up with melted cement.

I then drew the air out of the receiver, upon which innumerable air bubbles iffued continually out of the ftick into the water $x$. I kept the receiver exhaufted all that day, and the following night, and till the nexe day at noon, the air all the while iffuing into the water $x$ : I continued it thus long in this ftate, that I might be well affured, that the air muft pafs in through the bark, to fupply that great and long flux of air at $x$. I then cemented up five old eyes in the Atick, between $z$ and $n$, where little thoots had formerly been, but were now perifhed, 
perifhed, yet the air ftill continued to flow freely at $x$.

It was obfervable in this, and many of the Experiments on fticks of other trees, that the air which could enter only thro" the bark between $z$ and $n$, did not iffue in: to the water, at the bottom of the ftick, only at or near the bark, but through the whole and inmoft fubftance of the wood, and that chiefly, as I guefs, by the largenef's of the bafes of the hemifpheres of air thro $0^{\circ}$ the largeft veffels of the wood; which obfervation corroborates Dr. Grew's and Malpighi's opinion, that they are air veffels.

I then cemented upon the receiver the cylindrical glafs $y y$, and filled it full of water, fo as to ftand an inch above the top $n$ of the Atick.

The air ftill continued to flow at $x$, but in an hour's time it very much abated, and in two hours ceafed quite; there being now no paffage for frefh air to enter, and fupply what was drawn out of the ftick.

I then with a glafs crane drew off the water out of the cylinder $y$, yet the air did not iffue thro' the wood at $x$.

I therefore rook the receiver with the Atick in it, and held it near the fire, till the 
I 8 Vegetable Staticks.

bark was well dried; after which I fet it upon the air pump, and exhaulted the air, upon which the air iffued as freely at $x$ as it did before the bark had been wetted, and continued fo to do, tho' I kept the receiver exhaufted for many hours.

I fixed in the fame manner as the preceding Birch ftick, three joints of a Vinebranch, which was two years old, the uppermoft knot $r$ being within the receiver; when I pumped, the air paffed mort freely into the water $x x$.

I cemented faft the upper end of the ftick $n$ and then pumped, the air ftill iffued out at $x$, tho' I pumped very long, but there did not now pafs the twentieth part of the air which paffed when the end $n$ was not cemented.

I then inverted the ftick, placing $n$ fix inches deep in the water, and covered all the bark from the furface of the water to $z$ the top of the receiver with cement; then pumping the air which entered at the top of the ftick, paffed thro' the immerfed part of the bark: When I ceafed pumping for fome time, and the air had ceafed iffuing out; upon my repeating the pumping it would again iffue out. 
I found the fame event in Birch and Mulberry fticks, in both which it iffued moft plentifully at old eyes, as if they were the chief breathing places for trees.

And Dr. Grew obferves, that " the pores " are fo very large in the trunks of fome " plants, as in the better fort of thick walk" ing canes, that they are vifible to a good. " eye, without a glafs; but with a glafs the " cane feems as if it were ftuck top full of " holes, with great pins, being fo large as " very well to refemble the pores of the "skin, in the end of the fingers and ball " of the hand.

"In the leaves of Pine they are like" wife, thro" a glafs, a very elegant thew, "ftanding all moft exactly in rank and file, " through the length of the leaves." Grew's Anatomy of Plants, $p .127$.

Whence it is very probable, that the air freely enters plants, not only with the principal fund of nourifhment by the roots, but alfo through the furface of their trunks and leaves, efpecially at night, when they are changed from a perfpiring to a ftrongly imbibing ftate.

I fix'd in the fame manner to the top of the air pump receiver, but without the $\mathrm{cy}$ - 


\section{0 \\ Vegetable Staticks.}

lindrical glafs $y y$, the young thoots of the Vine, Apple-tree, and Honyfuckle, both erected and inverted, but found little or no air came either from branches or leaves, except what air lay in the furrows, and the innumerable little pores of the leaves, which are plainly vifible with the microfcope. I tried alfo the fingle leaf of a Vine, both by immerfing the leaf in the water $x$, and letting the ftalk ftand out of the receiver, as alfo by placing the leaf out of the receiver, and the ftalk in the glafs of water $x$; but little or no air came either way.

I obferve in all thefe Experiments, that the air enters very flowly at the bark of young thoots and branches, but much more freely thro' old bark: And in different kinds of trees it has very different degrees of more or lefs free entrance.

I repeated the fame Experiment upon feveral roots of trees: The air paffed moft freely from $n$ to $x$; and when the glafs verfel $y y$ was full of water, and there was no water in $x$, the water paffed at the rate of 3 ounces in 5 minutes; when the upper end $n$ was cemented up, and no water in $y y$, fome air, tho not in great plenty, would enter the bark at $z f$, and pals thro' the water at $x$.

And 


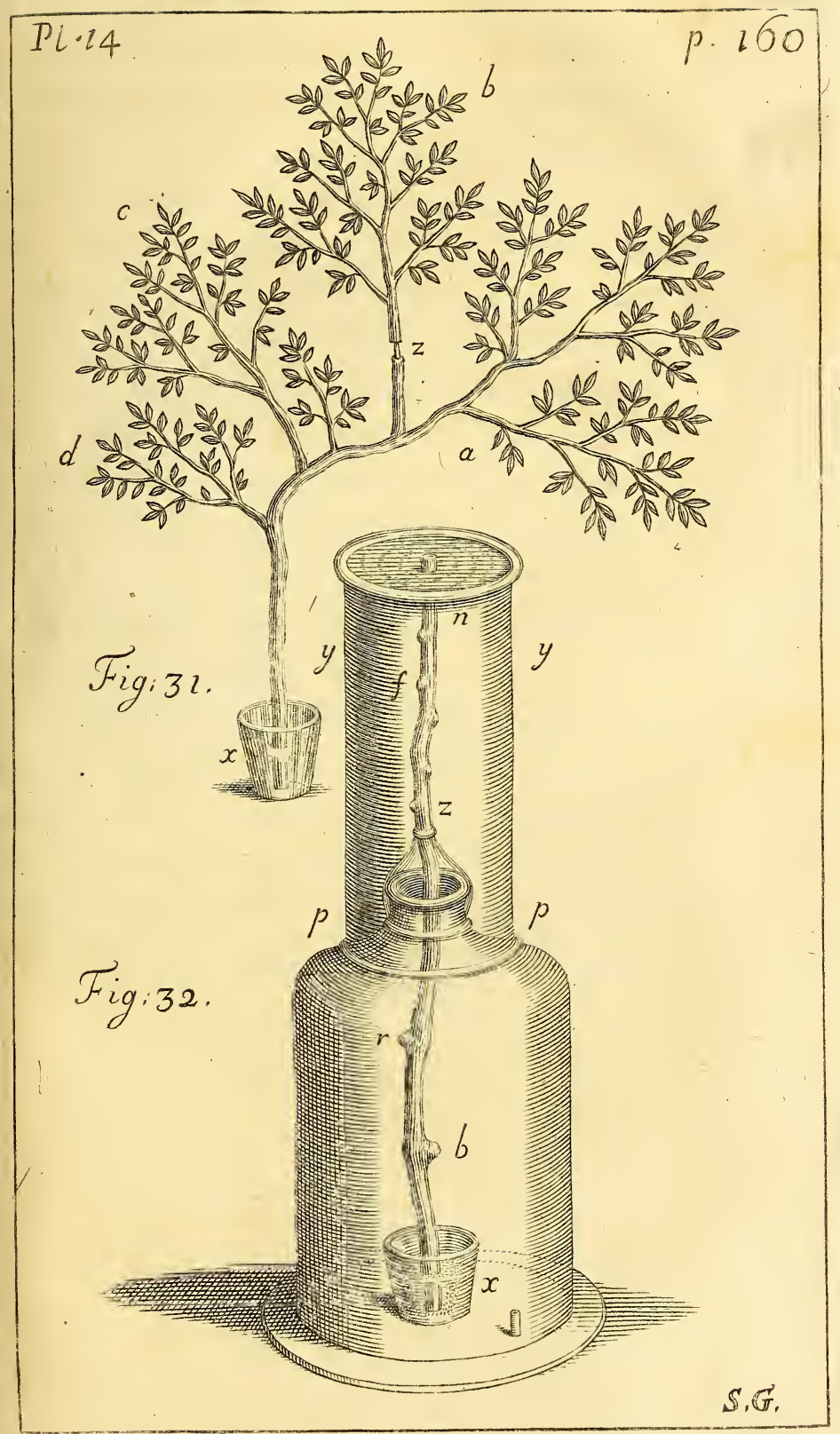



And that :here is fome air both in an claftirk and unelaftick ftate, mix'd with the earth, (which may well enter the roots with the nourifhment) I found by putting into the inverted glafs $z z a$ a full of water (Fig. 35.) fome earth dug up in an alley in the garden, which after it had ftood foaking for feveral days, yielded a little elaftick air, tho' the earth was not half diffolved. And in Experiment 68, we find that a cu. bick inch of earth yiclded 43 cubick inches of air by diftillation, a good part of which was roufed by the action of the fire from a fixed to an elaftick frate.

I fixed alfo in the fame manner young tender fibrous roots, with the fmall end upwards at $n$, and the veffel $y y$ full of wa. ter; then upon pumping large drops of water followed each other faft, and fell into the ciftern $x$, which had no water in it. 


\section{H A P. VI.}

A specimen of an attempt to analyse the Air by a great variety of chymio-ftatical Experiments, which hew in bow great a proportion Air is wrought into the compofition of animal, vegetable, and mineral Subftances, and withal how readily it refumes its former elaftick ftate, when in the diffolution of those Subftances it is difingaged from them.

Aving in the preceding chapter pro11 duced many Experiments, to prove that the Air is freely infpired by Vegetables, not only at their roots, but alfo thro' feveral parts of their trunks and branches, which Air was moft vifibly feen afcending in great plenty thro' the fap of the Vine, in tubes which were affixed to them in the bleeding feafon; this put me upon making a more particular enquiry into the nature of a Fluid, which is fo abfolutely neceffary for the fupport of the life and growth of Animals and Vegetables.

The excellent Mr. Boyle made many Experiments on the Air, and among other difcoveries, 


\section{Analyfis of the Air. $\quad{ }^{6} \sigma_{3}$}

coveries, found that a good quantity of Ais was producible from Vegetables, by putting Grapes, Plums, Goofeberries, Cherries, Peafe, and feveral other forts of fruits and grains into exhaufted and unexhaufted receivers, where they continued for feveral days emitting great quantities of Air.

Being defirous to make fome further refearches into this matter, and to find what proportion of this Air I could obtain out of the different fubftances in which it was lodged and incorporated, I made the following chymio-ftatical Experiments: For, as whatever advance has here been made in the knowledge of the nature of Vegetables, has been owing to ftatical Experiments, fo fince nature, in all her operations, acts conformably to thofe mechanick laws, which were eftablifhed at her firft inftitution; it is therefore reafonable to conclude, that the likelieft way to enquire, by chymical operations, into the nature of a fluid, too fine to be the object of our fight, mult be by finding out fome means to eftimate what influence the ufual methods of analyfing the animal, vegetable, and mineral king. doms, has on that fubtle fluid; and this I effected by affixing to retorts and boltheads M 2

hydro. 


\section{Analyfis of the Air.}

hydroftatical gages, in the following manner, viz.

In order to make an eftimate of the quantity of Air which arofe from any body by diftillation or fufion, I firf put the matter which I intended to diftil into the fmall retort $r$ (Fig. 33.) and then at $a$ cemented faft to it the glafs veficl $a b$, which was very capacious at $b$, with a hole in the bottom. I bound bladder over the cement which was made of tobacco-pipe clay and bean flower, well mixed with fome hair, tying over all four fmall fticks, which ferved as fplinters to ftrengthen the joint; fometimes, inflead of the glafs veffel $a b$, I made ufe of a large bolthead, which had a round hole cut, with a red hot iron ring at the bottom of it; through which hole was put one leg of an inverted fyphon, which reached up as far as z. Matters being thus prepared, holding the retort uppermot, I immerfed the bolthead into a large veffel of water, to $a$ the top of the bolthead; as the water rufhed in at the bottom of the bolthead, the Air was driven out through the fyphon: When the bolthead was full of water to $z$, then I clofed the outward orifice of the fyphon with the end of my finger, and at the fame time drew 


\section{Analy is of the Air. 165}

the other leg of it out of the bolthead, by which means the water continued up to $z$, and could not fubfide. Then I placed under the bolthead, while it was in the water, the veffel $x x$, which done, I lifted the veffel $x x$, with the bolthead in it, out of the water, and tied a waxed thread at $z$ to mark the height of the water: And then approached the retort gradually to the fire, taking care to fcreen the whole bolthead from the heat of the fire.

The defcent of the water in the boithead fhewed the fums of the expanfion of the Air in the retort, and of the matter which was diftilling: The expanfion of the Air alone, when the lower part of the retort was beginning to be red hot, was at a medium, nearly equal to the capacity of the retorts, fo that it then took up a double Space; and in a white and almoft melting heat, the Air took up a tripple fpace, or fomething more: for which reafon the leaft retorts are beft for thefe Experiments. The expanfion of the diftilling bodies was fometimes very little, and fometimes many times greater than that of the Air in the retort, according to their different natures. 
166 Analy/is of the Air.

When the matter was fufficiently diftilled, the retort, \& $c$. was gradually removed from the fire, and when cool cnough, was carried into another room, where there was no fire. When all was throughly cold, either the following day, or fometimes 3 or 4 days after, I marked the furface of the water $y$, where it then ftood; if the furface of the water was below $z$, then the empty fpace between $y$ and $z$ thewed how much Air was generated, or raifed from a fix'd to an elaftick ftate, by the action of the fire in diftillation: But if $y$, the furface of the water, was above $z$, the fpace between $z$ and $y$, which was filled with water, fhewed the quantity of Air which had been abforbed in the operation, i.e. was changed from a repelling elaftick to a fix'd ftate, by the ftrong attraction of other particles, which I therefore call abforbing.

When I would meafure the quantity of this new generated Air, I feparated the bolthead from the retort, and putting a cork into the fmall end of the bolthead, I inverted it, and poured in water to $z$. Then from another veffel (in which I had a known quantity of water by weight) I poured in water to $y$; fo the quantity of water which 
was wanting, upon weighing this veffel again, was equal to the bulk of the new generated Air. I chofe to meafure the quantities of Air, and the matter from whence it arofe, by one common meafure of cubick inches, eftimated from the fpecifick gravities of the feveral fubftances, that thereby the proportion of one to the other might the more readily be feen.

I made ufe of the following means to meafure the great quantities of Air, which were either raifed and generated, or abforbed by the fermentation arifing from the mixture of variety of folid and fluid fubftances, whereby I could eafily entimate the furprizing effects of fermentation on the air, viz.

I put into the bolthead $b$ (Fig. 34.) the ingredients, and then run the long neck of the bolthead into the deep cylindrical glafs $a y$, and inclined the inverted glafs $a y$, and bolthead almoft horizontally in a large veffel of water, that the water might run into the glafs $a y$; when it was almoft up to $a$ the top of the bolthead, I then immerfed the bottom of the bolthead, and lower part $y$ of the cylindrical glafs under water, raifing at the fame time the end a uppermort.

$$
\mathrm{M}_{4}
$$

Then 


\section{Analy is of the Air.}

Then before I took them out of the water, I fet the bolthead and lower part of the cylindrical glafs $a y$ into the earthen veffel $x x$, full of water, and having lifted all out of the great veffel of water, I marked the furface $z$ of the vater in the glafs $a y$.

If the ingredients in the bolthead, upon fermenting generated $\mathrm{Air}$, then the water would fall from $z$ to $y$, and the empty fpace $z y$ was equal to the bulk of the quantity of Air generated: But if the ingredients, upon fermentation, did abforb or fix the aetive particles of Air, then the furface of the water would afcend from $z$ to $n$, and the fpace $z n$, which was filled with water, was equal to the bulk of Air, which was abforbed by the ingredients, or by the fume arifing from them: When the quantities of Air, eicher generated or abforbed, were very great, then I made ufe of large chymical receivers inntead of the glafs a $y$ : But if thefe quantities were very fmall, then inftead of the bolthead and deep cylindrical glafs a y, I made ufe of a fmall cylindrical glafs, or a common beer glafs inverted, and placed under it a Viol or Jelly glars, taking care that the water did not come at the ingredients in them, which was eafily prevented 


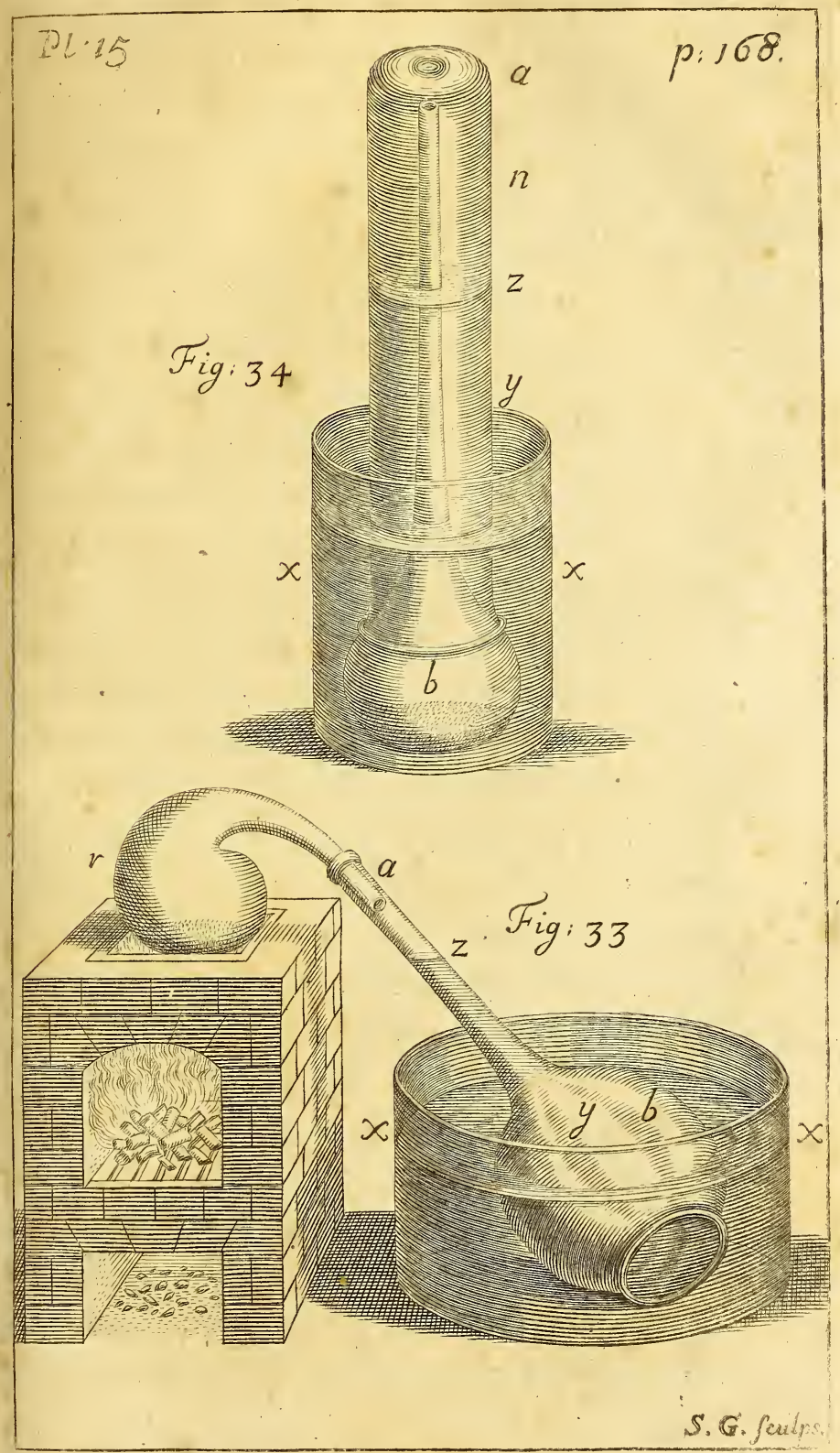





\section{Analyfis of the Air.}

by drawing the water up under the inverted glafs to what height I pleafed by means of a fyphon: I meafured the bulk of the fpaces $z y$ or $z n$, by pouring in a known quantity of water, as in the foregoing Experiment, and making an allowance for the bulk of the neck of the bolthead, within the fpace $z y$.

When I would take an eftimate of the quantity of Air abforbed and fixed, or generated by a burning candle, burning brimftone or nitre, or by the breath of a living animal, \&c. I firft placed a high ftand, or pedeftal in the veffel full of water $x x$; (Fig. 35.) which pedeftal reached a little higher than $z z$. On this pedeftal I placed the candle, or living animal, and then whelmed over it the large inverted glafs $z z a a$, which was fufpended by a cord, fo as to have its mouth $r r$ three or four inches under water; then with a fyphon I fucked the Air out of the glafs veffel till the water rofe to $z z$. But when any noxious thing, as burning brimftone, aquafortis, or the like, were placed under the glafs; then by affixing to the fyphon the nofe of a large pair of bellows, whofe wide fucking orifice was clofed up, as the bellows were enlarged, 
170 Analy is of the Air.

they drew the Air briskly out of the glafs $z z a a$ thro' the fyphon; the other leg of which fyphon I immediately drew from under the glafs veffel, marking the height of the water $z z$.

When the materials on the pedeftal generated Air, then the water would fubfide from $z z$ to $a a$, which fpace $z z a a$ was equal to the quantity of Air generated: But when the materials deftroyed any part of the Air's elafticity, then the water would rife from $a a$ (the height that $I$ in that cafe at firt fucked it to) to $z z$, and the fpace a $a z z$ was equal to the quantity of Air, whore elafticity was deftroyed.

I fometimes fired the materials on the pedeftal by means of a burning glafs, viz. fuch as phorphorus and brown paper dipped in water, ftrongly impregnated with nitre and then dried.

Sometimes I lighted the candle or large matches of brimftone before I whelmed the glafs $z z a$ a over them; in which cafe I inftantly drew up the water to $a a$, which by the expanfion of the heated Air would at firft fubfide a little, but then immediately turned to a rifing ftate, notwithftanding the flame continued to heat and rarify the Air 


\section{Analy is of the Air. $\quad 17$ I}

for 2 or 3 minutes: As foon as the flame was out, I marked the height of the water $z z$; after which the water would for 20 or 30 hours continue rifing a great deal above $z z$.

Sometimes when I would pour violently fermenting liquors, as aquafortis, $\delta c$. on any materials, I furpended the aquafortis in a viol at the top of the glafs veffel $z z$ $a$ a, in fuch manner, that by means of a ftring, which came down into the veffel $x x$, I could by inverting the viol pour the aquafortis on the materials, which were in

a veffel on the pedeftal.

I thall now proceed to give an account of the event of a great many Experiments, which I made by means of thefe inftruments, which I have here at firf defcribed, to avoid the frequent repetition of a defcription of 'em. It is confonant to the right method of philofophifing, firft, to analyfe the fubject, whofe nature and properties we intend to make any refearches into, by a regular and numerous feries of Experiments: And then by laying the event of thore Experiments before us in one view, thereby to fee what light their united and concurring evidence will give us. How rational 
I>2 Analy is of the Air.

this method is, the requel of thefe Experiments will hew.

The illuftrious Sir Ifaac Nereton (quemy 3 If of his Opticks) obferves, That "true " permanent Air arifes by fermentation or " heat, from thofe bodies which the chy" miftscall fixed, whore particles adhere by " a ftrong attraction, and are not therefore " feparated and rarified without fermenta"tion. Thofe particles receding from one " another with the greareft repulfive force, "s and being moft difficultly brought toge" ther, which upon contact were moft ftrong"ly united. And query 30. Denfe bodies " by fermentation rarify into feveral forts "of Air; and this Air by fermentation, and "fometimes without it, returns into denfe "bodies." Of the truth of which we have evident proof from many of the following Experiments, viz.

That I might be well affured that no part of the new Air which was produced in diftillation of bodies, arofe either from the greatly heated Air in the retorts, or from the fubftance of the heated retorts, I firft gave a red hot heat both to an empty glafs retort, and alfo to an iron retort made of 2 musket barrel; when all was cold, I found the 


\section{Amaly is of the Air. $\quad 173$}

the Air took up no more room than before it was heated: whence I was affured, that no Air arofe, either from the fubftance of the retorts, or from the heated Air.

As to animal fubftances, a very confiderable quantity of permanent Air was produced by diftillation, not only from the blood and fat, but alfo from the moft folid parts of animals.

\section{EXPERIMENT XLIX.}

A cubick inch of Hog's blood, diftilled to dry fcoria, produced thirty three cubick inches of Air, which Air did not arife till the white fumes arofe; which was plain to be feen by the great defcent of the water at that time, in the receiver $a z y$ (Fig. 33.)

EXPERIMENT L。

Lefs than a cubick inch of Tallow, being all diftilled over into the receiver $a z y$ (Fig. 33.) produced I 8 cubick inches of Air.

EXPERIM ENT LI。

24I Grains, or half a cubick inch of the tip of a follow Deer's horn, being diftilled in the iron retort, made of a musket bar- 


\section{Analyfis of the Air.}

rel, which was heated at a fmith's forge, produced I 7 cubick inches, that is, 234 times its bulk of Air, which did not begin to rife till the white fumes arofe; but then ruthed forth in great abundance, and in good plenty, alfo with the fotid oil which came laft. The remaining calx was two thirds black, the reft afh-coloured; it weighed I 28 grains, fo it was not half wafted, whence there muft remain much fulphur in it; the weight of water to Air, being nearly as 885 to one, as Mr. Harvksbee found it, by an accurate Experiment. A cubick inch of Air will weigh $\frac{2}{7}$ of a grain, whence the weight of Air in the horn was 33 grains, that is, near $\frac{x}{7}$ part of the whole horn.

We may obferve in this, as alfo in the preceding Experiment, and many of the following ones, that the particles of new Air were detached from the blood and horn, at the fame time with the white fumes, which conftitute the volatile falt : But this volatile falt, which mounts with great activity in the Air, is fo far from generating true elaftick Air, that on the contrary it abforbs it, as I found by the following Experiment. 


\section{Analy is of the Air.}

EXPER I E N T LII.

A dram of volatile falt of fal armoniack, foon diftilled over with a gentle heat; but tho' the expanfion in the receiver was double that of heated Air alone, yet no Air was generated, but two and an half cubick inches were abforbed.

\section{EXPERIMNT LIII.}

Half a cubick inch of Oyfter-jhell, or 266 grains diftilled in the iron retort, generated 162 cubick inches, or 46 grains, which is a little more than $\frac{1}{6}$ part of the weight of the thell.

\section{EXPERIMEN T LIV.}

Two grains of Phophorus eafily melted at fome diftance from the fire, flamed and filled the retort with white fumes, it $a b$ forbed three cubick inches of Air. A like quantity of $P$ hosphorus, fired in a large receiver (Fig. 35. ) expanded into a (pace equal to fixty cubick inches, and abforbed $28 \mathrm{cl}^{\text {- }}$ bick inches of Air: When 3 grains of Phof= phorus were weighed, foon after it was burnt, it had loft half a grain of its weight; but when two grains of Phosphorus were weighed, 
-76 Analyfis of the Air.

weighed, fome hours after it was burnt, having run more per deliquium by abforbing the moifure of the Air, it had increafed a grain in weight.

\section{EXPERIMENT LV.}

As io vegetable Subfances, from half a cubick inch, or I 35 grains of heart of Oak, frefh cut from the growing tree, was generated Ios cubick inches of Air, i. e. a quantity equal to 2 I 6 times the bulk of the piece of Oak, its weight was above 30 grains, 4 part of the weight of I 35 grains of Oak. I took a like quantity of thin thavings from the fame piece of Oak, and dried them gently at fome diftance from a fire for 24 hours, in which time 44 grains weight of moifture had evaporated; which being deducted from the I 35 grains, there remains 9I grains for the folid part of the Oak: Then the 30 grains of Air, will be $\frac{x}{3}$ of the weight of the folid part of the Oak.

Eleven days after this Air was made, I put a live Sparrow into it, which died inftantly.

\section{EXPERIMENT IVI.}

From 388 grains weight of Indian Wheat; which grew in my garden, but was not come 


\section{Analy is of the Air.}

come to full maturity, was generated 270 cubick inches of air, the weight of which air was 77 grains, viz. of the Wheat.

\section{EXPERIMNT LVII.}

From a cubick inch, or 3 I 8 grains of Peafe, was generated 396 cubick inches of air, or II 3 grains, $i$. $e$. fomething more than $\frac{\pi}{3}$ of the weight of the Peaje.

Nine days after this air was made, I lifted the inverted mouth of the receiver which contained it, out of the water, and put a lighted candle under it, upon which it inftantly flafhed: Then I immediately immerfed the mouth of the receiver in the water, to extinguifh the flame. This I repeated $\&$ or 10 times, and it as often flafhed, after which it ceafed, all the fulphureous fpirit being burnt. It was the fame with air of diftilled Oyfter-Thell and Amber, and with new diftilled air of Peafe and Bees-wax. I found it the fame alfo with another like quantity of air of Peafe; notwithftanding I wafhed that air no lefs than eleven times, by pouring it fo often under water, upwards, out of the containing veffel, into another inrerted receiver full of water.

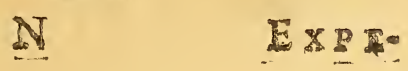


I78 Analyfis of the Air.

\section{EXPERIMENT LVIII.}

There was raifed from an ounce, or 437 grains of Muftard-feed, 270 cubick inches of air, or 77 grains; which is fomething more than $\frac{x}{6}$ part of the ounce weight. There was doubtlefs much more air in the feed; but it rofe in an unelaftick ftate, being not difentangled from the Oil, which was in fuch plenty within the gun-barrel, that when I heated the whole barrel red hot, in order to burn it out, it flamed vigorounly out at the mouth of the barrel. Oil alfo adhered to the infide of the barrel, in the diftillation of many of the other animal, vegetable, and mineral fubftances; fo that the elaftick air which I meafured in the receiver, was not all the air contained in the feveral diftill'd fubftances; fome remaining in the Oil, for there is unelaftick air in Oil, part being alfo reforbed by the fulphureous fumes in the receiver.

\section{EXPERIMENT LIX.}

From half a cubick inch of Amber, or 135 grains, was raifed I 35 cubick inches of air, or $3^{8}$ grains, viz, $\frac{x}{35}$ part of its weight. 


\section{Analyfis of the Air.}

\section{EXPERIMENT LX.}

From 142 grains of dry Tobacco was raifed Is 3 cubick inches of air, which is little lefs than $\frac{\pi}{3}$ of the whole weight of the Tobacco; yet it was not all burnt, part being out of the reach of the fire.

\section{EXPERIMENT LXI.}

Camphire is a mont volatile fulphureous fubttance fublimed from the Rofin of a tree in the Eaft-Indies. A dram of it melted into a clear liquor, at fome diftance from the fire, and fublimed in the form of white cryftals, a little above the liquor, it made a very fmall expanfion, and neither generated nor abforbed air. The fame Mr. Boyle found, when he burnt it in vacuo, Vol. II. p.605.

\section{EXPERIMENT LXII.}

From about a cubick inch of chymical Oil of Anifeed, I obtained 22 cubick inches of air; and from a like quantity of Oil of Olives, 88 cubick inches of air. The reafon of which difference was, as I fuppofe, this, viz. finding that the Oil of Anifeed came plentifully over into the receiver, in

$$
\mathrm{N} 3 \text { the }
$$


I80 Analy/is of the Air.

the diftillation of the Oil of Olives, I raifed the neck of the retort a foot higher, by which means the Oil could not fo eafily afcend, but fell back again into the hoteft part of the retort, whereby more air was feparated; yet in this cale good ftore of Oil came over into the receiver; in which there was doubtlefs plenty of unelaftick air: Whence by comparing this with Experiment 58 , we fee that air is in greater plenty feparated from the Oil, when in the Multard-feed, than it is from expreffed or chymical Oil.

\section{EXPERIMENT LXIII.}

From a cubick inch, or 359 grains of $\mathrm{Ho}_{\mathrm{O}}$ ney, mixed with calx of bones, there arofe $\$ 44$ cubick inches of air, or 4 I grains, viz. a little more than $\frac{x}{s}$ part of the weight of the whole.

\section{EXPERIMENT LXIV.}

From a cubick inch of yellow Bees-wax, $\mathrm{Ol}^{\circ} 243$ grains, there arofe 54 cubick inches of air, or Is grains; the $\frac{x}{5}$ part of the whole. 


\section{EXPERIMENT IXV.}

From 373 grains, or a cubick inch of the coarfeft Sugar, which is the effential falt of the fugar-cane, there arofe $126 \mathrm{cu}$ bick inches of air, equal to 36 grains, a little more than $\frac{\pi}{5}-$ part of the whole.

\section{EXPERIMENT IXVI.}

I found very little air in 54 cubick inches of Brandy, but in a like quantity of Wellwater I found one cubick inch. And it was the fame in a little quantity of Briftol hot well water, and of Holt water. In Piermont water thcre is near twice as much air, as in Rain or common water, which air contributes to the brisknefs of that and many other mineral waters. I found thefe reveral quantities of air, in there waters, by inverting the nores of botrles full of thefe feveral liquors, into fmall glafs cifterns full of the fame liquor. And then fetting them all together in a boiler, where having an equal heat, the air was thereby feparated, and afcended to the upper parts of the bottles.

$$
N_{3} \text { EXPE }
$$


182 Analy/is of the Air.

\section{EXPER I M ENT LXVII.}

By the fame means alfo, I found plenty of air might be obtained from minerals. Half a cubick inch, or Is 8 grains of Newcaffle coal, yielded in diftillation $180 \mathrm{cu}-$ bick inches of air, which arofe very faft from the coal, efpecially when the yellowith fumes afcended. The weight of this air is $I I$ grains, which is nearly $\frac{\pi}{3}$ of the weight of the coals.

\section{EXPERIMENT LXVIII.}

A cubick inch of frefh dug untried Earth off the common, being well burnt in diftillation, produced 43 cubick inches of air. From Chalk alfo I obtained air in the fame manner.

EXPERIMENT LXIX.

From a quarter of a cubick inch of $A n$. timony, I obtained 28 times its bulk of air. It was diftilled in a glafs retort, becaufe ir will demetalize iron.

EXPERIMENT IXX.

I procured a hard, dark, gray $\mathcal{P}$ yrites, a vitriolick mineral fubft ance, which was found 


\section{Analy is of the Air. $\quad I_{3}$}

7 feet under ground, in digging for prings on Walton-Heath, for the fervice of the Right Honourable the Earl of Lincoln, at his beautiful Seat at Oatlands in Surrey; this mineral abounds not only with fulphur, which has been drawn from it in good plenty, but alfo with faline particles, which fhoot vifibly on its furface. A cribick inch of this mineral yielded in diftillation 83 cubick inches of air.

\section{EXPERIMENT LXXI.}

Half a cubick inch of well decrepitated Sea-falt, mix'd with double its quantity of calx of bones, generated 32 times its bulk of air: It had fo great a heat given it, that all being diftilled over, the remaining fcoria did not run per deliquium. I cleared the gun-barrel of thefe and the like fcoria, by laying the end of the retort on an anvil, and friking long on the outfide with a hammer.

\section{EXPERIMENT LXXII.}

From 2 I I grains, or half a cubick inch of Nitre, mixed with calx of bones, there arofe 90 cubick inches of air, i.e. a quantity equal to I 80 times its bulk; fo the weight

$$
\mathrm{N}_{4}
$$


184 Analy is of the Air.

of air in any quantity of nitre is about $\frac{8}{8}$ part? $V$ itriol diftilled in the fame manner yields air too.

\section{EXPERIMENT LXXIII.}

From a cubick inch, or 443 grains of Renifh Tartar, there arofe very faft $\mathrm{SO}_{4} \mathrm{Cu}$ bick inches of air; fo the weight of the air in this Tartar was I 44 grains, i.e. $\frac{x}{3}$ part of the weight of the whole: The remaining fcoria, which was very little, run per deliquium, an argument that there remained fome Sal Tartar, and confequently more air; for

\section{EXPERIMENT LXXIV.}

Half a cubick inch, or 304 grains of $\mathrm{Sal}$ Tartar, made with nitre and tartar," and mixed with a double quantity of calx of bones, yielded in diftillation I I 2 cubick inches of air; that is, 224 times its bulk of air, which I 2 cubick inches weighing 32 grains, is nearly $\frac{?}{9}$ part of the weight of the Sal Tartar. There is a more intenfe degree of heat required to raife the air from Sal Tartar than from nitre.

Hence we fee, that the proportion of air in cqual bulks of Sal T artar and nitre is 


\section{Analy fis of the Air. is 5}

as 224 to 180 . But weight for weight, nitre contains a little more air in it, than this. Sal Tartar made with nitre. But Sal Tartar made without nitre, has probably a little more air in it than this had, becaufe it is found to make a greater explofion in the Pulvis Fulminans, than the nitrated Sal Tartar. But fuppofing, as is found by this Experiment, that Sal Tartar, according to its fpecifick gravity, contains $\frac{x}{5}$ part more in it than nitre; yet this excers of air is not fufficient to account for the vaftly greater explofion of Sal Tartar than of nitre; which feems principally to arife from the more fix'd nature of Sal Tartar; which therefore requires a more intenfe degree of fire, to feparate the air from the ftrongly adhering particles, than is found requifite to raife the air from nitre. Whence the air of Sal $\mathcal{T}_{\text {ar }}$ tar muft neceffarily thereby acquire a greater elaftick force, and make a more violent explofion, than that of nitre. And from the fame reafon it is, that Aurum Fulminans gives a louder explofion than Pulvis Ful-. minans. The fcoria of this operation did not run per deliquium, a proof that all the Sal T Trtar was diftilled over.

From 
186 Analy is of the Air.

From the little quantity of air which is obtained by the diftillation of that very fixt body fea-falt in Experiment $7 \mathrm{I}$. in comparifon of what arifes from nitre and Sal Tartar, we fee the reafon why it will not go off with an explofive force, like thofe when fired. And ac the fame time we may hence obferve, that the air included in nitre and Sal Tartar, bears a confiderable part in their explofion. For fea-falt contains an acid fpirit as well as nitre; and yet that without a greater proportion of air does not qualify it for explofion, tho' mixed like nitre in the compofition of gun-powder, with fulphur and charcoal.

Mr. Boyle found that Aqua-fortis poured on a ftrong folution of falt of tartar did not fhoot into fair cryftals of falt-petre, till it had been long expored to the open air; whence he furpected that the air contributed to that artificial production of falt-petre. And fays, "whatever the air hath to do in " this Experiment, we have known fuch " changes made in fome faline concretes, "chiefly by the help of the open air, as "very few would be apt to imagine." Vol. I. p. 302. and Vol. 3. p. 80. And Chymifts obferve, that when the effential falts 


\section{Analyjis of the Air. 187}

of vegetables are fet to cryftallize, it is needful to take off the skin or Pellicle, which covers the liquor, before the falts will thoot well.

We fee from the great quantity of air, which is found in falts, of what ufe it is in their cryftallization and formation; and particularly how neceffary it is in making falt-petre from the mixture of falt of tartar and fpirit of nitre. For fince by Experiment 72 and 73 , a great deal of air flies away, in the making of Sal T artar, either from nitre and tartar, or from tartar alone; it muft needs be neceffary, in order to the forming of nitre from the mixture of Sal Tartar and fpirit of nitre, that more air thould be incorporated with it, than is contained eicher in the Sal Tartar or fpirit of nitre.

\section{EXPERIMENT LXXV.}

Near half a cubick inch of compound $A$ qua-fortis, which bubbled and made a confiderable expanfion in diftillation was foon diftilled off: as it cooled the expanfion abated very fart, and a little air was abforb. ed. Whence it is evident that the air generated by the diftillation of nitre, did not arife from the volatile fpirituous particles. 
I8 Analy is of the Air.

Hence alfo it is probable that there is fome air in acid fpirits, which is reforbed and fixt by them in diftillation. And this is further confirmed from the many air bubbles which arife from Aqua-regia, in the folution of gold; for fince gold lofes nothing of its weight in being diffolved, the air cannot arife from the metalline part of the gold, but mult either arife from the Aqua-regia, or from latent air in the pores of the gold.

\section{EXPERIMENT LXXVI.}

A cubick inch of common Brimftone expanded very little in diftillation in a glafs retort; notwithftanding it had a great heat given it, and was all diftilled over into the receiver without flaming. It abforbed fome air, but flaming brimftone by Experiment I03, abforbs much air.

A good part of the air thus raifed from feveral bodies by the force of fire, was apt gradually to lofe its elafticity, in ftanding feveral days; the reafon of which was (as will appear more fully hereafter) that the acid fulphureous fumes raired with that air, did seforb and fix the elaftick particles. 
Analy is of the Air.

EXPERIMENT IXXVII.

To prevent which I made ufe of the following method of diftillation, which is much more commodious than with Glafs Retorts, whofe juncture at a (Fig. 33.) it is not eafy to fecure. Having firft put the matter to be diftilled into the iron retort $\operatorname{rr}$ (Fig. 38.) which was made of a musket barrel, I then fixed a leaden fyphon to the nofe of the retort, and having immerfed the fyphon in the veffel of water $x x$, I placed over the open end of the fyphon the inverted chymical receiver $a b$ which was full of water; fo that as the air which was raifed in diftillation, paffed thro' the water up to the top of the receiver $a b$, a good part of the acid fpirit and fulphureous fumes were by this means intercepted and retained in the water; the confequence of which was, that the new generated air continued in a more permanently elaftick ftate, very little of it lofing its clafticity, viz. not above a I sth or 18 th part, and that chiefly the firlt 24 hours; after which the remainder continued in a conftantly elaftick ftate; excepting the airs of tartar and calculus bumanus, which in 6 or 8 days lof conftantly above one third of their elafticity; after which 
190 Analyfis of the Air.

which the remainder was permanently elaftical. In which ftate it has continued, without any fenfible alteration, for thefe three years that I have kept fome of the air of calculus humanus by me.

That the great quantities of air which are thus obtained from thefe feveral fubftances by diftillation are true air, and not a mere flatulent vapour, I was affured by the following trials; viz. I filled a large receiver which contained 540 cubick inches, with air of tartar; and when it was cool, I furpended the receiver on the end of a ballance while its mouth was inverted in water. Then upon lifting the mouth of the receiver out of water, I immediately covered it by tying a piece of bladder over it. When I had found the exact weight, I blew out all the air of tartar with a pair of bellows which had a long additional nofe that reached to the bottom of the receiver. And then tying the bladder on, I weighed it again, but could find no difference in the fpecifick gravity of the two airs, and it was the fame with an air of tartar which was Io days old.

As to the other property of the air, elafiicity, I found it exactly the fame in the air of tartar, which was is days old, and com- 


\section{Analy is of the Air. I9.}

mon air; by filling two equal tubes with thefe different airs, the tubes were ro inches long and fealed at one end; I placed them at the fame time in a cylindrical glafs con-. denfing receiver, where I compreffed them with two additional atmofpheres, taking care to fecure myfelf from danger in cafe the glafs thould burf, by placing it in a deep wooden veffel, the water rofe to equal heights in both tubes. This receiver was gently annealed and thereby toughened, by being boiled in Urine where it lay till all was cold.

I put alfo into the fame tubes fome new made air of tartar, both the tubes ftanding in cifterns of water; the air of one of thefe tubes I compreffed in the condenfing engine for fome days, to try whether in that compreffed ftate, more of the air's elafticity would be deftroyed by the abforbing vapours than in an uncompreffed ftate; but I did not perceive any fenfible difference.

Lemery, in his courfe of chymiftry, $p .592$. obtained in the diffillation of 48 ounces of Tartar, 4 ounces of phlegm, 8 of pirits, 3 of oil, and 32 of fcoria, i. e. two thirds of the whole, fo one ounce was loft in the operation. 
In my diftillation of 443 grains of $T$ ar: tar in Exper. 73. there remained but 42 grains of fcoria, which is little more than is of the Tartar; and in this remainder, there was by Exper. 74 air, for there was Sal Tartar, it running per deliquium.

Whence by comparing Lemery's and my diftillation together, we hall find, that there remained in this 32 ounces of fcoria, and in the ounce that was loft, (which was doubtlefs moft of it air) fubftance enough to account for the great quantity of air, which in Exper. 73. was raifed from Tartar; efpecially, if we take into the account the proportion of air, which was contained in the oil, which was $\frac{r}{5}$ part of the whole $\mathcal{T}$ ar tar, for there is much air in oil.

The bodies which I diftilled in this manner (Fig. 3 8.) were Horn, calculus bumanus, Oyfter-hhell, Oak, Muftard-feed, Indianwheat, Peafe, Tobacco, oil of Anifeed, oil of Olives, Honey, Wax, Sugar, Amber, Coal, Earth, Walton Mineral, Sea-falt, Salt-petre, Tartar, Sal Tartar, Lead, Minium. The greateft part of the air obtained from all which bodies. was very permanent, except what the air of Tartar and calculus bumanus loft in fanding feveral days. Particularly that 


\section{Analy is of the Air.}

from nitre loft little of its elafticity, whereas moft of the air obtained from nitre, in diftlling with the receiver (Fig. 33.) was reforbed in a few days, as was alfo the air which was generated from detonized nitre in Experiment 102. Hence alfo we fee the reafon, why 19 parts in 20 , of the air which.was generated by the firing of Gunpowder, was in 18 days reforbed by the fulphureous fumes of the Gunpowder; as Mr. Hawksbee obferved, in his phyficomechanical Experiments, page 83.

In the diftillation of Horn, it was obfervable, that when towards the end of the operation the thick foetid oil arofe, it formed very large bubbles, with rough unctuous skins, which continued in that fate fome time; and when they broke, there arofe out of them volumes of rmoak, as out of a chimney, and it was the fame in the diftillation of Muftard-feed.

AN ACCOUNT OF SOME EXPERIMENTS MADE ON STONES TAKEN OUT OF HUMAN U. RINE AND GALL BLADDERS.

Aving procured, by the favour of Mr. 12 Ranby, Surgeon to His Majefty's Houbolds. 
194 Analyfis of the Air.

Houlfbold, fome calculi bumani, I made the following Experiments with them, which I Thall here infert, viz.

I diftilled a calculus in the iron retort (Fig. 38.) it weighed 230 grains, it was fomething lefs in bulk than $\frac{3}{4}$ of a cubick inch: There arofe from it very briskly, in diftillation, 5 I 6 cubick inches of elaftick air, that is, a bulk equal to 645 times the bulk of the Stone; fo that above half the Stone was raifed by the action of the fire into elaftick air; which is a much greater proportion of air than I have ever obtained by fire from any other fubftances, whether animal, vegetable or mineral. The remaining calx weighed 49 grains, that is, $\frac{x}{4.69}$ part of the calculus; which is nearly the fame proportion of calx, that the worthy Dr. Slare found remaining, after the diftilling and calcining two ounces of calculus, " one "ounce and three drams of which (he fays) " evaporated in the open fire (a mate"rial circumftance, which the Chymifts " rarely enquire after) of which we have no " account." Philof. Tranfact. Lowthorp's Abridgment, Vol. III. p. I79. The greateft part of which was, we fee by the prefent Experiment, raifed into permanently elaftick air. 


\section{Analyfis of the Air. I9s}

By comparing this diftillation of the calculus with that of Renifh Tartar, in Exper. 73. we fee that they both afford more air in diftillation, than any other fubftances: And it is remarkable, that a greater proportion of this new raifed air from thefe two fubftances, is reforbed, and lofes its elafticity, in ftanding a few days, than that of any other bodies; which are ftrong fymptoms that the calculus is a true animal Tartar. And as there was very confiderably lefs oil, in the diftillation of Renifh Tartar, than there was in the diftillation of the Seeds and folid parts of vegetables; fo I found that this calculus contained much lefs oil than the blood or folid parts of animals.

I diftilled in the fame manner as the $a^{-}$ bove mentioned calculus, fome ftones taken out of a human Gall Bladder, they weighed $\$ 2$ grains, fo their bulk was equal to $\frac{t}{6}$ part of a cubick inch, as I found by taking their rpecifick gravity. There was 108 cubick inches of elaftick air raifed from them in difillation, a quantity equal to 648 times their bulk; much the fame quantity that was raifed from the calcullus. About $\frac{x}{6}$ part of this elantick air was in four days reduced into a fix'd ftate. There arofe much more

$$
\text { O 2. oil }
$$


596 Analysis of the Air.

oil in the diftillation of thefe Stones, than from the Calculus, part of which oil did arife from the Gall, which adhered to and was dried on the furfaces of the Stones, which oil formed large bubbles, like thofe which arofe in the diffillation of Deer's Horn, p. I 87.

A fmall Stone of the Gall Bladder, which was as big as a Pea, was diffolved in a Lixivium of Sal $T$ artar in feven days, which Lixivium will alfo diffolve Tartar; yet it will not difiolve the Calculus, which is more firmly united in its parts.

A quantity of Calculus equal to one half of what was diftilled, viz. I Is grains, did, when a cubick inch of fpirit of nitre was poured on it, diffolve in 2 or 3 hours, with a large froth, and generated 48 cubick inches of air, none of which lof its elafticity, tho" it ftood many days in the glafs veffel. (Fig. 34.) And a like quantity of Tartar being mixed with fpirit of nitre, was in the fame time diffolved, but no elantick air was generated, notwithitanding T artar abounds fo much with air.

Small pieces of $\mathcal{T}$ artar and Calculus were in 12 or 14 days both diffolved by oil of Vitriol; the like pieces of Tartar and Cal- 


\section{Analyfis of the Air. $\quad 197$}

culus were diffolved in a few hours by oil of Vitriol, into which there was gradually poured near an equal quantity of fpirit of Harts-horn, made with Lime, which caufed a confiderable ebullition and heat.

Tho the remaining calx of the diftillation of Tartar, in Exper. 73. run per deliquium, and had therefore Sal Tartar in it; and tho' the calx of the diftilled Calculus did not run per deliquium, and had confequently no Sal Tartar in it; yet it cannot thence be inferred, that the Calculus is not a tartarine fubftance: Becaufe by Exper. 74. it is evident, that $S a l$ Tartar it felf, when mixed with an animal calx, diftils all over, fo that the calx will not afterwards run per deliquium.

By the great fimilitude there is therefore in fo many refpects between thefe two fubftances, we may well look upon the Calculus, and the Stone in the Gall Bladder, as true animal T artars, and doubtlefs Gouty concretions are the famc.

From the great quantities of air that are found in thefe Tartars, we fee that unclaftick air particles, which by their ftrongly attracting propercy are fo inftrumental in forming the nutritive matter of Animals 
198 Analy/is of the Air.

and Vegetables, is by the fame attractive power apt fometimes to form anomalous concretions, as the Stone, \&c. in Animals, efpecially in thofe places where any animal fluids are in a ftagnant ftate, as in the U. rine and Gall Bladders, they ftrongly adhere alfo to the fides of Urinals, \& $c$. The like tartarine concretions are alfo frequently formed in fome fruits, particularly in Pears; but they do then efpecially coalefce.in greateft plenty, when the vegetable juices are in a ftaguant ftate, as in wine veffels, \& $c$.

This great quantity of ftrongly attracting, unelaftick air particles, which we find in the calculus, fhould rather encourage than difcourage us, in fearching after fome proper diffolvent of the Stone in the Bladder, which, upon the analyfis of it, is found to be well ftored with active principles, fuch as are the principal agents in fermentation. For Mr. Boyle found therein a good quantity of volatile falt, with fome oil; and we fee by the prefent Experiment, that there is ftore of unclaftick air particles in it. The difficulty feems chiefly to lay, in the over proportion of thefe laft mentioned particles, which are firmly united together by fulphur and falt 
the proportion of caput mortuum, or carth being very Imall.

\section{EXPERIMENT LXXVIII.}

One eighth of a cubick inch of Mercury made a very infenfible expanfion in diffillation, notwithftanding the iron retort had an almoft melting heat given it at a fmith's forge, fo that it made an ebullition, which could be heard at fome diftance, and withal fhook the retort and receiver. There was no air generated, nor was there any expanfion of air in the following Exper. viz.

\section{EXPERIMENT LXXIX.}

I put into the fame retort half a cubick inch of Mercury, affixing to the retort a very capacious receiver, which had no hole in the bottom. The wide mouth of the receiver was adapted to the fmall neck of the retort (which was made of a musket barrel) by means of two large pieces of cork which entered and filled the mouth of the receiver, they having holes bored in them of a fit fize for the neck of the retort; and the juncture was farther fecured, by a dry fupple bladder tied over it; for I purpofely avoided making ufe of any moift lute, and took

$$
\mathrm{O}_{4}
$$

care 
care to wipe the infide of the receiver very dry with a warm cloth.

The Mercury made a great cbullition, and came fome of it over into the receiver, as foon as the retort had a red heat given it, which was increafed to a white and almort melting heat, in which ftate it continued for half an hour. During which time, I frequently cohobated fome part of the Mer. cury, which condenfed, and was lodged on an horizontal level, about the middle of the reck of the retort: And which upon raifing the receiver, flowed down into the bottom of the retort, and there made a frefh ebullition, which had ceared, when all the Mercury was diftilled from the bottom of the retort. When all was cool, I found apout two drams of Mercury in the retort, and loft in the whole 43 grains, but there was not the leaft moifture in the receiver.

Whence it is to be fufpected that $M r$. Boyle and others were deceived by fome unheeded circumftance, when they thought they obtained a water from Mercury in the diftillation of it; which he fays he did once, but could not make the like Experiment afterwards fucceed. Bayle, Vol. III. p. 416. 


\section{Analy is of the Air.}

I remember that about 20 years fince, I was concerned with feveral others in making this Experiment at the elaboratory in Trinity College Cambridge, when imagining there would be a very great expanfion, we luted a German earthen retort to three or four large Alodals, and a capacious re. ceiver; as Mr. Wilfon did in his courfe of Chymittry. Four pounds of Mercury was poured by little and little into the red hot retort, thro' a tobacco-pipe purpofely affixed to it. The event was, that we found fome fpoons full of water with the Mercury in the Alodals, which I then furpected to arife from the moifture of the earthen retort and lute, and am now confirmed in that fufpicion. It rained inceffantly all the day, when I made this prefent Experiment; fo that when water is obtained in the diftil: lation of Mercury, it cannot be owing to a moifter temperature of the air.

The effects of Fermentation on the Air.

Aving from the foregoing Experiments 11 feen very evident proof of the production of confiderable quantities of true claftick air, from liquors and folid bodics, 
202 Analyzis of the Air.

by means of fire; we thall find in the following Experiments many inftances of the production; and alfo of the fixing or abforbing of great quantities of air by the fermentation arifing from the mixture of variety of folids and fluids: Which method of producing and of abforbing, and fixing the elaftick particles of air by fermentation, feems to be more according to nature's ufual way of proceeding, than the other of fire.

\section{EXPERIMENT LXXX.}

I put into the bolthead 6 (Fig. 34.) I $6 \mathrm{cll}$ bick inches of Sheep's blood, with a little water to make it ferment the better. I found by the defcent of the water from $z$ to $y$ that in 18 days fourteen cubick inches of air were generated.

\section{EXPERIMENT IXXXI.}

Volatile Salt of Sal Ammoniac, placed in an open glafs ciftern, under the inverted glafs $z z a$ a (Fig. 35.) neither generated nor abforbed air. Neither did feveral other volatile liquors, as fpirits of Hartshorn, fpirits of Wine, nor compound Aquafortis, generate any air. But Sal Am- 


\section{Analyjis of the Air. 203}

moniac, Sal Tartar, and fpirits of Wine mixed together, generated 26 cubick inches of air, two of which was in four days reforbed, and after that generated again.

\section{EXPERIMENT LXXXII。}

Half a cubick inch of Sal Ammoniac, and double that quantity of Oil of Vitriol, generated the firft day five or fix cubick inches: But the following days it abforbed fifteen cubick inches, and continued many days in that Atate.

Equal quantities of fpirits of Turpentine, and oil of Vitriol, had near the fame effect, except that it was fooner in an abforbing ftate than the other.

Mr. Geoffroy thews, that the mixture of any vitriolic falts, with inflammable fubftances, will yield common Brimftone; and by the different compofitions he has made of fulphur; and particularly from oil of Vitriol, and oil of Turpentine; and by the Analyfis thereof, when thus prepared, he difcovered it to be nothing but vitriolic falt, united with the combuftible fubftance. French Memoirs, Anno 1704. p. 3 \$1. or Boyle's Works, Vol, III. p. 273. Notes 
EXPERIMEN T IXXXIII.

In February.I poured on fix cubick inches of powdered Oyftershell, an equa! quantity of common white-wine Vinegar. In five or fix minutes it generated 17 cubick inches of air, and in fome hours $\mathrm{I}_{2}$ cubick inches more; in all 29 inches. In nine days it had flowly reforbed 2 I cubick inches of air. The ninth day I poured warm water into the veffel $x x$, (Fig. 34.) and the following day, when all was cool, I found that it had reforbed the remaining 8 cubick inches. Hence we fee that warmth will fometimes promote a reforbing as well as a generating: ftate, viz. by raifing the reforbing fumes, as will appear more hereafter.

Half a cubick inch of Oyfterfhell, and a cubick inch of oil of Vitriol, generated 32 cubick inches of air.

Oyfterfbell, and 2 cubick inches of four Rennet, of a Calf's ftomach, generated in four days I I cubick inches. But Oyfterfhell with fome of the liquor of a Calf's ftomach, which had fed much upon hay, did not generate air. It was the fame with $O y f$ fer hell. and Ox-gall, Urime and Spittle. 


\section{Analyfis of the Air. 20 s}

Half a cubick inch of Oyefter/hell and Sevil Orange juice generated the firt day \& 3 cubick inches of air, and the following days it reforbed that, and three or four more cubick inches of air, and would fometimes generate again. It was the fame with Limon juice.

Oyfter hell and Milk generated a little air: But Limon juice and Milk did at the fame time abforb a little air; as did alfo Calves Rennet and Vinegar; fome of the fame Rennet alone generated a little air, and reforbed it again the following day. It had the fame cffect when mixed with crums of bread.

\section{EXPERIMENT IXXXIV.}

A cubick inch of Limon juice, and near an equal quantity of jpirits of Harts-born, per fe, i.e. not made with Lime, did in 4 hours abforb 3 or 4 cubick inches of air; and the following day it remitted or generated two cubick inches of air: The third day turning from very warm to cold, it again reforbed that air, and continued in an abforbing ftate for a day or two.

That there is great plenty of air incorporated into the fubftance of Vegetables, which by the antion of fermentation is rouzed 
206 Analyfis of the Air.

rouzed into an elaftick ftate, is evident by thefe following Experiments, viz.

EXPERIMENT LXXXV.

March the $2 \mathrm{~d}$ I poured into the bolthead b, (Fig. 34.) forty two cubick inches of Ale from the Tun, which had been there fet to ferment 34 hours before: From that time to the 9 th of Fune it generated 639 cubick inches of air, with a very unequal progreflion, more or lefs as the weather was warm, cool, or cold, and fometimes upon a change from warm to cool, it reforbed air, in all 32 cubick inches.

\section{EXPERIMENT LXXXVI.}

March the 2d, I 2 cubick inches of $M a$ laga Raifins, with 18 cubick inches of water, generated by the I6th of April 4 I I clbick inches of air; and then in 2 or 3 cold days it reforbed 35 cubick inches. From the 21 th of April to the I6th of May it generated 78 cubick inches; after which to the 9 th of $f$ une it continued in a reforbing ftate, fo as to reforb I3 cubick inches; there were at this feafon many hot days, with much Thunder and Lightning, which deftroys the air's elafticity; fo there was generated 


\section{Analy is of the Air.}

nerated in all 489 cubick inches, of which 4.8 were reforbed. The liquor was at laft very vapid.

From the great quantity of air generated from Apples, in the following Experiment, 'tis probable, that mueh more air would have rifen from the laxer texture of ripe undried Grapes, than did from thefe Raifins.

We fee from the Ee Experiments on Raifins and Ale, that in warm weather Wine and Ale do not turn vapid by imbibing air, but by fermenting and generating too much, whereby they are deprived of their enlivening principle, the air; for which realon thefeliquors are beft preferved in cool cellars, whereby this active invigorating principle is kept within due bounds, which when they exceed, Wines are upon the fret and in danger of being fpoiled.

\section{EXPERIMENT IXXXVII.}

Twenty-fix cubick inches of Apples being mafhed Auguft IO, they did in I 3 days generate 968 cubick inches of air, a quantity equal to 48 times their bulk; after which they did in 3 or 4 days reforb a quantity equal to their bulk, notwithftanding it was 


\section{Analy is of the Air.}

very hot weather; after which they were ftationary, neither reforbing nor generating air in many days.

A very coarfe Brown-fugar, with an equal quantity of water, generated nine times its bulk of air; Rice-flower fix times its bulk; Scurvy-grafs leaves gencrated and abforbed air; Peafe, Wheat and Barley did in Fermentation alfo generate great quantities of air.

That this air, which arifes in fuch great quantities from fermenting and diffolving vegetables is true permanent air, is certain, by its continuing in the fame expanded elaftick ftate for many weeks and months; which expanding watry vapours will not do, but foon condenfe when cool. And that this new generated air is elaftical is plain, not only by its dilating and contracting with heat and cold, as common air does, but alfo by its being comprefible, in proportion to the incumbent weight, as appears by the two following Experiments, which thew what the great force of thefe aerial particles is, at the inftant they efcape from the fermenting vegetables. 


\section{Analyfis of the Air. 209}

\section{EXPERIMENT IXXXVIII.}

I filled the ftrong Hungary-water Bottle $b c$ (Fig. 36.) near half full of Peafe, and then full of water, pouring in firft half an inch depth of Mercury; then I fcrewed at $b$ into the bottle the long Alender tube $a z$, which reached down to the bottom of the bottle; the water was in two or three days all imbibed by the Peafe, and they thereby much dilated; the Mercury was alfo forced up the flender glafs tube near 80 inches high; in which ftate the new generated air in the bottle was compreffed with a force equal to more than two atmofpheres and an half; if the bottle and tube were fwung to and fro, the Mercury would make long vibrations in the tube between $z$ and $b$, which proves the great clafticity of the compreffed air in the bottle.

\section{EXPERIMENT LXXXIX。}

I found the like elaftick force by the following Experiment, viz. I provided a ftrong iron pot $a b c d$ (Fig. 37.) which was 2 and $\frac{3}{4}$ inches diameter within fide, and five inches deep. I poured into it half an inch depth of Mercury; then I put a little coloured 
honey at $x$, into the bottom of the glals. tube $z x$, which was realed at the top. I fet this tube in the iron cylinder $n n$, to fave it from breaking by the fwelling of the Peafe. The pot being filled with Peafe and water, I put a leathern collar between the mouth and lid of the pot, which were both ground even, and then preffed the lid hard down in a Cyder-prefs: The third day I opened the pot and found all the water imbibed by the Peafe; the Honey was forced up the glafs-tube by the Mercury to $z$, (for fo far the glafs was dawbed) by which means I found the preffure had been equal to two atmorpheres and $\frac{x}{4}$; and the diameter of the pot being $2+\frac{3}{4}$ inches, its area was fix fquare inches, whence the dilating force of the air againf the lid of the pot was equal to I 89 pounds.

And that the expanfive force of new generated air is vaftly fuperior to the power with which it acted on the Mercury in thefe two Experiments is plain from the force with which fermenting Muft will burt the ftrongeft veffels; and from the vaft explofive force with which the air generated from nitre in the firing of gun-powder, will burt afunder the Atrongeft 


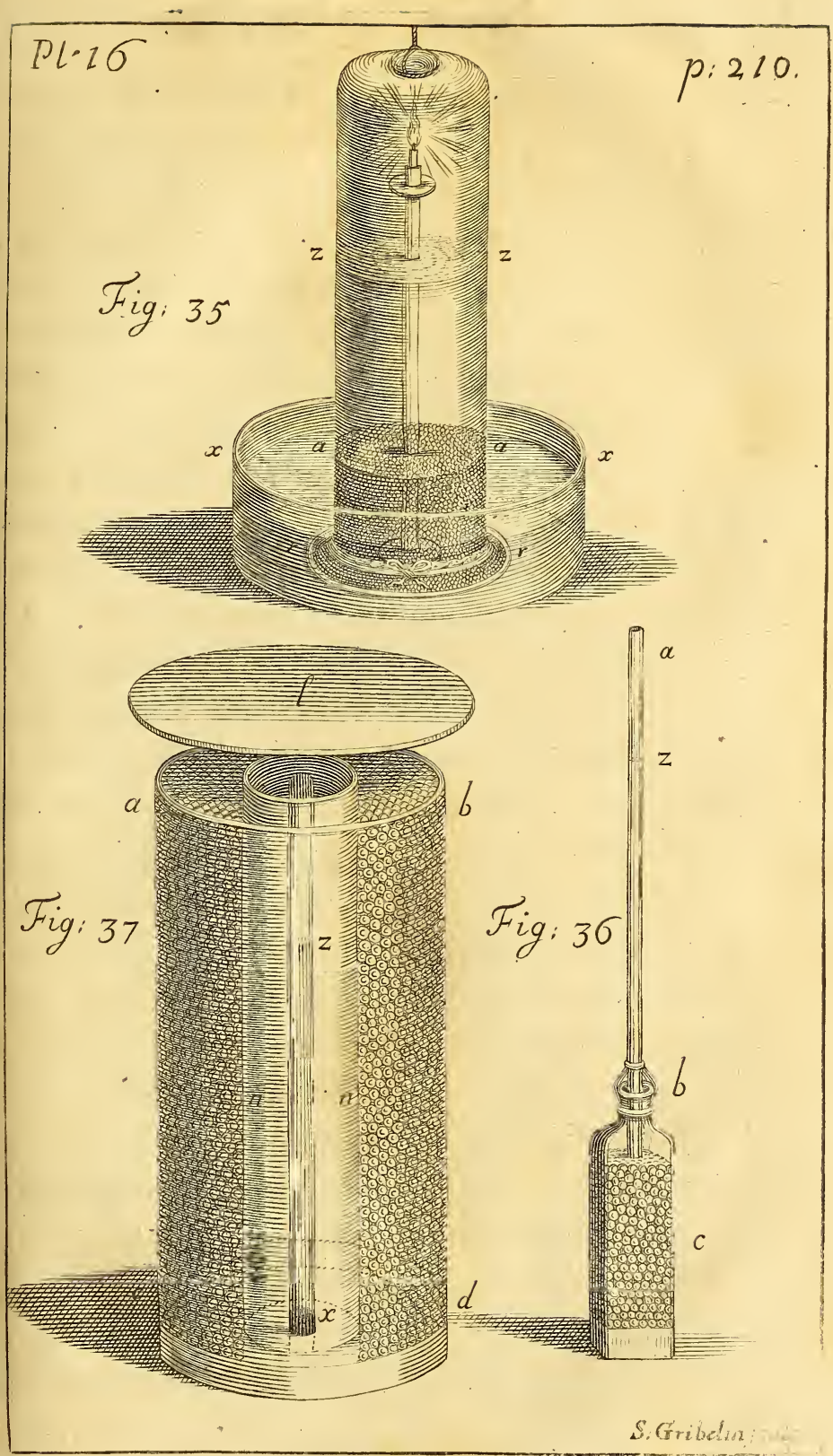





\section{Analy is of the Air. 211}

Atrongeft bombs or cannon, and whirl fortifications in the air.

This fort of mercurial gage, made ufe of in Experiment 89, with fome unctuous matter, as Treacle, or the like tinged liquor, on the Mercury in the tube, to note how high it rifes there, might probably be of fervice, in finding out unfathomable depths of the Sea, viz. by fixing this fea-gage to fome buoyant body which thould be funk by $a$ weight fix'd to it, which weight might by an ealy contrivance be detached from the buoyant body, as foon as it touched the bot. tom of the fea; fo that the buoyant body and gage would immediately arcend to the furface of the water; the buoyant body ought to be pretty large, and much lighter than the water, that by its greater eminence above the water it might the better be feen: for 'tis probable that from great depths it may rife at a confiderable diftance from the fhip, tho in a calm.

For greater accuracy it will be needful; firft to try this fea-gage, at feveral different depths, down to the greateft depth that 2 line will reach, thereby to difcover, whether or how much the fpring of the air is difturbed or condenfed, not only by the 
great preffure of the incumbent water, but alfo by its coldnefs at great depths; and in . hat proportion, at different known depths, and in different lengths of time, that an allowance may accordingly be made for it at unfathomable depths.

This gage will alfo readily thew the degrees of compreflion in the condenfing engine.

But to return to the fubject of the two laft Experiments, which prove the elafticity of this new generated air; which elafticity is fuppofd to confift in the active aerial particles, repelling each other with a force, which is reciprocally proportional to their diftances. That illuftrious Philofopher, Sir Ifaac Neroton, in accounting how air and vapour is produced, Opticks Quer. 3 I. fays, "The particles when they are thaken off " from bodies by heat or fermentation fo " foon as they are beyond the reach of the " attraction of the body receding from it, " as alfo from one another, with great "ftrength and keeping at a diftance, fo as " fometimes to take up above a million of "times more fpace than they did before in " the form of a denfe body, which vaft " contraction and expanfion feems unintel- 


\section{Analyjis of the Air.}

" ligible, by feigning the particles of air "t to be fpringy and ramous, or rolled up "like hoops, or by any other means than "by a repulfive power." The truth of which is further confirmed by thefe Experiments, which thew the great quantity of air emitted from fermenting bodies; which not only proves the great force with which the parts of thofe bodies muft be diftended; but thews allo how very much the particles of air mutt be coiled up in that ftate, if they are, as has been fuppofed, fpringy and ramous.

To inftance in the cafe of the pounded Apples which generated above 48 times their bulk of air; this air, when in the Apples, mut be compreffed into lefs than a forty-eighth part of the fpace it takes up, when freed from them, and it will confequently be 48 times more denfe; and fince the force of compreffed air is proportional to its denfity, that force which compreffes and confines this Air in the Apples, mult be equal to the weight of 48 of our atmorpheres, when the Mercury in the Barometer ftands at fair, that is 30 inches high. 
214 Analy/is of the Air.

Now a cubick inch of Mercury weigh: ing 3580 grains, thirty cubick inches (which is equal to the weight of our atmolphere on an area of a cubick inch) will weigh is pounds, 5 ounces, 215 grains; and 48 of them will weigh above 736 pounds; which is therefore equal to the force with which an inch fquare of the furface of the Apple would comprefs the air, fuppofing there were no other fubftance but air in the Apple: And if we take the furface of an Apple at I 6 fquare inches, then the whole force with which that furface would comprefs the included air, would be 15776 pounds. And fince action and re-action are equal, this would be the force, with which the air in the Apple would endeavour to expand itfelf, if it were there in an elaftick and ftrongly compreffed ftate: But fo great an expanfive force in an Apple would certainly rend the fubftance of it with a ftrong explofion, efpecially when that force was increafed, by the vigorous influence of the Sun's warmth.

We may make a like eftimate alfo, from the great quantities of air which arofe either by fermentation, or the force of fire from feveral other bodies. Thus in Exp. 55 . 


\section{Analyfis of the Air.}

there arofe from a piece of heart of Oak, 2 I 6 times its bulk of air. Now 216 cubick inches of air, compreffed into the rpace of one cubick inch, would, if it continued there in an elaftick ftate, prefs againft one fide of the cubick inch with an expanfive force equal to 33 ro pounds weight, fuppofing there were no other fubftance but air contained in it; and it would prefs againft the fix fides of the cube, with a force equal to I 9860 pounds, a force fufficient to rend the Oak with a vaft explofion: 'Tis very reafonable therefore to conclude, that moft of thefe now active particles of the new generated air were in a fix'd ftate in the Apple and Oak before they were roufed, and put into an active repelling ftate by fermentation and fire.

The weight of a cubick inch of Apple being I 9 I grains, the weight of a cubick inch of air $\frac{2}{7}$ of a grain, 48 times that weight of air is nearly equal to the fourteenth part of the weight of the Apple.

And if to the air thus generated from a veffel of any vegetable liquor by fermentation, we add the air that might afterwards be obtained from it by heat or diftillation; and to that alfo the vaft quantity of air

$$
\text { P 4 which }
$$




\section{Analyfis of the Air.}

which by Experiment 73 is found to be contained in its Tartar which adheres to the fides of the veffel; it would by this means be found that air makes a very confiderable part of the fubftance of Vegetables, as well as of Animals.

But tho' from what has been faid, it is reafonable to think, that many of thefe particles of air were in a fixt ftate, ftrongly adhering to and wrought into the fubftance of Apples; yet on the other hand it is moft evident from Exper 34, and 38 , where innumerable bubbles of air inceffantly arofe through the fap of Vines, that there is a confiderable quantity of air in Vegetables, upon the wing, and in a very active ftate, efpecially in warm weather, which enlarges the fphere of their activity.

The effects of the Fermentation of mineral Subftances on the air.

Have above thewn that air may be proL duced from mineral Subftances, by the action of fire in diftillation. And we have in the following Experiments many inftances of the great plenty of air which is generated by fome fermenting mixtures, abrorbed 


\section{Analyjis of the Air.}

abforbed by others, and by others alter. nately generated and abforbed.

\section{EXPERIMENT XC.}

I poured upon a middle fized Gold Ring, beat into a thin plate, two cubick inches of Aqua Regia; the Gold was all diffolved the next day, when I found four cubick inches of air generated; for air bubbles were continually arifing during the folution: But fince Gold lofes nothing of its weight in being thus diffolved, the four cubick inches of air, which weighed more than a grain, mult arife either out of the pores of the Gold, or from the Aqua Re. gia, which makes it probable, that there are air particles in acid fpirits; for by Experiment 75 , they abforb air, which air particles regained their elafticity, when the acid fpirits which adhered to them were more ftrongly attracted by the Gold, than by the air particles.

\section{EXPERIMENT XCI.}

A quarter of a cubick inch of Antimony, and two cubick inches of Aqua Regia, generated 38 cubick inches of air, the firt three or four hours, and then abrorbed If 


\section{Analyfis of the Air.}

cubick inches in an hour or two. It is very obfervable, that air was generated while the ferment was fmall, on the firf mixing of the ingredients: But when the ferment was greatly increafed, fo that the fumcs role very vifibly, then there was a change made from a generating to an $a b$ forbing ftate; that is, there was more air abforbed than generated.

That I might find whether the air was ab. forbed by the fumes only of the Aqua Regia, or by the acid fulphureous vapours, which arcended from the Antimony, I put a like quantity of Aqua Regia into a bolthead b, (Fig. 34.) and heated it by pouring a large quantity of hot water into the ciftern $x x$, which ftood in a larger veffel, that retained the hot water about it, but no air was abforbed; for when all was cold, the water ftood at the point $z$, where I firft placed it: And I found it the fame, when inftead of Aqua Regia, I put only fpirit of Nitre into the bolthead $b$ : Yet in the diftillation of compound Aquafortis, Exper. 75. a little was abforbed. Hence therefore it is probable, that the greateft part, if not all the air, was abforbed by the fumes which arofe from the Antimony.

EXP: 


\section{EXPERIMENT XCII.}

Some time in February, the weather very cold, I poured upon a quarter of a cubick inch of powdered Antimony, a cubick inch of compound or double Aqua-fortis, in the bolthead 6 , (Fig. 34.) in the firft 20 hours it generated about 8 cubick inches of air; after that, the weather being fomewhat warmer, it fermented fafter, fo as in two or three hours to generate 82 cubick inches of air more; but the following night being very cold, little was generated: So the next morning I poured hot water into the veffel $x x$, which renewed the ferment, fo that it generated 4 cubick inches more, in all $\square_{30}$ cubick inches, a quantity equal to 520 times the bulk of the Antimony.

The fermented mass looked like Brim: Atone, and when heated over the fire, there fublimed into the neck of the bolthead a red fulphur, and below it a yellow, which fulphur, as Mr. Boyle obferves, Vol. III. p. 272. cannot be obtained by the bare action of fire, without being firt well digefted in oil of Vitriol, or fpirit of Nitre. And by comparing the quantity of air obrained by fermentation in this Experiment, with 
with the quantity obtained by the force of fire in Exper. 69. we find that five times more air was generated by fermentation than by fire, which thews fermentation to be a more fubtle diffolvent than fire; yet in fome cafes there is more air generated by fire than by fermentation.

Half a cubick inch of oil of Antimony, with an equal quantity of compound Aquafortis, generated 36 cubick inches of elaftick air, which was all reforbed the fol. lowing day.

\section{EXPERIMENT XCIII.}

Some time in February, a quarter of a cubick inch of filings of Iron, and a cubick inch of compound Aqua-fortis, without any water, did in 4 days abrorb 27 cubick inches

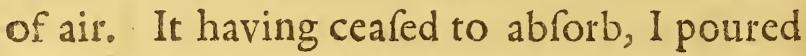
hot water into the veffel $x x$, to try if I could renew the ferment. The effect of this was, that it generated 3 or 4 cubick inches of air, which continued in that ftate for fome days, and was then again reforbed.

I repeated the fame Experiment in warm weather in April, when it more briskly abforbed 12 cubick inches in an hour. 


\section{Analyjis of the Air.}

\section{EXPERIMNT XCIV.}

March I 2 th, $\frac{*}{4}$ of a cubick inch of filings of Iron, with a cubick inch of compound Aqua-fortis, and an equal quancicy of water, for the firt half hour abforbed 5 or 6 cubick inches of air; but in an hour more it had emitted that quantity of air; and in two hours more it again reforbed what had been jutt before emitted. The day following it continued abforbing, in all 12 cubick inches: And then remained ftationary for 15 or 20 hours. The third day it had again remitted or generated 3 or 4 cubick inches of air, and thence continued ftationary for five or fix days.

It is remarkable, that the fame mixtures thould change from gencrating to abforbing, and from abforbing to gencrating ftates; Cometimes with, and fometimes without any fenfible alteration of the temperature of the air.

A like quantity of flings of Iron, and Oil of Vitriol, made no fenfible ferment, and generated a very little air; but upon pouring in an equal quantity of water, it generated in 2 I days 43 cubick inches of air; and in 3 or 4 days more it reforbed 3 cu- 


\section{Analy $\sqrt{15}$ of the Air.}

bick inches of air; when the weather turned warmer it was generated again, which was again reforbed when it grew cool.

One fourth of a cubick inch of flings of Iron, and a cubick inch of Oil of $V_{i}$ triol, with three times its quantity of water, generated 108 cubick inches of air.

Filings of Iron, with Spirit of Nitre, either with an equal quantity of water, or without water, abforbed air, but molt without water.

One fourth of a cubick inch of filings of Iron, and a cubick inch of Limon juice, ab. forbed two cubick inches of air.

\section{EXPERIMENT XCV.}

Half a cubick inch of Spirits of Hartsbors, with filings of Iron abforbed $I+\frac{\pi}{3}$ cubick inches of air, with flings of Copper double that quantity of air, and made a very deep blue tincture, which it retained long, when expoled to the open air. It was the fame with Spirit of Sal Ammoniac, and flings of Copper.

A quarter of a cubick inch of filings of Iron, with a cubick inch of powdered Brimftone, made into a pafte with a little water, 2brorbed I 9 cubick inches of air in two days. 


\section{Analyfis of the Air.}

$N$. B. I poured hot water into the ciftern $x x$, (Fig. 34.) to promote the ferment.

A like quantity of flings of Iron, and powdered Neweaftle Coal, did in 3 or 4 days generate 7 cubick inches of air. I could not perceive any fenfible warmth in this mixture, as was in the mixture of Iron and Brimftone.

Powdered Brimftone and Newcafle Coal neither generated nor abforbed.

Filings of Iron and Water abforbed 3 or 4 cubick inches of air, but they do not abforb fo much when immerfed deep in water; what they abforb is ufually the firft 3 or 4 days.

Filings of Iron, and the abovementioned Walton Pyrites, in Exper. 70. abforbed in 4 days a quantity of air nearly equal to double their bulk.

Copper Oar, and compound Aqua-fortis: neither generated nor abforbed air, but mixed with water it abforbed air.

A quarter of a cubick inch of $\mathcal{T i n}_{\text {, and }}$ double that quantity of compound Aquafortis, generated two cubick inches of air; part of the $\mathcal{T}$ in was diffolved into a very white fubftance. 
EXPERIMENT XCVI.

April I 6 th, a cubick inch of the aforementioned $W$ alton Pyrites powder'd, with a cubick inch of compound Aqua-fortis, expanded with great violence, heat and fume into a fpace equal to 200 cubick inches, and in a little time it condenfed into its former fpace, and then abforbed 85 cubick inches of air.

But the like quantity of the fame Mine$\mathrm{ral}$, with equal quantities of compound Aquafortis and $W$ ater, fermented more violently and generated above 80 cubick inches of air.

I repeated thefe Experiments feveral times, both with and without water, and found conftantly the fame effect. Yet Oil of $\mathrm{Vi}_{\text {- }}$ triol and Water, with fome of the fame Mineral, abforbed air. It was very warm, but did not make a great ebullition.

But this Walton Mineral with equal quantities of Spirit of nitre and water generated air, which air would abforb freth admitted air.

\section{EXPERIMENT XCVII.}

I chofe two equal fized boltheads, and put into each of them a cubick inch of powdered 


\section{Analy fs of the Air. 225}

powdered Walton Pyrites, with only a cubick inch of compound Aqua-fortis into one, and a cubick inch of Water and compound Aqua-fortis into the other: Upon weighing all the ingredients and veffels exactly, both before and after the fermentation, I found the bolthead with compound Aqua-fortis alone had loft in fumes I dram 5 grains: But the other bolthead with Water and comspound Aqua-fortis, which fumed much more, had loft 7 drams, I fcruple, 7 grains, which is fix times as much as the other loft.

\section{EXPERIMENT XCVIII.}

A cubick inch of Newcafte Coal powdered, and an equal quantity of compound Aqua-fortis poured on it, did in 3 days abforb I 8 cubick inches of air; and in 3 days more it remitted and generated I 2 clibick inches of air; and on pouring warm Water into the veffel $x x$, (Fig. 34.) it re: mitted all that had been abforbed.

Equal quantities of Brimftone and compound Aqua-fortis neither generated nor abforbed any air, notwithftanding hot Water was poured into the veffel $x x$.

A cubick inch of finely powdered Flint, and an equal quantity of compound Aqua- 
226 Analyfis of the Air.

fortis, abforbed in 5 or 6 days 12 cubick inches of air.

Equal quantities of powdered Briftol Diamond, and compound Aqua-fortis, and Water abforbed I 6 times their bulk of air.

The like quantities without Water abforbed more flowly 7 times their bulk of air.

Powdered Briftol Marble (viz. the thell in which thofe Diamonds lay) covered pretty deep with Water, neither generated nor abforbed air; and it is well known that Brifol Water docs not Pparkle like fome other Mineral Waters.

\section{E XPERIMENT XCIX.}

When Aqua Regia was poured on Oleum Tartari per deliquium much air was generated, and that probably chiefly from the Oleum Tartari; for by Exper. 74. Sal Tartar has plenty of air in it.

It was the fame when oil of Vitriol was poured on Olewm Tartari; and Oleum Tartari dropped on boiling Tartar generated much air.

When equal quantities of Water and oil of Vitriol were poured on fea falt it abforbed is cubick inches of air; but when 


\section{Arialy is of the Air. 227}

in the like mixture the quantity of Water was double to that of the oil of Vitriol, then but half fo much air was abforbed.

\section{EXPERIMENT C.}

I will next hew, what effects feveral $A l$ kaline Mineral bodies had on the air in fer. menting mixtures.

A folid cubick inch of unpowdered Chalk, with an equal quantity of oil of Vitriol, fermented much at firft, and in fome degree for 3 days; they generated 3 I cubick inches of air. The Chalk was only a little diffolved on its furface.

One hundred and forty fix grains, or near one third of a cubick inch of Chalk, being. let fall on two cubick inches of fpirit of falt, 8 I cubick inches of air were generated, of which 36 cubes were reforbed in 9 days,

Yet Lime made of the fame Chalk abforb. ed much air, when oil of Vitriol was poured on it; and the ferment was fo violent that it breaking the glafs veffels, I was obliged to put the ingredients in an Iron veffel.

Two cubick inches of freth Lime, and four of common white wine Vinegar abforbed in 15 days 22 cubick inches of air.

$$
\text { Q2 The }
$$


228 Analyfis of the Air.

The like quantity of frefh Lime and $W a^{*}$ ter abforbed in 3 days ro cubick inches of air.

Two cubick inches of Lime, and an equal quantity of Sal Ammoniac abforbed i is cubick inches: The fumes of this mixture are therefore doubtlefs very fuffocating.

A quart of unnaked Lime, left for 44 days, to lacken gradually by it felf without any mixture, abforbed no air.

March $3 \mathrm{~d}$, a cubick inch of powdered Belemnitis, taken from a Chalk pit, and an equal quantity of oil of Vitriol, generated in five minutes 35 cubick inches of air. March sth, it had generated 70 more. March 6 th, it being a hard froft, it reforbed I 2 cubick inches; fo it generated in all IOs inches, and reforbed 12 .

Powdered Belemnitis and Limon juice generated plenty of air too; as did alfo the Star-Stone, Lapis Fudaicus, and Selenitis with oil of Vitriol.

\section{EXPERIMENT CI.}

Gravelled, that is well burnt, Wood-aßhes, decrepitated Salt, and Colcothar of Vitriol, placed feverally under the inverted glafs $z z a a$, (Fig. 35.) increafed in weight by 


\section{Analy/is of the Air.}

imbibing the floating moifture of the air: But they abforbed no elaftick air. It was the fame with the remaining lixivious Salt of a diftillation of Nitre.

But 4 or 5 cubick inches of powdered frefh Cynder of Newcaftle Coal did in feven days abforb $s$ cubick inches of elaftick airAnd $I_{3}$ cubick inches of air were in 5 days abforbed by $P$ ulvis Urens, a powder which immediately kindles into a live Cole, upon being expored to the open air.

\section{EXPERIMENT CII.}

What effect burning and flaming bodies; and the refpiration of Animals have on the air, we thall fee in the following Experio ments, viz.

I fix'd upon the pedeftal under the in: verted glafs $z z a a$, (Fig. 35.) a piece of Brown Paper, which had been dipped in a folution of Nitre, and then well dried; I fet fire to the Paper by means of a burning glafs: The Nitre detonized and burnt briskly for fome time, till the glafs $z z a a$ was very full of thick fumes, which extinguifhed it. The expanfion caufed by the burning Nitre, was equal to more than two quarts: When all was cool, there was near

so clus. 
socubick inches of new generated air, which arofe from a fmall quantity of detonized Nitre; but the elafticity of this new air daiIy decreafed, in the fame manner as Mr. Hauksbee obrerved the air of fired Gunpowder to do, Phyfico-mechanical Exper. p.83. Fo that he found I 9 of 20 parts occupied by this air to be deferted in I 8 days, and its fpace filled by the afcending water; at which ftation it refted, continuing there for 8 days without alteration: And in like manner, I found that a confiderable part of the air which was produced by fire in the diftiliation of reveral fubftances, did gradually lore its elafticity in a few days after the difillation was over; but it was not fo when I diftilled air thro' water, as in Expegiment 77. (Fig. 38.)

\section{EXPERIMENT CIII.}

I placed on the fame pedeftal large Matches made of linen rags dipped in melted Brimfone: The capacity of the veffel, (Fig. 35.) above $z z$ the furface of the water, was equal to 2024 cubick inches. The quantity of air which was abforbed by the burning Match was 198 cubick inches, equal to $\frac{1}{10}$ part of the whole air in the veffel.

I made 


\section{Analysis of the Air.

$I$ made the fame Experiment in a leffer veffel $z z a a$, (Fig. 35.) which contained but 594 cubick inches of air, in which 150 cubick inches were abforbed; i.e. full $\frac{x}{4}$ part of the whole air in the receiver: So that tho more air is abforbed by burning Matches in large veffels, where they burn longeft, than in fmall ones, yet more air, in proportion to the bulk of the veffel, is abforbed in fmall than in large veffels: If a freth Match were lighted and put into this infected air, tho' it would not burn $\frac{1}{5}$ part of the time that the former Match burnt in freth untainted air, yet it would abforb near as much air in that fhort time; and it was the fame with Candles.

\section{EXPERIMENT CIV.}

Equal quantities of flings of Iron and Brimftone, when let fall on a hor Iron on the pedeftal under the inverted glars $z \approx a a$, (Fig. 35.) did in burning abforb much air; and it was the fame with Antimony and Brimftone: Whence it is probable, that $V u l$ cano's, whofe fewel confint chiefly of Brimftone, mix'd with feveral mineral and metaline fubftances, do not generate, but ra. ther abforb air.

$$
\text { Q4 We }
$$




\section{Analy/is of the Air.}

We find in the foregoing Experiment $\mathrm{IO}_{2}$ on Nitre, that a great part of the new generated air is in a few days reforbed, or lofes its elafticity: But the air which is abforbed by burning Brimftone, or the flame of a Candle, does not recover its elafticity again, at leaft, not while confined in my glaffes.

\section{EXPERIMENT CV.}

I made feveral attempts to try whether air full of the fumes of burning Brimftone was as compreffible as common frefh air, by compreffing at the fame time tubes full of each of thefe airs in the condenfing engine; and' I found that clear air is very little more compreffible than air with fumes of Brimftone in it: But I could not come to an exact certainty in the matter, becaufe the fumes were at the fame time deftroying the clafticity of the air. I took care to make the air in both tubes of the fame temperarure, by firf immerfing them in cold water, before I compreffed them.

\section{- EXPERIMENT CVI。}

I fet a lighted tallow Candle, which was about $\frac{6}{1}$ of an inch diameter, under the inverted 
verted receiver $z z a a$, (Fig.35.) and with a fyphon I immediately drew the water up to $z z$ : Then drawing out the fyphon, the water would defcend for a quarter of a minute, and after that afcend, notwithftanding the Candle continued burning, and heating the air for near 3 minutes. It was obfervable in this Experiment, that the furface of the water $z z$ did not afcend with an equal progreffion, but would be fometimes ftationary; and it would fometimes move with a flow, and fometimes with an accelerated motion; but the denfer the fumes the fafter it afcended. As foon as the Candle was out, I marked the height of the water above $z z$, which difference was equal to the quantity of air, whofe elaficity was deftroyed by the burning Candle. As the air cooled and condenfed in the receiver, the water would continue rifing above that mark, not only till all was cool, but for 20 or 30 hours after that, which height it kept, tho' it ftood many days; which mews that the air did not recover the elafticity which it had loft.

The event was the fame, when for greater accuracy I repeated this Experiment by lighting the Candle after it wâs placed un- 
der the receiver, by means of a burning-glafs, which fet fire to a fmall piece of brown paper fixed to the wick of a Candle, which paper had been firf dipped in a ftrong folution of Nitre in Water, and when well dried, part of it was dipped in melted Brimsftone; it will alfo light the Candle without being dipped in Brimftone. Dr. Mayow, found the bulk of the air leffened by $\frac{1}{30}$ part, but does not mention the fize of the glafs veffel under which he put the lighted Candle, De Sp. Nitro aereo.p. 10I. The capacity of the veffel above $z z$, in which the Candle burnt in my Experiment, was equal to 2024 cubick inches; and the elafticity of the $\frac{2}{2} \frac{2}{6}$ part of this air was deftroyed.

The Candle cannot be lighted again in this infected air by a burning-glafs : But if I firft lighted it, and then put it into the fame infected air, tho' it was extinguithed in $\frac{x}{5}$ part of the time, that it would burn in the fame veffel, full of frefh air; yet it would deftroy the elafticity of near as much air in that fhort time, as it did in five times that fpace of time in frefh air; this I repeated feveral times, and found the fame event : Hence a grofs air which is loaded with vapours, is more apt in equal times to 


\section{Analyfis of the Air.}

lore its elafticity in greater quantities, than a clear air.

I obferve that where the veffels are equal, and the fize of the Candles unequal, the elafticity of more air will be deftroyed by the large than by the fmall Candle: and where Candles are equal, there moft air in proportion to the bulk of the veffel will be abforbed in the fmalleft veffel: Tho' with equal Candles there is always moft elaftick air deftroyed in the largeft veffel, where the Candle burns longeft.

I found alfo in fermenting liquors, that cateris paribus, more air was either generated or abforbed in large, than in Imall veffels, by generating or abforbing mixtures: As in the mixture of Aqua Regia and Antimony in Experiment 91. by enlarging the bulk of the air in the veffel, a greater quantity of air was abforbed. Thus alfo filings of Iron and Brimftone, which in a more capacious veffel abforbed ig cubick inches of air, abforbed very little when the bulk of air above the ingredients was but 3 or 4 cubick inches: For I have often obferved; that when any quantity of air is faturated with abforbing vapours to a certain degree, then no more elaftick air is abforbed: Not-

withftanding 


\section{Analy is of the Air.}

withftanding the fame quantity of abforbing fubftances would, in a larger quantity of air, have abforbed much more air; and this is the reafon why I was never able to deftroy the whole elafticity of any included bulk of air, whether it was common air, or new generated air.

\section{EXPERIMENT CVII.}

May 18, which was a very hot day, I repeated Dr. Mayow's Experiment, to find how much air is abforbed by the breath of Animals inclofed in glaffes, which he found with a moufe to be $\frac{x}{2} 7$ part of the whole air in the glars veffel, De Sp. Nitro aereo, p. ro4.

I placed on the pedeftal, under the inverred glars $z z a a_{3}$, (Fig. 35. ) a full grown Rat. At firft the water fubfided a little, which was occafioned by the rarifaction of the air, caufed by the heat of the animal's body. But after a few minutes the water began to rife, and continued rifing as long as the Rat lived, which was about I 4 hours. The bulk of the air in which the Rat lived fo many hours was 2024 cubick inches; the quantity of elaftick air which was abforbed was 73 cubick inches, above $\frac{x}{\Rightarrow}$ part 
of the whole, nearly what was abforbed by a Candle in the fame veffel, in Experiment I06.

I placed at the fame time, in the fame manner, another almolt half grown $R a t$ under a veffel, whofe capacity above the furface of the water $z z$, (Fig. 35.) was but 594 cubick inches, in which it lived Io hours; the quantity of elaftick air which was abforbed, was equal to 45 cubick inches, viz. $\frac{z}{T}$ part of the whole air, which the Rat breathed in: A Cat of three months old lived an hour in the fame receiver, and abforbed 16 cubick inches of air, viz. $\frac{\pi}{3} \div$ part of the whole; an allowance being made in this eftimate for the bulk of the Cat's body. A candle in the fame veffel continued burning but one minute, and $a b$. forbed 54 cubick inches, $\frac{T}{T T}$ part of the whole air.

And as in the cafe of burning Brimftone and Candles, more air was found to be abforbed in large veffels than in fmall ones: and vice ver $\int a$, more air in proportion to the capacity of the veflel was abforbed in fmall than in large veffels, fo the fame holds rrue here too in the cafe of animals.

EXPE. 


\section{2,8 Analygs of the Air.}

\section{EXPER I MENT CVIII.}

The following Experiment will Mew; that the elafticity of the air is greatly deftroyed by the refpiration of buman Lungs, viz.

I made a bladder very fupple by wetting of it, and then cut off fo much of the neck as would make a hole wide enough for the biggeft end of a large foffer to enter, to which the bladder was bound faft. The bladder and foffet contained 74 cubick inches. Having blown up the bladder, I put the fmall end of the folfet into $\mathrm{my}$ mouth; and at the fame time pinched my noftrils clofe that no air might pafs that way, fo that I could only breath to and fro the air contained in the bladder. In lefs than half a minute I found a confiderable difficulty in breathing, and was forced after that to fetch my breath very falt; and at the end of the minute, the fuffocating uneafinefs was fo great that I was forced to take away the bladder from my mouth. Towards the end of the minute the bladder was become fo flaccid, that I could not blow it above half full with the greatef expiration that I could make: And at the 


\section{Analy is of the Air.}

fame time I could plainly perceive that my. lungs were much fallen, juft in the fame manner as when we breathe out of them all the air we can at once. Whence it is plain that a confiderable quantity of the elafticity of the air contained in my lungs, and in the bladder, was deftroyed; which fuppofing it to be 20 cubick inches, it will be $\frac{r}{T_{3}}$ : part of the whole air, which I breathed to and fro; for the bladder contained 74 cubick inches, and the lungs, by the following Experiment, about I 66 cubick inches, in all 240.

Thefe effects of refpiration on the elafticity of the air, put me upon making an attempt to meafure the inward furface of the lungs, which by a wonderful artifice are admirably contrived by the Divine Artificer, fo as to make their inward furface to be commenfurate to an expanfe of air many times greater than the animal's body; as will appear from the following eftimate, viz.

\section{EXPERTM N T CIX.}

I took the lungs of a Calf and cut off the heart and wind-pipe an inch above its branching into the lungs; I got nearly the fpecifick 
fpecifick gravity of the fubftance of the lungs, (which is a continuation of the branchings of the wind-pipe, and bloodveffels) by finding the fpecifick gravity of the wind-pipe, which I had cut off; it was to Well-water as r.os to I. And a cubick inch of water weighing 254 grains; I thence found by weighing the lungs the whole of their folid fubftance to be equal to $37+\frac{x}{2}$ cubick inches.

I then filled a large earthen veffel brim full of water, and put the lungs in, which I blew up, keeping them under water with a pewter plate. Then taking the lungs out and letting the plate drop to the bottom of the water, I poured in a known quantity of water, till the veffel was brimful again; that water was 7 pounds 6 ounces and $\frac{\pi}{2}$, equal to 204 cubick inches; from which deducting the fpace occupied by the folid fubftance of the lungs, viz. $37+\frac{\pi}{2}$ cubick inches, there remains $166+\frac{x}{2}$ cubick inches for the cavity of the lungs. But as the Pulmonary Veins, Arteries and Lymphaticks will, when they are in a natural ftate replete with blood and lymph, occupy more fpace than they do in their prefent empty Atate; therefore fome allowance mult alfo be 


\section{Analy is of the Air. 24 I}

be made, out of the above taken cavity of the lungs, for the bulk of thofe fluids; for which $25+\frac{x}{2}$ cubick inches feems to be a fufficient proportion, out of the 166 $t_{\frac{1}{2}}$ cubick inches; fo there remains I4! cubick inches for the cavity of the lungs.

I poured as much water into the Broncbice as they would take in, which was I pound 8 ounces, equal to $4 \mathrm{I}$ cubick inches; this deducted from the above found cavity of the lungs, there remains roo cubick inches for the fum of the cavity of the veficles.

Upon viewing fome of thefe veficles with a microfcope, a middle fized one feems to be about $\frac{r}{10}$ part of an inch diameter; then the fum of the furfaces in a cubick inch of thefe fmall veficles (fuppofing them to be fo many little cubes, for they are not fpherical) will be 600 fquare inches; for if the number of the divifions of the fide of the cubick inch be 100, there will be 100 plancs, containing each one fquare inch, in each dimenfion of the cube, which having three dimenfions, the fum of thore planes will be 300 fquare inches, and the fum of the furfaces of cach fide of thofe planes will be 600 fquare inches; which multiplied

$\mathrm{R}$ 


\section{Analyfis of the Air.}

by the fum of all the veficles in the lungs, viz. 100 cubick inches, will produce 60000 fquare inches; one third of which muft be deducted, to make an allowance for the abfence of two fides in each little veficular cube, that there might be a free communication among them for the air to pafs to and fro; fo there remains 40000 fquar inches for the fum of the furface of all the veficles.

And the Broncbice containing 4I cubick inches, fuppofing them at a medium to be cylinders of $\frac{\mathrm{I}}{\mathrm{T}}$ of an inch diameter, their furface will be 1635 fquare inches, which added to the furface of the veficles makes the fum of the furface of the whole lungs to be 41635 fquare inches, or 289 fquare feet, which is equal to Io times the furface of a man's body, which at a medium is computed to be equal to is fquare feet.

I have not had an opportunity to take in the fame manner the capacity and dimenfions of human lungs; the bulk of which Dr. Fames Keill, in his Tentamina Medicophyfica, p. 8o. found to be equal to $226 \mathrm{cu}$ bick inches. Whence he eftimated the fum of the furface of the veficies to be 21906 fquare inches. But the bulk of human lungs 


\section{Analyjis of the Air. 243}

langs is much more capacious than 226 cu-m bick inches; for Dr. Furin, by an accurate Experiment, found that he breathed our, at one large expiration, 220 cubick inches of air; and I found it nearly the rame; when I repeated the like Experiment in another manner: So that there mut be a large allowance made for the bulk of the remaining air, which could not be expired from the lungs; and alfo for the fubftance of the lungs:

Suppofing then, that according to Dr. Furrin's eftimate (in Moti's Abridgment of the Philosophical Tranfact. Vol. I. p. 4I s.) we draw in at each common infpiration $40 \mathrm{cu}$. bick inches of air; that will be 48000 clibick inches in an hour, at the rate of 20 infpirations in a minute. A confiderable part of the elafticity of which air is, we fee by the foregoing Experiment, conftantly de. Atroyed, and that chiefly among the veficles, where it is charged with much vapour.

But it is not eafy to determine how much is deftroyed. I attempted to find it out by the following Experiment, which I thall here give an account of, tho' it did not fucceed fo well as I could have withed, for want of much larger veffels; for if it was repeated

$$
\text { R } 2
$$

with 


\section{Analy is of the Air.}

with more capacious veffels, it would determine the matter pretty accurately; becaufe by this artifice frefh air is drawn into the lungs at every infpiration, as well as in the free open air.

\section{EXPERIMENT CX.}

I made ufe of the fyphon (Fig. 39.) taking away the bladders, and diaphragms $i i$ $n n 0$ : I fixed by means of a bladder one end of a thort leaden fyphon to the lateral foffet $i i$ : Then I faftened the large fyphon in a veffel, and filled it with water, till it rofe within two inches of $a$, and covered the other open end of the thort fyphon, which was deprefled for that purpofe. Over this orifice I placed a large inverted chymical receiver full of water; and over the 0 ther leg $0 s$ of the great fyphon, I whelmed another large empty receiver, whore capacity was equal to I 224 cubick inches; the mouth of the receiver being immerfed in the water, and gradually let down lower and lower by an afliftant, as the water a. feended in it. Then ftopping my noftrils, 1 drew in breath at $a$, thro the fyphon from the empty receiver: And when that breath was expired, the valve $b$ iftopping its return 


\section{Analyys of the Air.}

down thro the fyphon, it was forced thro the valve $r$, and thence through the fmall leaden fyphon into the inverted receiver full of water, which water defcended as the breath afcended. In this manner I drew all the air, except $s$ or 6 cubick inches, out of the empty receiver at $\theta$, the water at the fame time afcending into it and filling it; by which means all the air in the empty receiver, as alfo all the air in the fyphon os b, was infpired into my lungs, and breathed out thro' the valve $r$ into the receiver, which was at firt full of water. I marked the boundary of air and water, and then immerfed the whole receiver, which had the breath in it, under water, and there gradually poured the contained breath up into the other full receiver, which ftood inverted over $O s$; whereby I could readily find whether the air had loft any of its elafticity: And for greater furety, I alfo meafured the bulk of breath by filling the receiver with a known quantity of water up to the above mentioned mark; making alfo due allowance for a bulk of air, equal to the capacity of the large fyphon os $b$, which was at laft fucked full of water.

$$
\text { R3 The }
$$


246. Analy/is of the Air.

The event was, that there was i 8 cubick inches of air wanting; but as thefe receivers. were much too fmall to make the Experiment with accuracy; that fome allowance may be made for errors, I will fet the lofs of elaftick air at 9 cubick inches, which is but $\frac{x}{3}-5$ part of the whole air refpired, which will amount to 353 cubick inches in one hour, or 100 grains, at the rate of 48000 cubick inches infpired in an hour, or one ounce and a half in 24 hours.

By pouring the like quantity of air to and fro under water, I found that little or none of it was loft; fo it was not abforbed by the water: To make this trial accurately, the air muft be detained fome time under water, to bring it firft to the fame temperature with the water. Care alro mult be taken in making this Experiment, that the lungs be in the fame degree of contraction at the laft breathing, as at the firt, elfe a confiderable error may arife from thence.

But tho' this be not an exact eftimate, yet it is evident from the foregoing Experiments on refpiration, that fome of the elafticity of the air which is infpired is deftroyed; and that chiefly among the veficles, where it is most loaded with vapours; whence probably fome 


\section{Analyfis of the Air.}

fome of it, together with the acid fpirits, with which the air abounds, are conveyed to the blood, which we fee is by an admirable contrivance there fpread into a vaft expanfe, commenfurate to a very large furface of air, from which it is parted by very thin partitions; fo very thin, as thereby probably to admit the blood and air particles (which are there continually changing from an elaftick to a ftrongly attracting ftate) within the reach of each other's attraction, whereby a continued fucceflion of freth air may be abforbed by the blood.

And in the analyfis of the blood, either by fire or fermentation in Exper. 49, and 80, we find good plenty of particles ready to refume the elaftick quality of air: But whether any of thefe air particles enter the blood by the lungs, is not eafy to determine; becaufe there is certainly great ftore of air in the food of animals, whether it be vegetable or animal food. Yet when we confider how much air continually lores its elafticity in the lungs, which feem purpofely framed into innumerable minute meanders, that they may thereby the better feize and bind that volatile Hermes: It makes it very probable, that thofe particles which are R 4 now 
248 Analy is of the Air.

now changed from an elaftick, repulfive, to a ftrongly attracting ftate, may eafily be attracted thro' the thin partition of the veficles, by the fulphureous particles which a: bound in the blood.

And nature feems to make ufe of the like artifices in vegetables, where we find that air is freely drawn in; not only with the principal fund of nourifhment at the root, but alfo thro' feveral parts of the body of the vegetable above ground, which air was feen to afcend in an elaftick ftate moft freely and vifibly thro' the larger trachece of the Vine; and is thence doubtlefs carried with the fap into minuter veffels, where being intimately united with the fulphureous, faline and other particles, it forms the nutritive ductile matter, out of which all the parts of vegetables do grow.

\section{EXPERIMENT CXI.}

It is plain from thefe effeets of the fumes of burning Brimftone, lighted Candle, and the breath of Animals on the elanicity of the air, that its elanticity in the veficles of the lungs muft be continually decreafing, by reafon of the vapours it is there loaded with fo that thore veficles would in a little time 


\section{Analyfis of the Air.}

time fubfide and fall flat, if they were not frequently replenifhed with frefh elaftick air at every infpiration, thro' which the inferior heated vapour and air afcends, and leaves room for the frefh air to defcend into the veficles, where the heat of the lungs make it expand about $\frac{r}{8}$ part; which degree of expanfion of a temperate air, I found by inverting a fmall glafs bubble in water, a little warmer than a Thermometer is, by having its ball held fome time in the mouth, which may reafonably be taken for the des gree of warmth in the cavity of the lungs. When the bubble was cool, the quantity of water imbibed by it was equal to $\frac{7}{8}$ of the cavity of the whole bubble.

But when inftead of thefe frequent recruits of frefh air, there is infpired an air, furcharged with acid fumes and vapours, which not only by their acidity contract the exquifitely fenfible veficles, but alfo by their groffnefs much retard the free ingrefs of the air into the veficles, many of which are exceeding fmall, fo as not to be vifible with. out a microfcope; which fumes are alfo continually rebating the elafticity of that air; then the air in the veficles will, by Ex. per. 107, and 108, lofe its elafticity very 
2 so Analy is of the Air.

falt, and confequently the veficles will fall flat, notwithftanding the endeavours of the extending Thoras to dilate them as ufual; whereby the motion of the blood through the lungs being ftopped, inftant death enfues.

Which fudden and fatal effect of thefe noxious vapours, has hitherto been fuppofed to be wholly owing to the lofs and wafte of the vivifying Jpirit of air; but may not unreafonably be alfo attributed to the lofs of a confiderable part of the air's elafticity, and the groffnefs and denfity of the vapours, which the air is charged with; for mutually attracting particles, when floating in fo thin a medium as the air, will readily coalefce into groffer combinations: 'Which effect of thefe vapours, having not been duly obferved before, it was concluded, that they did not affect the air's elafticity; and that confequently the lungs muft needs be as much dilated in infpiration by this, as by a clear air.

But that the lungs will not rife and dilate as ufual, when they draw in fuch noxious air, which decreafes faft in its elafticity, I was affured by the Experiment I made on my relf, in Exper. 1os. for when towardş, the 


\section{Analy is of the Air. $25 \mathrm{I}$}

the latter end of the minute, the fuffocating quality of the air in the bladder was greateft, it was with much difficulty that I could dilate my lungs a very little.

From this property in the vapours arifing from animal bodies, to rebate and deftroy part of the elafticity of the air, a probable account may be given of what becomes of a redundant quantity of air, which may at any time have gotten into the cavity of the Thorax, either by a wound, or by fome defect in the fubltance of the lungs, or by very violent exercife. Which if it was to continue always in that expanded ftate, would very much incommode refpiration, by hindering the dilatation of the lungs in infpiration. But if the vapours, which do continually arife in the cavity of the Thorax, deftroy fome part of the elarticity of the air, then there will be room for the lungs to heave: And probably, it is in the fame manner that the winds are reforbed, which in their elaftick ftate fly from one part of the body or limbs to another, caufing by their diftention of the veffels much pain. 


\section{Analyfis of the Air.}

\section{EXPERIMENT CXII.}

I have by the following Experiment found, that the air will pafs here and there thro' the fubftance of the lungs, with a very fmall force, viz.

I cut afunder the bodies of feveral young and fmall animals juft below the Diaphragm, and then taking care not to cut any veffel belonging to the lungs, I laid the Thorax open by taking away the Diaphragm, and fo much of the ribs, as was needful to expore the lungs to full view, when blown up. And having cut off the head, I faftned the windpipe to a very fhort inverted leg of a glafs fyphon; and then placed the inverted lungs and fyphon in a large and deep glafs veffel $x$ full of water, (Fig. 32 .) under the air pump receiver $p p$, and paffing the longer leg of the fyphon thro' the top of the receiver, where it was cemented faft at $z$, as I drew the air out of the receiver, the lungs dilated, having a free communication with the outward air, by means of the glafs fyphon; fome of which air woutd here and there pals in a few places thro the fubftance of the lungs, and rife in fmall itreams thro the water, when the receiver 


\section{Analyfis of the Air. 253}

was exhauted no more than to make the Mercury in the gage rife lefs than 2 inches. When I exhaufted the receiver, fo as to raife the Mercury 7 or 8 inches, though it made the air rufh with much more violence thro' thofe frall apertures in the furface of the lungs, yet I did not perceive that the number of thofe apertures was increafed, or at leaft very little. An argument that thofe apertures were not forcibly made by exhaufting the receiver lefs than two inches, but were originally in the live animal; and that the lungs of living animals are fometimes raifed with the like force, efpecially in violent exercife, I found by the follow: ing Experiment, viz.

\section{EXPERTMENT CXIII.}

I tied down a live $\mathcal{D o g}$ on his back; near the edge of a table, and then made a fmall hole thro' the intercoftal mufcles into his Thorax, near the Diapbragm. 'I cemented faft into this hole the incurvated end of a glals tube, whofe orifice was covered with a little cap full of holes, that the dilatation of the lungs might not at once ftop the orifice of the tube. A fmall vial full of fpirit of Wine was ticd to the 


\section{Analyfis of the Air.}

bottom of the perpendicular tube, by which means the tube and vial could eafily yield to the motion of the Dog's body; without danger of breaking the tube, which was 36 inches long. The event was, that in ordinary infpirations, the fpirit rofe about fix inches in the tube; but in great and laborious infpirations, it would rife 24 and 30 inches, viz. when I ftopped the Dog's nof trils and mouth, fo that he could not breathe: This Experiment Thews the force with which the lungs are raifed by the dilatation of the Thorax, either in ordinary or extraordinary and laborious infpirations. When I blew air with fome force into the Thorax, the Dog was juft ready to expire.

By means of another thort tube, which had a communication with that which was fixed to the Thorax, near its infertion into the Thorax, I could draw the air out of the Thorax, the height of the Mercury, inftead of fpirit in the tube, thewing to what degree the Thorax was exhaufted of air: The Mercury was hereby raifed nine inches, which would gradually fubfide as the air got into the Thorax thro' the lungs.

I then laid bare the windpipe, and having cut it off a little below the Larynx, I 


\section{Analysis of the Air.

affixed to it a bladder full of air, and then continued fucking air out of the Thorax, with a force fufficient to keep the lungs pretty much dilated. As the Mercury fubfided in the gage, I repeated the fuction for a quarter of an hour, till a good part of the air in the bladder was either drawn thro" the fubftance of the lungs into the Thorax, or had loft its elafticity. When I preffed the bladder, the Mercury fubfided the fafter; the Dog was all the while alive, and would probably have lived much longer, if the Experiment had been continued; as is likely from the following Experiment, viz.

\section{EXPERIMENT CXIV.}

I tied a middle-fized Dog down alive on a table, and having laid bare his wind-pipe, I cut it afunder juft below the Larynx, and fixed faft to it the fmall end of a common folfet; the other end of the foffet had a large bladder tied to it, which contained 162 cubick inches; and to the other end of the bladder was tied the great end of anorher foffet, whofe orifice was covered with a valve, which opened inward, fo as to ad. mit any air that was blown into the bladder, but none could return that way; yee 
256 Analy is of the Air.

for further fecurity, that paffage was alfo flopped with a fpiggot.

As foon as the firft forfet was tied faft to the wind pipe, the bladder was blown full of air thro' the other foffet; when the Dog had breathed the air in the bladder to and fro for a minute or two, he then breathed very faft, and thewed great uneafinefs, as being almoft fuffocated.

Then with my hand I preffed the bladder hard, fo as to drive the air into his lungs with fome force; and thereby make his $A b$. domen rife by the preflure of the Diaphragm, as in natural breathings: Then taking alter. nately my hand off the bladder, the lungs with the Abdomen fubfided; I continued in this manner to make the Dog breathe for an hour; during which time I was obliged to blow freth air into the bladder every five minutes, three parts in four of that air being either abforbed by the vapours of the lungs, or efcaping thro the ligatures, upon my preffing hard on the bladder.

During this hour, the Dog was frequently near expiring, whenever I preffed the air but weakly into his lungs; as I found by his pulfe, which was very plain to be felt in the great crural artery near the groin, 


\section{Analyfis of the Air. 257}

which place an affittant held his finger on moft part of the time; but the languid pulfe was quickly accelerated, fo as to beat faft; foon after I dilated the lungs much, by preffing hard upon the bladder, efpecially when the motion of the lungs was promoted by preffing alternately the Abdomen and the bladder, whereby both the contraction and dilatation of the lungs was increafed.

And I could by this means roufe the languid gulfe whenever I pleafed, not only at the end of every s minutes, when more air was blown into the bladder from a man's lungs, but alfo towards the end of the s minutes, when the air was fulleft of fumes.

At the end of the hour, I intended to try whether I could by the fame means have kept the Dog alive fome time longer, when the bladder was filled with the fumes of burning Brimftone: But being obliged to ceafe for a little time from preffing the air into his lungs, while matters were preparing for this additional Experiment, in the mean time the Dog died, which might otherwire have lived longer, if I had continued to force the air into his lungs.

Now, tho' this Experiment was fo frequently difurbed, by being obliged to blow 


\section{Analyfis of the Air.}

more air into the bladder twelve times during the hour; yet fince he was almoft fuffocated in lefs than two minutes, by breathing of himfelf to and fro the firft air in the bladder, he would by Experiment 106. on Candles, have died in lefs than two minutes, when one fourth of the old air remained in the bladder, immediately to taint the new admitted air from a man's lungs; fo that his continuing to live thro' the whole hour, muft be owing to the forcible dilatation of the lungs, by compreffing the bladder, and not to the vivifying spirit of air. For without that forcible dilatation, he had, after the firn $s$ or 10 minutes, been certainly dead in lers than a minute, when his pulfe was fo very low and weak, which I did not find to be revived barely by blowing 3 parts in 4 of new air from the lungs of a man into the bladder: But it was conftantly roufed and quickned, whenever I increafed the dilatations of the lungs, by comprefling the bladder more vigorouny; and that whether it was at the beginning or end of each $s$ minutes, yet it was more eafily quickned, when the bladder was at any time newly filled, than when it was near empty. 


\section{Analy is of the Air. 259}

From the re violent and fatal effects of very noxious vapours on the refpiration and life of animals, we may fee how the refpiration is proportionably incommoded, when the air is loaded with leffer degrees of vapours, which vapours do in fome meafure clog and lower the air's elafticity; which it beft regains by having thefe vapours difpelled by the ventilating motion of the free open air, which is rendered wholefome by the agitation of winds: Thus what we call a clofe warm air, fuch as has been long confined in a room, without having the vapours in it carried off by communicating with the open air, is apt to give us more or lefs uneafinefs, in proportion to the quantity of vapours which are floating in it. For which reafon the German ftoves, which heat the air in a room without a free admittance of freth air to carry off the vapours that are raifed, as alfo the modern invention to convey heated air into rooms thro' hot flues, feem not fo well contrived, to favour a free refpiration, as our common method of fires in open chimneys, which fires are continually carrying a large ftream of heated air out of the rooms up the chimney, which fteam muft neceffarily be fup-

$$
S 2
$$

plied 


\section{Analy is of the Air.}

plied with equal quantities of freth air, thro' the doors and windows, or the cranies of them.

And thus many of thofe who have weak lungs, but can breathe well enough in the frefh country air, are greatly incommoded in their breathing, when they come into large cities where the air is full of fuliginous vapours, arifing from innumerable coal fires, and ftenches from filthy lay-ftalls and fewers : And even the mort robut and healthy in changing from a city to a country air, find an exhilarating pleafure, arifing from a more free and kindly infpiration, whereby the lungs being lefs loaded with condenfing air and vapours, and thereby the veficles more dilated, with a clearer and more elaftick air, a freer courfe is thereby given to the blood, and probably a purer air mixed with it; and this is one realon why in the country a ferene dry conftitution of the air is more exhilarating than a moift thick air.

And for the fame reafon, 'tis no wonder, that peftilential, and other noxious epidemical infections are conveyed by the breath to the blood (when we confider what great quantities of the airy vehicle lofes its elafticity among the veficles, whereby the 


\section{Analyfis of the Air. $26 \mathrm{I}$}

infectious Miafma is lodged in the lungs.

When I reflect on the great quantities of elaftick air, which are deftroyed by fulphureous fumes; it feems to me not improbable, that when an animal is killed by lightning without any vifible wound, or immediate ftroke, that it may be done by the air's elafticity, being inftantly deftroyed by the fulphureous lightning near the animal, whereby the lungs will fall flat, and caufe fudden death; which is further confirmed by the flatners of the lungs of animals thus killed by lightning, their veficles being found upon diffection to be fallen flat, and to have no air in them: The burfting alfo of glafs windows outwards, feems to be from the fame effect of lightning on the air's elafticity.

It is likewife by deftroying the air's elafticity in fermented liquors, that lightning renders them flat and vapid: For fince fulphureous fteams held near or under veffels will check redundant fermentation, as well as the putting of fulphureous mixtures into the liquor, 'tis plain, thofe fteams can eafily penetrate the wood of the containing veffels. No wonder then, that the more fubtile lightning thould have the like effeets. I

$$
\mathrm{S}_{3} \text { know }
$$




\section{Analy is of the Air.}

know not whether the common practice of laying a bar of iron on a veffel, be a good prefervative againft the ill effects of lightning on liquors. I fhould think that the covering a veffel with a large cloth dipped in a ftrong brine, would be a better prefervative; for falts are known to be ftrong attracters of fulphur.

The certain death which comes on the explofion of Mines, feems to be effected in the fame manner: For tho at firft there is a great expanfion of the air, which muft dilate the lungs, yet that air is no fooner filled with fuliginous vapours, but a good deal of its elafticity is immediately deftroy'd : As in the cafe of burning Matches in Experiment 103 . the heat of the flame at firft expanded the air; but notwithftanding the flame continued burning, it immediately contracted, and loft much of its elafticity, as foon as fome quantity of fulphureous iteams afcended in it.

Which fteams have doubtlefs the fame effect on the air, in the lungs of animals held over them; as in the Grotto di cani, or when a clofe room is filled with them, where they certainly fuffocate. 


\section{Analyfis of the Air. $\quad 2 \sigma_{3}$}

It is found by Experiments 103, 106, and 107, that an air greatly charged with vapours lofes much of its elafticity, which is the reafon why fubterraneous damps fuffocate Animals, and extinguifh the flame of Candles. And by Experiment 106, we fee that the fooner a Candle goes out, the fafter the air lofes its elafticity.

\section{EXPERIMENT CXV.}

This put me upon attempting to find fome means to qualify and rebate the deadly noxious quality of thefe vapours: And in order to it, I put thro' the hole, in the top of the air pump receiver, (Fig. 32.) which contained two quarts, one leg of an iron fyphon made of a gun-barrel, which reached near to the bottom of the receiver: It was cemented faft at $z$, I tied three folds of woollen cloth over the orifice of the fyphon, which was in the receiver. The Candle went out in lefs than two minutes, tho' I continued pumping all the while, and the air paffed fo frecly thro' the folds of cloth into the receiver, that, the Mercury in the gage did not rife above an inch.

When I put the other end of the fyphon into a hot iron pot, with burning Brimftone

$$
S_{4}
$$


264 Analy/is of the Air.

in it; upon pumping, the Candle went out in Is feconds of a minute; but when I took away the 3 folds of cloth, and drew the fulphurcous fteams thro' the open fyphon, the light of the Candle was inftantly extinguifhed; whence we fee the 3 folds of cloth preferved the Candle alight is". And where the deadly quality of vapours in Mines is not fo ftrong as thefe fulphureous ones were, the drawing the breath thro' many folds of woollen cloth may be a means to preferve life a little longer, in proportion to the more or lefs noxious quality of the damps.

When, inftead of the 3 folds of cloth, I immerfed the end of the fyphon 3 inches deep in water in the veffel $x$, (Fig. 32.) tho' upon pumping the fulphureous fumes did afcend vifibly through the water, yet the Candle continued burning half a minute, i. e. double the time that it did when fumes paffcd thro' folds of woollen cloth.

\section{EXPERIMENT CXVI.}

$I$ bored a hole in the fide of a large wooden foliet $a b$, (Fig. 39.) and glewed into it the great end of another foffet $i i$, covering the orifice with a bladder valve $r$ : Then I fit ted a valve $b i$, to the orifice of the iron

fyphon 


\section{Analy is of the Air. 265}

fyphon $\iint$, fixing the end of the fyphon faft at $b$ into the forfet $a b$ : Then by means of narrow hoops I placed four Diaphragms of flannel at half an inch diftance from each other, into the broad rim of a fieve, which was about 7 inches diameter. The fieve was fixed to, and had a free communication with both orifices of the fyphon, by means of two large bladders $i$ i $n n o$.

Linen would probably be more proper to make thefe Diaphragms of than Flannel, becaufe oil or greafe is ufed in the making of Flannel: And as I have heard, it is whitened by the fumes of burning Brimftone; which I was not aware of, when I made ufe of Flannel in thefe Experiments.

The inftrument being thus prepared, pinching my noftrils clofe, when I drew in breath with my mouth at $a$, the valve $i b$ being thereby lifted up, the air paffed freely through the fyphon from the bladders, which then fubfided, and thrunk confiderably: But when I breathed air out of my lungs, then the valve ib clofing the orifice of the fyphon, the air paffed thro' the valve $r$ into the bladders, and thereby dilated them; by which artifice the air which Iexpired munt necelfarily pafs thro' all the Dia- 


\section{Analy is of the Air.}

phragms, before it could be infpired into my lungs again. The whole capacity of the bladders and fyphon was 4 or 5 quarts.

Common fea-falt, and SalTartar, being ftrong imbibers of fulphureous fteams, I dipped the four Diaphragms in ftrong folutions of thofe falts, as alfo in white wine vinegar, which is looked upon as a good anti-peftilential: Taking care after each of thefe Experiments to cleanfe the fy phon and bladder well from the foul air, by filling them with water.

I could breathe too and fro the air inclofed in this inftrument for a minute and half, when there. were no Diaphragms in it; when the 4 Diaphragms were dipped in vinegar, 3 minutes; when dipped in a ftrong folution of fea-falt, 3 minutes and an half. In a Lixivium of Sal Tartar, 3 minutes; when the Diapbragms were dipped in the like Lixivium, and then well dried, 5 minutes; and once $8+\frac{r}{2}$ minutes, with very highly calcined Sal Tartar; but whether this was owing to the Tartar's being greatly calcined, whereby it might more ftrongly attract fulphureous grofs vapours, or whether it was owing to the bladder and fyphon's being entirely dry, or whether it was 


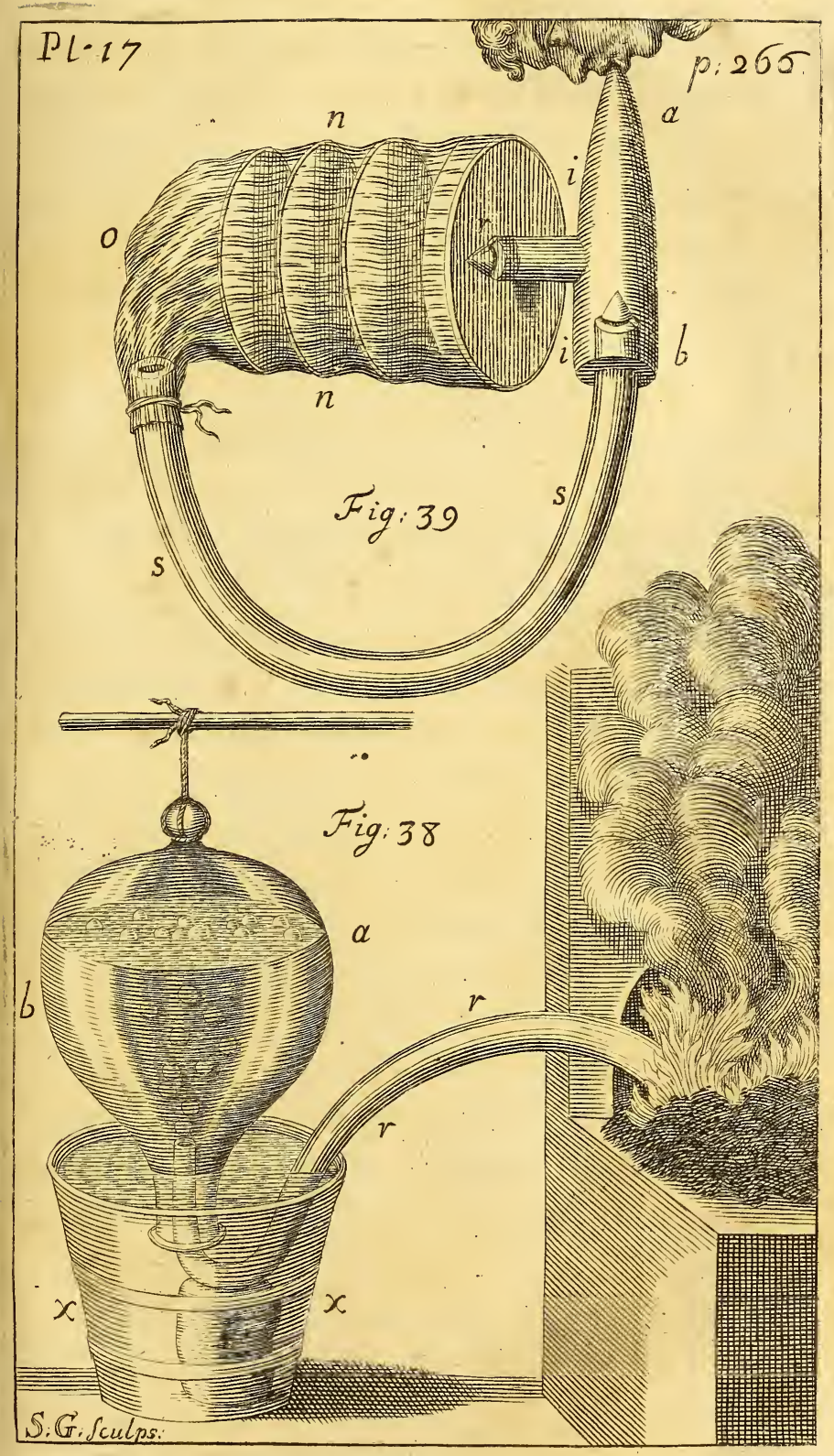





\section{Analy is of the Air.}

occafioned by fome unheeded paffage for the air thro' the ligatures, I am uncertain; neither did I care to afcertain the matter by repeated Experiments, fearing I might thereby fome way injure my lungs, by frequently breathing in fuch grofs vapours.

Hence Sal Tartar fhould be the beft prefervative againft noxious vapours, as being a very ftrong imbiber of fulphureous, acid and watry vapours, as is fea-falt alfo: For having carefully weighed the ${ }_{4}$ Diaphragms, before I fix'd them in the inftrument, I found that they had increafed in weight 30 grains in 5 minutes; and it was the rame in two different trials; fo they increafed in weight at the rate of 19 ounces in 24 hours. From which deducting $\frac{x}{6}$ part for the quantity of moifture, which I found thofe Diaphragms attracted in $s$ minutes in the open air ; there remains is $+\frac{2}{3}$ ounces, for the weight of the moifture from the breath in 24 hours: But this is probably too great an allowance, confidering that the Diaphragms might attract more than $\frac{x}{6}$ part from the moifture of the bladders and of the $\mathrm{fy}$ phon.

I have found that when the Diaphragms had fome fmall degree of dampnefs, they increafed 


\section{Analy is of the Air.}

increafed in weight fix grains in 3 minures; but they made no increafe in weight in the fame time, when in the open air: which fix grains in 3 minutes, is at the rate of about $6+\frac{r}{2}$ ounces in 24 hours; and this is nearly the fame proportion of moifture that I obtained by breathing into a large receiver full of fpunges. But the 6 grains imbibed by the four Diaphragms in $3 \mathrm{mi}$ nutes, was not near all the vapours which were in that bulk of inclofed air; for at the end of the 3 minutes, the often refpired air was fo loaded with vapours, which in that floating ftate were eafily, by their mutual attraction, formed into combinations of particles, too grols to enter the minute veficlés of the lungs, and was therefore unfit for refpiration: fo that it is not eafy to determine what proportion is carried off by refpiration, efpecially confidering that fome of the infpired air, which has loft its elafticity in the lungs, is mingled with it. But fuppofing $6+\frac{\pi}{2}$ ounces to be the quantity of moifture carried off by refpiration in 24 hours, then the furface of the lungs being found as above 41635 fquare inches only $\frac{x}{575 T}$ part of an inch depth, will be evaporated off their inward furface in that time, 


\section{Analy is of the Air. $\quad 269$}

time, which is but $\frac{x}{75}$ part of the depth of what is perfpired off the furface of a man's body in that time.

If then life can by this means be fupported for $s$ minutes with \& Diaphragms and a gallon of air, then doubtlefs, with double that quantity of air and 8 Diaphragms we might well expect to live at leaft ro minutes. It was a confiderable difadvantage that I was obliged to make ufe of bladders, which had been often wetted and dried, fo that the unfavoury fumes from them mult needs have contributed much to the unfitting the included air for refpiration: Yet there is a neceffity for making ufe of either bladder or leather in thefe cafes; for we cannot brearhe to and fro the air of a veflel, whofe fides will not dilate and contract in conformity with the expirations and infpirations, unlefs the veffel be very large, and too big to be conveniently portable.

Having ftopped up the wide fucking orifice of a large pair of kitchen bellows, they being firit dilated, I could breathe too and fro at their nofe, the air contained in them for more than 3 minutes, without much inconvenience, they heaving and falling very eafily by the aqtion of refpiration. Some fuch 


\section{Analy is of the Air.}

like inftrument might be of ufe in any cafe where a room was filled with fuffocating vapours, where it might be neceffary to enter for a few minutes, in order to remove the caufe of them, or to fetch any perfon or thing out; as in the cafe when houfes are firft beginning to fire, in the chymifts elaboratories; and in many other cafes where places were filled with noxious deadly vapours, as in the cafe of ftink-pots thrown into fhips, in mines, \& $c$. And might it not alfo be ferviceable to Divers?

But in every apparatus of this kind great care muft always be taken, that the infpiration be as free as poffible, by making large paffages and valves to play moft eafily. . For tho' a man by a peculiar action of his mouth and tongue may fuck Mercury 22 inches, and fome men 27 or 28 high; yet I have found by experience, that by the bare infpiring action of the Diaphragm, and dilating Thorax, I could fcarcely raife the Mercury 2 inches. At which time the Diaphragm muft act with a force equal to the weight of a Cylinder of Mercury, whofe bafe is commenfurate to the area of the Diaphragm, and its height 2 inches, whereby the Diaphragm muft at that time fuftain a 
weight equal to many pounds. Neither are its counter-acting mufcles, thofe of the $A b$ domen, able to exert a greater force.

For notwithftanding a man, by ftrongly comprefling a quantity of air included in his mouth, may raife a column of Mercury in an inverted fyphon, to 5 or 7 inches height, yet he cannot with his utmoft ftrainings raife it above 2 inches, by the contracting force of the mufcles of the Abdomen; whence we fee that our loudeft vociferations are made with a force of air no greater than this. So that any fmall impediment in breathing will haften the fuffocation, which confits chiefly in the falling flat of the lungs, occafioned by the groffnefs of the particles of a thick noxious air, they being in that floating ftate moft eafily attracted by each other: As we find in the foregoing experiments that fulphur and the elaftick repelling particles of air do: And confequently unelaftick, fulphureous, faline and other floating particles will moft eafily coalefce, whereby they are rendred too grofs to enter the minute veficles; which are alfo much contracted, as well by the lofs of the elafticity of the contained air, as by the contraction occafioned by the ftimulating, acid, fulphu- 
fulphureous vapours. And 'tis not impro. bable that one great defign of nature, in the ftructure of this important and wonderful vifcus was to frame its veficles fo very minute, thereby effectually to hinder the ingrefs of grofs feculent particles, which might be injurious to the animal oeconomy.

This quality of falts ftrongly to attract fulphureous, acid and other noxious particles, might make them very beneficial to mankind in many other refpects. Thus in reveral unwholefome trades, as the fmelters of metals, the ceruis-makers, the plumbers, orc. it might not unlikely be of good fervice to them in preferving them in fome meafure at leaft, from the noxious fumes of the materials they deal in, which by many of the foregoing experiments we are affured muft needs coalefce with the elaftick air in the lungs, and be lodged there; to prevent which inconvenience the workmen might, while they are at work, make ufe of pretty broad mufflers, filled with 2, 4, or more Diaphragms of flannel or cloth dipped in a folution of Sal Tartar or Pot-ajh, or Sea Salt and then dried.

The like mufflers might alfo be of fervice in many cafes where perfons may have urgent

occafion 


\section{Analy is of the Air.}

occafion to go for a thort time into an in. fectious air: Which mufflers might, by an eafy contrivance, be fo made as to draw in breath thro' the Diaphragms, and to breathe it out by another vent.

In there and the like cafes this kind of mufflers may be very ferviceable; but in the cafe of the damps of mines they are by no means to be depended on, becaufe they are not a fufficient fcreen from fo very noxious vapours.

\section{EXPERIMENT CXVII.}

We have from the following Experiment a good hint, to make thefe Salts of fervice to us in fome orher refpects, $b c$.

I fet a lighted Candle under a large recciver (Fig. 35.) which contained about 4 gallons, it continued burning for $3+\frac{1}{2}$ minutes, in which time it had abforbed about a quart of air. I then filled the receiver with frefh air, by pouring it full of water, and then emptying of it; when having wiped it dry, I lined all the infide with a piece of flannel dipped in a lixivium of Sal Tartar, and then dryed; the flannel was extended with little hoops made of pliant twigs. The Candle continued burning under the recei- 
274 Analyfis of the Air.

ver thus prepared $3+\frac{s}{2}$ minutes, yet it abforbed but two thirds of the quantity of air which it abforbed when there was no flannel in the receiver.

The reafon of which difference in the quantities of elaftick air abforbed, appears from Experiment 106. where leaft air was always abforbed in leaft receivers, which was the prefent cafe: For the flannel lining, befides the fpace it took up, could not be fo clofely adapted, but that there was left a full third of the capacity of the receiver, between the lining and the receiver: So that the Candle burnt in a bulk of air lefs by one third than the whole capacity of the receiver; for which reafon lefs air alfo was abforbed.

And we may further obferve, that fince the Candle continued burning as long in a quantity of air, equal but to two thirds of the receiver, as in the whole air of the receiver; this muft be owing to the Sal Tartar in the flannel lining, which mutt needs have abforbed one third of the fuliginous vapours, which arofe from the burning candle. Hence we may not unreafonably conclude, that the pernicious quality of noxious vapours in the air might, in many cafes, be much rebated and qualified by the ftrongly abforbing power of Salts.

Whether 


\section{Analy is of the Air.}

Whether Salts will have a good effect in all, or any of thefe cafes, experience will beft inform us. There is certainly fufficient ground, from many of the foregoing Experiments, to encourage us to make the tryal, and they may at leaft be hints for further improvements.

We fee that Candles and burning Brim: ftone do in a much greater degree deftroy the elafticity of the air, than the breath of Animals; becaufe their vapours are more plentiful, and abound more with acid fulphureous particles, and are alfo lefs diluted with watry vapours, than the breath of Animals is: In which alfo there are fulphureous particles, tho' in leffer degrees; for the animal fluids, as well as folids, are ftored with them: And therefore the Candle andMatches ceafing to burn, foon after they are confined in a fmall quantity of air, feems not to be owing to their having rendred that air effete, by having confumed its vivifying Jpirit; but fnould rather be owing to the great quantity of acid fuliginous vapours, with which that air is charged, which deftroy a good deal of its elafticity, and very much clog and retard she elaftick motion of the remainder.

$$
\text { I } 2 \text { And }
$$




\section{Analy is of the Air.}

And the effect the half exhauting of a receiver has upon the elafticity of the remaining half of the air, feems to be the reafon why the flame of a Candle does not continue burning, till it has filled the receiver it ftands in with fumes, but goes out the quicker, the fooner the air is drawn out to that degree; which feems therefore to be owing to this, that an air rarified to double its fpace, will not expand fo briskly with the warmth of flame, as a more condenfed air will do: And confequently action and re-action being reciprocal, will not give fo brisk a motion to the flame, which fubfints by a conftant fucceflion of frefh air, to fupply the place of the either abforbed, or much dilated air, which is continually flying off. And the quicker the fucceflion of this frefh air is, by blowing, the more vigoroufly does a fire burn.

If the continuance of the burning of the Candle be wholly owing to the vivifying fpirit, then fuppofing in the cafe of a receiver, capacious enough for a Candle to burn a minute in it, that half the vivifying spirit be drawn out with half the air; in ten feconds of time; then the Candle fhould not go out at the end of thofe Io feconds, but burn 


\section{Analy is of the Air.}

burn 20 feconds more, which it does not; therefore the burning of the Candle is not wholly owing to the vivifying spirit, but to certain degrees of the air's elanticity. When a wholly exhaufted receiver was by means of a burning glafs firft filled with the fumes of brown paper with Nitre, and then filled with frefh air, the nitrous paper upon applying the burning glafs did freely detonize; and a Candle put into a like air, burnt for $28^{\prime \prime}$; which in a frefh air, in the fame receiver, burnt but $43^{\prime \prime}$; but when the fame receiver with air in it, was filled full of fumes of detonized Nitre, and a Candle placed in that thick vapour, it went out inftantly, for a Candle will not burn, nor the Nitre detonize in a very rare, nor a very thick air; whence the reafon why the Nitre detonized, and the Candle burnt, when placed in the receiver, after freth air was let in upon the fumes which were made in vacuo, was that thofe fumes were much difperfed and condenfed on the fides of the glafs, upon the ruthing in of the frefh air, for the fumes were then much more rare and tranfparent, than before the air was let in. 


\section{Analy/is of the Air.}

That a Fire which is fupplied with a hot air will not burn fo briskly as a Fire which is fed by a cool air is evident from hence; that when the Sun thines on a Fire, and thereby too much rarifies the ambient air, that Fire will not bnrn well, nor will a fmall Fire burn fo well near a large one as at fome diftance from it. And e contra, it is a common obfervation, that in very cold frofty weather, Fires burn moft briskly; the reafon of which feems to be this, that the elaftick expanfion of the cold condenfed air to a rarified ftate, when it enters the Fire, is much brisiker than that of an air already rarified in a good meafure by heat, before it enters the Fire; and confequently a continued fucceffion of cold air mult give a brisker motion to the Fire, than the like fucceffion of hot air: And fuch colder and more condenfed air will alfo (as Sir I faac Newton obferves qu. II.) by its greater weight check the afcent of the vapours and exhalations of the Fire, more than a warmer lighter air. So that between the action and re-action of the air and fulphur of the fuel, and of the colder and denfer circumambient air, which rarifies much upon entring the Fire, the heat of the Fire is greatly increafed.

This 


\section{Analygs of the Air.}

This continual fupply of frefh air to the fuel feems hence alfo very neceffary for keeping a Fire alive; becaufe it is found, that a Brimftone Match will not take Fire in a vacuum, but only boil and fmoke; nor will Nitre incorporated into Brown Paper then detonize, except here and there a fingle grain, that part only of the Paper turning black on which the focus of the burning glafs falls; nor would they burn when a half exhaufted receiver with fumes in it was filled with frefh air added to thofe fumes: In which cafe it is plain, that a good quantity of the fuppofed vivifying fpirit of air muft enter the receiver with the frefh air, and confequently thofe fubftances fhould take fire, and burn for a fhort time at leaft, which yet they did not.

And that the air's elafticity conduces much to the intenfe burning of Fires, feems evident from hence; that Spirit of Nitre (which by Experiment 75 his but little elaftick air. in it) when poured upon live Coals, extinguifhes inftead of invigorating them: But Spirit of Nitre, when by being mixt with Sal Tartar it is reduced to Nitre, will then flame, when thrown into the Fire, viz. becaufe Sal Tartar abounds with claftick acrea!

$$
\text { T } 4 \text { par }
$$


280 Analy is of the Air.

particles, as appears by Experiment 74, where 224 times its bulk of air arofe from a quantity of $S a l T$ artar And for the fame reafon it is that common Nitre, when thrown into the Fire, flames, tho' its Spirit will not, viz. becaufe there is much elaftick air in it, as appears from Experiment 72 , as well as from the great quantity of it, gencrated in the firing of Gun-poweder.

The reafon why $S_{a}$ T Tartar, when thrown on live Coals, does not detonize and flame like Nitrè, (notwithftanding by Experiment 74 plenty of claftick particles did arife from it) is this, viz, becaufe by the fame Experiment, compared with Experiment 72, it is found, that a much more intenfe degree of heat was required to extricate the elaftick. air from Sal Tartar, the more fix'd body than from Nitre; the great degree of Fire with which Sal Tartar is made, rendering the cohefion of its parts more firm: For it is well known that fire; inftead of difuniting, does in many cafes infeparably unite the parts of bodies: And hence it is that Pulvis Fulminans, which is a mixture of SalTartar, Nitre and fulphur, gives a greater explofion than Gunpoweder: Becaufe the particles of whe Sal Iartar, cohering more firmly in a fix'd 


\section{Analyfis of the Air. $\quad 28 \mathrm{I}$}

fix'd fate than thofe of Nitre, they are there. fore thrown off with a greater repulfive force, by the united action and re-action of all thofe ingredients armed each with its acid Spirit.

\section{EXPERIMENT CXVIII。}

Which acid Spirits confifting of a volatile acid Sali diluted in phlegm do contribute much to the force of explofion; for when heated to a certain degree, they make a great explofion, like water heated to the fame degree, as I found by dropping a few drops of Spirit of Nitre, oil of Vitriol, water, and fpittle on an Anvil; and then holding over thole drops a piece of Iron which had a white heat given it; upon ftriking down the hot Iron with a large Hammer, there was a very great explofion made by each of thofe liquors: But frothy fpittle, which had air in it, made a louder explofion than water; which thews that the valt explofion of the Nitre and Sal Tartar, which are compored of elantick air particles, included in an acid Spirit, is owing to their united force.

We may therefore from what has been faid, with good reafon conclude, that Fire is chiefly invigorated by the action and re-ac-

tion 
282 Analy is of the Air.

tion of the acid fulphureous particles of the fuel, and the elaftick ones which arife and enter the Fire, either from the fuel in which they abound, or from the circumambient air: For by Experiment 103, and many others, acid fulphureous particles act vigorouny on air; and fince action and re-action are reciprocal, fo mult air on fulphur; and there is we fee, plenty of both, as well in mineral as vegetable fuel, as alfo in animal fubftances, for which reafon they will burn.

But when the acid fulphur, which we fee acts vigoroufly on air, is taken out of any fuel, the remaining Salt, Water and Earth are not inflammable, but on the contrary quench and retard fire; and, as air cannot produce fire without fulphur, fo neither can fulphur burn without air: Thus Charcoal heated to an intenfe degree for many hours in a clofe veffel will not burn as in the open air, it will only be red hot all the time like a mals of Gold without wafting: But no fooner is it expofed to the free air, but the fulphur, by the violent action and re-action between that and the elaftick air, is foon feparated and carrice off from the Salt and Earth, which are thereby reduced from a folid and hard to a foft impalpable calx. 


\section{Analy is of the Air.}

And when a Brimftone Match which was placed in an exhaufted receiver was heated by the focus of a burning glafs fo as to melt the Brimftone, yet it did not kindle into fire nor confume, notwithftanding the ftrength and vigour of the action and re-action that is obferved between light and fulphureous bodies. Which is affigned by the illuftrious Sir Ifaac Newton, as " one reafon " why fulphureous bodies take fire more " readily, and burn more vehemently than " other bodies do, qu. 7." What his notion of fire and flame is, he gives us in qu. 9. and 10. Qu. 9" "Is not fire a body heated " fo hot as to emit light copiouny? For " what clfe is a red hot Iron than fire? And " what elfe is a burning Coal, than red hot "Wood? Qu. IO. Is not flame a vapour, " fume or exhalation heated red hor, that is "fo hot as to flame? For bodies do not flame "without emitting a copious fume, and " this fume burns in the flame. - Some " bodies heated by motion or fermentation, "if the heat grow intenfe, fume copiounly, " and if the heat be great enough, the fumes "s will thine and become flame: Metals in "fufion do not flame for want of a copious "fume, except fpelter which fumes copiounly, 
284 Analyjis of the Air.

" and thereby flames: All flaming bodies; "as Oil, Tallow, Wax, Wood, foffil Coals,

"Pitch, Sulphur, by flaming wafte and vanifh "into burning fmoak; which fmoak, if the "flame be put out, is very thick and vifible, " and fometimes fmells ftrongly, but in c. fiame lofes its fmell by burning; and ac" cording to the nature of the fmoak the " fhame is of feveral colours, as that of "fulphur, blue; that of copper opened with " fublimate, green; that of tallow, yellow; " that of camphire, white; fmoak paffing " thro" flame cannot but grow red hot, and " red hot fmoak can have no other appea" rance than that of flame."

But Mr. Lemery the younger fays, "that " the matter of light produces fulphur, be" ing mixt with compofitions of falt, earth " and water, and that all inflammable mat"ters are fuch only in vertue of the par"ticles of fire which they contain. For in " the Analyfis, fuch inflammable bodies " produce falt, earth, water, and a certain " fubtle matter, which paffes thro" the clofeft "veffels, fo that what pains foever the ar"tift ufes, not to lofe any thing, he fill "finds a confiderable diminution of weight. 


\section{Analyfis of the Air. 285}

"Now thefe principles of falt, earth and "water are inactive bodies, and of no ufe, " in the compofition of infiammable bo" dies, but to detain and arreft the parti"cles of fire, which are the real and only " matter of flame.

"It appears rherefore to be the matter " of flame that the artift lofes in decom"pounding inflammable bodies, Mem. de "I Acad. Anno I7 I3."

But by many of the preceding Experiments, it is evident, that the matter loft in the Analyfis of there bodies was elaftick air, a very active principle in fire, but not an clemental fire, as he fuppores.

"Mr. Geoffrey compounded fulphur of " acid Salt, Bitumen, a little Earth and oil " of Tartar." Mem. de l" Acad. Anno I703. In which oil of $\mathcal{T}$ artar there is much air by Experiment 74, which air was doubtlefs by its elafticity very inftrumental in the inflammability of this artificial fulphur.

If fire was a particular diftinat kind of body inherent in fulphur, as Mr. Homberg, Mr. Lemery, and fome others imagin, then fuch fulphureous bodies, when ignited, fhould rarify. and dilate all the circumambient air; whereas it is found by many of the preceding 
286 Analy is of the Air.

ing Experiments, that acid fulphureous fuel conftantly attracts and condenfes a confiderable part of the circumambient elaftick air ; An argument, that there is no fire endued with peculiar properties inherent in fulphur ; and alfo that the heat of fire confifs principally in the brisk vibrating action and reaction, between the elaftick repelling air, and the ftrongly attracting acid fulphur, which fulphur in its Analyfis is found to contain an inflammable oil, and acid falt, a very fix'd earth, and a little metal.

Now fulphur and air are fuppofed to be acted by that ethereal medium, " by which (the great. Sir Ifaac Newton fuppofes) " light is refracted and reflected, and by "whofe vibrations light communicates heat " to bodies, and is put into fits of eafy "reflection, and eafy tranfmiffion: And " do not the vibrations of this medium " in hot bodies contribute to the intenfe"nefs and duration of their heat? And do " not hot bodies communicate their heat " to contiguous cold ones, by the vibra"c tions of this medium, propagated from " them into cold ones? And is not this " medium exceedingly more rare and fubis the than the air, and exceedingly more w the than the air, and excectick 


\section{Analy is of the Air.}

" elaftick and active? And does it not rea" dily pervade all bodies, Optick qu. I8. "The elattick force of this medium, in "proportion to its denfity, muft be above "490,000,000,000 times greater than the " elaftick force of the air is, in proportion " to its denfity, ibid. qu. 2 r." A force fufficient to give an intenfe degree of heat, efpecially when its elafticity is much increafed by the brisk action and re action of particles of the fuel and ambient air.

From this manifert attraction, action and re-action, that there is between the acid, fulphureous and elaftick aereal particles, we may not unreaionably conclude, that what we call the fire particles in Lime, and feveral other bodies, which have undergone the fire, are the fulphureous and elaftick particles of the fire fix'd in the Lime; which particles, while the Lime was hot, were in a very active, attracting and repelling ftate; and being, as the Lime cooled, detained in the folid body of the Lime, at the feveral attracting and repelling diftances, they then happened to be at, they muft neceffarily continue in that fix'd ftate, notwithftanding the ethereal medium, which is fuppofed freely to pervade all bodies, be continually 


\section{Analy is of the Air.}

folliciting them to action: Bur when the folid fubftance of the Lime is diffolved, by the affufion of fome liquid, being thereby emancipated, they are again at liberty to be influenced and agitated by each other's attraction and repulfion, upon which a violent ebullition enfues, from the action and re-action of thefe particles, which ebullition ceafes not, till one part of the elaftick particles are fubdued and fixed by the ftrong attraction of the fulphur, and the other part is got beyond the fphere of its attraction, and thereby thrown off into true permanent air: And that this is a probable folution of the matter, there is good reafon to conclude, from the frequent inftances we have in many of the foregoing Experiments, that plenty of elaftick air is at the fame time both generated and abforbed by the fame fermenting mixture; fome of which were obferved to generate more air than they abforbed, and others e contra abforbed more than they generated, which was the cafe of Lime.

\section{EXPERIMENT CXIX.}

And that the fulphureous and aereal particles of the fire are lodged in many of thofe bodies 


\section{Analy is of the Air.}

bodies which it acts upon, and thereby confiderably augments their weight, is very evident in Minium or Red Lead, which is obferved to increafe in weight about $\frac{x}{2}$ part in undergoing the action of the fire. The acquired rednefs of the Minium, indicating the addition of plenty of fulphur in the operation: For fulphur, as it is found to act moft vigorouly on light, fo it is apt to reflect the Atrongeft, viz. the red rays; and that there is good ftore of air added to the Minium, I found by diftlling firft 1922 grains of Lead, from whence I obtained only feven cubick inches of air; but from 1922 grains, which was a cubick inch of Red Lead, there arofe in the like fpace of time 34 cubick inches of air; a great part of which air was doubtlefs abforbed by the fulphureous particles of the fuel, in the reverberatory furnace, in which the Minium was made; for by experiment 106. the more the fumes of a fire are confined, the greater quantity of elaftick air they abforb.

It was therefore doubtlefs this quantity of air in the Minium which burft the hermetically fealed glaffes of the excellent Mr. Boyle, when he heated the Minium con- 


\section{Analyfis of the Air.}

tained in them by a burning glafs; but the pious and learned Dr. Nieuwentyt attributes this effect wholly to the expanfion of the fire particles lodged in the $\mathrm{Mi}$ nium, " he fuppofing fire to be a parti"c cular fluid matter, which maintains its " own effence, and figure, remaining al ways "fire, tho' not always burning. Religious "Philofopher, p. 3 10."

To the fame caufe alfo, exclufive of the air, he attributes the vaft expanfion of a mixture of compound Aqua-fortis and oil of Carraways, whereas by Exper. 62. there is a great quantity of air in all oils. And by pouring fome compound Aqua-fortis on oil of Cloves, the mixture expanded into a fpace equal to 720 times the bulk of the oil, that part of the expanfion, which was owing to the watry part of the oil and $\int p i$ rit was foon contracted; whereas the ocher part of the expanfion, which was owing to the elaftick air of the oil, was not all contracted, till the next day, by which time the fulphureous fumes had reforbed it.

It has been the opinion of fome that putrcfaction is the cffect of inherent fire: that Vegetables alone are the fubject of Fermentation, but both Vegetables and ani- 


\section{Analy is of the Air.}

mals of putrefaction; which operations they attribute to very different caufes, the immediate caufe of fermentation is (they fay) the motion of the air intercepted between the fluid and vifcous parts of the fermenting liquor; but the caufe of putrefaction they would have to be, fire itfelf, collected or included within the putrefying fubject. But I do not fee why thefe may not reafonably enough be looked upon as the effects of different degrees of fermentation; nutrition being the genuine effect of that degree of it, in which the fum of the attracting action of the particles is much fuperior to the fum of their repulfive power: But when their repelling force far exceeds their attractive, then the component pares of vegetables are diffolved. Which diffolving fubftances, when they are diluted with much liquor, do not acquire a great heat in the dif folution, the brisknefs of the inteftine motion being checked by the liquor: But when they are only moint, like green and damp Hay, in a large heap, then they acquire a violent heat fo as to fcorch, burn and flame, whereby the union of their conftituent parts being more throughly diffolved, they will neither produce a vinous, nor an acid fpirit:

$$
\text { U. Which }
$$




\section{Analyfis of the Air.}

Which great degree of folution may well be effected by this means, without the action of a fire, fuppofed to be included within the putrefying fubject. Wherefore according to the old Axiom, Entia non funt temere neque abfque neceffitate multiplicanda.

If the notion of fermentation be reftrained to the greater repelling degrees of fermentation, in which fenfe it has commonly been underftood; then it is as certain, that the juices of vegetables and animals do not ferment in a healthy ftate, as it is, that they do not at the fame time coalefce and difunite: But if fermentation be taken in a larger fenfe, for any the fmalleft to the greateft degree of inteftine motion of the particles of a fluid, then all vegetable and animal fluids are in a natural ftate, in fome degree of ferment, for they abound both with elaftick and fulphureous particles: And it may with as much reafon be argued, that there is no degree of warmth in animals and vegetables, becaufe a great degree of heat will caufe a folution of continuity, as to fay, there is no degree of ferment in the fluids of thofe bodies, becaure a great repelling degree of ferment will moft certainly diffolve them. 


\section{Analy/is of the Air.}

That illuftrious Philofopher Sir Ifaac Newton, in his thoughts about the nature of acids, gives this rational account of the nature of fermentation. "The particles of "acids-are endued with a great attractive "force, in which force their activity con" fifts - By this attractive force they get " about the particles of bodies, whether " they be of a metallick or ftony nature, "and adhere to them moft clofely on all "fides, fo that they can fcarce be feparated "from them by diftillation or fublimation; "when they are attracted and gathered to"gether about the particles of bodies, they "raile, disjoin, and thake them one from "s another, that is, they diffolve thofe bodies. "By their attractive force alfo, by which " they rufh towards the particles of bodies, " they move the fluid, and excite heat, and " they thake afunder fome particles, fo much " as to turn them into air, and generate " bubbles: And this is the reafon of diflo"lution, and all violent fermentation. Har" ris Lexicon Tech. Vol. II. introduction."

Thus we have from thefe Experiments many manifett proofs of confiderable quantities of true permanent air, which are by means of fire and fermentation raifed from, 
294 Analy is of the Air.

and abforbed by animal, vegetable and mineral fubftances.

That this air confifts of particles which are in a very active ftate, repelling each other with force, and thereby conftituting the fame kind of elaftick fluid with common air, is plain from its raifing the Mercury in Experiment 88 and 89 , and from its continuing in that elaftick ftate for many months and years tho' cooled by fevere frofts; whereas watry vapours, tho' they expand much with heat, yet are found immediately to condenfe into their firf dimenfions when cold,

The air generated by fire was not, in many infances, feparated without great vio. lence from the fix'd bodies, in which it was incorporated; as in the cafe of Nitre, Tartar, Sal Tartar and Copperas: whence it hould $\mathrm{feem}$, that the air generated from thefe Salts, may probably be very inftrumental in the union of Salts, as well as that central, denfer, and compacter particle of earth, which Sir Ifaac Newton obferves, does by its attraction make the watry acid flow round it, for compofing the particles of Salt. qu. $3 \mathrm{r}$. For fince upon the diffolution of the conftituent parts of Salt by fire, it is found, that upon feparating and volatilizing 


\section{Analyy is of the Air.}

the acid fpirit, the air particles do in great abundance rufh forth from a fixt to a repelling elaftick ftate; it muft needs be, that the fe particles did in their fixt ftate frongly attract the acid fpirits, as well as the fulphureous earthy parts of the Salt; for the moft frongly repelling and elaftick parti. cles are obferved, in a fixt ftate, to be the mok ftrongly attracting.

But the watry acid, which when feparated from Salt by the action of fire, makes a very corrofive fuming fpirit, will not make elaftick air, tho its parts were put into a brisk motion by fire in Exper. 75. And the event was the fame with feveral other volatile fubftances, as volatile Salt of Sal Ammoniac, Camphire and Brandy, which tho' diftilled over with a confiderable heat, yet generated no elaftick air, in Exper. $52,6 \mathrm{I}$, 66. Whence 'tis plain, the acid vapours in the air only float in it like the watry vapours; and when ftrongly attracted by the elaftick particles of the air, they firmly adhere to them, and make Salts.

Thus in Experiment 73 we fee by the val quantity of air there is found in Tartar, that tho' it contains the other principles of vegetables, yet air with fome volatile Salt 
296 Analy/ts of the Air.

fecms to make up a confiderable part of its compofition; which air, when by the action of fire it is more firmly united with the earth, and acid fulphureous particles, requires a more intenfe degree of heat, to extricate it from thofe adhering fubfances, as we find in the diftillation of Sal Tartar, Exper. 74. which Air and volatile Salt are molt readiJy leparated by fermentation.

And by Experiment 72 , plenty of air arifes alfo from Nitre, at the fame time that the acid fpirit is reparated from it by the action of fire.

We find alfo by Experiment 7I, that fome air is by the fame means obtained from common fea Salt, tho not in fo great plenty, nor fo eafily, as from $T$ artar and $\mathrm{Ni}$ tre, it being a more fixt body, by reafon of the fulphur which abounds in it; neither is it fo eafily changed in animal bodies, as other Salts are, yet fince it fertilizes ground, it muft needs be changed by vegetables.

There is good reafon alfo to furpect, that thefe acid fpirits are not wholly free from air particles, notwithftanding there were no elaftick ones produced, when they were put into a brisk motion, by the action of fire in Expcriment 75. which might be occafioned 


\section{Analy is of the Air. $\quad 297$}

by the great quantity of acid fpirit, in which they were involved. For we fee in Experiment 90, that when the acid fpirit of Aqua Regia was more ftrongly attracted by the diffolving gold, than by the air particles, then plenty of air particles, which were thus freed from the acid fpirit, did continually arife from the Aqua Regia, and not from the gold, at leaft not from the metallick particles of the gold, for that lofes nothing of its weight in the folution; fo that if any does arife from the gold, it muft be what may be latent in the pores of the gold. Whence it is probable that the air which is obtained by the fermenting mixture of acid and alkaline fubftances may not arife wholly from the diffolved alkaline body, but in part alfo from the acid. Thus the great quantity of elaftick air, which in Exper. 83. is generated from the mixture of Vinegar and Oyfterhell, may as well arife in part from the Tartar, to which Vinegar owes its acidity, as from the diffolved Oyfterhell. And what makes it further probable is, that the Vinegar lofes its acidity in the ferment, that is its Tartar: for diffolving menftruums are generally obferved to be changed in fermentation, as well as the diffolved body. 


\section{Analy is of the Air.}

Have we not reafon alfo hence to con. clude, that the energy of acid fpirits may in fome meafure be owing to the ftrongly attracting air particles in them; which active principles may give an impetus to the acid fpicule, as well as the earthy oily matter, which is found in thefe acid fpirits?

There are we fee alfo great ftore of air particles found in the Analy fis of the blood, which arifes doubtlefs as well from the ferum as from the craffamentum, for all the animal fluids and folids have air, and fulphur in them: Which ftrongly attracting principles feem to be more intimately united together in the more perfect and elaborate part of it, its red globules; fo that we may not unreafonably conclude, that air is a band of union here, as well as in Salts: And accordingly we find the greateft plenty of air in the molt folid parts of the body, where the cohefion of the parts is the ftrongeft: For by comparing Experiment 49 and $5 \mathrm{I}$. we fee that much more air was found in the difillation of horn than of blood. And the cohefion of animal fubftances was not, as we find by the fame Experiment, diffolved even in the blood, without confiderable violence of fire; tho' it is fometimes done to a fa- 
cal degree in our blood, by that more fub: tile diffolvent fermentation: But we may obferve, that volatile Salts, Spirits, and fulphureous Oil, which are at the fame time feparated from there fubftances, will not make elaftick air.

\section{EXPERIMENT CXX。}

As elaftick air is thus generated bythe force of fire, from thefe and many other fubftances; fo is the elafticity of the air greatly deftroyed by fulphureous bodies. Sir Ifaac Newton obferves, "that as light acts upon "fulphur, fo fince all action is mutual, ful"phurs ought to aft moft upon light." And the fame may be obferved of air and futphur; for by Experiment 103, it is found that burning fulphur, which is a very ftrongly attracting fubftance, powerfully attracts and fixes the elaftick particles of air; fo that there muit needs be a good quantity of un-elaftick air particles in oil and flower of fulphur: The firf of which is made by burning fulphur under a bell, the other by fublimation : In further confirmation of this it is obferved, that Oleum Sulphuris per Campanam is with more difficulty made in a dry than a moilt air ; and I have found by Experiment purpore- 


\section{0 \\ Analy 2 of the Air.}

ly made, that a Candle which burnt 70" in a very dry receiver, burnt but 64 " in the fame receiver, when filled with the fumes of hot water; and yet abforbed one fifth part more air, than when it burnt longer in the dry air.

Sulphur not only abforbs the air when burning in a homogeneal mafs, but alfo in many fermenting mixtures; and as Sir Ifaac Newt on obferved the attractive and refractive power of bodies to be greater or lefs, as they partook more or lefs of fulphureous oily particles; fo there is good reafon from thefe Experiments to attribute the fixing of the elaftick particles of the air to the ftrong attraction of the fulphureous particles with which he fays it's probable that all bodies abound more or lefs. Electrical bodics are alfo obferved to attract more ftrongly, in proportion to the greater quantity of lulphur which they contain.

That great plenty of air is united with fulphur in the oil of vegetables, is evident from the quantity of air that arofe from the diftillation of oils of Annifeeds and Olives, in Experiment 62 . When by fermentation the conftituent parts of a vegetable are feparated, part of the air flies off in fermentation into an elaftick ftate; part unites with 


\section{Analyjis of the Air. $30 \mathrm{I}$}

the effential Salt, Water, Oil and Earth, which conftitute the Tartar which adhere to the fides of the veffel; the remainder which continues in the fermented liquor, is there, fome of it in a fix'd, and fome in an elaftick ftate, which gives brisknefs to the liquor; their expanding bubbles rifing of a very vifible fize when the weight of the incum: bent air is taken off the liquor in a vacuum.

And as there was found a greater quantity. of air in the deer's horn, than in blood; we may alfo obferve it to be in a much greater proportion in the more folid parts of vegetables, than in their fluid: For we find in Experiment 55. 57. and 60. that neas one third part of the fubftance of the Peafe! heart of Oak and Tobacco, were by the ac: tion of fire changed from an un-elaftick ftate, to an elaftick air: And fince a much greater proportion of air is found in the folid than the fluid parts of bodies; may we not with good reafon conclude, that it is very inftrumental, as a band of union in thore bodies, "Thore particles (as Sir Ifaac Nereton obferves) "receding from one " another with the greateft repulfive force, "a and being moft difficultly brought together, "which upon contact cohere moft ftrongly?

qu. $3 \mathrm{I}_{0}$, 


\section{Analy is of the Air.}

qu. 3 I." And if the attraction of cohefion of an un-elaftick air particle be proportionable to its repulfive force in an elaftick ftate; then fince its elaftick force is found to be fo vaftly great, fo muft that of its cohefion be alfo. Sir Ifaac Nereton calculates from the inflection of the rays of light, that the attracting force of particles, near the point of contact, is $10000,0000,0000,0000$ greater than the force of gravity.

Sulphur in a quiefcent fix'd ftate in a large body does not abforb the elaftick air, for a hard roll of Brimftone does not abforb air: But when fome of that Brimftone, by being powdered and mixt with filings of Iron, is fet a fermenting, and thereby reduced into very minute particles, whofe attraction increales, as their fize decreafes; then it abforbs elaftick air vigoroufly: As may be feen in many inftances under Experiment 95. The Walton mineral, in which there is a good quantity of fulphur, did; when conpound Aqua-fortis was pour'd on it, in Experiment 96 , make a confiderable fermentation, and abforb a great quantity of elaftick air: But when the ferment was much increafed, by adding an equal quantity of water to the like mixture, chen inftead of ablosb: 


\section{Analyfis of the Air. $\quad 303$}

abrorbing \&s cubick inches as before, it generated 80 cubick inches of air: So that fermenting mixtures, which have fulphur in them, do not always abforb, but fometimes generate air: The reafon of which in the Experiment now under confideration feems to be this, viz. in the firft cafe a good quantity of elaftick air was generated, by the intertine motion of the fermenting ingredients; but there arifing thence a thick, acid, fulphurcous fume, this fume abforbed a greater quantity of elaftick air than was before generated: And we find by Experiment Io3 that the fulphureous particles which fly off in the air, do by theirattraction deftroy its clafticity; for in that Experiment burning Brimftone greatly deftroyed the air's elafticity: which muft be done by the flame, and afcending fumes; becaufe in the burning of any quantity of Brimftone, the whole mals is in a manner wafted, there remaining only a very little dry Earth: And therefore the abforbed air cannot remain there, but muft be abforbed by the afcending fumes which then attract moft ftrongly, when reduced ad minima: And 'tis well known that a Candle in burning flies all off into flame and vapour, fo that what air it abrorbs muft be by thole fumes.

EXP E- 


\section{EXPERIMENT CXXI.}

And further I have found that thefe fumes deftroy the air's elafticity, for many hours after the Brimftone Match, which made them, was taken out of the veffel, $z z a a$ : (Fig. 35.) Thore fumes being firft cooled by immerfing that veffel and its ciftern $x x$, (or an inverted wine Flask, full of the fumes) under cold water for fome time; then marking the furface of the water $z z I$ immerfed the veffels in warm water: And when all was cold again the following day, I found a good quantity of the air's elafticity was deftroyed by the water's afcending above $z z$. And the event was the fame upon frequent repetitions of the fame Experiment.

But if inftead of the fumes of burning Brimftone, I filled a Flask full of fumes from the fmoak of wood, after it had done flaming, then there was but half as much air abforbed by thofe fumes, as there was by the fumes of Brimftone; viz. becaufe the fmoak of wood was much diluted with the watry vapour which afcended with it out of the wood. And this is doubtlefs the seafon why the fmoak of wood, tho' it in-

commodes 


\section{Analy is of the Air. 305}

commodes the lungs, yet it will not fuffocate like that of Charcoal, which is withe al more fulphureous, without any mixture of watry vapours.

And that new generated elaftick air is reforbed by there fumes, I found by attempting to fire a Match of Brimftone with a burning glafs, by means of a pretty large piece of Brown Paper which had been dipped in a ftrong folution of Nitre, and then dryed: Which Nitre in detonizing generated near two quarts of air, which quantity of air, and a great deal more, was abforbed, when the Brimftone took fire and flam'd vigorounly.

So that the 85 cubick inches of air, Experiment 96 , which I found upon meafuring was abforbed by the Walton mineral and compound Aqua-fortis, was the excefs of what was abforbed by thore fumes above what was generated by the fermenting mixture.

And the reafon is the fame in filings of Iron and Spirit of Nitre, Experiment 94, which alfo abforbed more than they generated, whether with or without water.

Hence alfo we fee the reafon why filings of Iron and compound Aqua-fortis in the fame 94 Experiment abforbed air; and why when mixed with an equal quantity of water 


\section{Analy/is of the Air.}

it moftly abforbed, but did fometimes generate, and then abforb again: And it was the fame with Oil of Vitriol, filings of Iron and Water, and Nerw-caftle Coal and compound Aqua-fortis and others: viz. At firft, when the ferment was brisk, the abforbing fumes rofe fafteft, whereby more air was abforbed than generated; but as the ferment abated, to fuch a degree as to be able ftill to generate elaftick air, but not to fend forth a proportionable quantity of fumes, in that cafe more air would be generated than abforbed.

And in Experiment 95, there are feveral inftances of the air's being in like manner abforbed in leffer degrees, by other fermenting mixtures: As in the mixture of Spirit of Harts-horn with filings of Iron, and with filings of Copper: And Spirit of Sal Ammoniac with filings of Copper; and alfo filings of Iron and Water; powdered Flint and Compound Aqua-fortis; powdered Briftol Diamond with the fame liquor.

It is probable from Experiment $\mathrm{IO}_{3}$ and 106, where it was found that the thicker the fuliginous vapours were, the fafter they abforbed the air, that if the above-mentioned fermenting mixtures had not been confined in clofe veffels, but in the open air, where

the 


\section{Analy is of the Air. $\quad 307$}

the vapours would have been lefs dence, that in that cafe much lefs air would have been abforbed, perhaps a great deal lefs than was generated.

In the fecond cale of the Walton mineral, Experiment 96, when inftead of abforbing, it generated air, the parts of the Compound Aqua-fortis were then more at liberty to act by being diluted with an equal quanticy of water; whereby the ferment being more violent, the particles which conftituted the new elaftick air were thereby thrown off in greater plenty, and perhaps with a greater degree of elafticity, which might carry them beyond the fphere of at traction of the fulphureous particles.

This is further illuftrated by Experiment 94, where filings of Iron and oil of Vitriol alone generated very little; but the like quantities of filings of Iron, with an equal quantity of water, generated 43 cubick inches of air; and the like ingredients, with three times that quantity of water, generated 108 cubick inches.

And tho' the quantity of the afcending fumes (which was in this cafe of the Walton mineral very great) muft needs in their afcent abforb a good deal of elaftick air for they 


\section{Analy is of the Air.}

will abforb air; yet if where the ferment was fo much greater, more elaftick air was generated by the fermenting mixture than was abforbed by the afcending fumes; then the quantity of new generated air, which I found between $z z$ and $a a$, (Fig. 35.) when I meafured it, was equal to the excefs of what was generated above what was abforbed.

And probably in this cafe the air was not abforbed fo much in proportion to the denfity of the fumes as in the firft cafe; becaufe here the fulphureous fumes were much blended with watry vapours: For we find in Experiment 97 , that fix times more was wafted in fumes in this cafe than in the other; and there: fore probably a good part of the cubick inch of water afcended with the vapour, and might thereby weaken its abforbing power: For watry vapours do not abforb elaftick air as the fulphureous ones do; tho' by Experiment 120, a Candle abforbed more in a damp than in a dry air.

And 'tis from thefe diluting watry vapours that filings of Iron with Spirit of Nitre and Water, abforbed lefs than with Spirit of Nitre alone, for in both cafes it abforbs more than it generates. 


\section{Analys of the Air.}

Thus alfo oil of Vitriol and Chalk gemerate air, their fume being fmall, and that much diluted with the watry vapours in the Chalk.

But Lime with oil of Vitriol, or WhiteWine Vinegar or Water, make a confiderable fume, and abforb good quantities of air: Lime alone left to naken gradually, as it makes no fume, fo it abforbs no air.

We fee in Experiment 92, where the ferment was not very fudden nor violent, nor the quantity of abforbing fumes large, that the Antimony and Aqua-fortis generated a quantity of air equal to 520 times the bulk of the Antimony; thus alfo in the mixture of Aqua-regia and Antimony, in Experiment $9 \mathrm{I}$, while at firt the ferment was fmall, then air was generated; but when with the increafing ferment plenty of fumes arofe, then there was a change from a generating to an abforbing ftate.

Since we find fuch great quantities of elaftick air generated in the folution of animal and vegetable fubftances; it muft needs be that a good deal does confantly arife, from the diffolving of thefe aliments in the ftomach and bowels, which diffolution it greatly promotes: Some of which may very probably 
be re-forbed again, by the fumes which arife with them; for we fee in Experiment 83 that Oyfter-fhell and Vinegar, Oyfter-fhell and Rennet, Oyfter-thell and Orange juice, Rennet alone, Rennet and Bread, firft generat ed and then abforbed air;butOyfter-fhell with fome of the liquor of a Calve's ftomach which had fed much upon Hay, did not generate air; and it was the fame with Oyfter-fhell and Ox gall, and fpittle, and urine; Oyfter-fhell and Milk generated a little air, but Limon juice and Milk did at the fame time abforb a little: Thus we fee that the varicty of mixtures in the ftomach appear fometimes to generate, and fometimes to abforb air; that is, there is fometimes more generated than abforbed, and fometimes an equal quantity, and fometimes lefs according to the proportion the generating power of the diffolving aliments bears to the abforbing power of the fumes which arife from them. In a true kindly digeftion, the generating power exceeds the abforbing power but a little: But whenever the digeftion deviates in fome degree from this natural ftate, to generate a greater proportion of elaftick air, then are we troubled more or lefs with diftending Flatus's. I had intended to make thefe and many more

Experiments 


\section{Analy is of the Air. $3 \mathrm{II}$}

Experiments relating to the nature of digeftion in a warmth equal to that of the ftomach, but have been hitherto prevented by purfuing other Experiments.

Thus we fee that all thefe mixtures do in fermentation generate elaftick air, but thofe which emit thick fumes, charged with fulphur, reforb more than was generated in proportion to the fulphureoufinefs and thicknefs of thofe fumes.

I have alfo thewn in many of the fore. going Experiments, that plenty of true permanent elaftick air is generated from the fermenting mixtures of acid and alkaline fubftances, and efpecially from the fermentation and diffolution of animal and vegetable bodies:- Into whofe fubftances we fee it is in a great proportion intimately and firmly incorporated; and confequently, great quantities of elaftick air muft be continually expended in their production, part of which does we fee refume its elaftick quality, when briskly thrown off from thofe bodies by fermentation, in the diffolution of their texture. But part may probably never regain its elafticity, or at leaft not in many centuries, that efpecially which is incorporated into the more durable parts of animals and ve-

$$
\mathrm{X}_{4} \quad \text { getables. }
$$




\section{Analyfis of the Air.}

getables. However we may with pleafure fee what immenfe treafures of this noble and important element, endued with a moft aeive principle, the all-wife Providence of the great Author of nature has provided; the conftant wafte of it being abundantly fupplied by heat and fermentation from innumerable denfe bodies; and that probably from many of thore bodics, which when they had their afcending fumes confined in my Glaffes, abforbed more air than they generated, but would in a more free, open fpace generate more than they abforbed.

I made fome atempts both by fire, and allo by fermenting and abforbing mixtures, to try if I could deprive all the particles of any quantity of elaftick air of their elafticity, but I could not effect it: There is therefore no direet proof from any of thefe Expcriments, that all the elaftick air may be abforbed, tho' tis very probable it may, fince we find it is in fuch grear plenty generated and abforbed; it may well therefore bc ail abforbed and changed from an elafrick to a fixt ftate: For as Sir IsAac Newron obferves of light, " that nothing more ' $"$ is requifite for producing all the variety of ec colours, and degrees of refrangibility, than 


\section{Analy/is of the Air.}

at that the rays of light be bodies of different "fizes; the leaft of which may make the "weakeft and darkeft of the colours, and " be more eafily diverted, by refracting fur"faces from the right courfe; and the reft, " as they are bigger and bigger, may make " the frronger and more lucid colours* and be more and more difficultly diverted. "2u. 29. So 2u. 30, he obferves of air, that " denle bodies by fermentation rarify into " feveral forts of air, and this air, by fer" mentation, and fometimes without, returns " into denre bodies." And fince we find in fact from thefe Experiments, that air arifes from a great variety' of denfe bodies, both by fire and fermentation, it is probable that they may have very different degrees of elafticity, in proportion to the different fize and denfity of its particles, and the different force with which they were thrown off in. to an elaftick fate. "Thore particles (as "Sir ISAAC Newton obferves) receding "from one another, with the greateft re"pulfive force, and being moft dificultly " brought together, which upon contact " cohere moft frrongly." Whence thofe of the weakeft elafticity, will be leaft able to gefift a counter-acting power, and will there. fore 


\section{Analyfis of the Air.}

fore be fooneft changed from an elaftick to a fixt ftate. And 'tis confonant to reafon to think, that the air may confift of infinite degrees of thefe, from the moft elaftick and repelling, till we come to the more fluggith, watry and other particles, which float in the air ; yet the repelling force of the leaft elaftick particle, near the furface of the earth while it continucs in that elaftick flate, muft be fuperior to the incumbent preffure of a column of air, whore height is equal to that of the atmofphere, and its bafe to the furface of the fphere of its clattick activity.

Thus upon the whole, we fee that air abounds in animal, vegetable and mineral fubftances; in all which it bears a confiderable part; if all the parts of matter were only endued with a ftrongly attracting power, whole nature would then immediatcly become one unactive cohering lump; wherefore it was abfolutely neceffary, in order to the actuating and enlivening this vaft mafs of attracting matter, that there hould be every where intermixed with it a due proportion of ftrongly repelling elanick particles, which might enliven the whole mals, by the inceffant action between them and the attracting particles: And fince thefe claftick 


\section{Analy is of the Air. 315}

particles are continually in great abundance reduced by the power of the ftrong attracters, from an elaftick to a fixt ftate; it was therefore neceffary that thefe particles fhould be endued with a property of refuming their elaftick ftate, whenever they were difengaged from that mafs, in which they were fixed; that thereby this beautiful frame of things might be maintained, in a continual round of the production and diffolution of animal and vegetable bodies.

The air is very inftrumental in the production and growth of animals and vegetables, both by invigorating their feveral juices while in an elaftick active ftate, and alfo by greatly contributing in a fix'd ftate to the union and firm connection of the feveral conftituent parts of thofe bodies, viz. their water, falt, fulphur and earth. This band of union, in conjunction with the external air, is alfo a very powerful agent in the diffolution and corruption of the fame bodies, for it makes one in every fermenting mixture; the action and re-action of the aereal and fulphureous particles is in many fermenting mixtures fo great, as to excite a burning heat, and in others a fudden flame: And it is we fee by the like action and re-ac-

tion 


\section{I6 Analyfis of the Air.}

tion of the fame principles, in fuel and the ambient air, that common culinary fires are produced and maintained.

Tho' the force of its elafticity is fo great as to be able to bear a prodigious preflure, without lofing that elafticity, yet we have from the foregoing Experiments evident proof, that its elatticity is eafily, and in great abundance deftroyed; and is thereby reduced to a fixt ftate, by the ftrong attraction of the acid fulphureous particles, which arife either from fire or from fermentation: And therefore elafticity is not an effential immutable property of air particles; but they are, we fee, eafily changed from an elaftick to a fixt Rate, by the frong attraction of the acid, fulphureous and faline particles which abound in the air. Whence it is reafonable to conclude, that our atmofphere is a Chaos, con. fifting not only of elaftick, but allo of unelaftick air particles, which in great plenty float in it, as well as the fulphureous, faline, watry and earthy particles, which are no ways capable of being thrown off into a permanently elantick fate, like thofe particles which confticute true permanent air.

Since then air is found fo manifenty to abound in almoft all natural bodies; fince we 


\section{Analy is of the Air.}

find it fo operative and active a * principle in every chymical operation, fince its com. ftituent parts are of fo durable a nature, that the moft violent action of fire, or fermentation, cannot induce fuch an alteration of its texture, as thereby to difqualify it from refuming, either by the means of fire, or fermentation, its former elaftick ftate; unlefs in the cafe of vitrification, when with the vegetable Salt and Nitre, in which it is incorporated, it may perhaps fome of it with other chymical principles be immutably fixt: Since then this is the cale, may we not with good reafon adopt this now fixt, now volatile Proteus among the chymical principles, and that a very active one, as well as acid fulphur; notwithftanding it has hitherto been overlooked and rejected by Chymifts, as no way intitled to that denomination?

If thofe who unhappily fpent their time and fubftance in fearch after an imaginary production, that was to reduce all things to gold, had, inftead of that fruitlefs purfuit, beftowed their labour in fearching after this much neglected volatile Hermes, who has fo often efcaped thro' their burft receivers, in

* Joris ommia plena. Firgilo 
the difguife of a fubtile fpirit, a mere fiarulent explofive matter; they would then infead of reaping vanity, have found their refearches rewarded with very confiderable and ufeful difcoveries.

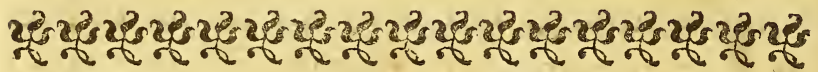

\section{H A P. VII.}

Of Vegetation.

V ${ }^{E}$ are but too fenfible, that our reafonings about the wonderful and intricate operations of nature are fo full of uncertainty, that as the wife man truly obferves, hardly do we giefs aright at the things that are upon earth, and with labour do we find the things that are before us. Wifdom Chap. ix. v. r6. And this obferva: tion we find fufficiently verified in vegetable nature, whofe abundant productions, tho' they are moft vifible and obvious to us, yet are we much in the dark about the nature of them, becaufe the Texture of the veffels of plants is fo intricate and fine, that we can trace but few of them, tho' affifted with the beft microfcopes. We have however good 


\section{Of Vegetation.}

reafon to be diligent in making farther and farther refearches; for tho we can never hope to come to the bottom and firft principles of things, yet in fo inexhauftible a fubject, where every the fmalleft part of this wonderful fabrick is wrought in the mof curious and beautiful manner, we need not doube of having our inquiries rewarded, with fome further pleafing difcovery; but if this fhould not be the reward of our diligence, we are however fure of entertaining our minds after the moft agreeable manner, by feeing in every thing, with furprifing delight, fuch plain fignatures of the wonderful hand of the divine Architeet, as muft neceffarily difpofe and carry our thoughts to an act of adoration, the beft and nobleft employment and entertainment of the mind.

What I hall here fay, will be chiefly founded on the following experiments; and on feveral of the preceding ones, without repeating what has already been occafionally obferved on the fubiect of vegetation.

We find by the chymical analy fis of vegetables, that their fubftance is compofed of fulphur, volatile falt, water and earth; which principles are all endued with mutually attracting powers, and alfo of a large portion 


\section{Of Vegetation.}

of air, which has a wonderful property of ftrongly attracting in a fixt ftate, or of repelling in an elaftick ftate, with a power which is fuperior to vaft compreffing forces, and it is by the infinite combinations, action and re-action of thefe principles, that all the operations in animal and vegetable bodies are effected.

Thefe active aereal particles are very ferviceable in carrying on the work of vegetation to its perfection and maturity. Not only in helping by their elafticity to diftend each ductile part, but alfo by enlivening and invigorating their fap, where mixing with the other mutually attracting principles they are by gentle heat and motion fet at liberty to affimilate into the nourifhment of the refpective parts: "The foft and moift nou" rifhment eafily changing its texture by gen" tle heat and motion, which congregates " homogeneal bodies, and feparates hete"rogeneal ones." Newton's Opticks, qu. $3 \mathrm{I}$. The fum of the attracting power of thefe mutually acting and re-acting principles being, while in this nutritive ftate, fupcrior to the fum of their repelling power, whereby the work of nutrition is gradually advansed by the neazer and nearer union of thefe 


\section{of Vegeration}

principles, from a leffer to a greater degree of confiftency, till they are advanced to that vifcid ductile ftate, whence the feveral parts of vegetables are formed; and are at length firmly compacted into hard fubftances, by the flying off of the watry diluting vehicle; fooner or later, according to the different degrees of cohefion of thefe thus compacted principles.

But when the watry particles do again foak into and dif-unite them, and their repelling power is thereby become fuperior to their attracting power; then is the union of the parts of vegetables thereby fo thoroughly diffolved, that this ftate of putrefaction does by a wife order of Providence fit them to refufcitate again, in new vegetable productions; whereby the nutritive fund of nature can never be exhaufted: Which being the fame both in animals and vegetables, it is thereby admirably fitted by a little alteration of its texture to nourifh either.

Now, tho' all the principles of vegeta. bles are in their due proportion neceffary to the production and perfection of them; yet we generally find greater proportions of Oil in the more claborate and exalted parts of vegetables: And thus Sceds are

$$
\text { Y found }
$$




\section{2 \\ Of Vegetation.}

found to abound with Oil, and confequently with fulphur and air, as we fee by Exper. 56 , 57,58 . which Seeds containing the rudiments of future vegetables, it was neceffary that they fhould be well ftored with principles that would both preferve the Seed from putrefaction, and alfo be very active in promoting germination and vegetation. Thus alfo by the grateful odours of flowers we are affured, that they are ftored with a very fubtile, highly fublimed Oil, which perfumes the ambient air, and the fame may be obferved from the high taftes of fruits.

And as Oil is an excellent prefervative againf the injuries of cold, fo it is found to abound in the fap of the more northern trees; and it is this which in ever-greens keeps their leaves from falling.

But plants of a lefs durable texture, as they abound with a greater proportion of Salt and Water, which is not fo ftrongly attracting as fulphur and air, fo are they lefs able to endure the cold; and as plants are obferved to have a greater proportion of Salt and Water in them in the fpring, than in the autumn, fo are they more eafily injured by cold in the fpring, than in a more advan- 


\section{Of Vegetation.}

ced age, when their quantity of oil is increafed with their greater maturity.

Whence we find that nature's chief bufinefs, in bringing the parts of a vegetable, efpecially its fruit and feed to maturity, is to combine together in a due proportion, the more active and noble principles of fulphur and air, that chiefly conftitute oil, which in its moft refined ftate is never found without fome degree of earth and falt in it.

And the more perfect this maturity is, the more firmly are thefe noble principles united. Thus Rhenifh Wines, which grow in a more northern climate, are found to yield their Tartar, i. e. by Exper. 73 . their incorporated air and fulphur in greater plenty, than the ftronger Wines of hotter countries, in which thefe generous principles are more firmly united : And particularly in Madera Wine, they are fixt to fuch a degree, that that Wine requires a confiderable degree of warmth, fuch as would deftroy the more delicate texture of many other Wines, to keep it in order, and give it a generous tafte; and 'tis from the fame reafon, that rmall French Wines are found to yield more fpirit in diftillation, than ftrong Spamijh Wines.

$$
\text { Y } 2
$$

But 


\section{4 \\ Of. Vegetation.}

But when, on the other hand, the crude watry part of the nutriment bears too great a proportion to the more noble principles, either in a too luxuriant ftate of a plant, or when its roots are planted too deep, or it ftands in too thady a pofition, or in a very cold and wet fummer; then it is found, that either no fruit is produced, or if there be any, yet it continues in a crude watry ftate; and never comes to that degree of maturity, which a due proportion of the more noble principles would bring it to.

Thus we find in this and every other part of this beautiful fcene of things, when we attentively confider them, that the great Author of nature has admirably tempered the conflituent principles of natural bodies, in fuch due proportions as might beft fit them for the ftate and purpores they were intended for.

It is very plain from many of the foregoing Experiments and Obfervations, that the leaves are very ferviceable in this work of vegetation, by being inftrumental in bringing nourifhment from the lower parts, within the reach of the attraction of the growing fruit; which like young animals is furnifhed with proper inftruments to fuck it thence. 


\section{Of Vegetation.}

But the leaves feem alfo defigned for many other noble and important fervices; for nature admirably adapts her inftruments fo as to be at the fame time ferviceable to many good purpofes. Thus the leaves, in which are the main excretory ducts in vegerables, feparate and carry off the redundant watry fluid, which by being long detained, would turn rancid and prejudicious to the plant, leaving the more nutritive parts to coalefce; part of which nourifhment, we have good reafon to think, is conveyed into vegetables thro' the leaves, which do plentifully imbibe the Dew and Rain, which contain Salt, Sulphur, \& c. For the air is full of acid and fulphureous particles, which when they abound much, do by the action and re-action between them and the elaftick air caufe that fultry heat, which ufually ends in lightning and thunder: And thefe new combinations of air, fulphur and acid fpirit, which are conftantly forming in the air, are doubtlefs very ferviceable, in promoting the work of vegetation; when being imbibed by the leaves, they may not improbably be the materials out of which the more fubtile and refined principles of vegetables are formed: For fo fine a fuid as

$$
\text { Y } 3
$$

the 


\section{Of Vegetation.}

the air feems to be a more proper medium, wherein to prepare and combine the more exalted principles of vegetables, than the groffer watry fluid of the fap; and for the fame reafon, 'tis likely, that the molt refined and active principles of animals are alfo prepared in the air, and thence conveyed thro' the lungs into the blood; and that there is plenty of thefe fulphureo-aereal particles in the leaves, is evident from the fulphureous exudations, which are found at the edges of leaves, which Bees are obferved to make their waxen cells of, as well as of the duft of flowers: And that wax abounds with fulphur is plain from its burning freely, \&c.

We may therefore reafonably conclude, that one great ufe of leaves is what has been long fufpected by many, viz. to per form in fome meafure the fame office for the fupport of the vegetable life, that the lungs of animals do, for the fupport of the animal life; Plants very probably drawing thro' their leaves fome part of their nourifhment from the air.

But as plants have not a dilating and contracting Thorax, their infpirations and expirations will not be fo frequent as thofe of 


\section{Of Vegetation.}

Animals, but depend wholly on the alternate changes from hot to cold, for infpiration, and vice,ver $\int \hat{a}$ for expiration; and'tis not improbable, that plants of more rich and racy juices may imbibe and afimilate more of this aereal food into their conftitutions, than others, which have more watry vapid juices. We may look upon the Vine as a good inftance of this, which in Exper. 3. perfpired lefs than the Appletree. For as it delights not in drawing much watry nourifhment from the earth by its roots, fo it muft therefore neceffarily be brought to a more ftrongly imbibing ftate at night, than other trees, which abound more with watry nourifhment; and it will therefore confequently imbibe more from the air. And likely this may be the reafon, why plants in hot countries abound more with fine aromatick principles, than the more northern plants, for they do undoubtedly imbibe more dew.

And if this conjecture be right, then it gives us a farther reafon, why trees which abound with moifture, either from too thaded a pofition, or a too luxurious ftate are unfruitful, viz. becaufe, being in thefe cafes more replete with moifture, they can.

$$
\mathrm{Y}_{4}
$$

not 
not imbibe fo ftrongly from the air, as others do, that great bleffing the dew of Heaven.

And as the moft racy generous taftes of fruits, and the grateful odours of flowers, do not improbably arife from thefe refined aereal principles, fo may the beautiful colours of flowers be owing in a good meafure to the fame original; for it is a known obfervation, that a dry foil contributes much more to their variegation than a frong moint one does.

And may not light alfo, by freely entring the expanded furfaces of leaves and flowers, contribute much to the ennobling the principles of vegetables? for Sir Ifaac Nereton puts it as a very probable query, "Are "not grofs bodies and light convertible into "One another" and may not bodies receive "6 much of their activity from the particles " of light, which enter their compofition? "The change of bodies into light, and of "2 light into bodies, is very conformable to "the courfe of nature, which feems de"lighted wich tranfmutations. Opt.q.30." 


\section{Of Vegetation.}

\section{EXPERIMENT CXXII.}

That the Leaves and Stems of Plants do imbibe elaftick air, there is fome reafon to furpect, from the following Experiment, which in the firt edition of this book, I mentioned as not made with accuracy enough, but I have fince repeated it with greater accuracy, viz. Fune $29^{\text {th }}$ I fet a well rooted plant of Pepper-mint in a glafs ciftern full of earth, and then poured in as much water as it would contain; over this glafs ciftern I placed an inverted glafs $z z$, $a a$, as in Fig. 35. the water being drawn up by means of a fyphon to $a a$. At the fame time alfo, I placed in the fame manner another inverted glafs $z z$, $a$ a of equal fize with the former, but without any plant under it: the capacity of thefe veffels above the water $a$ a was equal to 49 cubick inches. In a month's time the Mint had made feveral weak flender thoots, and many fmall hairy roots thot out at the joints that were above water, occafioned probably by the great moifture of the air, in which the plant ftood; half the leaves of the old ftem were now dead; but the leaves and ftem of the young thoots continued green moft part of the 
the following winter: The water in the two inverted glaffes rofe and fell as it was either affected by the different weight of the Atmorphere, or by the dilatation and contraction of the air above $a a$. But the water in the veffel in which the Pepper-mint ftood, rofe fo much above $a a$, and above the furface of the water in the other veffel, that one feventh part of that air muft have been reduced to a fixt ftate, either by being imbibed into the fubftance of the plant, or by the vapours which arofe from the plant. This was chiefly done in the two or three fummer months, for after that no more air was abforbed. The beginning of April in the following fpring, I took out the old mint, and put a frefh plant in its place, to try if it would abforb any more of the air, but it faded in 4 or 5 days. Yet a frefh plant put into the other glals, whofe air had been confined for 9 months, lived near a month, almoft as long as another plant did in frefh confined air; for I have found that a tender plant confined in this manner in April, would not live fo long as a ftronger grown plant put in, in yune. 
The like plants placed in the fame manner feparately, in the diffilled airs of Tartar and Newcaftle coal, foon faded; yet a like plant confined in three pints of air, a quart of which was diftilled from an Ox's tooth, grew about two inches in height, and had fome green leaves on it, after 6 or 7 weeks confinement.

Finding that a frefh plant could not live in the air, which had been for feveral months infected by the mine which was placed in it the $19^{\text {th }}$ of Fune; inftead of a plant I placed in that air a mixture of powdered Brimftone and filings of Iron moiftened with water; this mixture abforbed four cubick inches of this air.

\section{EXPERIMENT CXXIII.}

In order to find out the manner of the growth of young thoots, I firt prepared the following inftrument, viz. I took a fmall ftick $a$, (Fig. 40.) and at a quarter of an inch diftance from each other, I run the points of five pins, $1,2,3,4$, 's, thro' the ttick, fo far as to ftand $\frac{1}{4}$ of an inch from the ftick, then bending down the great ends of the pins, I bound them all faft with waxed thread; I provided alfo fome red lead mixed with oil. 
In the fpring when the Vines had made fhort thoots, I dipped the points of the pins in the paint, and then pricked the young thoot of a Vine, (Fig. 4r.) with the five points át once, from $t$ to $p$ : I then rook off the marking inftrument, and placing the loweft point of it in the hole $p$, the upper. moft mark, I again pricked frefh holes from $p$ to $l$, and then marked the two other points $i b$; thus the whole thoot was marked every $\frac{1}{4}$ inch, the red paint making every point remain vifible.

(Fig. 42.) fhews the true proportion of the fame fhoot, when it was full grown, the September following; where every correfponding point is noted with the fame letter.

The diftance from $t$ to $s$ was not enlarged above $\frac{3}{60}$ part of an inch; from $s$ to $q$, the $\frac{\frac{8}{2}}{26}$ of an inch; from $q$ to $p, \frac{3}{8}$; from $p$ to $0, \frac{3}{8}$; from $o$ to $n, \frac{6}{10}$; from $n$ to $m \frac{2}{10}$; from $m$ to $l, \mathbf{I}+\frac{8}{i_{0}}$ of an inch; from $l$ to $i, I+\frac{3}{10}$ inch nearly; and from $i$ to $b$ three inches.

In this Experiment we fee that the firft joint to $r$ extended very little; it being almoft hardened, and come near to its full growth, when I marked it: The next joint, 


\section{Of Vegetation.}

from $r$ to $n$, being younger, extended fomething more; and the third joint from $n$ to $k$ extended from $\frac{3}{4}$ of an inch, to $3+\frac{x}{2}$ inches; but from $k$ to $h$, the very tender joint, which was but ${ }_{4}$ inch long, when I marked it, was when full grown three inches long.

We may obferve, that nature in order to fupply thefe young growing fhoots with plenty of ductile matter is very careful to furnifh at fmall diftances the young thoots of all forts of trees, with many leaves throughout their whole length, which ferve as fo many jointly acting powers placed at different ftations, thereby to draw with more eafe plenty of fap to the extending thoot.

The like provifion has nature made in the Corn, Grafs, Cane, and Reed kind; the leafy fpires, which draw the nourifhment to each joint, being provided long before the ftem thoots, which flender ftem in its tender ductile ftate would moft eafily break and dry up too foon, fo as to prevent its due growth, had not nature to prevent both thefe inconveniences provided ftrong Thecas or Scabbards, which both fupport and keep long in a fupple duatile ftate the tender extending ftem. 


\section{4 \\ Of Vegetation.}

I marked in the fame manner as the Vine; at the proper feafons, young Honey fuckle Thoots, young ASparagus, and young Sunflowers; and I found in them all a gradual fcale of unequal extenfions, thofe parts extending moft which were tendereft. The white part of the $A \int p a r a g u s$, which was under ground, extended very little in length, and accordingly we find the fibres of the white part very tough and Atringy: But the greateft extenfion of the tender green part; which was about 4 inches above the ground when I marked it, reparated the marks from a quarter of an inch, to twelve inches diftance; the greateft diftention of the Sunflower was from $\frac{2}{4}$ inch, to four inches diftance.

From thefe Experiments, it is evident, that the growth of a young bud to a thoot confilts in the gradual dilatation and extenfion of every part; the knots of a thoot being very near each other in the bud, as may plainly and diftinctly be feen in the $\Omega_{i t}$ bud of the Vine and Fig-tree; but by this gradual diftention of every part, they are extended to their full length. And we may eafily conceive how the longitudinal capillary tubes ftill retain their hollownels, notwith- 
withftanding their being diftended, from the like effect in melted glars tubes, which retain a hollownefs, tho' drawn out to the fineft thread.

The whole progrefs of the firft joint $r$ is very thort in comparifon of the other joints; becaufe, at firft fetting out its leaves being very fmall, and the feafon yet cooler than afterwards, 'tis probable, that but little fap is conveyed to it; and therefore it extending but flowly, its fibres are in the mean time grown tough and hard, before it can arrive to any confiderable length. But as the feafon advances, and the leaves inlarge, greater plenty of nourihment being thereby conveyed, the fecond joint grows longer than the firft, and the $3 \mathrm{~d}$ and 4th fill on gradually longer than the preceding; thefe do therefore in equal times make greater advances than the former.

The wetter the feafon, the longer and larger thoots do vegetables ufually make; becaufe their foft ductile parts do then continue longer in a moift, tender ftate; but in a dry feafon the fibres fooner harden, and Atop the further growth of the thoot; and this may probably be one reafon why the Ewo or three laft joints of every foot are ufually 


\section{$33^{6}$ Of Vegetation:}

ufually fhorter than the middle joints; viz. becaufe they fhooting out in the more advanced hot dry fummer feafon, their fibres are foon hardened and dryed, and are withal checked in their growth by the cool autumnal nights: I had a vine thoot of one year's growth which was 14 feet long, and had 39 joints, all pretty nearly of an equal length, except fome of the firft and laft.

And for the fame reafon, Beans and many other plants, which ftand where they are much thaded, being thereby kept continually moift, do grow to unufual heights, and are drawn up as they call it by the over hadowing Trees, their parts being kept long, foft and ductile: But this very moift haded ftate is ufually attended with fterility; very long joints of vines are alfo obferved to be unfruitful.

This Experiment, which thews the manner of the growth of thoots, confirms Borellis opinion, who in his Book De motu Animalium, part fecond Chap. I 3, fuppores the tender growing fhoot to be diftended like foft wax by the expanfion of the moifture in the fpongy pith; which dilating moifture, he with good reafon concludes is hindered from returning back, (while it 


\section{Of Vegeiation.}

expands) by the (ponginefs of the pith, without the help of valves. For 'tis very pro. bable that the particles of water, which immediately adhere to, and are ftrongly im: bibed into, and attracted by every fibre of the fpongy pith, will fuffer fome degree of expanfion before they can be detached by the fun's warmth from each attracting fibre, and confequently the mals of fpongy fibres, of which the pith confifts, muft thereby be extended.

And that the pith may be the more fer: viceable for this purpore, nature has provided in moft thoots a ftrong partition at every knot, which partitions ferve not only as plinths, or abutments for the dilating pith to exert its force on, but alfo to prevent the rarified fap's too free retreat from the pith, as well as for the thooting forth of branches, leaves, and fruit.

But a dilating fpongy fubftance, by equally expanding it felf every way, would not produce an oblong fhoot, but rather a globore one, like an Apple; to prevent which inconvenience we may obferve, that nature has provided feveral Diaphragms, befides thofe at each knot, which are placed at fmall diftances acrols the pith; thereby preventing 


\section{$33^{8}$ \\ Of Vegetation.}

its too great lateral dilatation. Thefe are very plain to be feen in Walnut-tree fhoots; and the fame we may obferve in the pith of the branches of the fun-flower, and of feveral other plants; where tho thefe Diaphragms are not to be diftinguifhed while the pith is full and replete with moifture, yet when it drys up, they are often plain to be feen; and it is further obferved, that where the pith confints of diftinet veficles, the fibres of thofe veficles are often found to run horizontally, whereby they can the better refif the too great lateral dilatation of the fhoot.

We may obferve that nature makes ufe of the fame artifice, in the growth of the feathers of Birds, which is very vifible in the great pinion feathers of the wing, the fmaller and upper part of which is extended by a fpongy pith, but the lower and bigger quill-part, by a feries of large veficles, which when replete with dilating moifure do extend the quill, and keep it in a fupple ductile ftate, but when the quill is full grown, the fe veficles are al ways dry; in which ftate we may plainly obferve every veficle to be contracted at each end by a Diaphragm or Sphinder, whereby its too great lateral dilatation is prevented, but not its siftenfion lengthwife. 
And as this pith in the quill grows dry and ufelefs after the quill is full grown, we may obferve the fame in the pith of trees, which is always fucculent and full of moifture while the Thoot is growing, by the expanfion of which the tender ductile thoot is diftended in every part, its fibres being at the fame time kept fupple by this moifture; but when each year's thoot is full grown, then the pith gradually drys up, and continues for the future dry and kikfey, its veficles being ever after empty; na. ture al ways carefully providing for the fucceeding year's growth by preferving a tender ductile part in the bud replete with fucculentpith.

And as in regetables, fo doubtlers in animals, the tender ductile bones of young animals are gradually increaled in every part, that is not hardened and offified; but fince it was inconfiftent with the motion of the joynts to have the ends of the bones foft and ductile as in vegetables; therefore nature makes a wonderful provifion for this at the glutinous ferrated joyning of the heads to the thanks of the bones; which joyning while it continues ductile the animal grows, but when it offifies then the animal can no longergrow. As I was affured by the following Experiment, viz. I took a half grown Chick,

$$
Z_{2} \text { whore }
$$




\section{$34^{\circ}$ \\ of Vegetation:}

whofe leg-bone was then two inches long, and with a fharp pointed Iron at half an inch diftance I pierced two fmall holes through the middle of the fcaly covering of the leg, and fhin-bone; two months after I killed the Chick, and upon laying the bone bare, I found on it obfcure remains of the two marks I had made at the fame diftance of half an inch: So that that part of the bone had not at all diftended lengthwire, fince the time that I marked it : Notwithntanding the bone was in that time grown an inch more in length, which growth was moftly at the upper end of the bone, where a wonderful provifion is made for its growth at the joining of its head to the thank, called by Anatomits Symphyfis.

And as the bones grow in length and fize; fo muft the membranous, the mufcular, the nervous, the cartilaginous and vafcular fibres of the animal body neceffarily extend and expand, from the ductile nutriment which nature furnithes every part withal ; in which rerpects animal bodies do as truly vegetate as do the growing vegetables. Whence it muft needs be of the greateft confequence, that the growing animal be fupplied with proper nourifhment for that purpofe, in order to form a ftrong 
ftrong athletick conftitution: For when growing nature is deprived of proper materials for this purpofe, then is the under a neceffity of drawing out very nender threads of life, as is too often the cafe of young growing perfons, who by indulging in 1 pirituous liquors, or 0 ther exceffes, do thereby greatly deprave the nutritive ductile matter, whence all the diftending fibres of the body arc fupplied.

Since we are by thefe Experiments affured that the longitudinal fibres, and fap veffels of wood in its firft year's growth, do thus diftend in length by the extenfion of every part; and fince nature in fimilar productions makes ufe of the fame or nearly the fame methods: Thefe confiderations make it not unreafonable to think, that the fecond and following years additional ringlets of wood are not formed by a merely horizontal dilatation of the veffels; for it is not eafy to conceive, how longitudinal fibres and tubular fap-veffels fhould thus be formed; but rather by the thooting of the longitudinal tubes and fibres lengthways, from thofe of the laft year's wood, whereby there is a free communication main. tained between there, and the fap-veffels of all the preceding year's growth. The obfervations on the manner of the growth of the

$$
\mathrm{Z} 3 \text { ringlets }
$$




\section{$34^{2}$ \\ of Vegetation.}

ringlets of wood in Experiment 46 (Fig. 30.) do further confirm this.

But whether it be by an horizontal or longitudinal fhooting, we may obferve that nature has taken great care to keep the parts between the bark and wood always very fupple with flimy moiture, from which ductile matter the woody fibres, veficles and buds are formed.

Thus we fee that nature, in order to the production and growth of all the parts of animals and vegetables, prepares her ductile matter: In doing of which the felects and combines particles of very different degrees of mutual attraction, curioufly proportioning the mixture according to the many differenc purpoles the defigns it for; cither for bony or more lax fibres of very different degrees in animals, or whether it be for the forming of woody or more foft fibres of various kinds in vegetables.

The great variety of which different fubftances in the fame vegetable prove, that there are appropriated veffels for conveying very different forts of nutriment. And in many vegetables fome of thofe appropriate veffels are plainly to be feen replete either with milky, yellow, or red nutriment. 
Dr. Keill, in his account of animal fecretion, page 49, obferves, that where nature intends to feparate a vifcid matter from the blood, the contrives very much to retard its motion, whereby the inteftine motion of the blood being allayed, its particles can the better coalefce in order to for $m$ the vifcid fecretion. And Dr. Grew, before him, ob. ferved an inftance of the fame contrivance in vegetables where a fecretion is intended, that is to compore a hard fubftance, viz. in the kernel or feed of hard ftone fruits, which does not immediately adhere to, and grow from the upper part of the ftone, which would be the fhorteft and neareft way to convey nourifhment to it; but the fingle umbilical veffel, by which the kernel is nourifhed, fetches a compals round the concave of the ftone, and then enters the kernel near its cone, by which artifice this veffel being much prolonged, the motion of the fap is thereby retarded, and a vifcid nutriment conveyed to the feed, which turns to hard fubftance.

The like artifice of nature we may obferve in the long capillary fibrous veffels which lie between the green hull, and the hard thell of the Walnut, which are analogous

$$
\text { Z } 4
$$




\section{Of Vegetation.}

to the fibrous Mace of Nutmegs, the ends of whofe hairy fibres are inferted into the an. gles of the furrows in the Walnut-fhell: Their ufe is therefore doubtlefs to carry in thofe long diftinet veffels the very vifcous matter which turns, when dry, to a hard fhell; whereas were the thell immediately nourithed from the foft pulpous hull that furrounds it, it would certainly be of the fame foft conftitution: The ufe of the hull being only to keep the thell in a foft ductile Atate till the Nut has done growing.

We may obferve the like effeet of a llower motion of the fap in Ever-greens, which perfpiring little, their fap moves much more flowly than in more perfpiring Trees; and is therefore much more vifcid, whereby they are better enabled to outlive the winter's cold. It is obferved that the fap of Evergreens in hot Countries is not fo vifcous as the fap of more Northern Ever-greens, as the fir, \& $c$. for the fap in hotter Countries muft have a brisker motion, by means of its greater perfpiration.

\section{EXPERIMENT CXXIV.}

In order to enquire into the manner of the expanfion of leaves, I provided a little

Oaken 
Oaken board or fpatula, $a b c d$ of this thape and fize, (Fig. 43.) thro the broad part at a quarter of an inch diftance from each other, I run the points of 25 pins $x x$ which ftood $\frac{3}{4}$ inch thro, and divided a fquare inch into 16 equal parts.

With this inftrument in the proper feafon, when leaves were very young, I pricked feveral of them thro at once, with the points of all there pins, dipping them firt in the red lead, which made lafting marks.

(Fig. 44.) reprefents the fhape and fize of a young Fig-leaf, when firt marked with red points, $\frac{3}{4}$ inch diftance from each other.

(Fig. 45.) reprefents the fame full grown leaf, and the numbers anfwer to the correfponding numbers in the young leaf: Whereby may be feen how the feveral points of the growing leaf were feparated from each other, and in what proportion, viz. from 2 quarser of an inch, to about three quarter's of an inch diffance.

In this Experiment we may obferve that the growth and expanfion of the leaves is owing to the dilatation of the veficles in every part, as the growth of a young thoot was thewn to be owing to the fame caufe in the foregoing Experiment; and doubtlefs the çafe is the fame in all fruits. 


\section{Of Vegetation.}

If thefe Experiments on leaves were further purfued, there might probably be many curi. ous obfervations made in relation to the fhape of leaves: By obferving the difference of the progreflive and laceral motions of thefe points in different leaves, that were of very different lengths in proportion to their breadths.

That the force of dilating fap and air, included in the innumerable little veficles of young tender thoots and leaves, is abundantly fufficient for the extending of thoots, and expanding of leaves; we have evident proof from the great force we find in the fap of the Vine, chap. $3 \mathrm{~d}$. and from the valt force, with which infinuating moifture expanded the Peafe. Experiment 32. we fee the great power of expanding water, when heated in the engine to raife water by fire: And wa. ter with air and other active particles in ca: pillary tubes, and innumerable fmall veficles, do doubtlers act with a great force, tho' expanded with no more heat than what the Sun's warmth gives them.

And thus we fee that nature exerts a confiderable, tho' fecret and filent power, in carrying on all her productions; which demonftrates the wirdom of the Author of nature in giving fuch due proportion and direction 


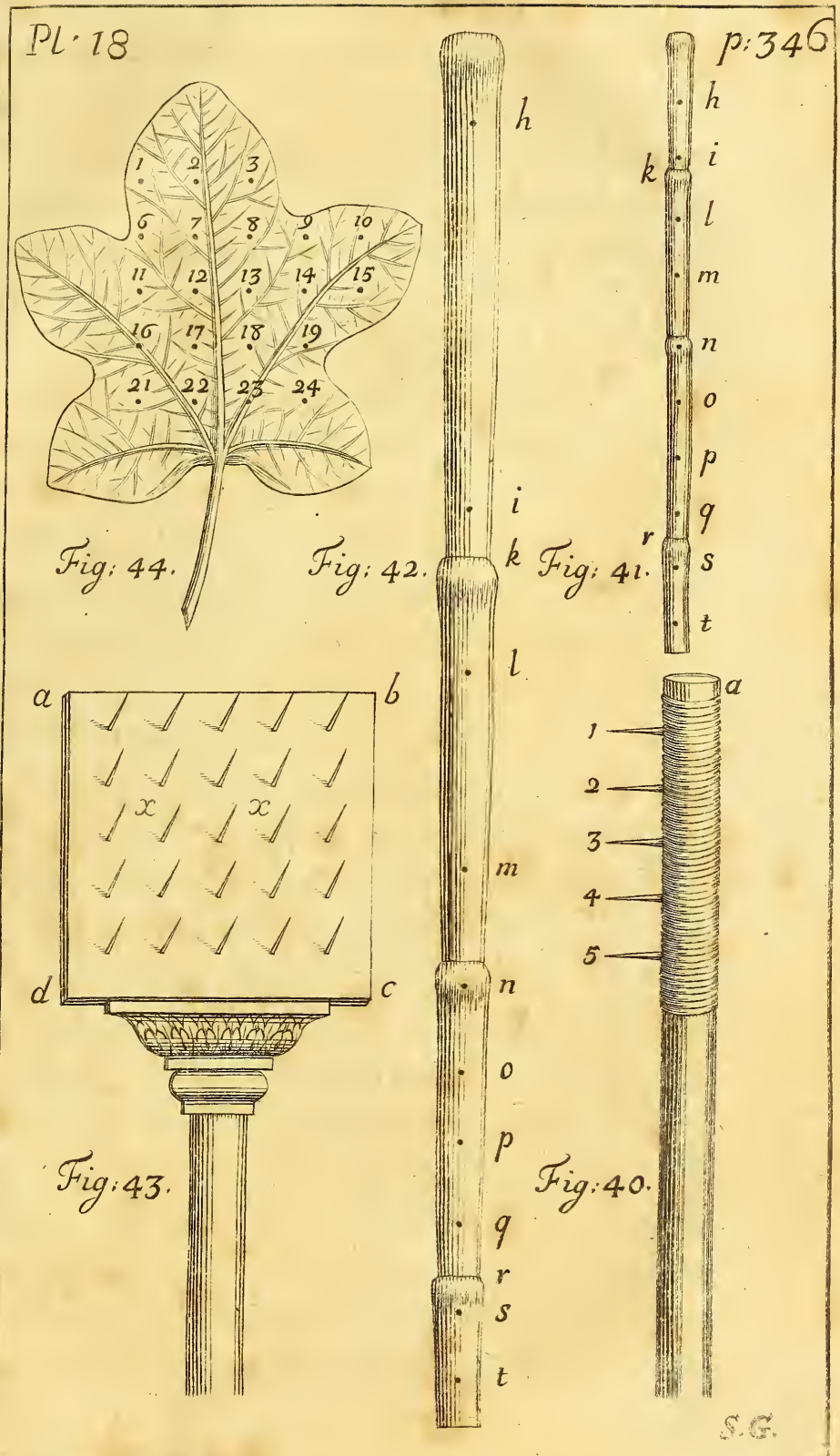





\section{Of Vegetation.}

to thefe powers, that they uniformly concur to the production and perfection of natural Beings; whereas were fuch powers under no guidance, they muft neceffarily produce a Chaos, inftead of that regular and beautiful fyftem of nature which we fee.

We may plainly fee the influence of the Sun's warmth in expanding the fap in all the parts of vegetables, as well in the roots as the body that is above ground, by the influence it has on the fix Thermometers defcribed under Experiment 20, five of which were fixed at different depths from two inches, to two feet under ground, the other being expofed to the open air.

When in the greateft noon tide heat the fpirit of that which was expored to the Sun was rifen, fince the early morning, from $2 \mathrm{r}$ to 48 degrees; then the fpirit in the fecond Thermometer, whofe ball was two inches under ground, was at 45 degrees, and the $3 \mathrm{~d}, 4$ th, and sth $T$ hermometers were gradually of lefs and lefs degrees of heat, as they were placed lower in the ground to the fixth Thermometer, which was two feet under ground, in which the fpirit was 3 I degrees high. In this ftate of heat on all the parts of the vegetable, we fee the Sun muft have 


\section{$34^{8}$ \\ Of Vegetation.}

a very confiderable influeace in expanding the fap in all its parts. The warmth was much greater on the body above ground, than on the roots which were two feet deep; thofe roots, and parts of roots which are deepeft, as they feel much lefs of the Sun's warmth, fo are they not fo foon, nor fo much affected by the alternacies of day and night, warm and cold: but that part of vegetables, which is above ground, muft have its fap confiderably rarified, when the heat increafed from morning to two a clock afternoon, fo much as to raife the fpirit in the If Thermometer from 21 to 48 degrees above the freezing point.

When in the coldeft days of the winter 1724 , the froft was fo intenfe-as to freeze the furface of ftagnant water near an inch thick, then the fpirit in the Thernometer which was expofed to the open air, was fallen four degrees below the freezing point; the fpirit of that whofe ball was two inches under ground, was four degrees above the freezing point; the $3 \mathrm{~d}$, 4 th and 5 th $T$ hermometers were proportionably fallen lefs and lefs, as they were deeper, to the 6 th $T$ Thermometer, which being two feet under ground, the fpirit was 10 degrees above the freezing point. In this ftatc of 


\section{Of Vegetation.}

things the work of vegetation feemed to be wholly at a ftand, at leaft within the reach of the froft.

But when the cold was fo far relaxed, as to have the fipirit in the firft Thermometer but 5 degrees above the freezing point, the fecond 8 degrees, and the 6 th $\mathrm{x} 3$ degrees, tho' it was ftill very cold, yet this being fome advance from freezing towards warm, and there being confequently fome expanfion of the fap, feveral of the hardy vegetables grew, viz. fome Ever-greens, Snow-drops, Crocus's, $b c$. which forward hardy plants do probably partake much of the nature of Ever-greens in perfpiring little; and the motion of their fap being confequently very now, it will become more vifcous, as in Ever-greens; and thereby the better able to refift the winter's cold: and the fmall expanfive force, which this fap acquires in the winter, is moftly exerted in extending the plant, little of it being wafted in proportion to the fummer's perfpiration.

Supported by the evidence of many of the foregoing Experiments, I will now trace the vegetation of a tree from its firf feminal plant in the Seed to its full maturity and pro. duction of other Seeds, withoutentring into 


\section{0 \\ Of Vegetation.}

a particular defcription of the ftructure of the parts of vegetables, which has already been accurately done by Dr. Grew and Malpigbi.

We fee by Experiment $56,57,58$, on diftilled Wheat, Peare and Muftard-leed, what a wonderful provifion nature has made, that the Seeds of Plants hould be well ftored with very active principles, which principles are there compacted together by him, who curiouny adapts all things to the purpofes for which they are intended, with fuch a juft degree of cohefion as retains them in that ftate till the proper feafon of germination; for if they were of a more lax conftitution, they would too foon diffolve like the other tender annual parts of plants: And if they were more firmly conneeted, as in the heart of Oak, they muft neceffarily have been many years in germinating, tho' fuppled with moifture and warmth.

When a Seed is fown in the ground, in a few days it imbibes fo much moifture, as to fwell with very great force; as we fee in the Experiment on Peafe in an iron pot, this forcible fwelling of the lobes of the Seed ar, ar (Fig. 46.) does probably protrude moifture and nourifhment from the capillary veffels $r r$, which are called the 


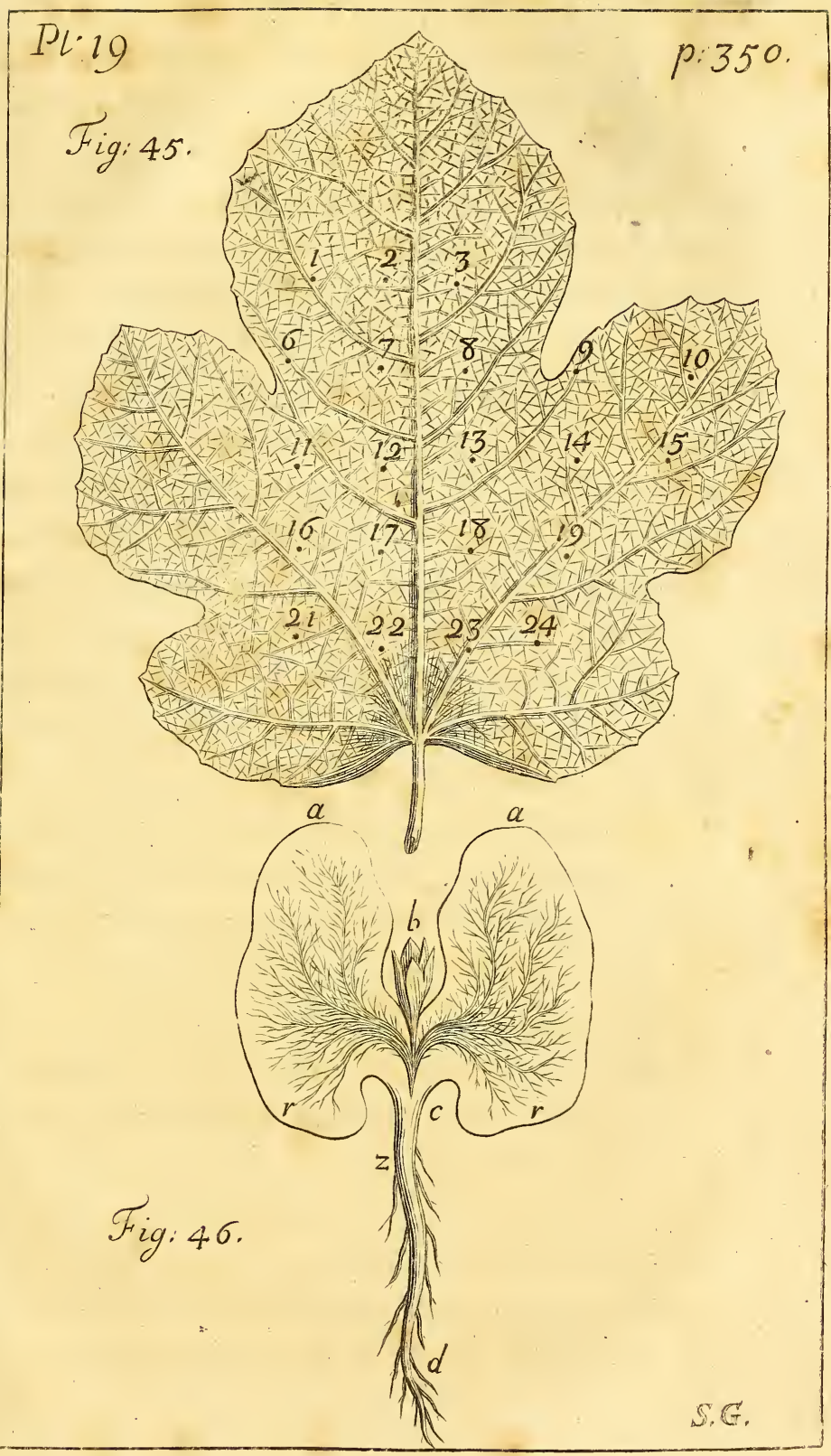





\section{Of Vegetation.}

Seed roots, into the radicle $c, z, d$, which radicle, when it has thot fome length into the ground, does then imbibe nourifhment from thence; and after it has acquired fufficient Atrength, as this tender ductile root is extending from $z$ to $c$, it muft neceffarily carry the expanding Seed-lobes upwards, at the fame time that the dilating from $z$. to $d$ makes it thoot downwards; and when the root is thus far grown, it fupplies the Plume $b$ with nourifhment, which thereby fwelling and extending opens the lobes $a r$, $a r$, which are at the fame time raifed above ground with the Plume; where they by expanding and growing thinner turn to green leaves, (except the Seeds of the pulfe kind) which leaves are of fuch importance to the yet tender Plume, that it perifhes, or will not thrive if they are pulled off; which makes it probable, that they do the fame office to the Plume that the leaves adjoyning to Apples, Quinces and other fruits do ro them, viz. they draw fap within the reach of their attraction; fee Exper. 8 and 30. But when the Plume is fo far advanced in growth, as to have branches and expanded leaves to draw up nourithment; then thefe fupplemental feminal leaves, ar, ar, being of 


\section{2}

no farther ufe, do perifh; not only becaufe the now grown and more expanded leaves of the young plant or tree, do fo over-thadow the fupplemental leaves, that their former more plentiful perfpiration is much 2 bated; and thereby alfo their power of attracting fap fails; but alfo becaufe the fap is drawn from them by the leaves, and they being thus deprived of nourifhment, do perifh.

As the tree advances in fature, the firft, fecond, third, and fourth order of lateral branches thoot out, eacis lower order being longer than thofe immediately above them; not only on account of primogeniture, but alfo becaufe being inferted in larger parts of the trunk, and nearer the root, they have the advantage of being ferved with greater plenty of fap, whence arifes the beautiful parabolical figure of trees.

But when trees ftand thick together in Woods or Groves, this their natural thape is altered, becaufe the lower lateral branches being much thaded, they can perfpire little; and therefore drawing little nourifhment, they perifh; but the top branches, being expofed to a free drying air, they perfire plentifully, and thereby drawing the fap to the top, they advance much in height: But vice verfâ, 
wer $\int a$, if when fuch a Grove of tall trees is cut down, there be left here and there a fingle tree, that tree will then fhoot out lateral branches; the leaves of which branches now perfpiring freely, will attract plenty of fap, on which account the top being deprived of its nourifhment, it ufually dies.

And as trees in a Grove or Wood grow only in length, becaure all the nourifhment is by the leaves drawn to the top, moft of the fmall lateral fhaded branches in the mean time perifhing for want of perfpiration and nutrition; fo the cafe is the very fame in the branches of a tree, which ufually making an angle of about 45 degrees with the frem of the tree, do thereby beautifully fill up at equal and proper diftances the fpace between the lower branches, and the top of the tree, forming thereby as it were a parobolical Grove or 'Thicket; which thading the arms, the fmall lateral thoots of thofe arms ufually perifh for want of due perfpiration; and therefore the arms continue naked like the bodies of Trees in a grove; all the nourifhment being drawn up to the tops of the feveral branches by the leaves which are there expofed to the warm fun and free drying air, whereby the branches of Treess expand much. 


\section{4

And where the lateral branches are very vigorous, fo as to make ftrong thoots, and attract the nourifhment plentifully, there the tree ufually abates in its height: But where the tree prevails in height, as in groves, there commonly its lateral branches are fmalleft. So that we may look upon a tree as a complicated Engine which has as many different powers as it has arms and branches, each drawing from their common fountain of life the root : and the whole of each yearly growth of the tree will be proportionable to the fum of their attracting powers, and the quantity of nourithment the root affords: But this attracting power and nourifhment will be more or lefs, according to the different ages of the tree, and the more or lefs kindly feafons of the year.

And the proportional growth of their lateral and top branches, in relation to each other, will much depend on the difference of their feveral attracting powers. If the perfpiration and attraction of the lateral branches is little or nothing, as in woods and groves, then the top branches will mightily prevail; but when in a free open air, the perfpiration and attraction of the lateral branches comes nearer to an equality 


\section{of Vegetation.}

with that of the top, then are the afpirings of the top branches greatly checked. And the cafe is the fame in moft other vegetables, which when they fand thick together, grow much in length with very weak lateral fhoots.

And as the leaves are thus ferviceable in promoting the growth of a tree, we may ob. ferve that nature has placed the pedals of the leaves-ftalks where moft nourifhment is wanting, to produce leaves, fhoots and fruit; and fome fuch thin leafy expanfion is fo ne. ceffary for this purpore, that nature provides fmall thin expanfions, which may be called primary leaves, that ferve to protect and draw nourifhment to the young fhoot and leaf-buds before the leaf itfelf is expanded.

And herein we fee the admirable contrivance of the Author of nature in adapting her different ways of conveying nourihment to the different circumfances of her productions. For in this embrio ftate of the buds a fuitable provifion is made to bring nourifhment to them in a quantity fufficient for their then fmall demands: But when they are in fome degree increafed and formed, a much greater quantity of nourifhment is neceffary, in proportion to their greatcr increafe: Nature, that the may then no

$$
\mathrm{A}_{\mathrm{a}} \mathrm{2} \text { longer }
$$




\section{Of Vegetation.}

longer fupply with a fcanty hand, immediately changes her method, in order to convey nourifhment with a more liberal hand to her productions; which fupply daily increafes by the greater expanfion of the leaves, and confequently the more plentiful attraction and fupply of fap, as the greater growth and demand for it increafes.

We find a much morc elaborate and beautiful apparatus, for the like purpofe, in the curious expanfions of bloffoms and flowers, which fecm to be appointed by Nature not only to proteet, but alfo to draw and convey nourifhment to the embrio fruit and feeds. But as foon as the Calix is formed into a fmall fruit, now impregnated with irs minute feminal tree, furnifhed with its Secondine, Corion and Amnion, (which new fet fruit may in that fate be looked upon as a compleat egg of the tree, containing its young unhatched tree, yet in embrio) then the bloffom falls off, leaving this new formed egg, or firft-fet fruit in this infant ftate, to imbibe nourihment fufficient for it felf, and the Fotus with which it is impregnated: Which nourifment is brought within the reach and power of its fuction by the adjoining leaves. 


\section{Of Vegetation.}

If I may be allowed to indulge conjecture in a cafe in which the moft diligent inquirers are as yet, after all their laudable refearches, advanced but little farther than mere conjecture, I would propofe it to their confideration, whether from the manifert proof we have that fulphur ftrongly attracts air, a hint may not be taken, to confider whether this may not be the primary ufe of the Farina facundans, to attract and unite with it felf elaftick or other refined active particles. That this Farina abounds with fulphur, and that a very refined fort, is probable from the fubtle oil which chymifts obtain from faffron. And if this be the ufe of it, was it poffible that it could be more aptly placed for the purpore than on very moveable Apices fixt on the flender points of the Stamina, whereby it might eafily with the leaft breath of wind be difperfed in the air, thereby furrounding the plant, as it were, with an Atmoiphere of fublimed fulphureous pounce? (for many trees and plants abound with it) which uniting with the air particles, they, or a very fublimed fpirit from them, may perhaps be infpired or imbibed at feveral parts of the plant, and efpecially at the Piftillum, and be thence conveyed to 


\section{$35^{8}$ The Conclujion.}

the Capfula feminalis, efpecially towards evening, and in the night when the beautiful Petala of the flowers are clofed up, and they, with all the other parts of the vegetable, are in a ftrongly imbibing ftate. And if to thefe united fulphureous and aereal particles we fuppofe fome particles of light to be joined, (for Sir Ifaac Newton has found that fulphur attracts light frongly) then the refult of thefe three by far the moft active principles in nature, will be a Punctum Saliens to in. vigorate the feminal plant: And thus we are at laft conducted, by the regular Analyfis of vegetable nature, to the firf enlivening principle of their minuteft origin.

\section{The Conclufion.}

E have from the foregoing Experiments many proofs of the very great and different quantities of moifture imbibed and perfpired by different kinds of Trees, and alfo of the infuence the feveral ftates of the air, as to warm or cold, wet or dry, have on that perfpiration. We fee alfo what ftores of moifture Nature has provided in the Earth againft a dry feafon, to anfwer this great expence of it in the production and fupport of vegetables; how far the dew can 


\section{The Conclufion.}

contribute to this fupply, and how infufficient its fimall quantity is towards making good the great demands of perfiriation: And that plants can plentifully imbibe moifture thro'. their ftems and leaves, as well as perfpire it.

We fee with what degrees of warnth the Sun, that kindly natural genius of vegetation; acts on the feveral parts of vegetables, from their tops down to their roots iwo feet under ground.

We have alfo many proofs of the great force with which plants and their feveral branches and leaves imbibe moifture, up their capillary fap veffels: The great influence the perfpiring leaves have in this work, and the care Nature has taken to place them in fuch order and at fuch proper diftances, as may render them moft ferviceable to this purpofe, efpecially in bringing plenty of nourifhment to the young growing fhoots and fruit, whofe ftem is uftually furrounded with them near the fruil's infertion into the twig.

We fee here too that the growth of thoots, leaves and fruit, confifts in the extenfion of every part; for the effeeting of which, nature has provided innumerable little veficles, which being replete wirh dilating moifture, it does thereby powerfully extend, and draw out every ductile part.

A a 4 .

We 


\section{$3^{60}$ The Conclufion.}

We have here alfo many inftances of the great force of the afcending fap in the vine in the bleeding feafon; as alfo of the fap's freely either afcending or defcending, as it thall happen to be drawn by the perfpiring leaves; and alfo of its ready lateral motion thro the laterally communicating fap veffels; together with many proofs of the great plenty of air drawn in and mixed with the fap, and incorporated into the fubftance of vegetables.

If therefore thefe Experiments and Obfervations give us any farther infight into the nature of plants, they will then doubtlefs be of fome ufe in Agriculture and Gardening, either by ferving to rectify fome miftaken notions, or by helping farther to explain the reafons of many kinds of culture, which long repeated experience has found to be good; and perhaps by leading us to make fome advances therein: But as it requires a long feries and great variety of frequently repeated Experiments and Obfervations, to make a very fmall advance in the knowledge of the nature of vegetables; fo proportionably we are from thence only to expect fome gradual improvements in the culture of them.

The fpecifick differences of vegetables, which afe all fuftained and grow from the 


\section{The Conclufion. $36 \mathrm{I}$}

fame nourifhmeni, is doubtlefs owing to the very different formation of their minute veffels, whereby an almoft infinite variety of combinations of the common principles of vegetables is made; whence fome abound more with fome principles and fome with others. Hence fome are of a warmer and more fulphureous, others of a more watry, faline, and therefore colder nature; fome of a more firm and lafting, others of a more lax and perifhable conftitution. Hence alfo it is that fome plants flourifh beft in one climate, and others in another; that much moifture is kindly to fome, and hurtful to others; that fome require a ftrong, rich, and others a poor, fandy foil; fome do beft in the thade, and others in the fun, $\& c$. And could our eyes attain to a fight of the admirable texture of the parts on which the fpecifick differences in plants depend, what an amazing and beautiful feene of inimitable embroidery fhould we behold? what a variety of mafterly ftrokes of machinery? what evident marks of confummate wifdom thould we be entertained with ?

We may obferve that the conftitution of plants is curiouny adapted to the prefene ftate of things, fo as to be moft flourifhing and vigorous in a middle flate of the air, viz.

when 


\section{$3^{62}$ The Conclufion.}

when there is a due mixture and proportion of warm and cold, wet and dry; but when the fesfons deviate far to any extreme of thefe, then are they lefs or more injurious to the feveral forts of vegetables, according to the very different degrees of hardinefs, or healthy latitude they enjoy.

The different feafons in which plants thrive beft, feems to depend, among other caufes, on the very-different quantities imbibed and perfpired by different kinds of plants. Thus the Ever-greens perfpiring little, and having thereby a thick, vifcid, oily fap, they can the better endure the winter's cold, and fubfift with little frefh nourifhment: They feem many of them to flourifh moft in the temperate feafons of the year, but not fo well in the hotteft part of fummer, becaufe their perfpiration is then fomewhat too great, in proportion to the flow afcent of the fap, which makes fome of them at that feafon to abate of their vigor: Thus fome plants, which grow and thrive with the flow perfiration of $\mathfrak{F} a-$ nuary and February, perifh as the fpring advances, and the warmth and perfpiration is too great for them. And thus garden Peafe and Beans, which are fown in what is found to be their proper feafon, viz. in November, 


\section{The Conclinficn.}

Fanuary, or February, tho' they make but a flow progrefs in their growth upwards, during the cold feafon, yet their roots, as alfo thofe of winter corn, do in the mean time fhoot well into the warmer earth, fo as to be able to afford plenty of nourifhment when the feafon advances, and there is a greater demand of it both for nutrition and perfipiration. But when Peafe are fown in fune, in order for a crop in September, they rarely thrive well, unlefs in a cool moift fummer, by reafon of the too great perfiriation caufed by the fummer's heat, which dries and hardens their fibres before they are full grown.

Tho' we have from thefe Experiments, and from common obfervation, many proofs of the great expanfive force, with which the fibrous roots of plants thoot, yet the lefs refiftance thefe tender fhoots meet with, the greater progrefs they will certainly make in equal times: And therefore one confiderable ufe of fallowing and trenching ground, and of mixing therewith feveral forts of compoft, as Chalk, Lime, Marle, Mgld, \&c. is not only thereby to replenifh it with rich manure, but alfo to loofen and mellow the foil, not only that the air may the more eafily penetrate to the roots, but alfo that the 


\section{The Conclufion.}

the roots may the more readily make vigorous fhoots. And the greater proportion the furface of the roots bears to the furface of the plants above ground, fo much the greater quantity of nourifhment they will afford, and confequently the plants will be the more vigorous, and better able to weather it out, againft unkindly feafons, than thofe plants whofe roots have made much thorter thoots. Herein therefore confifts the great care and skill of the Husbandman, to adapt his different forts of Husbandry to the very different foils, feafons and kinds of grain; that the feveral forts of earth, from the very ftiff and ftrong ground, to the loofe light earths, may be wrought to the beft temper they are capable of, for the kindly mooting and nourifhing of the roots. And probably the Husbandman might get many ufeful hints, to direct him in adapting the feveral kinds of manure, and different forts and feafons of culture to his different foils and grains: If in the feveral fages and growth of his Corn, he would not only make his obfervations, on what appears above ground, but would alfo frequently dig up, compare and examine the soots of plants of each fort, efpecially of thofe 


\section{The Conclufion.}

thore which grew in different foils, and were any how cultivated in a different manner from each other; this would inform them alfo, whether they fowed their Corn too thick or too thin, by comparing the branchings and extent of each root, with the fpace of ground allotted it to grow in.

And fince we find fo great a quantity of air infpired and mixt with the fap, and wrought into the fubftance of vegetables, the advantage of ploughing and fallowing ground feems to arife not only from the killing the weeds, and making it more mellow, for the thooting of the roots of Corn; but it is thereby alfo the better expofed to have the fertilizing, fulphureous, aereal and acid particles of the air mixt with it, which make land fruitful, as is evident from the fertility which the fword or furface of land acquires, by being long expored to the air, without any culture or manure whatever.

We have feen many proofs of the great quantities of liquor imbibed and perfpired by plants, and the very fenfible influence which different fates of the air had on their more or lefs free perfpiration: A main intention therefore to be attended to in the culture of them, is to take due care, that 


\section{$3^{66}$ The Conclusion.}

they be fown or planted in proper feafons and foils, fuch as will afford them their due proportion of nourifhment; which foils, as they are exhafted, muft, as 'tis well known, from time to time, be replenifhed with frofh compoft, fich as is full of faline, fulphureous and aereal particles, with which common dung, lime, afhes, fword, or burnbated turf abound: As alfo fuch manures as have nitrous and other falts in them; for tho" neither nitre nor common falt be found in vegetables; yet fince they are obferved to promote fertility, it is reafonable to conclude, that their texture is greatly altered in vegetation, by having their acid volatile. falts feparated from the attracting central air and earthy particles, and thereby making new combinations with the nutritive juice; and the probability of this is further confirmed from the great plenty of air and volatile falt, which is found in another combination of them, viz. in the Tartar of fermenting liquors: For it is the opinion of Chymints, that there is but one volatile falt in nature, out of which all other kinds of falts are formed by very different combinations, all which nutritive principles do by various combinations with the cultivated 


\section{The Conchufion.}

earth, compofe that nutritive ductile maiter; out of which the parts of vegetables are formed, and without which the watry vehicle a: lone cannot render a barren foil fruitful.

Nor is this the only care, the thriving and fertility of plants and trees depends much upon the happy influence and concurrence of a great variety of other circumftances. Thus many trees are unfruitful by being planted too deep, whereby their roots being in too moift a ftate, and too far from the proper influence of the Sun, whole power greatly decreafes the deeper we go, as we fee in Experiment 20. they imbibe too much crude moifure, which tho' productive of wood, is yet unkindly for fruit.

Or if when not planted too deep, they are full of crude fap, either by being too luxurious, or too much fhaded; or are planted in a moift, when they delight in a dry foil, then the fap is not fo fufficiently digefted by the Sun's warmth, as to be in that ductile ftate, which is proper for the producing of fruit.

And thus the Vine, which is known to thrive well in a dry, gravelly, rocky foil, will not be fo fruitful in a moift, ftiff, clay. ground: And accordingly we may obferve 


\section{The Conclufion.}

in Experiment the $3 \mathrm{~d}$, that tho the Vine imbibed and perfpired more than the Evergreen, yet it perfpired lefs than the Appletree, which delights in, and bears beft in a Atrong brick-earth clay; for tho' the Vine bleeds moft freely in its feafon, produces many long fucculent thoots, and bears great plenty of a very juicy fruit, yet from that Experiment it is plain, that it is not a great perfpirer, and therefore thrives beft in a dry, rocky, or gravelly foil.

The confiderable quantity of moifture, which by Experiment 16 . is perfpired from the branches of trees, during the cold winter feafon, plainly thews the reafon, why in 2 long feries of cold north-eafterly winds, the bloffoms, and tender young fet fruit and leaves, are in the early fpring fo frequently blafted, viz. by having the moifture exhaled fafter than it can be fupplied from the trees: for doubtlefs that moifture rifes the flower from the root, the colder the feafon is, tho". it rifes in fome degree all the winter, as is evident from the fame Experiment.

And from the fame caufe it is, that the leafy Ipires of Corn are by thefe cold dry: ing winds often faded and turned yellow; which makes the Husbandman, on thefe oc- 
cafions, wifh for fnow; which tho it be very cold, yet it not only defends the root from being frozen, but alfo fcreens the Corn from the fe drying winds, and keeps it in a moift, florid, fupple ftate.

It feems therefore to be a very reafonable direction which is given by fome of the Authors who write on Agriculture and Gardening, viz. during thefe cold drying winds, when little dew falls, to water the trees in dry foils, in the bloffoming feafon, and while the young fet fruit is tender; and provided there is no immediate danger of a froft, or in cafe of continued froft, to take care to cover the trees well, and at the fame time to fprinkle them with water, which is imitating nature's method of watering every part: But if the fuecefs of this practice in cold weather may be thought a little doubtful; yet the fprinkling the bodies and leaves of trees, in a very hot and dry fummer feafon, feems moft reafonable, for by Exper. 42 . they will imbibe much moifture.

As to noping fhelters over Wall-trees, I have often found, that when they are fo broad as to prevent any rain or dew coming at the trees, they do more harm than good, in thefe long eafterly drying winds; becaufe they prevent the rain and dews 


\section{0}

The Conclufion.

falling on them, which would not only refrefh and fupple them, but alfo convey nourifhment to them: But in the cafe of tharp frofts after fhowers of rain, thefe fhelters and other fences mutt needs be of ex. cellent ufe to prevent the almoft total deftruction which is occafioned by the freezing of the tender parts of vegetables, when they are full faturate with rain.

The full proof we have from thefe Ex. periments, of the ferviceablenefs of the leaves in drawing up the fap, and the care we fee Nature takes, in furnifhing the twigs with plenty of them, principally near the fruit, may inftruct us on the one hand, not to be too lavih in pruning them off, and to be ever mindful to leave fome on the branch beyond the fruit; and on the other hand, to be as careful to cut off all fuperfiuous thoots, which we are affured do draw off in wafte great quantity of nourifhment. And might it not be advifeable, among many other ways which are prefcribed, to try whether the too great luxuriancy of a tree or branch could not be much checked by pulling off fome of its leaves? How many experience will beft teach us, the pulling all off will endanger the killing the branch or tree.

There is another very confiderable ure of the 


\section{The Conclufion.}

the leaves, viz. to keep the growing fruit in a fupple ductile ftate, by defending it from the Sun and drying winds, which by toughning and hardening its fibres fpoil its growth, when too much expofed to them; but when. full grown, or near it, a little more Sun is often very needful to ripen it. In hotter climates fruits want more thade than in this country, and here too, more thade is needful in a hot dry fummer, than in a wet cool one.

The confideration of the frong imbibing power of the branches of trees, and the rea. dinefs with which we ree the fap paffes to and fro, to follow the ftrongeft attraction, may per: haps give fome ufeful hints to the Gardiner; in the pruning and thaping of his trees, in checking the too luxuriant, and helping and encouraging the unthriving parts of trees.

It is a conftant rule among Gardiners? founded on long experience, to prune weak trees early in the winter, becaufe they find that late pruning checks them; and for the fame reafon to prune luxuriant trees late in the fpring, in order to check their luxuriancy. Now it is evident that this check does not proceed from any confiderable lors of fap at the wounds of the pruned tree, (excepting the cafe of a few bleeding trees when

$$
\mathrm{Bb} z \quad \text { cut }
$$




\section{2

cut in that feafon, but muft arife from fome other caufe; for by Experiment 12 and 37 , where mercurial gages were fixed to the ftems of freth cut trees, thofe wounds were conftantly in a ftrongly imbibing ftate, except the Vine in the bleeding feafon.

When a weak tree is pruned early in the beginning of the winter, the orifices of the fap-veffels are clofed up long before the fpring, as is evident from many Experiments in the Ift, $2 \mathrm{~d}$ and $3 \mathrm{~d}$ chapters; and confequently when in the fpring and fummer the warm weather advances, the attracting force of the perfpiring leaves is not then weakened by many inlets from frefh wounds, but is wholly exerted in drawing fap from the root. Whereas on the other hand, when a luxuriant tree is pruned late in the fpring, the force of its leaves to attract fap from the root will be much fpent and loft at the feveral frefh cut inlets.

Befides, the early pruned tree being eafed of feveral of its twigs or branches, has thereby the advantage of ftanding thro' the whole winter, with a head better proportioned to its weak root. And fince by Exper. 16. the fap is found to afcend in the winter, lefs of that than cold crude juice is drawn thro' the roots and ftem, to fupply the perfpi- 


\section{The Conclufion.}

ration of the remaining boughs, whereby the fap of the tree is probably lefs depau. perated than it would have been, if all the boughs had remained on. For thefe reafons, early pruning fhould in the main, and excepting fome cafes, be better than late.

And the reafonablenefs of this practice is further confirmed by the experience of fome, who have found, that by pruning Vines, and pulling all the leaves off them in September, as foon as the fruit was off, they have borne greater plenty of Grapes than other Vines, particularly in the year 1726 . when by reafon of the extreme wetnefs and coldnefs of the preceding fummer, the unripe fhoots produced generally very little fruit. But early pruning feems to be the more preferable, becaufe pulling off the leaves may poffibly both wound the adjoining bud, and injure it, by depriving it of the nourifhment which the leaf would have brought to it.

From many Experiments in the fecond Chapter, the Gardiner will fee with what force his grafts imbibe fap from the ftock, efpecially that ductile nourifhment from between the bark and wood; which correfponding parts he well knows by confant experience mut be carefully adapted to each other 


\section{The Conclufion.}

in grafting, thofe grafts being always beft whofe buds are not far afunder, viz. becaufe their expanding leaves can therefore draw up fap the more vigoroufly.

The great quantities of moifture which we find by Experiment $I_{2}$ are imbibed at wounds where branches are cut off, Thews the reafonablenefs of the caution ufed by many who are defirous to preferve their trees, viz. either by plaiftering or covering with Sheet-lead the very large wounds of trees, to defend their trunks from being rotted by the foaking in of rain.

And from the fame is th Experiment a Lint may be taken to make fome attempts to give an artificial tafte to fruits, by making trees imbibe in the fame manner fome ftrongly tinged or perfumed liquor, which is not fpirituous, for that we fee will kill the tree. I have made the ftem of a branch of a tree imbibe two quarts of water without killing it: If any are defirous to make this Experiment, they thould take care to cut the ftump which is to imbibe the liquor as long as they can, that there may be the more room, from time to time, to cut off an inch $O \mathrm{O}^{\circ}$ two of the top, when it is grown fo faturate with liquor that more will not pafs.

Tho Ever-greens are found to imbibe and 


\section{The Conclufion.}

perfpire much lefs than other trees, yet is the quantity they perfpire fo confiderable, that it has always been one of the greatert difficulties in the ordering of a Green-houre to let in frefh air enough without expofing the plants to too much cold. For fince the perfpiration of trees will not be free and kindly in a clofe damp air, the fap will be apt to ftagnate, which will make the plants grow moldy, or they will be fickly, by imbibing fuch damp rancid vapours; for by Mr. Miller's curious obfervations on the perfpiration of the Plantain tree of the Weft-Indies, and of the Aloe under Experiment 5 , plants will often imbibe moifture in the night as well in ftoves as common Greenhoufes without fire ; it is certainly of as great importance to the life of the plants to difcharge that infected rancid air, by the admittance of frelh, as it is to defend them from the extream cold of the outward air, which will deftroy them if let in immediately upon them. It reems therefore to be a very reafonable method which fome ufe, viz. to cover fome of the inlets of their Green-houfes on all fides with canvals, and in extream cold weather with fhutters made of reed or ftraw, through which the air can only pafs in little frreams: The like contrivance would pro- 


\section{6 \\ The Conclufion.}

bably alfo be of good fervice to purify gradually the thick rancid fumes which arife from the dung of hot beds, and are often very deftructive of the tender plants: This is to imitate Nature, which while he provides for the defence of living creatures againft the cold, by a good covering of Hair, Wool, or Feathers, at the fame time the takes care that the air may have admittance through innumerable narrow meanders in fuch quantities as may be fufficient to carry off the perfpiring matter.

I have here, and as occafion offered under feveral of the foregoing Experiments, only touched upon a few of the moft obvious inftances; wherein thefe kind of refearches may poffibly be of fervice in giving us ufeful hints in the culture of plants: Tho' I am very fenfible, that it is from long experience chiefly that we are to expect the moft certain rules of practice; yet it is withal to be remembred, that the likelieft method to enable us to make the moft judicious obfervations, and to put us upon the moft probable means of improving any art, is to get the beft infight we can into the nature and properties of thofe things which we are defirous to cultivate and improve.

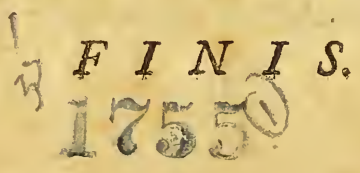






. 
I

(3)

(3)

(3)

13.

(6)

f(t)

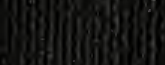

(3)

ying

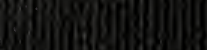

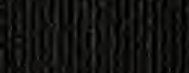

(1)

AnI

m)

(13)

4||$|(\mid)|$

sis

36)

(6)

inges.

13||ำ|

Bojng

ได่

4

fing:(n)

ainis.

fis:

(6)

cosmons

HII

(B)

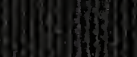

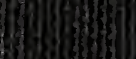

